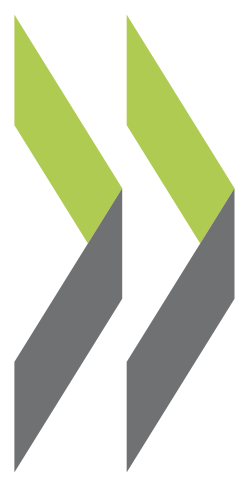

SIGMA Papers No. 18

Law Drafting and Regulatory Management in Central OECD and Eastern Europe 


\section{LAW DRAFTING AND REGULATORY MANAGEMENT IN CENTRAL AND EASTERN EUROPE}

SIGMA PAPERS: No. 18

ORGANISATION FOR ECONOMIC CO-OPERATION AND DEVELOPMENT

Paris

57790

Document complet disponible sur OLIS dans son format d'origine

Complete document available on OLIS in its original format 


\section{THE SIGMA PROGRAMME}

SIGMA -- Support for Improvement in Governance and Management in Central and Eastern European Countries -- is a joint initiative of the OECD Centre for Co-operation with the Economies in Transition and the European Union's Phare Programme. The initiative supports public administration reform efforts in thirteen countries in transition, and is financed mostly by Phare.

The Organisation for Economic Co-operation and Development is an intergovernmental organisation of 29 democracies with advanced market economies. The Centre channels the Organisation's advice and assistance over a wide range of economic issues to reforming countries in Central and Eastern Europe and the former Soviet Union. Phare provides grant financing to support its partner countries in Central and Eastern Europe to the stage where they are ready to assume the obligations of membership of the European Union.

Phare and SIGMA serve the same countries: Albania, Bosnia-Herzegovina, Bulgaria, the Czech Republic, Estonia, the Former Yugoslav Republic of Macedonia, Hungary, Latvia, Lithuania, Poland, Romania, Slovakia and Slovenia.

Established in 1992, SIGMA works within the OECD's Public Management Service, which provides information and expert analysis on public management to policy-makers and facilitates contact and exchange of experience amongst public sector managers. SIGMA offers beneficiary countries access to a network of experienced public administrators, comparative information, and technical knowledge connected with the Public Management Service.

SIGMA aims to:

- assist beneficiary countries in their search for good governance to improve administrative efficiency and promote adherence of public sector staff to democratic values, ethics and respect of the rule of law;

- help build up indigenous capacities at the central governmental level to face the challenges of internationalisation and of European Union integration plans; and

- support initiatives of the European Union and other donors to assist beneficiary countries in public administration reform and contribute to co-ordination of donor activities.

Throughout its work, the initiative places a high priority on facilitating co-operation among governments. This practice includes providing logistical support to the formation of networks of public administration practitioners in Central and Eastern Europe, and between these practitioners and their counterparts in other democracies.

SIGMA works in five technical areas: Administrative Reform and National Strategies, Management of Policy-making, Expenditure Management, Management of the Public Service, and Administrative Oversight. In addition, an Information Services Unit disseminates published and on-line materials on public management topics.

\section{Copyright OECD, 1997}

Applications for permission to reproduce or translate all or part of this material should be made to: Head of Publications Service, OECD, 2 rue André-Pascal, 75775 Paris Cedex 16, France.

Views expressed in this publication do not represent official views of the Commission, OECD Member countries, or the central and eastern European countries participating in the Programme. 


\title{
FOREWORD
}

The regulatory framework is a defining element of effective governance as it determines the rules of the game for both the private and the public sector. The quality of legislation can strongly influence economic development and the well-being of the citizen.

Central and eastern European countries have exerted considerable effort to create the institutional and regulatory environment necessary for a market economy and pluralistic democracy. In the process, they have encountered various problems, many of them related to a lack of information. Some countries have asked SIGMA and other donors for methodological assistance.

In response to such requests, and with the objective of helping the countries to improve their law drafting methodology and techniques, SIGMA launched a project in 1996 to take stock of practices in selected countries, namely Albania, Bulgaria, Estonia, Lithuania, Slovakia and Slovenia. The project, entitled "Law Drafting and Regulatory Management," resulted in the following country-specific reports of law drafting methodology and techniques, written by national experts, and a detailed comparative report, produced by Professor Keith Patchett of the University of Cardiff, Wales, UK. Professor Patchett's contribution points out crucial issues to be considered when creating or reviewing regulations on law drafting.

Five appendices follow the country reports: List of Country Reports and Authors; Glossary of Terms; Country Documents Relating to the Law-Making Process; the OECD Reference Checklist for Regulatory Decision-Making; and a List of Legislative Verifications.

This SIGMA Paper aims to enhance the comparative knowledge in this field not only in central and eastern European countries, but also among the donor community. The information presented in the country profiles is accurate as of May 1997. To learn about more recent developments, and about SIGMA advisory services in this subject area, contact Anke Freibert at the address below.

Law Drafting and Regulatory Management in Central and Eastern Europe will be available in French under the title La rédaction des lois et la gestion réglementaire dans les pays de l'Europe centrale et orientale. If your organisation is interested in translating this publication into another language -something we would welcome -- please contact us.

A separate but related publication is SIGMA Paper No. 15 Checklist on Law Drafting and Regulatory Management in Central and Eastern Europe (French version forthcoming). This checklist contains questions on policy development, organisational structure, staff, actual drafting and impact assessment. It is designed as a practical methodological tool.

These SIGMA papers are available on the SIGMA Internet site at: http://www.oecd.org/puma/sigmaweb.

This report is published on the responsibility of the Secretary-General of the OECD.

\author{
SIGMA-OECD \\ 2, rue André-Pascal \\ 75775 Paris Cedex 16, France \\ Tel (33.1) 45.24.79.00 or 45.24.13.94 \\ Fax (33.1) 45.24.13.00 \\ e-mail: sigma.contact@oecd.org \\ http://www.oecd.org/puma/sigmaweb
}




\section{EXECUTIVE SUMMARY}

This SIGMA publication is made up of a general report, six country reports and several appendices, such as relevant regulations and the OECD checklist for regulatory decision-making.

The general report on law drafting and regulatory management is designed as a hands-on tool for policymakers and law drafting personnel. It points out crucial issues for improving law drafting through creating and enforcing an adequate institutional framework, improving policy development, setting and maintaining law drafting standards, making fuller use of consultation, and improving access to legislation. This report also explains how procedures and standards should be applied to parliamentary initiatives and secondary legislation, as well as discussing the training of law drafters.

The country reports offer a full account of law drafting regulations and drafting practice in Albania, Bulgaria, Estonia, Lithuania, Slovakia and Slovenia.

While reforming regulatory programmes in any democracy is a major endeavour replete with potential pitfalls, central and eastern European countries confront even greater challenges in this area. They must build up regulatory frameworks for economic and political conditions radically different than those which existed just a few years before. In particular, these countries must align their regulatory practices with those of the European Union. This implies the creation of new institutions, and control and monitoring systems.

In most central and eastern European countries, responsibility for producing legislation is typically given to an official or a working group (made up mainly of officials, including legally qualified officials) from the competent ministry. In some cases, lawyers from outside the public service may be contracted to perform this function. In both circumstances, however, there has been tendency to concentrate on producing a legislative draft, with insufficient prior consideration of the policy which it should reflect. Such an approach can lead to the completion of a draft that for example incorporates the policy choices of some expert lawyer (sometimes from outside the public service) which are conditioned by his or her own knowledge or experience, rather than upon a thorough appraisal of the true problem and the impact of the available policy choices taking into account local needs and circumstances.

OECD Member countries have developed a more or less sophisticated system to assess the possible impact of regulations and to monitor legal quality. These various verifications can be put into two broad categories: those which should be carried out repetitively during the whole process, i.e. when the policy options are being considered, when the preferred policy option is developed and when the legal instrument is being developed; and those that should be applied to ensure the legal and technical quality of the legal instrument that gives effect to that option. These checks are basically as follows they are explained in depth in Appendix 5: 


\section{Checks in Respect of Policy Options}

General regulatory checks; checks on administrative requirements; impact checks regarding e.g. budgetary, economic and social costs, environmental impact; efficiency checks; practicability checks; implementation checks

\section{Checks of Legislative Drafts}

Checks for constitutional and legal compliance; checks for approximation to EU law; checks for compliance with international treaties; implementation checks; checks as to secondary law-making powers; checks on legal form, clarity and comprehensibility.

Concerns about the quality and impact of legislation are widespread. A collective effort to improve the quality of legislation in OECD Member countries has been instituted. Explicit standards (listed in the report) have been identified as desirable both for regulatory systems and for individual instruments. These standards, as well as the OECD Reference Checklist (see Appendix 4), are equally relevant to the lawmaking systems in central and eastern European countries. 


\section{TABLE OF CONTENTS}

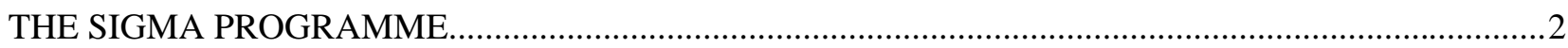

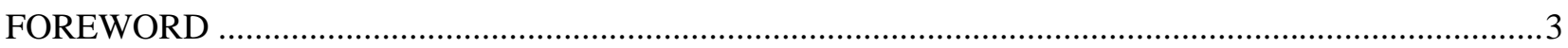

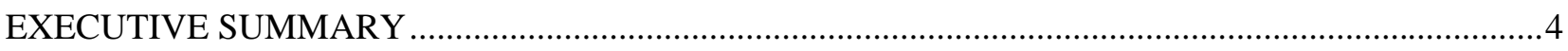

REPORT ON LAW DRAFTING AND REGULATORY MANAGEMENT …........................................11

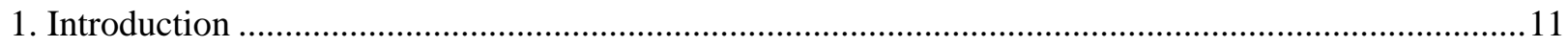

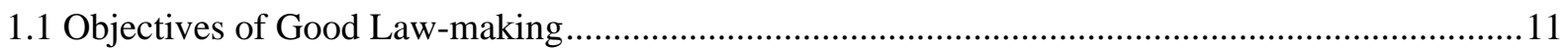

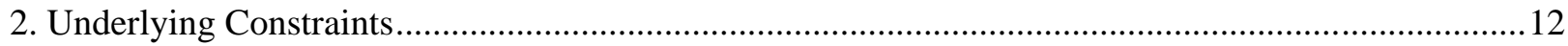

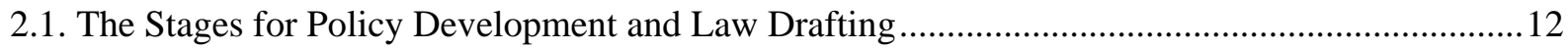

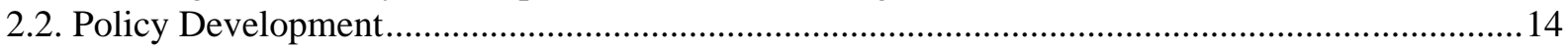

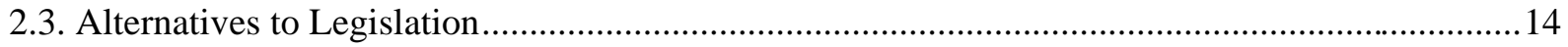

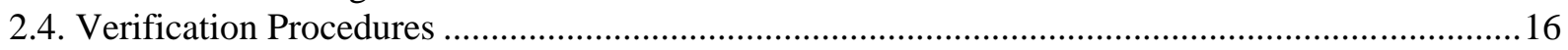

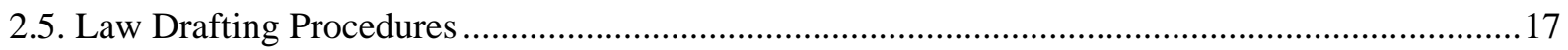

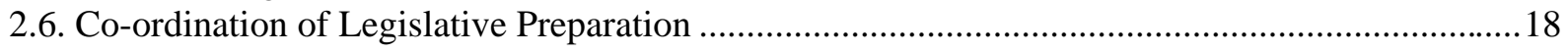

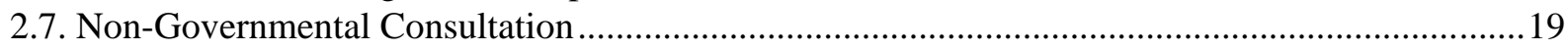

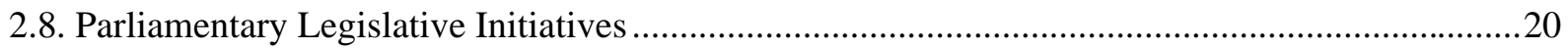

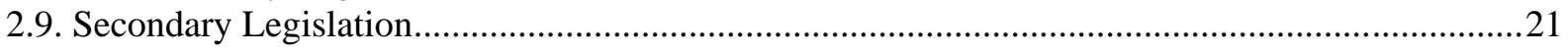

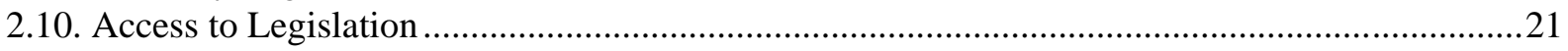

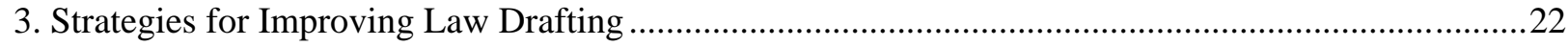

3.1. Creating and Enforcing a Regulatory Framework for Law Drafting …......................................22

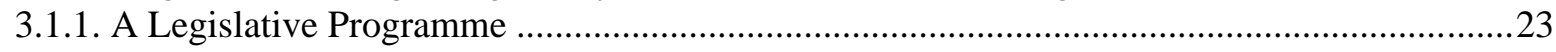

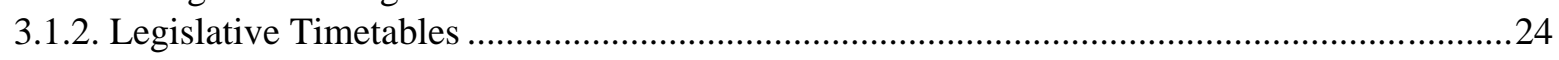

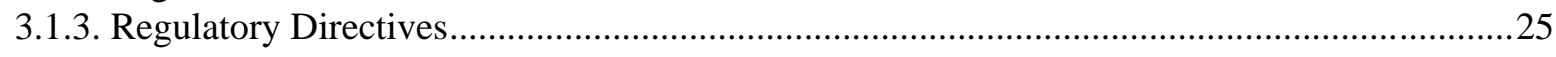

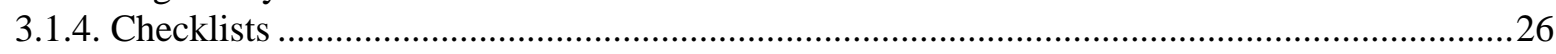

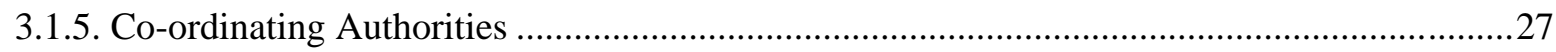

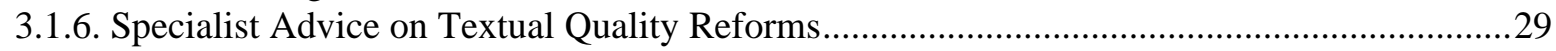

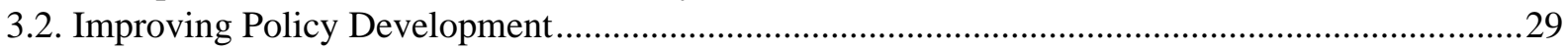

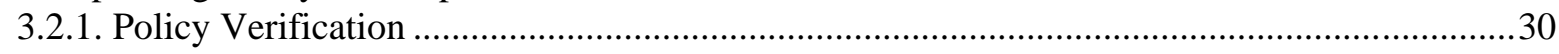

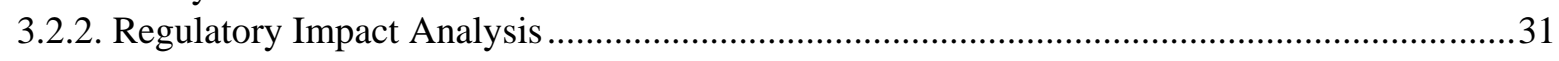

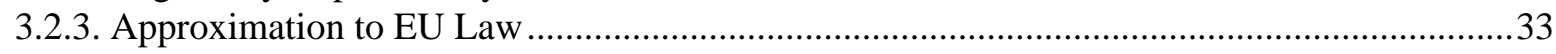

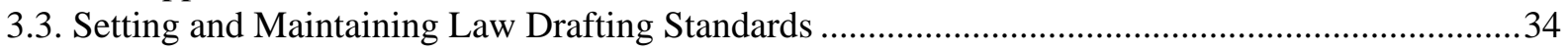

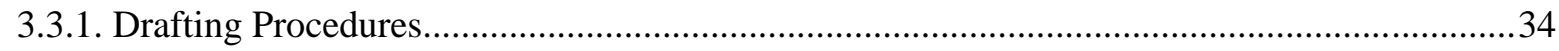

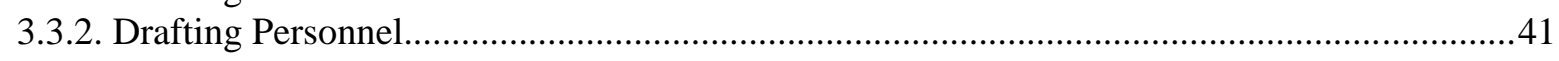

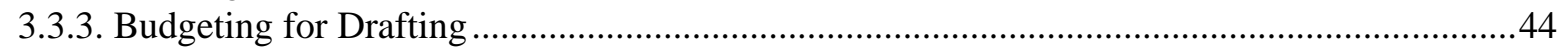

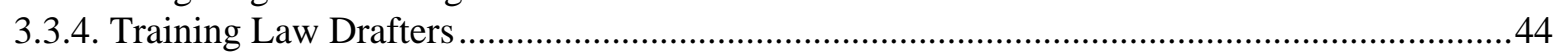

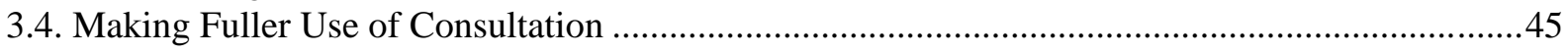

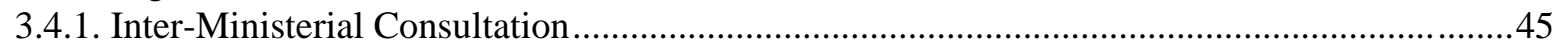

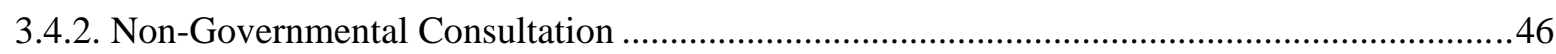


3.5. Applying Equivalent Procedures and Standards to Parliamentary Initiatives ...............................49

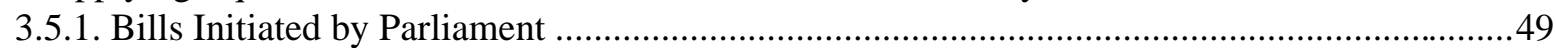

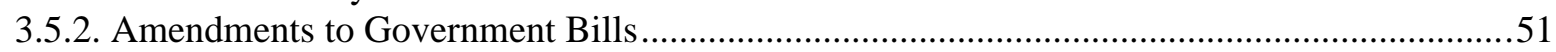

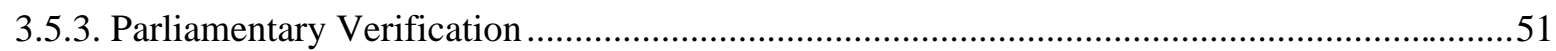

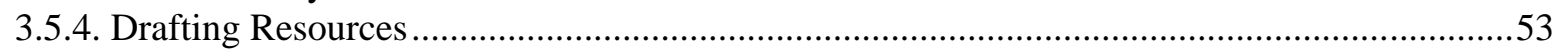

3.6. Applying Equivalent Procedures and Standards to Secondary Law-Making.................................54

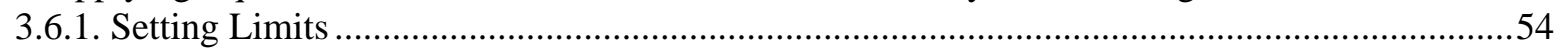

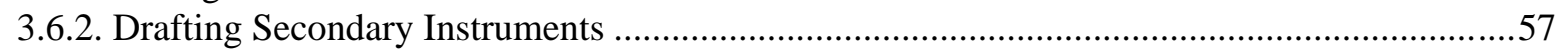

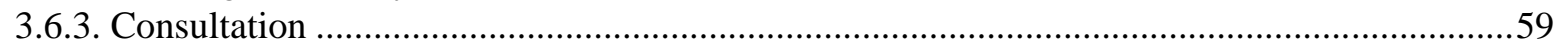

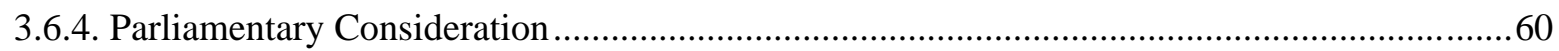

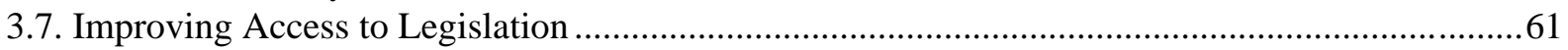

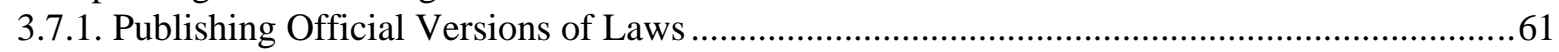

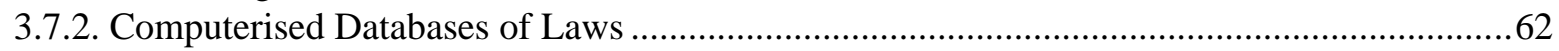

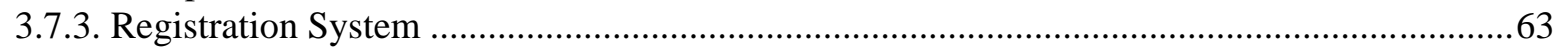

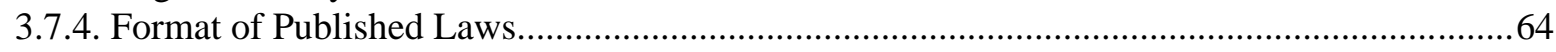

LAW DRAFTING AND THE REGULATORY PROCESS — REPUBLIC OF ALBANIA .....................65

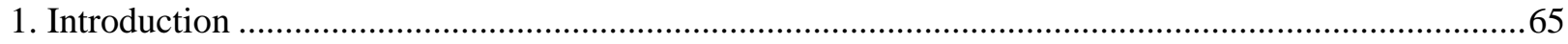

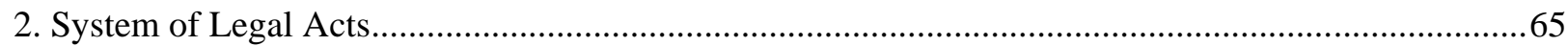

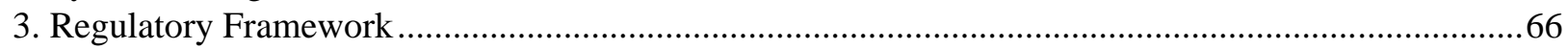

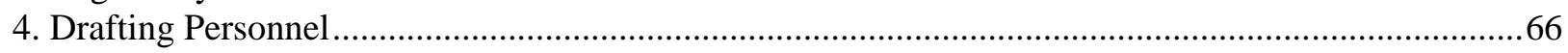

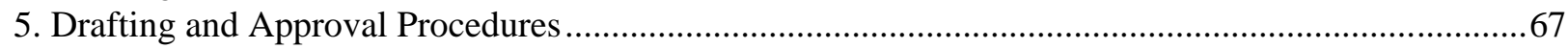

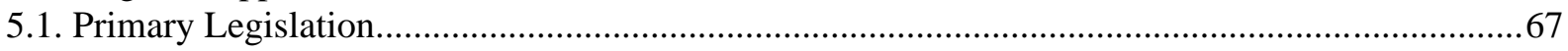

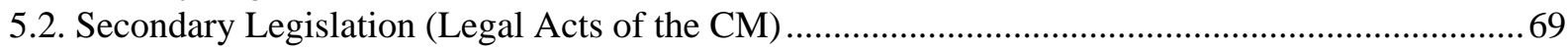

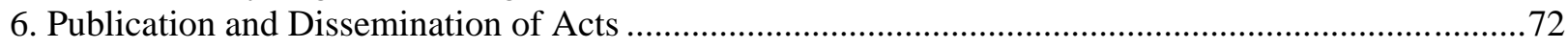

7. Legal Acts of the President of the Republic and Approval Procedures ……........................................72

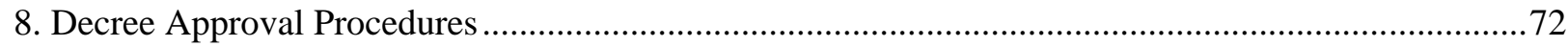

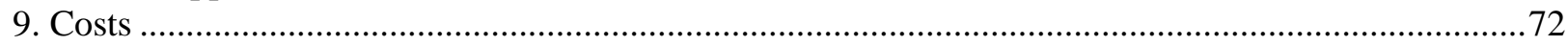

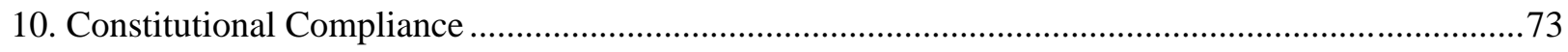

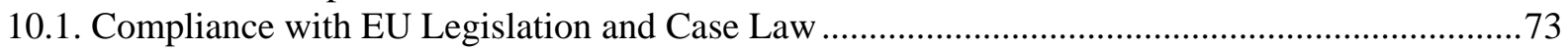

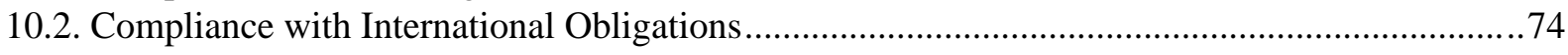

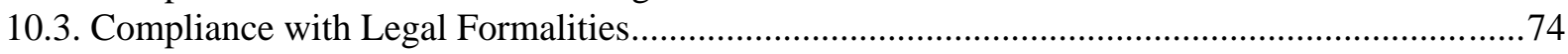

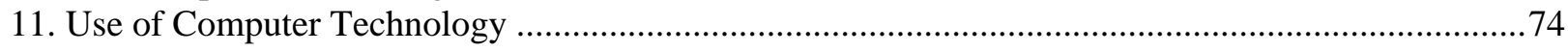

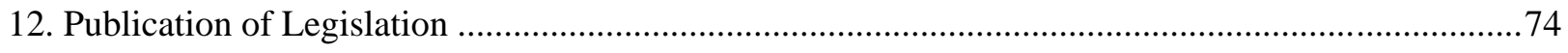

LAW DRAFTING AND REGULATORY MANAGEMENT — BULGARIA ..........................................76

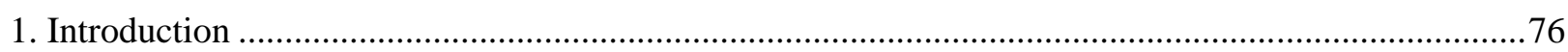

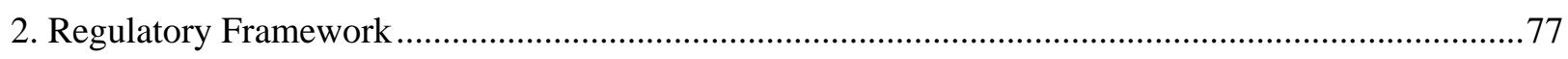

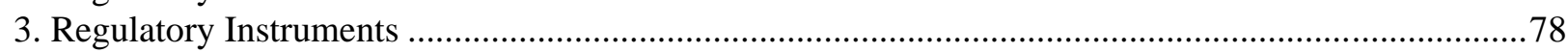

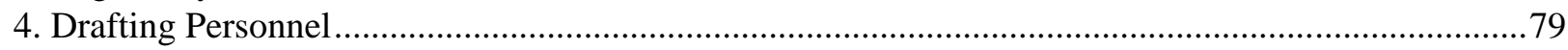

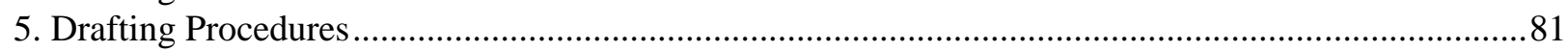

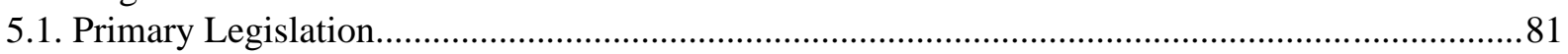

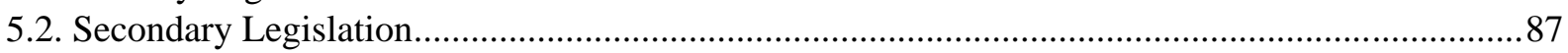

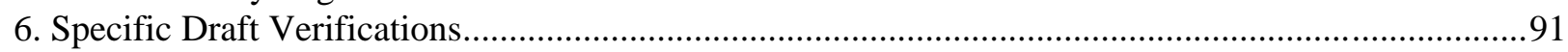

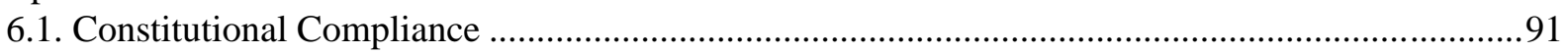

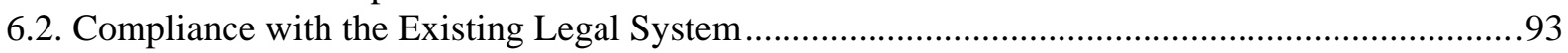

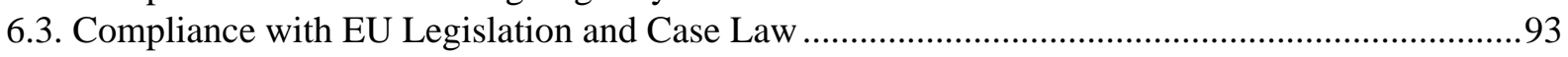

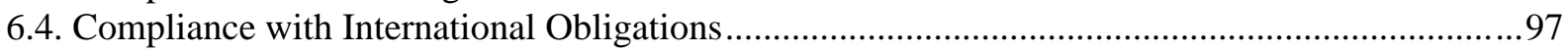

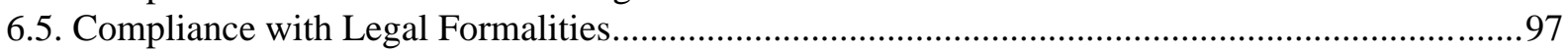

6.6. Compliance with Administrative and Information Technology Demands...................................98 


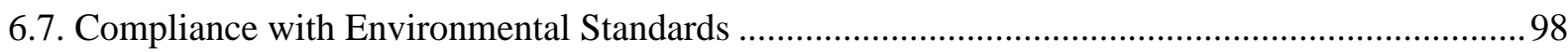

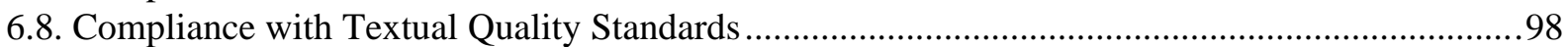

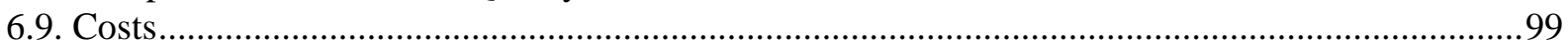

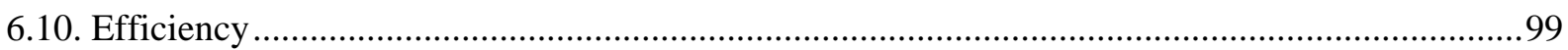

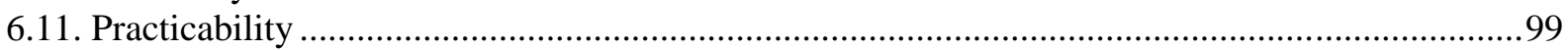

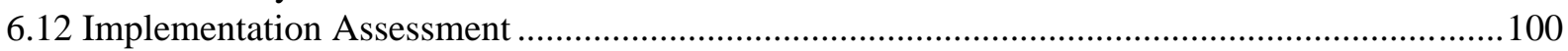

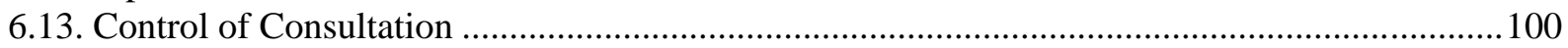

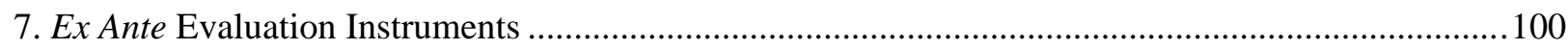

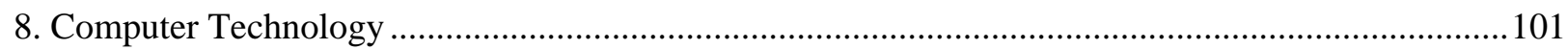

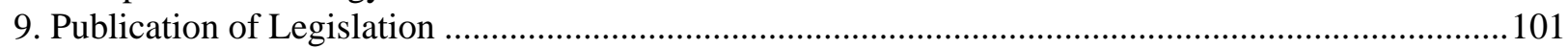

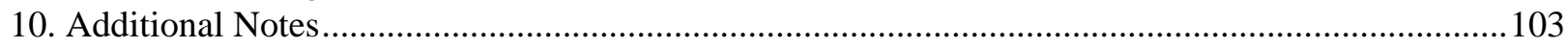

LAW DRAFTING AND REGULATORY MANAGEMENT — REPUBLIC OF ESTONIA ..................105

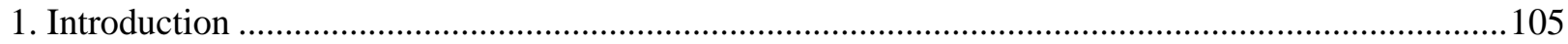

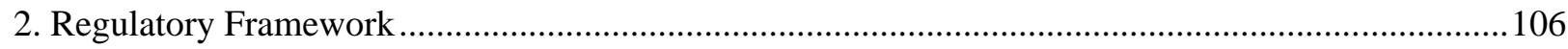

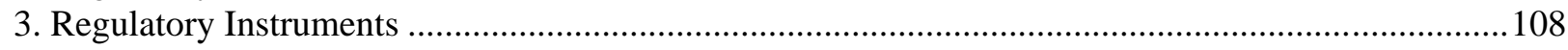

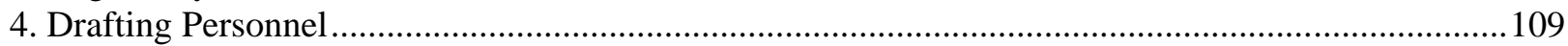

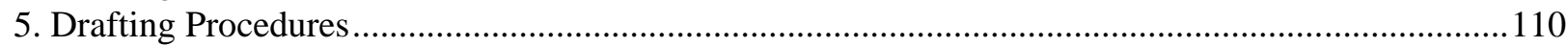

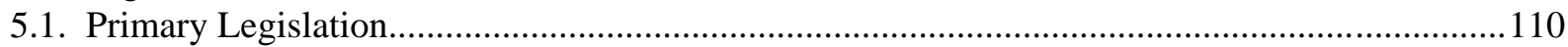

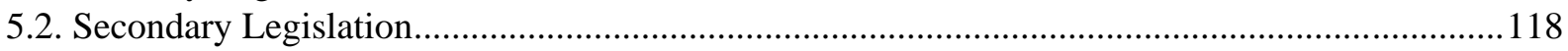

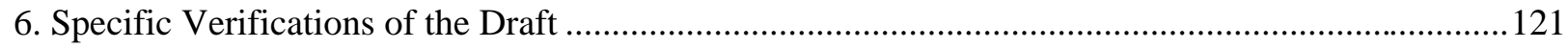

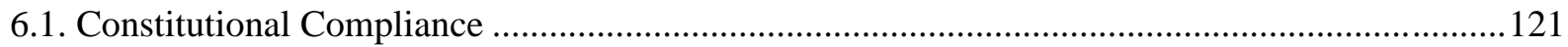

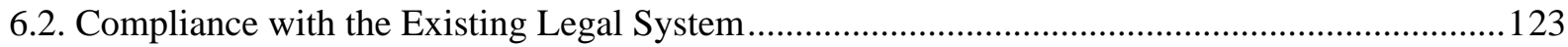

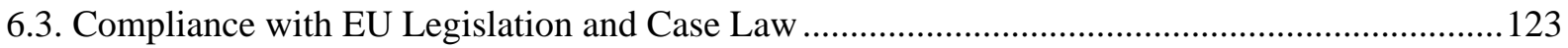

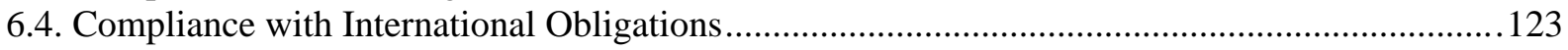

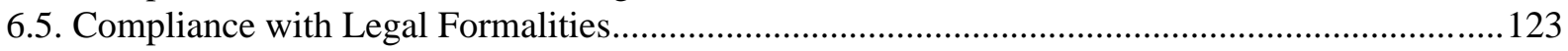

6.6. Compliance with Administrative and Information Technology Demands..................................124

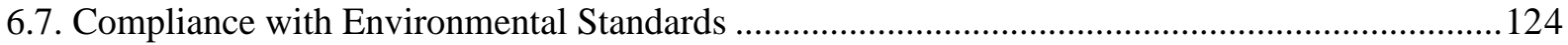

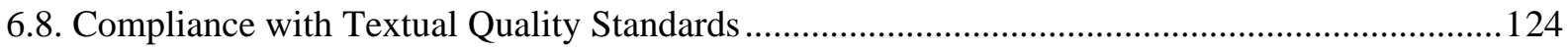

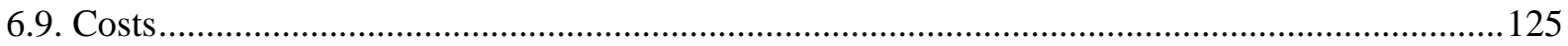

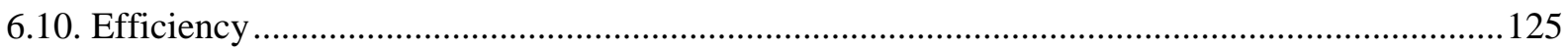

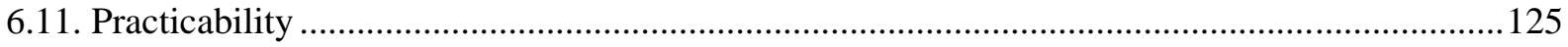

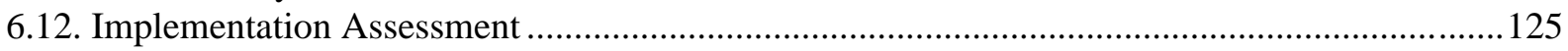

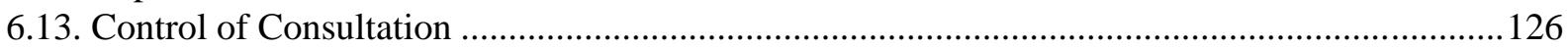

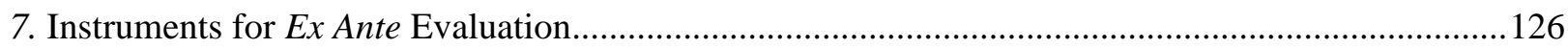

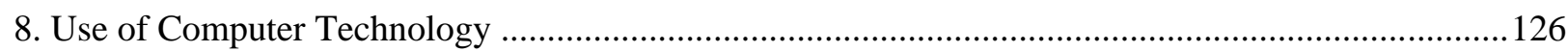

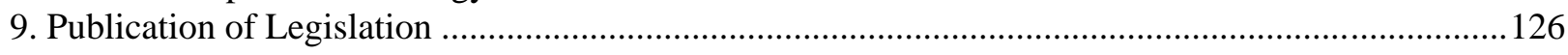

LAW DRAFTING AND REGULATORY MANAGEMENT — LITHUANIA .....................................129

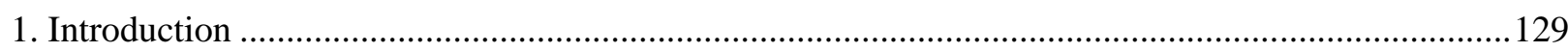

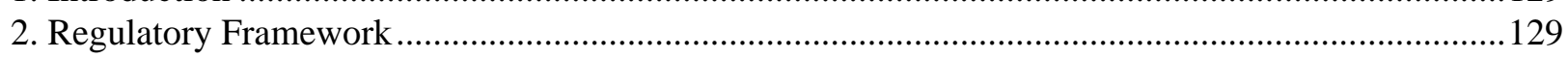

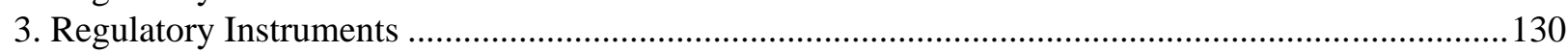

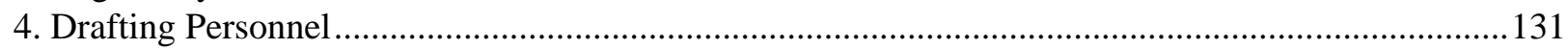

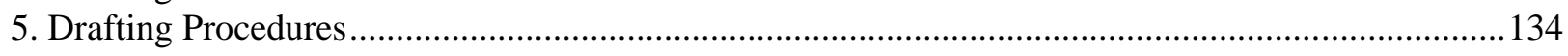

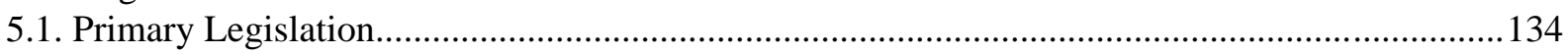

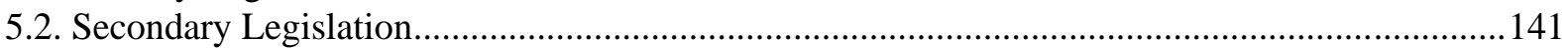

6. Specific Verifications of the Drafts and Instruments for Ex Ante Evaluation ...................................143

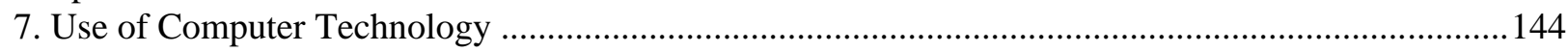

8. Publication of Legislation (Register of Legal Acts and State News) …...........................................145 
LAW DRAFTING AND REGULATORY MANAGEMENT — SLOVAKIA .......................................148

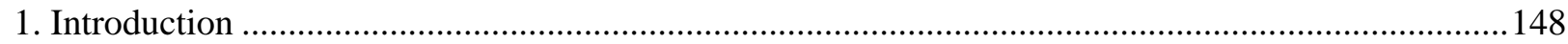

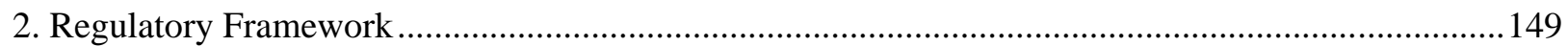

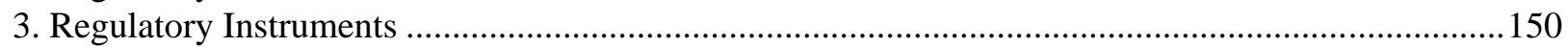

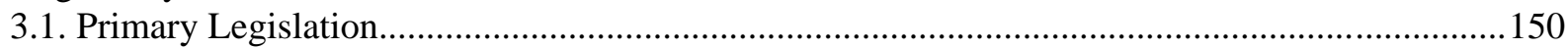

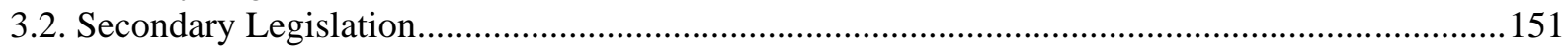

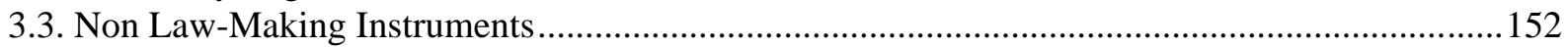

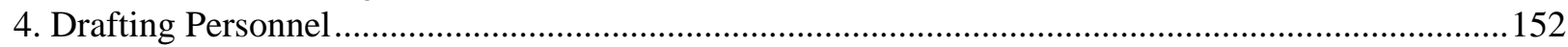

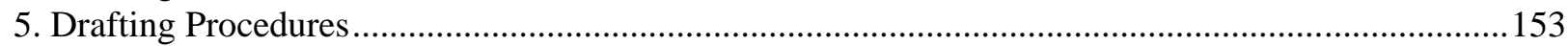

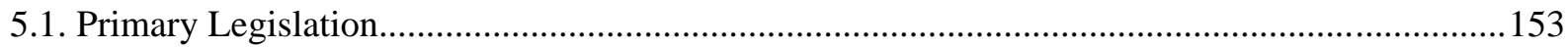

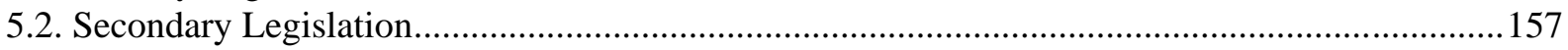

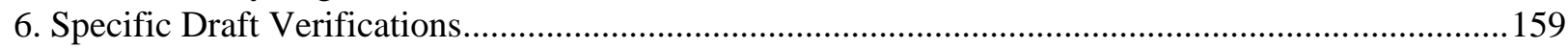

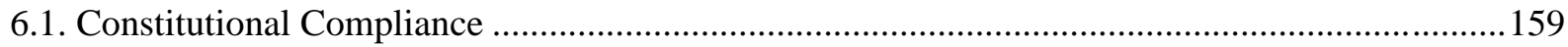

6.2. Compliance with the Existing Legal System........................................................................ 160

6.3. Compliance with European Union Legislation and Case Law and 6.4. Compliance with

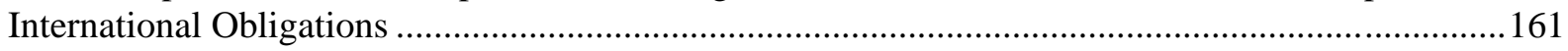

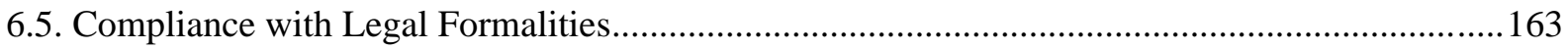

6.6. Compliance with Administrative and Information Technology Demands...................................163

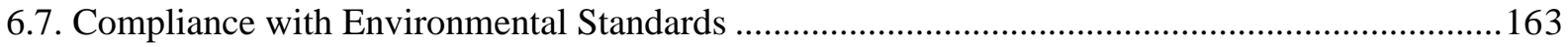

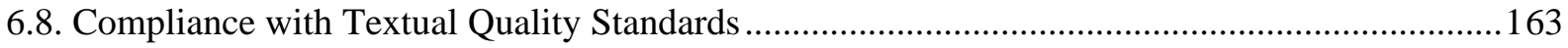

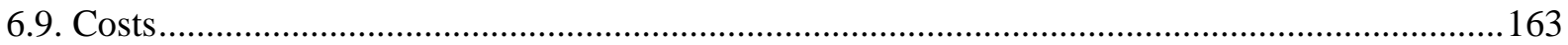

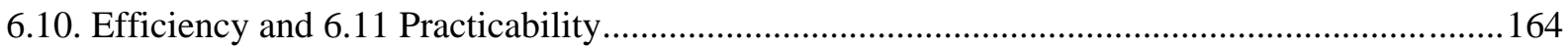

6.12. Implementation Assessment and 6.13. Controls of Consultation.............................................164

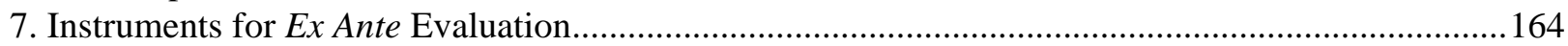

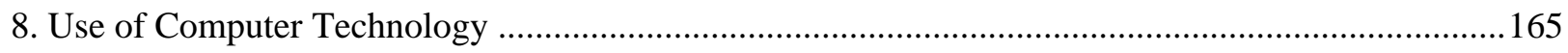

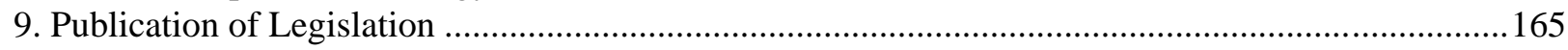

LAW DRAFTING AND REGULATORY MANAGEMENT ～SLOVENIA …....................................167

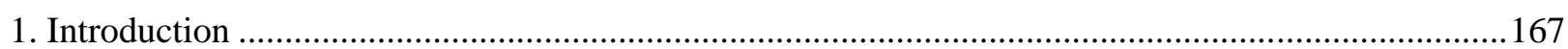

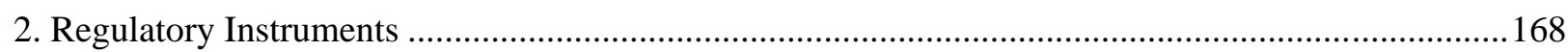

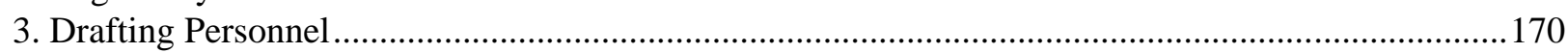

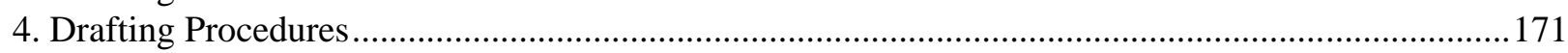

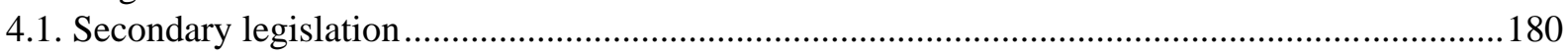

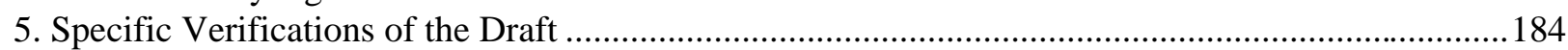

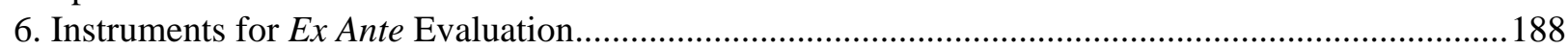

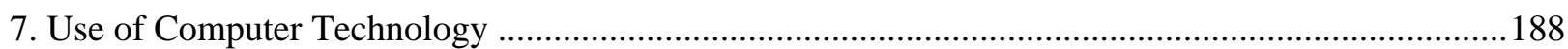

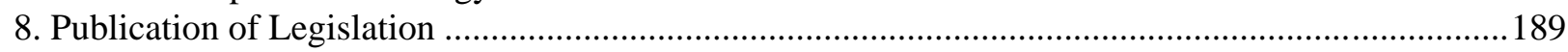


ANNEX 1. LIST OF SLOVENIAN LAWS

ANNEX 2. LIST OF SLOVENIAN STANDING ORDERS 192

ANNEX 3. LIST OF SLOVENIAN DECREES. 193

ANNEX 4. SLOVENIA COUNTRY REPORT: ADDITIONAL INFORMATION .194

APPENDIX 1. LIST OF COUNTRY REPORTS AND AUTHORS.. 199

APPENDIX 2. GLOSSARY OF TERMS USED 200

APPENDIX 3. COUNTRY DOCUMENTS RELATING TO THE LAW-MAKING PROCESSES .201 APPENDIX 4. OECD REFERENCE CHECKLIST FOR REGULATORY DECISION-MAKING. .203 APPENDIX 5. LEGISLATIVE VERIFICATIONS 205 


\section{REPORT ON LAW DRAFTING AND REGULATORY MANAGEMENT ${ }^{1}$}

\section{Introduction}

Profound changes in the nature of legislation are taking place in many countries. These result, in part, from changing attitudes towards the role of the State in market economies, and not least, in Europe, from the growing importance and influence of European Union law. Concerns about the quality and impact of legislation are widespread. The way in which legislation is prepared and enacted has come under scrutiny in many places. There is a developing understanding that both the content of legislation and the methods by which it is made must be more responsive to the context in which it is to operate. As a consequence, improved and more systematic methods of law-making have been adopted or recommended in a growing number of countries.

\subsection{Objectives of Good Law-making}

A collective effort to improve the quality of legislation in OECD Member countries has been instituted. Explicit standards have been identified as desirable both for regulatory systems and for individual instruments ${ }^{2}$. In outline, these are as follows:

1. A glossary of terms used in this report is contained in Appendix 2.

2. See Improving the Quality of Laws and Regulations: Economic, Legal and Managerial Techniques, OCDE/GD(94)59, SIGMA publication, 1994. 


\section{OECD STANDARDS FOR ACHIEVING REGULATORY QUALITY}

\section{System Standards:}

- Coherence, consistency, and balance between competing policies;

- Stability and predictability of regulatory requirements;

- Ease of management and oversight, and responsiveness to political direction;

- Transparency and openness to the political level and to the public;

- Consistency, fairness and due process in implementation;

- Adaptation to changing circumstances.

\section{Standards For Regulatory Instruments:}

- user standards, e.g. clarity, simplicity, and accessibility for private citizens and businesses;

- design standards, e.g. flexibility and consistency with other rules and international standards;

- legal standards, e.g. structure, orderliness, clear drafting and terminology, and the existence of clear legal authority for action;

- effectiveness standards, e.g. relevance to clearly-defined problems and real-world conditions;

- economic and analytical standards, e.g. benefit-cost and cost-effectiveness; measurement of impacts on business, competitiveness and trade;

- implementation standards, e.g. practicability, feasibility, enforceability, public acceptance and availability of necessary resources.

These standards are equally relevant to the law-making systems in CEE countries; they were influential in the formulation of the questionnaire upon which the country reports are based. From those reports, it is apparent that application of standards such as these is a perceived objective in CEE countries, and that active steps are being taken, or are under consideration, in many of them for that purpose. But a number of underlying constraints are obstructing the achievement of that aim.

\section{Underlying Constraints}

\subsection{The Stages for Policy Development and Law Drafting}

In principle, the preparation of legislation is best conducted in two stages: policy development, followed by the formulation of the legislative text ("law drafting") to give effect to the policy adopted.

At the first stage, certain key decisions are needed, on such questions as:

- What is the precise nature of the problem to be dealt with, and what are the policy objectives for its resolution?

- What are the possible options for giving effect to the desired policy and which of these is to be preferred?

- Should this option be realised through legislation rather than by non-legislative means?

- Which authorities or agencies should be given responsibility for putting the legislation into effect? 
- What is the basic approach that the legislation should adopt and what are the essential legal and administrative mechanisms that are necessary to put that approach into effect and make it workable?

Decisions on such questions as these are necessary to provide the foundations upon which effective work can be done on the legislative text. Producing answers is properly the task of policy-developers (typically officials in the competent ministry) who are able to bring or draw upon the appropriate expertise in the particular subject matter, including legal expertise. Setting the policy objectives and final decisions whether to endorse the answers provided by the policy-developers rest with those holding political office (i.e. the minister and, ultimately, the Council of Ministers). The system should ensure that those political endorsements are sought and given whenever a significant policy decision is required.

At the stage of law drafting, these key policy decisions must be converted into legal text. Other specialist legal skills are necessary to turn the policy and administrative requirements into practicable, effective and clear legal rules which use the appropriate legal concepts and terminology, and follow the prevailing drafting conventions as to legislative structure, form and style. This is properly the task of law drafters (typically officials with legal training).

In the Anglo-Saxon tradition, the task of law drafting is separated from that of policy development, at least in relation to Government bills. A cadre of Government lawyers has the responsibility of drafting the text of the legislation, giving effect to detailed instructions prepared by the policy-developers in the competent ministry. Although the legal text is worked out by these specialist law drafters, detailed expert policy and legal inputs on substantive matters continues to be given by the policy-developers through a regular process of consultation.

In continental Europe, drafting is typically undertaken by officials from the competent ministries. Very often they are also the policy-developers for the particular project; the functions of policy development and drafting are generally undertaken by the same official or group of officials, though in consultation with other concerned ministries. This practice is facilitated by the fact that most officials are lawyers. Some develop a special expertise in law drafting through experience and training. A benefit from using an experienced law drafter is that, at the drafting stage, he or she is often able to elicit policy refinements which will enable greater certainty and practicability to be achieved in the normative requirements in the legal text.

In most CEE countries responsibility for producing legislation is typically given to an official or a working group (made up mainly of officials, including legally qualified officials) from the competent ministry. In some cases, lawyers from outside the public service may be contracted to perform this function. In both circumstances, however, there has been tendency to concentrate on producing a legislative draft, with insufficient prior consideration of the policy which it should reflect. Such an approach can lead to the completion of a draft that e.g. incorporates the policy choices of some expert lawyer (sometimes from outside the public service) which are conditioned by his own knowledge or experience rather than upon a thorough appraisal of the true problem and of local needs and circumstances.

Too frequently, such an approach results in drafts that draw heavily upon legislative precedents, including those from other countries, with little consideration for their suitability for local conditions. It is only after the draft is completed (or more seriously after the draft has been made law) that policy shortcomings become evident. Not only does this waste the time of the working groups and the Parliament, who may have to start all over again, it delays the institution of necessary legal change and may damage the confidence of those concerned in this area of law. 


\subsection{Policy Development}

OECD Member countries have found that the quality of their legislation can be greatly enhanced if certain issues are specifically addressed at the policy stage. The OECD Council has recommended that the following questions should always be asked when regulatory action is under consideration.

\section{OECD REFERENCE CHECKLIST FOR REGULATORY DECISION-MAKING ${ }^{3}$}

\section{(Recommendation of the Council of the OECD, adopted 9 March 1995)}

1. Is the problem correctly defined?

2. Is government action justified?

3. Is regulation the best form of government action?

4. Is there a legal basis for regulation?

5. What is the appropriate level (or levels) of government for this action?

6. Do the benefits of regulation justify the costs?

7. Is the distribution of effects across society transparent?

8. Is the regulation clear, consistent, comprehensible, and accessible to users?

9. Have all interested parties had the opportunity to present their views?

10. How will compliance be achieved?

It can readily be seen that most are key policy questions that, properly, should be settled before any legislation is prepared. They may need to be asked with respect to each of the possible policy options in order to determine which is to be preferred. Only question 8 can be fully postponed to the stage of law drafting, although a question considered at the policy-development stage may sometimes have to be asked again at the drafting stage as the detailed, more fully-refined scheme emerges in the text.

The answers to all these questions are needed by law drafters. Indeed, if they are not provided in the course of the policy development, law drafters may have to ask that they be provided or may have to provide them themselves in the course of drafting. But the better the quality of the answers, the more likely it is that legislation of good quality will be planned and drafted. For certain of the questions, better quality answers are, in principle, more likely if they are reached by sensible use of such techniques as regulatory impact analyses ("RIA") and consultation with non-governmental interests.

In a number of CEE countries, draft legislation must be accompanied by an explanatory memorandum which sets out a number of policy considerations that underlie the legislative draft. Yet the procedures for systematically developing that policy, in particular, through a proper evaluation and costing of alternative policy alternatives, are often meagre and unproductive.

\section{3. $\quad$ Alternatives to Legislation}

Legal traditions in many CEE countries may mean that considerable emphasis is placed on dealing with social, economic and administrative issues through legislation (primary or secondary) - the so-called "command and control" approach. In many OECD Member countries, attempts are being made to control the tide of legislation by wider use of alternative devices. These may involve more frequent use of administrative directives of various kinds, often issued in the form of circulars, i.e. instruments do not lay

3. The full checklist is set out in Appendix 4. 
down normative rules that are directly enforceable through courts, but are intended to be made effective by other means, e.g. by administrators or by superior officials. The following are the kinds of documents that may be issued:

\section{ADMINISTRATIVE DIRECTIVES ${ }^{4}$}

- Procedural rules, determining the steps administrators are expected to follow in relation to particular administrative processes.

- Instructions, indicating by whom or how particular powers are to be exercised, typically to ensure consistency in decision-making and to allow decisions to be taken at a particular level in the administration without recourse to a higher level of direction.

- Interpretative guides, indicating to persons affected how they may expect particular powers or discretions to be used, in particular the matters that will be taken into account and the criteria that will be applied.

- Prescriptive rules, indicating the behaviour that persons affected are expected to adopt in order to comply with statutory requirements that are legally enforceable.

- Recommendations, providing advisory guidance as to expected actions or behaviour in order to achieve specific objectives.

- Codes of conduct, setting guidelines or generalised standards for action or behaviour in certain contexts.

- Practice rules, laying down the practices that will be followed in order to make statutory rules operative or effective.

- Voluntary codes for self-regulation adopted by private sector bodies on a proposal of Government or with Government encouragement.

Behaviour may also be influenced by other means, such as contracts and voluntary agreements, self-regulation, economic incentives and wider dissemination of information. These involve the use by Government of inherent powers other than that of proposing legislation. In a market economy, a regulatory framework is needed that enables Governments to make flexible and varied responses to changing circumstances. Legislation alone may not suffice to provide this capacity. The planning of legislative schemes in many OECD Member countries increasingly takes the availability of this Government tool kit into account. The range of alternative mechanisms enables a variety of approaches to be used, often in combination, and not least with powers that must be conferred by legislation.

4. This is adapted from the classification used by R. Baldwin, Rules and Government, Clarendon Press, Oxford (1995), pp. 81-85. 
1. Information - The Power of Influence

- Advice

- Guidance

- Directions

- Data and information

- Threats and persuasion

- Agreements
- Wide dissemination

- Selective distribution

- Advertisement and publicity

- Targeting on significant operators

- Responding to requests

2. Economic Measures - The Power of Money

- Bargains

- Incentives

- Negotiated benefits by means of:

3. Administrative Action - The Power of Government Resources

- Provision of a specialist service

- Use of skilled manpower

- Administration through an existing Government agency

- Monitoring and inspection

- Policing and corrective intervention

\section{Inaction - The Power to Decline to Intervene}

- Reliance on market forces

- Reliance on social controls

- Self-regulation
- Government contracting

- Fax inducements

- Grants, loans and subsidies

Although some of these devices are in use in CEE countries, there are often good reasons why legislation may be preferred. As an example, in many OECD Member countries, requirements such as those relating to the style, form, structure and terminology of legislative instruments are set by government handbooks or guides, not by law. Yet there are many examples in CEE countries where legislation has been used for this purpose, although enforcement by court action is improbable and some loss of flexibility occurs. The instruments are seen as having greater authority if contained in legislation; they can be made by a process which is binding on both Government and Parliament (both of which prepare legislation); they definitively replace earlier requirements or practice; the criteria they contain carry greater authority for refusing to allow an instrument to proceed in the law-making process.

Considerations such as these bear testimony to the fact that OECD Member country practices may not always be appropriate for adoption in CEE countries, particularly during the period of transition.

\subsection{Verification Procedures}

Regulatory frameworks in OECD Member countries typically provide a system of verifications to be applied at some stage in the law preparation process. These can be put into two broad categories: those which are best carried out when the policy options are being considered and when the development of the 
preferred policy option is under way; and those that should be applied to the legislative draft that gives effect to that option. These types of checks are set out in the following outline.

\section{A. Checks in Respect of Policy Options}

1. General regulatory checks

2. Checks on administrative requirements

3. Costs and economic impact checks

4. Efficiency checks

5. Practicability checks

6. Implementation checks

\section{B. Checks of Legislative Drafts}

1. Checks for constitutional and legal compliance

2. Checks for approximation to EU law

3. Checks for compliance with international treaties

4. Implementation checks

5. Checks as to secondary law-making powers

6. Checks on legal form, clarity and comprehensibility

There is a growing recognition in CEE countries that procedures should be put in place to enable verifications of these kinds to be carried out, and action is being taken for that purpose. Some are already undertaken, although on a number of matters in an informal or unsystematic way, and sometimes with little standardisation in the practice of ministries. There can be several reasons for this:

- inherited practices made little use of verifications and there is insufficient awareness both in Government and Parliament of their function and importance;

- too few officials have the necessary expertise and experience in using verification procedures;

- training arrangements in new verification techniques are lacking;

- also lacking are standard instructions as to the nature of the verifications and as to when in the law preparation process, and how, and for what cases, they are to be applied;

- the necessary quantitative data is unavailable, particularly in respect of those checks which would be effected through regulatory impact analysis;

- there is often no central authority in Government to set, monitor, enforce and co-ordinate the procedures.

\subsection{Law Drafting Procedures}

The actual drafting of legislation (i.e. the preparation of the legislative text which converts a policy into legally enforceable normative rules) is somewhat more expert work than is generally recognised. It cannot be assumed that it can be undertaken by every lawyer; the skill usually has not been acquired as part of

5. Appendix 5 lists specific matters that may be checked under each heading in the outline. 
legal education and in the course of legal practice. Law drafting is a type of specialist legal practice (for which some have more talent than others) which demands special skills and relevant experience. Expert understanding of the work is also desirable in those required to carry out verifications of legislative text, whether for Government or Parliament.

Law drafting may be undertaken by officials in a ministry (or in Parliament) who are principally engaged in legal work. Alternatively, and much less commonly in continental Europe, they can be provided as a central resource upon which individual ministries may draw. By either means, good quality drafting calls for a resource of skilled and experienced officials.

Most CEE countries report inadequacies in this respect. Many major ministries, and the public service as a whole, have too few officials with these qualifications. Similar shortages may exist in the staff of Parliaments. Formal, specialist training is rarely available, although it can be invaluable both for newcomers and, at an advanced level, for more experienced drafters. The skills have to be learned on the job, the success of which depends heavily upon the availability and ability of those who supervise the work. Certainly, good quality experience is the best teacher, but experience grounded in poor practices or superficial knowledge of legislative methodology merely perpetuates shortcomings.

The provision of officials with law drafting skills makes it more likely that uniform standards and practices, and compatible styles, will be adopted by everyone under taking legislative drafting. The use of external consultants to draft laws, as happens in many CEE countries, has presented problems when they are not equally versed in these matters. To an extent, consistency can be encouraged through the formulation of official directions and practice guides on these matters, and by making them available to all drafters. Steps of this kind are being taken in several CEE countries.

\subsection{Co-ordination of Legislative Preparation}

The transition has been a period of great legislative activity in CEE countries, e.g. to restore rule of law requirements, to introduce political and public service reforms and to lay the foundations for a market economy. An urgency to demonstrate that change is taking place and to remove obstacles inherited from the past may have resulted in too hasty consideration of what changes would be the most appropriate in the immediate and in the longer term. Serious policy inconsistencies have occurred, e.g. where creation of additional governmental functions by legislation has come into conflict with the objective of reducing the size and cost of public administration. Inevitably, recently enacted legislation has required significant amendments, sometimes in the same Parliamentary session. This may sometimes be the consequence of changes in political direction and in perceptions of how the public interest is to be secured. But in some cases it has been made necessary by, for example, the impracticability, ineffectiveness or expense of operating the legislation.

Law-making systems must, of course, allow for legislation that is urgently required, e.g. to deal with unforeseen events. But such a process should be treated as a special case. In the usual case, legislation should emerge as the result of a planned and co-ordinated process that has been deliberately devised to provide adequate time for preparation, consultation inside and outside Government, and Parliamentary consideration. In particular, if the resources and time of ministries are to be optimised, legislative projects must be instituted and carried forward as part of a planned work programme for Government as a whole.

Many CEE countries are already aware of these factors, and procedural rules made by Government and Parliament are beginning to include requirements that support a more organised regulatory framework. These deal with such central issues as: how to prioritise potential legislative projects, how to combine 
projects into a Government legislative programme, how to timetable the preparation, how to co-ordinate the progress of projects at the Government level in order to fit with Parliamentary timetables, how to ensure that the necessary steps are properly carried out to provide the justification for projects, both to Government and to Parliament.

\subsection{Non-Governmental Consultation}

Inter-ministerial consultation on new legislative projects has been a long standing practice in OECD Member countries; non-governmental consultation has been less routinely used in the past. A marked change of direction is taking place in this latter respect. Expanded use reflects recognition of its intrinsic democratic value. In any case, it is increasingly demanded as populations become more politically aware. But not only does it make greater public acceptance of legislative proposals more likely, but also it is valuable as a device to improve the quality of the proposals. Such consultations can be used both as an aid to the RIA process and to support other verifications. The principal benefits to be gained from this consultation are set out in the following outline:

\section{A. Consultation and RIA}

1. May broaden the range of policy alternatives;

2. May facilitate the collection of some categories of data needed for RIA;

3. May be used to verify the results of completed analyses;

4. May make the law-making process, and the reasons for policy choices, more transparent to affected groups.

\section{B. Consultation and Other Verifications}

1. May give rise to a better understanding of the activities to be regulated and the problems to be solved;

2. May result in more informed choices as to the appropriate legal mechanisms to give effect to the preferred policy;

3. May result in legal solutions more likely to encourage compliance;

4. May lead to improvements in the legal text, ensuring clearer communication of requirements;

5. May enable government to be more responsive to the needs and interests of affected persons.

These considerations suggest that in most respects consultation is likely to have its greatest impact if conducted while policy development is still under way (although, for complex matters particularly, it may be useful or necessary to employ it at later stages too). Once a legislative text is in an advanced state of preparation, it is often too late to review the policy premises on which it has been structured. At the same time, a draft of legislation itself can be a valuable consultative instrument, since it sets out, in precise terms, the requirements with which affected persons will have to comply. But it is often much more difficult to make fundamental improvements when a project has reached this stage.

In CEE countries, consultation with other ministries, typically those that have an immediate interest in the subject matter or in some aspect of the legislation, is now a widespread practice. However, consultation with non-governmental interest groups outside Government is far less common. Little use too appears to 
be made as yet of consultation e.g. with a standing or ad hoc advisory group or with a representative group of those principally affected). This device makes it possible to obtain the informed views of outsiders (who can be changed or added as the project develops), while retaining the decision-making responsibility in the hands of a small and more cohesive working group.

Rather than using consultation to provide external knowledge or experience, that is likely to be brought into the law-making process at present by adding suitable persons to the working groups assigned to particular projects. This can have the disadvantage of creating an unnecessarily large body for policy-making and law drafting, and may make decision-making more difficult and may increase the possibility of unsatisfactory compromises.

\subsection{Parliamentary Legislative Initiatives}

Although most primary legislation is prepared by or for Governments, the Parliaments of CEE countries regularly exercise their constitutional power to introduce their own legislation as well as their amendments to Government bills. These initiatives may be taken by Parliamentary committees or individual members of Parliament, acting on their own behalf or on behalf of external interest groups. Indeed, a Parliament dissatisfied with legislation presented by the Government may bring forward a bill containing its own solutions to the matter in question.

This means that legislative preparation is in two sets of hands, which do not necessarily grasp matters in the same way. Necessarily, there should be consistency in legislation prepared by both bodies; similar quality standards should be applied and similar verifications carried out in relation to both. CEE Parliaments are developing their procedures for evaluating legislation presented to them by Government in order to focus upon the matters that are of concern to the Parliament. But it is not equally evident that the procedures in Parliament for dealing with its own legislation or with amendments to Government bills offer adequate opportunity for Government (which usually will be charged with putting them into effect) to evaluate those from its standpoint. In particular, Parliaments are not usually well placed to carry out impact analyses, especially with respect to budgetary costs and government administrative resources. Such time as is afforded to Government to consider the legislation may not be sufficient to allow such checks to be made and reasoned counter-arguments to be prepared for consideration in Parliament.

When Parliament initiates a bill on a matter within a ministry's competence, Government may find itself obligated to implement a legislative solution which a thorough analysis of the policy would have shown to be impracticable or inefficient. Improvements in the quality of Government legislation, e.g. by improving the processes of policy development, may reduce the need for Parliaments to introduce legislation of their own on such matters. Indeed, such an objective could constitute an incentive to Governments to enhance their law preparation capacities.

Similar considerations apply with respect to major amendments to Government bills forced through by Parliament. Although it is usually possible, in the last analysis, for Government to withdraw its bill if Government finds the amendments unworkable, this does not advance the process of legal reform. The more that Government develops expertise in policy development and law drafting (which Parliament is unlikely to be able to replicate), the more a discrepancy in legislative quality is likely to occur between Government and Parliamentary legislation. 


\subsection{Secondary Legislation}

Government and individual ministries in CEE countries usually have constitutional power to make secondary normative acts to implement primary legislation in their area of competence. In some countries, the limits within which that power may be exercised can be set in the primary legislation on the particular topic. But even then the power is usually expressed in broad terms that carry few particularised restrictions. Little guidance is given as to the principles to be followed in determining which matters should be dealt with by primary legislation and which by secondary legislation. Further, it is not usually legally required nor is it the practice to specify the purposes, circumstances or cases for which secondary instruments can be made.

When considering bills, Parliaments do not concern themselves greatly with the nature of the secondary law-making powers that Government are acquiring, in particular whether any matters should specifically be excluded from those powers and retained by Parliament. Nor is there sufficient advance interest in the way in which those powers might actually be used.

The safeguards against misuse by Government of these powers are usually seen as resting with the courts, which can intervene if secondary legislation is made on matters that go beyond implementation. But such challenges, as with all judicial review, may be restricted either because specific categories of persons only may initiate them or for reasons of time or money. There is usually no possibility of a specific challenge to secondary legislation before a Parliamentary body on those, or other non-legal, grounds. Nor do Parliaments routinely examine how Governments are using these powers or the instruments themselves. Such verifications as take place with respect to secondary instruments take place within Government.

These arrangements could give rise to a serious democratic deficit if, as has been suggested in some CEE countries, there is a dramatic increase in the use of secondary, rather than primary, legislation to give effect to EU directives. Even without that development, there needs to be recognition that the more wide-ranging and generalised the provisions of primary legislation, the greater the potential range of the secondary powers. As legislative drafting skills evolve, so it may be expected, if experience elsewhere is relevant, that Governments will strive for a level of generalisation in normative provisions which will enable policy matters to be dealt with by secondary legislation. If Parliaments do not concern themselves with these issues, in particular by setting more precise limits in bills to secondary law-making powers, they may not be able to prevent some loss of legislative authority.

A different problem reported in some CEE countries arises from delays in making secondary legislation. In the modern state, much primary legislation is ineffective on its own; secondary regulation is needed to provide the detailed mechanisms and administrative arrangements essential to its implementation. If this is not provided, primary legislation, although technically in force, cannot be put into effect. Although, ideally, primary and secondary legislation should be prepared alongside each other in order to establish a new legislative scheme, practically this is often not feasible. Few countries permit the postponement of the commencement of primary legislation until the necessary secondary instruments have been made. This highlights the importance of integrated plans for entire legislative projects that include timetables for both primary and secondary legislation.

\subsection{Access to Legislation}

A principal aim of legislation is to enable those affected by it to organise and regulate their activities in accordance with its normative requirements, and so to provide security and legal guarantees for their transactions. Ready access to that legislation is a necessary concomitant. Full collections of legislation, 
primary and secondary, currently and formerly in force, must be readily available, and copies of individual instruments must be easily acquired by officials, legal representatives and members of the public. This appears to be accepted policy in all CEE countries, and steps are being taken in most of them to give effect to it.

The volume and speed with which legislation is made demand responsive techniques to ensure availability. Procedures for registering and archiving legislation need to be put in place, as a governmental responsibility, so as to establish a state guarantee of the sources. They must apply to secondary legislation, at least in so far as it has implications for interests outside government, as well as to all primary legislation. Indexes in an up-to-date form are needed for all current legislation. Repositories of printed legislation need to be conveniently placed. Consolidations of current laws need to be published regularly, both in totality and individually in cases where legislation has been amended frequently. This has important implications for government budgets.

Several CEE countries are taking steps to use electronic databases for these purposes. In many instances, state resources do not permit these features to be provided by an official government body for general public access. Commercially provided databases are increasingly found, which make publicly available by electronic means what government can only provide in paper copy. But unlike laws published and printed under state authority which carry a guarantee of authenticity, these databases generally can be accorded no such authoritative status, and paper copies may still have be produced for court and similarly formalised use.

\section{Strategies for Improving Law Drafting}

In this section, we examine ways in which improvements might be made with regard to problems of the kinds mentioned in the previous section. These draw in part upon initiatives already taken in one or another of the countries reported on. It is a matter for decision by other countries whether these innovations may be suitable for adoption or adaptation by them. Accordingly, we make no recommendation about such initiatives other than that they be carefully evaluated when improvements to existing arrangements are under review. The following are seven strategies for improving law drafting that should be considered:

1. Creating and enforcing a regulatory framework for law drafting;

2. Improving policy development prior to drafting;

3. Setting and maintaining law drafting standards;

4. Making fuller use of consultation;

5. Applying equivalent procedures and standards to Parliamentary initiatives;

6. Applying equivalent procedures and standards to secondary law-making;

7. Improving access to legislation.

\section{1. $\quad$ Creating and Enforcing a Regulatory Framework for Law Drafting}

One of the most important commodities for good law-making is time. Those preparing legislation must be afforded adequate time to complete properly the range of tasks arising from policy development through to the drafting of the legislative text before the legislation is introduced into Parliament. At the same time, law-makers have an interest in ensuring that new legislative projects become operational law as quickly as 
possible. In some cases, great speed is essential to deal with an urgent need. But undue hurry driven by short-term political objectives is a significant factor contributing to defective law. The question of how much time to allocate to a legislative project deserves deliberate attention.

Further, the human resources that can be made available for preparation and drafting are usually limited, sometimes scarce. So, It is equally important that their time is not wasted by unnecessary procedures, by delays caused by the inability of others to deliver their input on time, or by having to repeat a process carried out inadequately earlier. In particular, there is little value in ministries carrying out extensive work on legislative projects only to find, when they are submitted to the Council of Ministers, that they are not acceptable in principle or cannot be given any priority for presentation to Parliament.

These considerations make clear that the processes for developing and drafting a piece of legislation must be planned. Timetables and deadlines should be set for all persons involved, and co-ordinated with the similar arrangements made for all the other legislation that is in preparation at the same time. Of equal importance, there must be some authority in government that has the capacity to ensure that the planned arrangements are complied with.

\subsubsection{A Legislative Programme}

The basis for planning is necessarily an agreed programme of the legislation which Government intends to have drafted in the coming year. Ideally, this programme should be integrated with Government's plans for introducing the legislation into forthcoming sessions of Parliament. In those circumstances, it may be expected that the programme has to be presented to Parliament for its consideration and, usually, approval.

In principle, a legislative programme calls for:

- allocation to a body at the head of Government of the responsibility for developing the programme on behalf of, or for approval by, the Council of Ministers;

- a process to enable that body to decide legislative priorities, i.e. which of the possible legislative projects are to be part of its next programme (since there are invariably more projects than there is time or resources for Government to prepare and for Parliament to consider, if those functions are to be satisfactorily performed);

- stipulated procedures (e.g. as to the information to be provided in relation to proposed legislative projects) and an annual timetable for this process, so that ministries may plan ahead and prepare their positions in good time;

- working out the programme for a long enough period ahead to give ministries adequate time to complete larger, more complex legislative projects (which, if policy development and consultations are to be properly undertaken, may take more than, e.g. a year, the usual programming period);

- procedures for dealing with urgent legislative projects that arise after the legislative programme comes into effect;

- acceptance that ministries should not start to develop a legislative project until approved by Government collectively as part of the legislative programme (thereby saving resources from being used on projects that may not be proceeded with). 


\section{Legislative Programming in Estonia}

The Bill for the Legislative Drafting Act contains a detailed scheme for a

"Comprehensive Legislative Drafting Plan". This is provided for in Division

$4,1$ of the Bill ( $\S 42-50)$ and is described in the Country Report.

\subsection{2. $\quad$ Legislative Timetables}

Outline timetables for legislative projects are necessary to make a legislative programme effective, and should be set centrally. They enable Government to plan ahead for their consideration and approval of the legislative drafts and for staging their subsequent submission to Parliament. They facilitate the planning of the work of the Parliament. They also enable the body in Government co-ordinating the legislative projects to set deadlines for them and to monitor and secure the orderly progress of their preparation. They are necessary to enable ministries to set internal work plans and detailed timetables and to allocate the resources that are needed to complete their projects by the given deadlines.

\section{Legislative Programming and Work Plans in Slovenia}

The Standing Orders of the Government, Articles 57-63, provide for the establishment by Government of a work programme and periodic work plan, with deadlines. The General Secretary has responsibility for monitoring their implementation by the individual ministries. See Country Report.

In principle, timetabling calls for:

- a preliminary assessment of the steps that need to be followed for the particular project (e.g. the extent to which external consultation will be used);

- realistic and careful estimations of the time that will be needed for completing those steps;

- periodic reconsideration of the timetables, e.g. in the light of difficulties encountered, and a procedure for altering them.

Ideally, the timetables for primary legislation should relate also to the preparation of the secondary legislation which is essential for its implementation and enforcement ${ }^{6}$. In any case, individual timetables for the preparation of important secondary legislation are desirable.

\section{Legislative Programming and Timetabling in Bulgaria}

The Law on Normative Acts and the implementing Decree contain provisions stipulating requirements for the planning of bills and their timetabling. These are in the Law, Chapter 2 (Articles 19-25) and the Decree, Chapter 1 (Articles 1-8). They are described in the Country Report.

6. See, e.g. Bulgaria, Regulation on the Structure and Organisation of the Work of the Council of Ministers and its Administration, Article 25(2). 
In countries where ministries are linked through a computer network, ministry work plans and the related timetables can usefully be maintained in a database accessible to all other ministries. This enables all ministries interested in a particular legislative project to signal their interest in it, with a view to being represented on the working group or being consulted. It makes them aware of its timetabling and its progress, and the times at which they are likely to be consulted. It also allows a central co-ordinating authority to monitor progress of all projects and to intervene if necessary deadlines are not being respected.

\subsubsection{Regulatory Directives}

Common standards and uniform practices for preparing and drafting legislation are set most effectively through the provision of a single set of directives, which have behind them the authority of Government and, as needed, Parliament. In the present circumstances of CEE countries, the essential elements are most likely to be regulated by law. Not only is this the most powerful means by which reforms can be effected, but for the time being it may be the only sure way by which a single set of standards can be set to bind both Government and Parliament. Those provisions can be amplified by secondary instruments, such as Standing Orders, made by Government and Parliament separately to deal with matters that are of separate concern to them (e.g. Parliament usually has little concern in the processes of preparing and drafting secondary legislation). In some countries, certain matters relevant to drafting are contained in instruments which deal with a much wider range of matters. Ideally, all the directives concerned with legislative preparation should be collated into a single source (e.g. a Legislative Handbook) that is thoroughly known and used by everyone involved in preparing legislation. Such a document would be of particular value where external advisers or consultants are employed.

Three sets of circumstances are typically regulated in legislation specifically concerned with law drafting:

- procedures that are to be followed at different stages in the drafting process;

- uniform rules as to the application and operation of particular kinds of legislative provisions;

- standard requirements as to the form, terminology and style in which legislation is to be drafted. 


\section{Examples of Regulatory Directives}

- Bulgaria: the Law on Normative Acts (51 Articles) and the implementing Decree (56 Articles), 1973/74, amended 1995, concerned with all three matters.

- Estonia: the Bill for the Legislative Drafting Act (113 Articles) contains provisions on all three matters, but the procedural requirements relate to the stages involving Government.

- Lithuania: Drafting Procedure of Laws and other Legal Acts (13 Articles), 1995; concerned with the last of the matters.

- Slovakia: Legislative Rules on Law-making (13 Articles + 2 Annexes, including Legislative and Technical Instructions, 59 Articles), principally concerned with the first and third matters.

Even when basic standards are set by such instruments, there is value in developing a supplemental manual or style guide for law drafters. Such a document can build upon the basic standards by demonstrating, in a less prescriptive manner, preferred ways to fulfil them in particular circumstances or how to deal with particular drafting difficulties that often occur. It can be used to illustrate how legislative language can be made more accessible to ordinary users, and to support plain language drafting. It is a simple device for showing how to avoid past practices which have unduly relied upon, e.g. unduly legalistic language. These documents are also invaluable as a means of informing drafters from outside Government of current practices, and as a training aid.

\subsubsection{Checklists}

Another tool that can usefully be developed for use by law drafters is the checklist. This typically sets out issues or matters that should be borne in mind during a particular process. It may be useful both as a starting point for a systematic approach to a particular stage in the process and as an aid in reviewing the work done at any such stage. Checklists have particular value, of course, in regard to the various verifications that should be carried out at the policy and drafting stages.

It is common practice for individual drafters to devise checklists for their own use (perhaps adapted from those found in textbooks on law drafting). At the same time, particularly in areas where innovation is sought, their formulation by a central body for general use is obviously advantageous. This device has been used in this context in several OECD Member countries ${ }^{7}$.

7. Examples are cited in The Design and Use of Regulatory Checklists in OECD Countries, OECD/GD(93)181, 1993. 


\section{Checklists in Use in the United Kingdom}

The following are examples of short checklists issued by the Deregulation Unit, in the Cabinet Office, in 1996:

Good Regulation - The Principles of Good Regulation;

Compliance Cost Assessment;

European Law - A Deregulation Checklist for Ministers;

Implementing European Law.

Such checklists might be more readily developed for CEE countries if model checklists that could be adapted to local circumstances were provided. Checklists have already been developed by SIGMA for civil service legislation ${ }^{8}$ and on the law drafting process ${ }^{9}$, and other relevant examples can be found in a number of OECD publications ${ }^{10}$. The following matters for which model checklists could usefully be devised represent a potential area of SIGMA assistance.

\section{Model Checklists for CEE Countries}

1. Regulatory policy, and in particular Regulatory Impact Analysis.

2. Cost assessment.

3. Alternatives to legislating — using the Government "tool kit".

4. Verification of necessity and effectiveness of legislative proposals.

5. Administrative requirements and implementation methods.

6. Checking compliance with EU law.

7. Checking compliance with the European Convention on Human Rights.

8. Checking compliance with the Constitution and existing law.

9. Checking form, structure, language use and legal techniques in law drafts.

10. Minimum contents of explanatory memoranda.

\subsubsection{Co-ordinating Authorities}

Co-ordination is required at two levels: firstly, in creating and maintaining the regulatory framework, and secondly, in progressing individual legislative projects. In both respects, it should be carried out by a body which has the standing and political authority to make its actions effective, especially where reforms are

8. See Civil Service Legislation Contents Checklist, SIGMA Papers No.5, OCDE/GD(96)21, 1996, and Civil Service Legislation: Checklist on Secondary Legislation (and other Regulatory Instruments), SIGMA Papers No. 14, 1997.

9. Checklist on Law Drafting and Regulatory Management in Central and Eastern Europe, SIGMA Papers No. 15, 1997.

10. The Design and Use of Regulatory Checklists in OECD Countries, OECD/GD(93)181, 1993; Checklist on Regulatory Quality Techniques, in Improving the Quality of Laws and Regulations: Economic, Legal and Managerial Techniques, OECD/GD(94)59, SIGMA, 1994; OECD Reference Checklist for Regulatory Decision-making, set out in Appendix 4 below. 
being instituted. But both functions do not necessarily have to be performed by the same body. In any case, responsibility for co-ordination has to be divided on certain matters, since some features must be put into effect within Government, others by Parliament. In that case, machinery is usually necessary to co-ordinate the co-ordinating functions of Government and Parliament.

Most CEE countries do not appear to assign specific responsibility for developing a coherent policy with respect to the regulatory framework. The choice usually lies between a ministry, such as the Ministry of Justice, and an office attached to the Council of Ministers. It may be argued that the Ministry of Justice (which typically co-ordinates legislative projects) is best suited to this broader function, as it could bring unique experience to the task. On the other hand, a single ministry lacks the superior authority to develop and enforce a policy that must be put into effect by other ministries. For that reason, there is a stronger case for the function to be performed by a body that is backed by the collective authority of the Council of Ministers.

\section{Co-ordinating the Regulatory Framework in Slovakia}

The Cabinet has created its own Legislation Council, headed by a deputy Prime Minister for this purpose. This advisory body also reviews individual bills. See Country Report.

Responsibility for co-ordinating legislative projects on behalf of Government is commonly given to the Ministry of Justice, which establishes a department or council to perform the functions. These include checking that the requirements set by Government for legislative projects have been properly completed, and usually authorise the return of those which have not. Again, this can give rise to problems of authority, for example where the initiating authority considers that some circumstance justifies short-cutting the requirements. Such inter-ministry disputes may need resolution at the Government level. Regulations must provide for that contingency.

\section{Government Co-ordination of Legislative Projects}

In Lithuania, whilst all legislative drafts must be submitted to the Ministry of Justice, the results of the examination are passed to the Legal Department in the Office of the Government, which must issue its visa if the required standards are met. See Country Report.

In Estonia, the Bill for the Law Drafting Act contains detailed provision for the "concordance" of Government bills by the Ministry of Justice, which has the right to reject or send bills back on a wide range of grounds. However, a bill refused concordance a second time may be sent forward to Government for its decision. (Bill, Division 4.2 (§§51-58); see Country Report).

Parliaments too need some machinery to ensure that draft legislation meets its requirements. Preliminary consideration of the policy and substantive content is usually undertaken by specialist committees. But compliance with quality and technical standards is better verified by a single body which looks at all drafts separately from the policy examination. Again, a unit in the Parliament's Secretariat or a specialist committee supported by such a unit are favoured methods. 


\section{Parliamentary Co-ordination of Legislative Projects in Slovakia}

Legislative drafts are reviewed by the Legislative Department of the Chancellery of the Parliament, which has a wide range of other support functions. See Country Report.

Co-ordination between Government and Parliament is important, not only to ensure that their legislative programmes are integrated and that Government bills are presented in an orderly manner, but to provide some means by which duplication of verifications can be reduced. Inevitably, Parliaments wish to carry out their own checks on matters which have already been verified by Government. Information available to Government as a result of its own verifications may enable Parliament to perform its verifications more expeditiously. A common practice is for Government to assign a member of Government, and an official concerned in the drafting, to liaise with the appropriate Parliamentary committee with respect to particular drafts. But an appointment of a member of Government to liaise generally has merit.

\section{Co-ordination Between Government and Parliament in Lithuania}

Government appoints a Representative of the Government for the relations with the Seimas. See Country Report.

\subsection{6. $\quad$ Specialist Advice on Textual Quality Reforms}

Governments may not have the time or the expertise to carry out an overall review as to the form in which legislation is generally drafted, and particularly of textual and structural improvements that may make legislation easier to use and understand. There may be advantage in drawing on external resources, e.g. from academic institutions, lawyers and judges, to make recommendations for changes that will raise the textual quality of law-making instruments generally.

\section{Agency for Textual Quality Reforms in Estonia}

The Legal Terminology Committee of Government has the function of making proposals to improve the linguistic quality of legislation. See Country Report.

\subsection{Improving Policy Development}

Perhaps the most useful step in improving the quality of legislation would be the recognition that policy development is an essential precursor to law drafting. This would encourage the introduction of procedures and practices that would make it more likely that properly thought out answers will be provided on fundamental questions of policy and approach, especially for complex and difficult reforms. Such a recognition is implicitly required, e.g. for the institution of more systematic regulatory impact analyses than are conducted at present.

The regulatory directives in some CEE countries make it clear that, before a legislative proposal is adopted, a study must be carried out into such matters as the necessity for legislation, the reasons for adopting a new law and its objectives, the anticipated results and the costs and resources that would be 
required. But in reality these are often not carried out to a sufficient depth to produce the policy guidance the law drafters need. Indeed the drafters may have little choice but to make their own policy judgements in the course of drafting with little information to guide them.

\section{Directive as to Policy Development in Bulgaria}

Provision is made for a such a study in the Decree to implement the Law on Normative Acts, Chapter 1 (Articles 3-6). For actual practice, see Country Report.

Some CEE countries include in their regulatory directives requirements that specific verifications are to be made with respect to legislative drafts, and the results incorporated in the explanatory memorandum that accompanies the draft legislation. In fact some of these verifications should be carried out before drafting is begun, as they principally concern policy selection and development. But few directives make this clear. In practice, the checks may be applied only to the legislation when in draft form, may be conducted superficially and as a formality, and may have been written to justify a text that has been drafted with little prior consideration of alternatives.

At the same time, the explanatory memorandum can be a valuable technique for conveying essential background information about a bill, its objectives and justification, as well as the anticipated impact. In its most effective form, it also provides a narrative account of the legislative approach and the scope of the new arrangements, with a commentary on each of its provisions. It should also be used to indicate the nature and coverage of the secondary legislation that will be needed to implement the bill. This document enables both the Council of Ministers and Parliament, as well as the public, to obtain, in a more accessible form than from the bill itself, a full picture of the new legislative scheme and its intended effect. In principle, it may also be useful as an aid to interpretation of the legislation. For that reason, it is best prepared and checked by those responsible for drafting the bill to ensure complete consistency with the terms of the bill. On the other hand, as it is not usual practice to revise the memorandum when a bill is amended in Parliament, it is not an interpretative aid that can be relied upon in all cases.

\section{Contents of The Explanatory Memorandum in Estonia}

The Bill for the Law Drafting Act (Chapter 2, Division 3, §§28-41) contains detailed requirements as to the contents of the explanatory memorandum. These call for an explanation of the effects on the economy, environment and public administration and organisational changes and social consequences, as well as the costs necessary for implementation. See Country Report.

\subsubsection{Policy Verification}

A more systematic approach to verifications forces into the open the necessity to treat policy choice and development as a distinct process. A glance at the policy verifications listed in Section A of Appenidx 5 shows clearly that they must be carried out as a development stage if they are to perform a useful function. If they are postponed to the drafting stage, the legislative text may have to be rejected or fundamentally altered to take in policy considerations that only became evident as a result of the verification. This is an inefficient use of drafting resources. 
Such an approach can be encouraged by issuing clear guidance as to how and when particular verifications should be conducted (e.g. in formal directives or checklists). This should be the function of the body co-ordinating the regulatory framework.

\subsubsection{Regulatory Impact Analysis}

These considerations have special relevance with respect to Regulatory Impact Analysis (RIA). Strictly, RIA is a tool for assessing the impact of new legislative proposals in a variety of ways that assist in making the best choice between possible policy options and in developing the preferred option. It aims to enable informed decisions to be made about new policy initiatives and an acceptable balance to be struck between benefits that can be realistically obtained and additional restrictions, costs in particular, that will be imposed. It is in fact concerned with essential questions that should always be asked about any new legislative project, but which too often are not. RIA brings a structured approach to policy development, by requiring those questions to be asked and meaningful answers provided.

RIA plays its major role in respect of the policy verifications that, in Appendix 5, are grouped under costs and economic impact checks, and efficiency, practicability and implementation checks. To be most effective it needs to be applied early on in policy formation, when policy alternatives are still under consideration. At the same time, the results of an analysis may be valuable in determining some of the lesser policy-related issues that invariably arise both when developing the selected option and during the drafting of the necessary legislative norms (e.g. as to administrative mechanisms). In some circumstances, further checks may be called for at a later stage, e.g. as the legislative scheme takes a more settled form.

The importance of this approach is illustrated by cases where legislation has been passed by Parliament and has come into force on publication, although the necessary resources for its implementation were not available. Indeed, substantial parts of the legislation may not have been given effect for this reason, even after some years. Analysis of costs and other financial impacts cannot be left until the legislation becomes law. If implementation has to be phased in over a period of time, that should be ascertained by an RIA, and appropriate provision made in advance.

RIA then is a valuable aid to reaching decisions about the nature and content of a legislative project. But it may also assist in providing a much more reasoned justification for the new project to the politicians who have to decide to initiate the project and to the Parliament who have to decide whether to support it. Increasingly, regulations in CEE countries are requiring that explanatory memoranda (which typically have to be prepared by the drafters of the particular bill) must contain fuller information on these kinds of matters. Again, RIA enables more persuasive explanations to be given to affected parties and to the general public about new legislative projects, thereby improving the transparency of decision-making.

RIA is a tool that requires application of quantitative methods wherever possible. Those necessarily depend on the availability of reliable information, particularly quantitative data, to which such methods can be applied. RIA is designed to replace speculation and guesswork about the likely consequences of legislating. It is not enough that policy-developers come up with a proposal that is politically acceptable. It must be possible to offer more objective indicators that a proposal will produce the stated and desired results, without bringing more serious problems in its train.

A variety of analytical methods may be used. Experience in OECD Member countries shows that these differ from one country to another, both in their range and in their rigour. Indeed all countries are still developing their RIA approach by stages, having started from small beginnings. What is clear is that many CEE countries have a limited capacity, e.g. of trained economists in Government and outside, to undertake 
wide-scale and sophisticated RIA of legislative projects. There are also serious limitations in obtaining reliable statistical data and other quantitative information. We have noted earlier (Section on "Underlying Constraints", Subsection 2.4. "Verification Procedures") a number of other problems in instituting improved verification processes, especially with respect to RIA.

Accordingly, each CEE country must develop its own strategy, for both the short and longer terms, and within the resources available to it or in prospect, for incorporating RIA techniques with respect to legislative projects. The following are the kinds of issues that the strategy may need to embody:

\section{Elements to Be Defined in an RIA Strategy}

1. The bodies that are to be responsible for RIA: i.e. those bodies, including private bodies, that are actually to carry out RIA and those governmental or parliamentary bodies that are to exercise scrutiny or control over those activities.

2. Allocation of adequate resources, both financial and personnel, for undertaking RIA and for training.

3. The analytical methods to be used or developed.

4. The types of legislative project to which RIA is to be applied.

5. The procedures and criteria to be followed for targeting the projects for RIA, and for deciding the stage at which RIA is to be carried out and the analytical method to be used.

6. The procedures to be followed in RIA and for integrating RIA into the policy development process and for communicating the results.

7. Collection and provision of the data necessary for RIA.

8. Procedures for ensuring compliance with a requirement to carry out RIA.

SIGMA has already laid groundwork for assistance to CEE countries in developing their RIA strategies. Workshops have been conducted in the Baltics for senior officials (Latvia, October 1996 ${ }^{12}$; Lithuania, April 1997), which have examined in some detail considerations relevant to the circumstances of CEE countries, as well as options and possible ways forward. Similar workshops elsewhere would assist in gaining a clearer understanding of the constraints and possibilities for CEE countries generally, perhaps leading to a set of SIGMA guidelines for the introduction of a practical RIA strategy for countries in transition.

But an initial step would be the adoption of a checklist of the impacts that have to be examined by policy developers and reported on to the political authority making the final decisions on policy issues (e.g. the minister). This could be developed from the broader OECD checklist (See above Section on "Underlying

11. See further, Rex Deighton-Smith, Regulatory Impact Analysis, a paper prepared for the SIGMA Workshop on Regulatory Analysis/Consultation with NGO's, Vilnius, April 1997.

12. See SIGMA Paper No. 13 Assessing the Impacts of Proposed Laws and Regulations, OCDE/GD (97)126, OECD, Paris, 1997, which is a compilation of the papers that were prepared for the seminar by experts, along with a brief summary of discussions. 
Constraints, subsection 2.2. on "Policy Development") or from those in use in some OECD Member country systems, or even in the form of a simple computer programme. SIGMA may be the appropriate body to assist by producing a model checklist.

\section{Checklist in Use in Mecklenburg-West Pomerania}

In 1996 the Government of Mecklenburg-West Pomerania adopted guidelines for bills and draft secondary legislation which includes a suitable checklist for testing legislative projects ${ }^{13}$. This is based on a checklist developed for use by the Federal Government.

\subsubsection{Approximation to EU Law}

One consequence of the steps taken in individual CEE countries to integrate with the European Union is the need to take full account of the EU law when preparing legislation on a matter that is regulated by that law. (It is also necessary to set up arrangements for reviewing existing legislation for the same purpose). In some cases a Framework Programme for the Approximation of Legislation has been launched under EU/Phare. ${ }^{14}$ This has led to the creation of special ministries or units within ministries to bring expert knowledge of EU law to the task, as well as special co-ordinating authorities ${ }^{15}$. For our purposes, the central feature is the need to institute a system for verifying compatibility of new legislation with EU law as part of the drafting process. In a number of countries, there is a specific requirement that the explanatory memorandum in justification of a new bill must cover this question of compatibility.

Consideration of compatibility must be a principal element in policy development; it is needed in order to shape the content and approach of the legislation. One important issue, particularly pertinent to CEE countries, emphasises the need to examine compatibility in depth before starting drafting. In certain matters, full implementation of EU law in a CEE country still in transition is not practicable or desirable. Applicants for EU membership have the right to set priorities as to what is most needed. Accordingly, policy development must include checks of the extent to which the priorities have been set in respect of the particular subject, and that they are being followed, in order to determine, for example, whether full compatibility should be postponed to a later date, and if so, how far towards that objective the new legislation is to go. Such decisions are vital preliminaries to drafting the text.

Some form of RIA may be needed to develop such a policy. A clear picture is needed of such matters as the local capacity to approximate to EU standards and the relative costs to the business sector of a possible staged approach to approximation. It is noteworthy that regulatory directives dealing with compatibility tend to be concerned with the position achieved in the draft law; they give little guidance as to procedures to be followed at the policy development stage.

13. Described in a paper prepared by Dieter Hofs, for the SIGMA Workshop on Regulatory Impact Analysis/Consultation with NGO's, Vilnius, April 1997.

14. A detailed account of the Bulgarian programme and the arrangements for its implementation is contained in the Country Report.

15. For example, the Institute for Approximation of Law, in Slovakia. For a detailed account of the Slovak arrangements, see the Country Report. 


\section{Approximation of Laws in Bulgaria}

The regulations contain detailed arrangements for examining the compatibility of draft legislation with EU law, including consideration by a special Work Group on Approximation of Law. Policy issues that give rise to conflicts, e.g. between ministries, are resolved by that Group or at the higher level of the Co-ordination Commission on European Integration. (See Decree No. 66 of 1995; see Country Report.)

It is usually the case that further confirmatory checks are required in relation to the completed draft, not least to establish that the results of the new law are consistent with those intended under EU law. In many instances, the EU law sets policy objectives and so may limit the policy choices. It may also heavily influence the drafting itself (copying the terms of an EU directive, although open to criticism, is a widely used device). But the method of giving legislative effect to the policy is dictated by local drafting approaches. Consistency with those is as important as compatibility with the requirements of the particular EU directive.

Approximation to EU law is an issue which, in principle, affects all ministries, although some more than others. EU countries have found that EU law cannot be considered as a separate system of law; integration of its requirements on any subject matter is the responsibility of the ministry with the competence and expertise in the national law on that matter. This suggests that this question of compatibility should be dealt with by all ministries, rather than by a central unit, and that each ministry should be required to develop the necessary capacity to undertake this.

\section{3. $\quad$ Setting and Maintaining Law Drafting Standards}

\subsubsection{Drafting Procedures}

We have suggested earlier (See above Section on "Underlying Constraints", Subsection 2.5. on "Law Drafting Procedures") that law drafting calls for special legal skills. Those skills derive, in part, from a special understanding of legislative methodology and, in part, from distinctive experience in drafting techniques. Drafting legislation calls for a systematic, often painstaking, application of a particular expertise in a range of analytical and writing skills. Law drafters are primarily concerned with converting policy into a coherent body of normative rules. At some stage, they must approach the policy proposals from that standpoint. Moreover, it is principally the function of the drafter to ensure that the draft is compatible with other legislation, that the methods it uses will be practical and legally effective, that it follows conventional forms and uses appropriate and comprehensible language and terms. The final draft must communicate legislative requirements with clarity and certainty. Those functions call for the drafters to apply a series of verifications throughout the drafting process, although other persons, including officials from other ministries, will also carry out similar, confirmatory checks when they are consulted and particularly after the draft is complete. 
An experienced law drafter ${ }^{16}$ has suggested that drafting should follow a logical progression through five stages, although these cannot be regarded as self-contained since it is often necessary to go back to an earlier stage to deal with issues that have come to light at a later one.

\section{The Five Stages of the Drafting Process}

1. Understanding the project.

2. Analysing the project.

3. Designing the scheme.

4. Composing and developing the draft.

5. Scrutinising and testing the draft.

a)

\section{Understanding the Project}

The choice of the appropriate legislative approach, legal concepts and means of implementation, as well as legislative structure and language, cannot be made unless the drafter is fully informed of what is intended. Part of this knowledge comes from the drafter's participation in the policy development. But the drafter must also ensure that issues and uncertainties about policy that affect the drafting of the normative rules are focused upon and resolved. In particular, in addition to full background information on the problem to be solved, drafting calls for a complete understanding of the intended and achievable objectives of the project, the mechanisms selected to achieve those objectives, and foreseeable consequences of implementation. Much of that information should be available if the policy development has been effectively carried out. If the development was deficient or essential answers were not provided, it must be sought. This may call for consultation with the appropriate persons or bodies in other ministries or outside Government.

In countries, such as Anglo-Saxon countries, where the drafting is provided by a different authority from the one developing policy, this kind of information is typically provided in a systematic and narrative form ("instructions"), usually written by lawyers from the policy group (who are likely to have legal expertise in the subject matter). But for other countries too, especially those CEE countries where the drafting is undertaken by persons outside the policy-developing ministries, such provision of information is a sound preliminary step to drafting as well as a good discipline. Moreover, it provides a resource that can be drawn upon when political endorsement of the policy is being sought before the actual drafting is begun.

\section{b) Analysing the Project}

Drafters need to analyse a number of issues for themselves. Not only should they not rely upon the judgement of others, but they need to have a clear grasp for themselves of matters that will affect the way in which they draft individual provisions.

16. G. Thornton, Legislative Drafting, 4th ed, 1996, p. 128. 
Even before drafting, the following matters should be verified by the drafter:

\section{Matters for Consideration by the Drafter at the Analysis Stage}

- the extent to which the proposals impinge upon matters already governed by existing law;

- that the project and the legal means to be used are compatible with the Constitution, especially the provisions guaranteeing individual rights;

- matters that will need to be drafted in a special way to ensure that compatibility;

- the places in which existing law may need to be repealed or amended, because it is incompatible with the proposals;

- matters that may need to be drafted in a special way in order to make them compatible with applicable treaties, in particular the European Convention on Human Rights;

- the need to take account of EU law affecting this area, and particularly if the proposals are not fully compatible with that law, the extent to which they are to diverge;

- that the means of implementation and enforcement proposed are the practicable and efficient, and how they can be formulated to ensure fairness and transparency;

- the extent to which secondary legislation is likely to be needed to enable the legislation to be implemented;

- whether the project should be given effect by amending an existing law or by a self-contained bill.

c)

\section{Designing the Scheme}

A piece of legislation, as any writing project, needs to be carefully designed before its composition is started. A structure for the entire instrument that is deliberately planned can ensure that the legislation is organised in the most logical form, and therefore aids communication. This is particularly important in the case of complex or lengthy legislation. Pre-planning has other advantages too. 


\section{Benefits from Designing a Legislative Plan}

- it encourages decisions on the basic concepts and terminology to be used in composition;

- it is a useful tool for testing whether all aspects of the policy proposal will be fully dealt with when the plan is put into effect in the draft;

- it reduces the likelihood that major restructuring changes will have to be made during the composition, or that the draft must be discarded because fundamental structural flaws have appeared;

- it provides a checklist of matters that require legislative provisions, enabling progress on drafting to be monitored and any necessary timetable adjustments made;

- it provides an opportunity to determine the matters that should be dealt with by the primary legislation, and those that are to be covered by secondary instruments;

- it may be used by the working group to check the shaping of the legislative provisions.

Of course, the plan must take into account such matters as:

- the usual position in a legislative instrument of formal and technical provisions;

- conventional practices for dividing legislative instruments, e.g. into parts and divisions;

- the special form usually used for amending bills.

But the substantive provisions can be deliberately arranged to bring out inter-relationships that would be meaningful to the end-users. A number of general principles can be applied to legislative ordering: 


\section{Principles of Legislative Design}

1. Related provisions should be gathered together in the same part of the bill, and distinct groups of related provisions should be created as separate Parts of the bill.

2. Groups of provisions, and Parts, should be ordered according to the same principles that govern individual provisions (as follow).

3. Primary (or basic) provisions should come before those subsidiary provisions that develop or expand or depend upon them.

4. In particular, general propositions should come before a statement of exceptions to them.

5. Provisions of universal or general application should come before those that deal only with specific or particular cases.

6. Provisions creating bodies should come before those that govern their activities and the performance of their functions.

7. Provisions creating rights, duties, powers or privileges ("rules of substance") should come before those that state how things are to be done ("rules of administration or procedure").

8. Provisions that will be frequently referred to should come before those which will not be in regular use.

9. Permanent provisions should come before those that will be in force or have application for only a limited time (e.g. during a transitional period).

10. Provisions affecting a series of related events or actions should be set out following the chronological order in which those events or actions will occur.

11. The objectives of the bill should be stated at the beginning, since they set the context in which the provisions that follow must be read.

12. Any definitions provided for terms used in a bill should be set out before the terms are used; in any case, the way in which a bill is using a term should be self-explanatory from the first occasion that the term is used.

13. The application or coverage of the bill (i.e. the statement of general cases dealt with and not dealt with) should come before the provisions that apply to those cases.

14. Provisions setting out the scope of powers to make secondary legislation should be dealt with after the substantive provisions of the legislative scheme.

Almost all legislation requires the composition of a series of drafts in order to reach the necessary quality. How many is usually dictated as much by the time available as by the complexity of the subject matter. But such a process has considerable benefits, since it enables each version or each completed chapter to be 
reviewed by the working group (or in appropriate cases by a differently composed working group), and gaps in policy or problems to be identified and resolved. Similarly, each draft (or each chapter of a substantial draft) can be sent for review by other interested ministries, in particular to obtain as early as possible their reactions with respect to the issues that concern them.

The mode and style of writing legal rules vary from one country to another, in part in response to peculiarities of grammar and language. Moreover, the level of generalisation at which rules are expressed may differ, materially affecting the length and complexity of bills. But certain common principles are widely accepted.

\section{Some Principles of Legislative Composition}

1. Express normative rules as prescriptions rather than in narrative form.

2. Express norms directly, avoiding circumlocution, and include only those norms that perform a necessary legal function.

3. Avoid long sentences.

4. Follow word order in conventional usage.

5. Use expressions in every day usage, wherever possible; avoid unnecessary legal jargon, but use legal terms to express legal concepts.

6. Omit unneeded words.

7. Use terminology consistently throughout a bill and in all secondary legislation implementing it; use the same term for the same case, and a different term for a different case.

8. Avoid ambiguous expressions and terms that are vague and lack clear definition.

9. Limit cross-referencing to other norms as a method of providing the content to norms.

10. Make amendments to other laws by express alteration of specified provisions.

Some CEE countries have introduced their own guidelines for the linguistic and technical practices that all drafters (whether in ministries or outside the public service) are expected to follow. This is a desirable initiative that could usefully be adopted elsewhere.

\section{Guidelines for Legislative Composition in Slovakia}

Legislative and Technical Instructions (59 Articles) are annexed to the Legislative Rules on Law-making, made by the National Council in 1996.

\section{e) Scrutinising and Testing the Draft}

The process of scrutinising the legislative text is continuous throughout the drafting, particularly to improve its clarity. But in best practice each version should be subjected to a specific scrutiny as the last 
step to check on legal form, clarity and comprehensibility ${ }^{17}$. This first and foremost is the responsibility of the law drafters, but ideally it should be carried out also by fresh eyes. A more thorough scrutiny should be given as the last step in drafting the final version; this should cover a wider range of matters, including a series of legal verifications. These may repeat checks carried out at an earlier stage, but are necessary as the working out of policy into precise norms may have introduced new features into the text. Again, checklists can provide a useful aid to verification.

\section{Verification of the Final Version of the Text}

1. constitutional and legal compliance;

2. approximation to EU law;

3. compliance with international treaties, notably the ECHR;

4. implementation arrangements;

5. secondary law-making powers;

6. legal form, clarity and comprehensibility.

(More detail on these checks is contained in Part B of Appendix 5.)

This sound practice may be enforced by requiring the drafter to prepare a compatibility certificate, which confirms that the checks have been carried out and that compatibilities either have been removed or are retained for reasons that are made explicit. Failure to provide such a certificate may be used as a reason for not permitting the draft to be forwarded to Government or Parliament. This practice merits consideration in CEE countries where the device is not used.

\section{Compatibility Certificates}

In Bulgaria, compatibility certificates are used with respect to compatibility of laws with the Constitution and with EU law (see Country Report).

In Slovakia, an amalgamating clause must be prepared in standard form indicating compliance with EU law (Legislative Rules on Law-making, Article 3 and Annex 1; see Country Report).

Alternatively, drafters may be required to report on matters such as these in the explanatory memorandum that must accompany the completed bill (See above Section on "Strategies for Improving Law Drafting", Subsection 2.1. "Policy Verification"). This is of particular value since it lays the foundation for external scrutiny by other bodies in Government and by Parliament. Again, failure to indicate that the checks have been completed or to provide information that may be relevant to further consideration may constitute grounds for holding the legislation back.

17. For more detail on this check, see item B.6. in Appendix 5. 


\section{Checks Noted in Explanatory Memoranda}

In Estonia, explanatory memoranda are expected to deal with the compatibility of laws with the EU law ( $\$ 34$ of the Bill for the Legislative Drafting Act; see Country Report).

In Slovakia, they are expected to report on compatibility with the Constitution, other laws, international treaties and EU law (Act for the Rules of Procedure of the National Council, 1996, Article 68(3); see Country Report).

Consultation on draft legislation with other ministries or governmental bodies with an interest in the subject matter is a necessary feature of scrutiny (see above Section 3.3.1.d. "Composing and Developing the Draft"). It is a standard requirement almost everywhere. Not only is it designed to remove the possibility of opposition when the bill is under consideration by Government, it ensures that the text is examined from fresh viewpoints, and in some cases that the drafters are made better informed on particular aspects of the matter. Again, the results of the consultation may need to be reported in the explanatory memorandum.

\section{Reporting on Consultations in Estonia}

Explanatory memoranda are also required to indicate any opinions of consulted ministries that were not taken into account and the reasons for ignoring them ( $\$ 34$ of the Bill for the Legislative Drafting Act).

External consultation at this stage with those persons whose activities are to be regulated by the new law can also be valuable. A number of OECD Member countries use testing techniques by which those persons can assess how the legislation might work in practice and how readily they can understand what they will be required to do. This may be undertaken e.g. through a questionnaire carefully designed by the ministry to suit the circumstances of those testing. This is of particular value for secondary legislation which contains detailed requirements as to implementation directly affecting those who will have to comply with the legislation. Those procedures do not appear to have been tried out in CEE countries, and they necessarily involve added expenditure and a longer time lag before the legislation is made. But their value in improving the effectiveness of law suggests that they should be used for matters where implementation is likely to be problematic.

\subsubsection{Drafting Personnel}

We have given an extended treatment of the drafting process in the previous paragraphs in order to bring home the nature of the work that good drafters engage in and the special qualities and skills that they bring to the work. It is an area of specialist legal practice for which many lawyers are unsuited or ill-equipped. A country that wishes to improve the quality of its legislative drafting has to invest in lawyers who have the aptitude and interest to undertake it. It should pursue a strategy for selection of adequate numbers of persons to be primarily engaged in law drafting, for their systematic training and acquisition of essential experience. 
CEE countries (like most EU countries) do not, as a rule, establish posts in the public service which are specifically for law drafting. Although some legal officers may be regularly engaged in the work, there is usually no guarantee that they will have a public service career as a specialist drafter. In most ministries, simple drafting tasks, e.g. for routine secondary legislation which requires no special knowledge, can usually be undertaken by its legal officers as one of their functions. But if, as has been argued, experienced legal officers with the specialist drafting skills are needed for more complex tasks, deliberate steps have to be taken by ministries to ensure that they have posts which are filled by such persons. This can be met by creating a designated post of law drafter or by including appropriate qualifications in the job description of a number of the posts. It can also be met by providing in-service drafting training, both of a basic nature and in specialist areas, for officials in post. It cannot be assumed that, because an officer has legal qualifications, he or she is competent to undertake law drafting at every level required. More than in the past, quality drafting calls for persons who have systematically prepared themselves for this kind of specialist legal work.

A particular difficulty is that some ministries are much less likely than others to be engaged in major legislative projects; the main drafting work may be confined to secondary legislation and occasional amending bills. It is a waste of resources to have specialist and experienced law drafters in ministries where their capacities are not used efficiently. But even ministries where substantial drafting is needed often report a serious shortage of officials with the necessary legal and drafting competence. Considerations such as these have led some CEE countries to contemplate establishing a centralised drafting service to undertake drafting for all ministries and government agencies for, at least, significant legislative projects. Such a mechanism is standard in Anglo-Saxon countries and may offer practicable way forward for some CEE countries, if only as an interim measure. But there are both advantages and disadvantages in such a course: 


\section{Advantages and Disadvantages of a Centralised Drafting Service}

\section{Advantages:}

1. constitutes a standing resource of high quality lawyers with expert knowledge of existing legislation and extensive experience in solving legislative problems;

2. provides collective experience and know-how, in relation to the drafting procedure and techniques, which is handed on to newcomers;

3. ensures that standard procedures will be followed by all ministries in relation to the preparation of legislation;

4. leads to consistent standards and greater uniformity in legislation and legislative approaches;

5. facilitates the proper management of the Government's legislative programme;

6. makes the best use of limited numbers of well-qualified law drafters.

\section{Disadvantages:}

1. will usually not be large enough to undertake all drafting, e.g. of secondary legislation, needed by ministries, which may be handicapped by having no specialist drafters of their own;

2. has little specialist subject knowledge (which ministry lawyers acquire), which may result in legislative solutions that do not reflect specialist requirements as well as they might;

3. is rarely able to be concerned in the process of policy development, given the overall demand on its drafting capacity;

4. accordingly, is heavily dependent upon instructions prepared by the ministries as to the legislative requirements, which may vary widely in quality and must compensate for the law drafters' lack of subject knowledge;

5. tends to become a distinct cadre of specialists who see themselves in elitist terms, which may develop into what has been called an "arcane and somewhat inflexible craft tradition";

6. is usually put under extreme pressure since the drafters tend to be brought in when the project is already well advanced (it is inefficient for the service to be used until it is clear that the project will be approved), and because tight timetables tend to be set for this stage.

Introduction of a centralised service instead of ministry drafters would involve a distinct shift of culture and bring with it the need to deal with legislative projects in very different ways from at present. A more appropriate strategy may be for those ministries regularly involved in heavy legislative activity to develop their own drafting resources (e.g. by induction and in service training), and for some central facility to be 
available from which qualified drafters can be allocated to other ministries when needed. ${ }^{18}$ That facility might carry other functions that are centrally required, such as co-ordination and verification of legislative drafts on behalf of Government. A possible home for such a facility would be the Ministry of Justice.

\subsubsection{Budgeting for Drafting}

Where drafting is undertaken within ministries, ministry budgets must include adequate funding to pay for all drafting activities expected in the next financial year. In most countries, no separate budget item is provided for drafting. Since the costs principally relate to personnel, they are covered by the staffing and general administrative allocations. Accordingly, when staffing levels are under consideration for purposes of planning budgetary allocations, attention should be paid to the future demands that legislative preparation is likely to make upon the ministry's human resources.

But where future drafting requirements are likely to be heavy or to involve complex issues, the ministry may need further funding to discharge its functions to the appropriate standard. If none has been specifically allocated in the ministry's budget, expenditure on drafting must compete with other claims. So, if it is anticipated that additional expenditure will be needed, e.g. in the form of consultants or contracted drafters from outside the ministry or on consultation or RIA, specific budgetary provision may need to be made. If the conclusion of the Government legislative programme can be integrated with the preparation of the draft budget, the estimated drafting costs in the coming year can be factored into the ministries' draft budgets. Such planning may avoid the possibility that agreed legislative initiatives are frustrated or weakened because the responsible ministry lacks the necessary funds.

\section{Budgeting for Drafting in Estonia}

The state budget is to include separate items for the expenses of legislative drafting in individual ministries (Bill for the Law Drafting Act, §43; see Country Report).

\subsubsection{Training Law Drafters}

Ministry budgets might also, under the general heading of training, allocate funding to enable entrants to obtain induction training in drafting and existing law drafters to upgrade their skills. A case can be made for providing all entrants with legal qualifications with induction training in the basics of drafting, with a view to enabling as many as possible to be engaged in this type of work that is within their capacity. A general awareness in every ministry of the standards and techniques required for drafting legislation can only serve to improve the overall quality of the ministry's work in that respect. Those who show particular aptitude may be encouraged to raise their level of skills through further in-service training. These officials may then be in a position to concentrate on this work, particularly in respect of more demanding projects, in so far as the ministry's work plans require. Officials of this standing would be needed in any central drafting facility, where such an arrangement exists.

Formal induction training in drafting is valuable. It is no substitute for learning on the job (although the quality of on the job training is heavily dependent upon efficient supervision and guidance by competent senior law drafters, which are not always available). But a sustained training programme that provides a

18. Such an arrangement exists in Slovenia; see the Country Report. 
basic understanding of how to draft and that introduces newcomers to essential procedures and techniques, e.g. by practical exercises, enables the lessons of experience to be learned more quickly. Such courses are not yet available in most CEE countries; they are not usually offered as part of university legal study nor in institutes providing training in public administration. Programmes of this kind have been put in place in a number of OECD Member countries, and could indicate the direction that CEE programmes might take. Development of national training for legislative drafting is a further matter on which SIGMA assistance should be considered.

With respect to advanced training, many CEE countries arrange short workshops and seminars for the purpose, as the Country Reports indicate, though these are not usually organised with the particular objective of enabling a law drafter to improve his or her qualifications. In most CEE countries, considerable innovation is taking place or is being considered in relation to drafting procedures and techniques. All drafters need to be introduced systematically to new practices to ensure that they will be adopted consistently throughout the public service. This calls for a directed programme of advanced training for all established law drafters. Similar training is needed too for those consultants from outside Government who undertake drafting assignments, as well as for Parliamentary officials who are engaged in this kind of work for Parliament.

\subsection{Making Fuller Use of Consultation}

Many CEE countries have put in place procedures for inter-ministerial consultations to take account of wider Government interests. In most countries, however, there is little tradition of consulting with interests outside Government (e.g. with non-governmental organisations - "NGO's"). In this latter respect, new procedures would greatly contribute to the quality and transparency of legislative projects.

\subsubsection{Inter-Ministerial Consultation}

Few legislative projects are of concern to one ministry only. The way particular aspects are dealt with may impinge on matters that are the responsibility of another ministry. It may be important for the coherence of a new scheme to have the expert or specialist assessment of such matters, in addition to ensuring that possible policy conflicts are identified sufficiently early on to resolve them before work on a particular scheme has gone too far. Consultation usually seeks reactions from other ministries to initial decisions already taken within the competent ministry (e.g. by the working group) and generally is a continuous process. But where the substantial involvement of another ministry is foreseen, the Government should consider establishing a joint working group, so that all major interests are party to the policy development from the start. In principle, there is no reason why a joint working group should not be established merely for the purposes of consultation and verification.

As this procedure is internal to Government, it is sufficient that it is regulated by Government standing orders. In fact, in CEE countries the standing orders rarely contain detailed arrangements relating to these consultations. Fuller provisions on the matter, indicating the procedures and timescales allowed, may be appropriate. In particular, these consultations can be made mandatory, and enforced by a requirement that a bill may not be forwarded to Government if the co-ordinating authority is not satisfied that adequate consultations have taken place. 


\section{Enforcing the Requirement for Inter-Ministerial Consultation in Estonia}

The Bill for a Law Drafting Act, $\S 54$, requires the Ministry of Justice to return a bill that has not been considered by all appropriate ministries and the State Chancellery. See Country Report.

In typical practice, a ministry consults only with those other ministries that it considers are concerned. This may result in some interests being overlooked. For that reason, some countries, e.g. Bulgaria, require that all bills be sent to all ministries. This in turn may lead to fruitless work by ministries with no connection with the bill and to problems of co-ordination and delay when so many potential respondents are involved. General publication of all ministries' work plans is usually sufficient to give ministries the opportunity to notify the responsible ministry that their interests may be affected by a particular bill.

Consultation is usually with respect to a draft of the whole or of chapters of the legislation, which should be in a sufficiently advanced form to indicate clearly the nature and the detail of the project. In some circumstances, where a ministry has a particular interest in an aspect of the scheme, more than one consultation may be appropriate. (A ministry that has a substantial interest in the matter is better able to make its contribution through representation on a joint working group). As a rule, when and how often to consult is for the initiating ministry to decide. On the other hand, the length of the consultation may be regulated by Government directive. This should be sufficiently long to enable the particular draft to be studied and for considered comments prepared. Accordingly, a minimum period may be prescribed, which should be capable of being extended for the more complex texts.

One issue for Government regulations should be to provide a mechanism for settling contentious issues, where ministries are in disagreement.

\section{Resolution of Inter-Ministerial Conflicts in Slovenia}

Article 22 of the Standing Orders of Government requires conflicts to be resolved by co-ordination between the ministries concerned or between their Ministers of State. Failing that, the issue may be dealt with by Government, although the Prime Minister may first invite the relevant ministers to discuss possible resolution.

\subsubsection{Non-Governmental Consultation}

To be most effective, consultations should be deliberately designed to produce useful information which can contribute to policy development, rather than as a device merely for achieving a consensus with affected parties (although greater transparency, acceptance and compliance may be a side benefit). Accordingly, consultation should be instituted at the time and in the manner that it can be most helpful to the formulation of the new legislation. Usually this is early in the policy development process, but in cases of complex or wide-ranging legislation, it may have to be conducted at more than one stage in the policy and drafting processes.

Further, the procedures followed should enable those consulted to offer experience, special knowledge and relevant data. For this they need to be provided with a clear statement of objectives of the proposals, and the policy-developers' current thinking on the nature of the problem, the method or methods for its 
resolution and the likely impact of proposed changes. But the precise nature of the information provided will depend in part on the purpose of the consultation. If a ministry is using consultation as a mode of checking whether a new scheme is complete and workable, it may be sensible to circulate the draft bill, with a series of precise questions. In practice, this form of consultation is the one most widely used.

A single method of consultation is unlikely to suffice; the form must be considered case by case. Some issues benefit from consultations with a standing group of experts or with specific interest groups, while others call for a wider public response. Accordingly, Government needs to develop an overall consultation policy to be pursued by all ministries. But such a policy has to be flexible enough to permit selection of the consultation process best suited to a particular matter. It should also determine when consultation is not appropriate for reasons, e.g. of confidentiality, security or another such public interest, or because the matters are based on essentially political considerations. Such a policy should also require individual ministries to develop means for identifying those who should properly be consulted. There is always a risk that smaller interest groups or less organised interests may be overlooked, or that the process is not truly or fully representative, giving rise to criticisms as to its legitimacy.

Some CEE countries have made limited provision for consultation with outside interests on specific matters. So, for example, changes in the Labour Code may have to be discussed with bodies representing employees and employers.

\section{Consultation with Labour Interests in Bulgaria}

The Labour Code, Article 3.1, requires that regulation of labour and social security relations is to be carried out in consultation with representative employees' and employers' organisations. Consultation takes place by means of a Tripartite Commission. (See Country Report).

But this useful device of requiring, in the law on a particular subject, that identified groups are consulted when regulations are made on that subject is not commonly found. It could be used more extensively, at least for cases where legislation will have an impact on a definable group with truly representative bodies. Properly used, it can be a method for testing the likely efficacy of new legislation by those who will have to use the legislation or will be directly affected by it.

In most instances, there are no formal requirements. Individual ministries are free to decide whether, with whom and how to consult.

\section{Regulation of Consultation on Bills in Estonia}

The Bill for the Law Drafting Act, §53 empowers drafters to submit bills to other agencies, persons or associations for their opinion and proposals (see Country Report).

Various informal devices are used, e.g. seminars, discussions with selected persons or bodies, and written correspondence. But these may be superficial and are often limited by the short time that ministries can allow for consultation in the drafting process. Again, if consultation is to be more widely used, it must be factored into the legislative work plans, and sufficient time allowed to enable it to be productive. 
Further, if consulted bodies are to co-operate, they need some guarantee that their contributions have been taken into account. This is the case whether they are asked for their opinions on a draft or, at an earlier stage, to provide essential information so that policy developers can have a better understanding of the issues. At present, drafters usually do not have to record with whom they have consulted and for what purposes, nor the extent to which they have used what they obtained from the consultation, nor why they may have rejected views they received. Such information could readily be incorporated into the explanatory memorandum attached to a bill, providing some reassurance to consulted parties. It would also allow the co-ordinating authority to monitor the use of consultation.

Input from outside Government is often sought from specialist or experts. This may occur on the initiative of the working groups or the drafters, and is a valuable way of supplementing the expertise available in the ministry. In areas where there is likely to be significant legislative activity or where complex legislation is required, the appointment of an advisory committee of outside experts or practitioners provides a readily accessible resource. The extent to which such persons may be used often turns upon the availability of funds in a ministry's budget. Part of the planning process should be to ensure that the provision of funds foreseen as necessary for this purpose in the coming financial year is considered during the budget discussions.

Similar assistance may be sought when the bill is with the Parliament. It is common practice for the rules of Parliamentary procedure to permit Parliamentary committees to obtain such assistance.

\section{Expert Input to Legislation in Slovakia}

Under the Act on Rules of Procedure of the National Council, Article 54, committees may invite specialists to their meetings and may request experts to provide them with expert analyses and opinions (see Country Report).

The Parliament may set up its own standing agency of outside specialists to provide it with advice, e.g. expert legal advice on legislation referred to it by a committee.

\section{Expert Input to Legislation in Bulgaria}

A Legislative Council of the National Assembly has been established under the Rules on the Organisation and Structure of the National Assembly, Article 123. This is made up of academics from outside Government service who are expert in various branches of the law. It can only concern itself with those bills that are referred to it. (See Country Report.)

Few countries have created a system which permits the public at large to contribute to the drafting process. Indeed, in some cases, bills submitted to Parliament are not generally published, making it difficult for interested groups to initiate representations to Members of the Parliament. This may be remedied by information made available through the press or by the Parliament itself seeking reactions from the public. But there is a strong democratic argument that all bills should be formally published and made available for acquisition by the public after they are submitted to the Parliament and before they are substantively considered there. 


\section{Publication of Bills in Lithuania}

Although the Law on the Official Announcement and Coming into Force of other Legal Acts, 1993, contains detailed legislation governing the publication and contents of the official gazette, State News, there is no general requirement that all bills be published in that way. Article 16 recognises that draft laws which are announced by the Seimas for public discussion are "usually" published in a supplement, Informative Reports. At the same time, drafts are available to all persons and institutions interested (see Country Report).

\subsection{Applying Equivalent Procedures and Standards to Parliamentary Initiatives}

Parliaments in CEE countries have important powers to initiate new bills of their own and to propose amendments to Government bills submitted to them. The quality of that legislation has to be measured by the same standards as are applied to bills prepared by Government. Whereas Parliaments are formally required to apply a series of verifications to all Government and Parliament legislation, independently of Government, the converse is not usually the case. Typically Governments are afforded fewer opportunities to carry out the same verifications of Parliamentary legislation as they carry out in relation to their own drafts. Further, the verifications which Parliaments carry out are usually applied with respect to completed drafts, and not at the stage of policy development. The same is true of any verification of Parliamentary drafts carried out by Government. If, as suggested earlier, the ideal is for certain policy verifications to be conducted early in policy development, Parliaments seem ill-equipped for that purpose. Some verifications require access to information that would have to be provided by ministries, and many require an expert knowledge of the subject matter as well as a clear grasp of administrative and implementation needs and resources, which usually rest with Government.

Parliaments, in preparing new bills of their own, tend to rely upon the services of outside specialists or experts or upon individual Members of Parliament who have some special knowledge of the subject area. In matters that require public resources for implementation particularly, that may not be enough. However well a committee is serviced by Parliamentary staff and external experts, it is unlikely that it would be able to bring expertise of its own, e.g. in RIA, and certainly not to the standard which may be achieved by Government. Especially in areas of law which they will be required to administer, Governments have a legitimate claim to be involved in some significant way in the development of legislation by Parliament, and the extent of that involvement should not depend solely on the judgement of Parliament. If ministries generally find inter-ministerial consultation a necessity in relation to their bills, it is difficult to deny ministries such an entitlement when Parliamentary legislation affects their area of competence. Yet the present arrangements do not usually take full account of these factors, in the case of either bills or amendments.

\subsubsection{Bills Initiated by Parliament}

Some alleviation of this situation may arise where a bill is being developed through a committee or Parliamentary working group if it is expressly authorised to request and obtain from Government information or documentation important for the formulation of policy or a new law. In principle, such authorisation might permit a request for Government to undertake some form of RIA. 


\section{Request for Government Information in Slovenia}

The Standing Orders of the State Assembly, Article 141, authorise requests not only from Government but from other state and public institutions. A time limit has to be stipulated. (See Country Report.)

Although this permits Government to provide information, it does not confer the right to convey its views or opinion. Nor does this procedure guarantee that Government can become involved with the project if Government considers that necessary.

Governments have no powers to prevent a Parliamentary legislative project proceeding, although Constitutions usually allow the President certain powers to veto legislation that has been passed or vest in the President or Government the right to require Parliament to reconsider it. But in some countries ${ }^{19}$, there is no opportunity afforded to Government even to pass its comments on these bills to the Parliament. Regulations are needed to confer rights upon the Government in this context, in particular the right to be sent every bill initiated in Parliament as soon as it is formally submitted to Parliament, with a request for an opinion on it within a prescribed time limit. Of course, such an opinion can have persuasive power only. But it is necessary for Government to have the means to point out to Parliament, for example, that a bill has significant implications for the Government's budget and that it is not open to Parliament to determine Government's expenditure priorities in this way.

\section{Government Opinions Relating to Parliamentary Bills}

In Estonia, the bill must be sent to the appropriate ministry, which must submit its opinion within three days to the Government. The collective opinion of the Government must be sent to the leading committee within three weeks. There is a right for a minister to present the opinion to a selected session of the Parliament (Bill for the Law Drafting Act, §59-60; see Country Report).

In Slovakia, the bill must be submitted to the Government, which must make its observations within 30 days (Act for the Rules of the National Council, s. 70.2).

This procedure calls for adequate time to be allowed for Government to prepare its opinion. Indeed, some flexibility is called for in this respect since comments on complex or controversial legislation may require extensive work, involving several ministries. Current practices do not appear to have been devised in order to enable Government to undertake some form of RIA of the kind that it might have used for its own project. Existing procedures may need to be re-examined as a more systematic process of policy development is adopted by Government.

19. e.g. Bulgaria; see the Country Report. 


\subsubsection{Amendments to Government Bills}

Since amendments to Government bills can substantially affect the original objectives and approach envisaged by the Government, it is essential that the Parliament has a clear understanding of the effects of its amendments and that Government has an opportunity to protect its project. In particular, it needs to be able to make its opinion known on amendments that may make implementation difficult or have significant resource implications. In some instances, some form of RIA may be sensible, and Government may need adequate time to carry that out. Accordingly, regulations should provide guarantees for Government with respect to amendments. The present arrangements in a number of CEE countries may need reconsideration in this respect. The following may be appropriate guarantees:

\section{Parliamentary Amendments: Protecting Government's Position}

1. The right of a member of Government to justify the original bill before the appropriate committee (Slovakia, Act on Rules of Procedure for the National Council, s.76).

2. The right to receive copies of all amendments before they are discussed by the Parliament (Slovenia, Standing Orders of the Government, Article 72).

3. The right to submit an opinion on any amendment and to request the right to justify that opinion when the amendment is under discussion by a committee or in Parliament (Slovenia, ibid, Articles 69-70).

4. The right of a member of the Government to participate in sittings when Government bills are under discussion.(Lithuania, Working Regulation of the Government, Article 106).

5. The right to submit its own further amendments (Lithuania, Act concerning Legislative Procedure, 1994, Article 159).

6. The possibility of an impact study analogous to that undertaken on the original bill (Ibid).

7. The right to withdraw a bill which it has initiated, at any time (Estonia, Bill for a Law Drafting Act, §61).

8. The possibility of a parliamentary commission obtaining assistance from Government experts to draft amendments to Government laws under consideration in Parliament (Bulgaria, see Country Report).

\subsubsection{Parliamentary Verification}

Most CEE countries specifically direct that drafts submitted to Parliament must be subjected to a series of formal verifications there. These are usually concerned with legal and technical issues, such as whether the law is drafted in conformity with prescribed standards and is compatible with the Constitution and other laws and with treaty obligations, as well as examining the issue of approximation to EU law. These checks are commonly carried out by the Parliament secretariat, and may lead to a decision that the bill is not in a suitable form for Parliamentary consideration. In the case of Government bills, these matters should have been verified by Government already; parliamentary verification provides a check on the quality of that Government work. But their major value is in relation to bills, and usually amendments too, 
initiated in Parliament. As these may not always be produced as professionally as Government bills, this check makes it possible to assess them by the same technical standards.

\section{Parliamentary Verification of Bills}

In Lithuania, the Legal Department of the Seimas Secretariat carries out a check on compatibility and drafting requirements. The bill with the report is then sent by the Seimas Chancellor to the Speaker who may refer it to a committee for a preliminary consideration of such matters (Statute as concerns Legislative Procedure, Article 141; see Country Report).

In Slovakia, the bill must be considered by the Legislative Department of the Chancellery of the National Council. The President of the National Council, on their report, may recommend that any defects be corrected (Act for the Rules of the National Council, s.70(1), see Country Report).

In some CEE countries, a specific committee may be charged with debating all bills in respect of these types of issues before the bills are presented to the full Parliament to which the committee's recommendations must be reported.

\section{Compatibility Verification by Parliamentary Committee}

In Lithuania, the Speaker may refer it to a committee for a preliminary consideration of compatibility issues. A bill cannot be forwarded to the Seimas if the Seimas Committee on State and Law finds that it does not conform to the Constitution (Statute as concerns Legislative Procedure, Articles 143-146; see Country report).

In Slovakia, these checks are carried out by the Committee on Constitutional and Legal Matters, to whom all bills must be referred as part of the second reading (Act on the Rules of Procedure of the National Council, ss. 59, b, 71, 74).

However, it is not usual for these checks to extend to broader issues, such as costs and impact. The bill must usually be accompanied by an explanatory document, which often is required to contain information on those matters. The secretariat has the responsibility of checking that such information has been provided, but not of carrying out its own verification. Indeed, the secretariats are not usually resourced for that purpose. On the other hand, the Parliamentary committee to which a bill may be assigned usually has wide enough terms of reference to examine those kinds of matter and, as we have seen, generally has the power to ask for expert assistance, which could be applied to that end. 


\section{General Verifications by Parliamentary Committee}

In Lithuania, the committee to which a bill is remitted for a preliminary consideration may report on such questions as budgetary implications, expediency from political, economic and social standpoints and whether the criteria of efficiency, specificity and completeness have been met (Statute as concerns Legislative Procedure, Article 144; see Country Report).

These checks are potentially important in the drafting process, as their existence and the way they are carried out influence the quality of the preparation. The greater the rigour with which they are applied, the more the initiators of the legislation must do by way of preparation to satisfy the parliamentary body. On the other hand, the quality of the Government verification, and thus of the legislative drafts themselves, is likely to suffer if this procedure is used only intermittently or is carried out superficially. An apparent duplication of effort is in reality a valuable means of ensuring that standards do not slip.

\subsubsection{Drafting Resources}

Since Parliaments carry out specific technical functions in connection with law drafting, they must have access to the resources that enable them to perform them. In this context, these functions relate to the drafting of laws and amendments and to verification of legislative drafts. They call for both specialist legal expertise (e.g. on constitutional questions) and specialist legal skills (e.g. drafting legislative text). On some matters, individual Members of the Parliament may, as lawyers, be able to contribute in this respect, or outside experts may be brought in for particular matters, or arrangements to use specialists in Government service may sometimes be possible. To some extent, the standards can be set and maintained by verification carried out by or with the advice of an expert body. But in the last analysis, if legislative drafting is to be carried out to the same high standard, Parliaments need to develop their own cadre of officials within their secretariats who can undertake drafting, or provide drafting advice, as one of their principal functions. This requirement has been recognised in a number of CEE countries.

\section{Drafting And Legal Services In Parliament}

In Lithuania, these services are provided by the Legal Department of the Seimas (see Country Report).

In Slovenia, they are provided by the Secretariat for Legislation and Legal Affairs, under the Secretary General of the Parliament (see Country Report).

In Slovakia, these functions are performed by the Legislative Department of the Chancellery of the National council, which works in two Divisions: the Legislative Division and the Division for the Approximation of Laws (see Country Report).

Just as drafters in Government service have to develop the special skills required for that task, so too must the lawyers in the Parliamentary service. The arguments for this specialisation examined earlier apply with equal force here. Further, these officials when performing drafting duties must adopt essentially the same techniques, approaches and style as are used for Government bills. Accordingly, they need to be 
subject to the same directives on these matters as those in Government service. As we have seen, those directives, if issued by both Government and Parliament, must be fully co-ordinated. They are probably best given effect by law. A further point on which there should be equivalence is in the provision to these officials of training comparable to that given to Government law drafters. Interchange of law drafters between the two services should be encouraged to broaden experience and increase awareness of the drafters' responsibilities in the other service.

\subsection{Applying Equivalent Procedures and Standards to Secondary Law-Making}

Several CEE countries make extensive use of secondary law-making powers to supplement primary laws. Although many instruments are of little enduring legal significance, many others are designed to implement primary legislation and are essential to its continued operation. Those cases especially should be subject to the same quality standards as are applied to primary legislation. In a few CEE countries, the directives governing law-making and legal instruments make explicit provision for this purpose.

\section{Directives Governing Secondary Legislation}

In Estonia, the Bill for the Law Drafting Act, Ch. 4, §§67-87, sets out the principal requirements for Government regulations, and regulates the mode of their preparation (see Country Report).

In Lithuania, the Law on Drafting Procedure of Laws and Other Acts (1995) makes provision with respect principally to the form, structure and contents of secondary legislation. The procedures for making are dealt with in the regulations governing the work of the Government and other authorities (see Country Report).

In Slovakia, new Legislative Rules of the Cabinet are in preparation to deal with this matter (see Country Report).

\subsection{1. $\quad$ Setting Limits}

Constitutions in CEE countries generally indicate in broad terms the extent of the Government's power, either collectively or through individual ministries or other public authorities, to make normative legal acts. This is typically expressed as the power to issue legal acts necessary to implement primary laws. As a rule, Governments do not have independent powers to regulate matters that are not subject to some primary law. Accordingly, secondary instruments have legal validity only in so far as they are based on, and give effect to or carry out, a primary law; if they contradict it, they are void.

Directives give relatively little guidance as to the matters which are best suited for treatment by regulations, rather than in the primary law. At best the scope of each is expressed in very broad terms ${ }^{20}$. This is, however, a matter to which the drafter of the primary law should give considerable attention. In principle, it is desirable that implementing regulations are prepared at the same time as the primary law,

20. The Law on Normative Acts of Bulgaria provides, Article 3, that a law shall provide full regulation of all principal social relations subject to permanent regulation, within the subject matter that it governs. A law may provide for the issue of secondary acts to govern other relations within that subject matter. 
and made available for consideration with the bill to which they relate. Often the primary legislation, even though approved by Parliament and legally in force, cannot be given effect without them. In many cases, Parliament cannot gain a full picture of what is intended without knowing what the secondary legislation will include. RIA of the legislative scheme may be incomplete if it does not take account of features that are dealt with by secondary legislation. At the same time, for practical reasons of time and drafting resources, it may not be feasible to prepare the secondary instruments (and in any case they may be ineffectual if the bill were to be substantially changed in Parliament).

Some CEE countries do specifically provide for Parliament to examine the matter of implementing regulations alongside the bill. Where it is not practicable to make the actual drafts of the instruments available, there is a strong case for requiring that an account be given, e.g. in the explanatory memorandum, of the intended contents of implementing regulations.

\section{Provision of Implementing Regulations}

In Lithuania the explanatory memorandum accompanying a bill must indicate the secondary acts that will be needed and who is to draft them, and provide an outline of their content (Working Regulations of Government, s.95; see Country Report).

In Slovakia, the Rules of Procedure of the National Council permit the President of the Council to request the introducer of a bill to present a draft of the implementing regulations.[s.68(4)].

But in every case the drafter of a primary law should have a clear idea of what matters will have to be covered by implementing regulations, having decided what to put in the primary law. The division of matters between the two should be the result of a deliberate planning decision taken when designing the project. If there is a doubt, legally or politically, whether a matter can properly be dealt with by regulations, it must be resolved in the bill. Since Parliaments have limited powers to examine secondary regulations, it should be of concern to drafters to ensure that matters which are proper for the Parliament to decide upon are dealt with in the bill. 


\section{Dividing Matters Between Primary and Secondary Instruments}

Bills should contain the principal substantive rules of a new legislative scheme, which give effect to the new policy and should settle its core features, in particular:

- matters that involve significant questions of policy;

- rules which will have a significant effect on individual rights and duties;

- significant criminal offences and penalties;

- taxes and significant fees and charges;

- procedural matters that go to the essence of the legislative scheme;

- amendments and repeals to existing law.

Secondary regulations should build upon the policy and principles established by the parent Act, and deal with matters of less significance or with the detail of the legislative scheme, filling it out and supplementing the core features in the Act and providing for procedures and administrative arrangements.

Uncertainties can arise as to the extent of Government's secondary powers. It may be unclear what is the exact scope of the power in any particular case, whether the power is to be exercised collectively by the Government or by a specific ministry, and whether any particular procedural requirements should be followed in the making the secondary legislation. These doubts can usefully be resolved by making explicit provision in the primary legislation on a particular subject matter ${ }^{21}$. Such a provision has several side benefits, in addition to giving greater certainty as to Government's powers. It provides Parliament with an opportunity to consider what may need to be done through implementing regulations, and to impose limits or controls in appropriate cases. It also provides a more precise legal framework which makes it easier for a court to determine whether Government has exceeded the limits of its authority.

This issue has led to a growing practice of inserting authorisation clauses in the primary legislation. A number of CEE countries have reinforced the practice through their directives on law-making.

21. The scope for making secondary legislation may be circumscribed by a primary law of general application, as well as by primary laws on particular matters. (Slovenia, Law on the Government, 1993, Article 26). 


\section{Directives on Authorisation Clauses}

In Bulgaria, the Decree to Implement the Law on Normative Acts, Article 42, directs that such a clause be used to specify the type of instrument, the body responsible and the parts of the primary law to which it applies (see Country Report).

In Estonia, the Bill for the Law Drafting Act. $\$ 7$ stipulates the contents of authorisation clauses. It makes clear that ministers' powers to make regulations are to derive from a power of delegation given to the Government in such a clause. $\$ 69$ states that draft regulations must comply with the requirements of such a clause to be valid (see Country Report).

In Slovakia, the Legislative Rules on Law-making, Article 6(2), make an authorisation clause necessary where regulations are to be made by ministries (Country Report). The form is regulated by the Legislative and Technical Instructions, par. 19.

Whether secondary law-making powers are needed for a particular scheme, and so whether an authorisation clause should be included in a particular law, as well as the exact form of the clause, are matters for consideration by the drafters of the law. They are issues to which specific attention has to be paid routinely in every legislative project, and may be ones on which political direction has to be specifically sought. A clear statement of the exact scope and limits of the Government's power to make secondary legislation creates greater transparency as to the role of Government on particular matters. It enables Parliament to require a clearer account of the Government's plans as to the use of the powers. This may serve to build the confidence of the public in these institutions.

This issue may become more important, in the context of EU membership, in preparing legislation to give effect to EU directives 22 . Some countries use secondary instruments for this purpose since they permit rather speedier effect to be given to the expanding range of EU directives, and in particular since they enable amendments to be made rapidly without going back to Parliament. If this approach is adopted in CEE countries, it may require a new approach. Primary laws may be used merely to set a framework of the principles and basic rules essential to give effect to the EU directives, but would also include authorisation clauses that confer wide powers to make secondary legislation to provide the more detailed rules.

At the same time, it should be noted that framework laws present problems of accountability and scrutiny, since Parliaments generally have little power to restrain the way in which Government may decide to use the secondary powers. The wider the discretion give to the Government by such a law, the greater the opportunity for Government to effect a change of policy through the secondary legislation without recourse to Parliament.

\subsubsection{Drafting Secondary Instruments}

In broad terms, preparation of secondary instruments in CEE countries is a streamlined form of the process used for primary legislation. In principle, as is desirable, this is undertaken by the same persons in

22. See further on this issue Estonia Country Report. 
the ministry who produced the primary law. The exact approach in an individual case is dictated by the size, importance and complexity of the task. A more structured approach is called for where the instruments are to be made by Government collectively, in contrast with those that are internal to ministries. In the former case, preparation has to be completed in accordance with the current Government work plan and some form of concerting is needed by the secretariat supporting the Council of Ministers. Typically, the drafts prepared in the ministries for a collective Government decision are checked by the legal office attached to the Council of Ministers for constitutional and legal compatibility and legal form, and they may be sent to a working body of Government for consideration of their substantive implications. Ideally, a Government directive should indicate when regulations may be sent back for further work or what action may be taken to resolve inter-ministerial conflicts.

\section{Concerting Government Regulations}

In Bulgaria, all drafts must be examined by the Legislative Council in the Ministry of Justice before they may be considered by the Council of Ministers (Decree on Establishing a Legislative Council in the Ministry of Justice, 1992: see Country Report).

In Slovenia, drafts must be submitted to the Government Legislation Office and their comments must be taken into account before the draft is formally remitted to the General Secretary, who may send to the relevant Government working body or, if it has not been prepared in accordance with the Standing Orders, return it (Standing Orders of the Government, Articles 24-29, see Country Report).

One useful requirement in these cases is that the draft instrument must be accompanied by an explanatory memorandum, which indicates the aims and an overall account of its content. This enables other issues to be explained which will be of concern to Government collectively, such as the extent to which the instrument is compatible with EU law.

\section{Explanatory Memoranda for Government Regulations}

In Estonia, the Bill for the Law Drafting Act, Ch. 4, Div. 2 ( $\S 82-84)$ contains detailed provisions as to the contents of explanatory memoranda that must accompany draft Government Regulations. These include information about the effects and expenses for implementation.

Where a ministry is the authorised regulation-maker, the drafting procedures are usually internal to that ministry; consideration by Government collectively is not commonly required. In these cases, the ministry works to its own timetable, establishes and co-ordinates its own procedures and carries out the necessary verification on constitutional and other legal compatibilities. Although no office has the formal function of verifying these regulations, consultation with concerned ministries provides opportunities for other officials from those ministries to draw attention to matters needing further consideration. In some instances, powers are expressly vested in Government collectively to intervene if ministerial regulations are considered to be unlawful. Such action is usually founded on a review conducted by the legal office attached to Government. 


\section{Powers of Government with Respect to Ministerial Regulations}

In Slovenia, the Government or the Prime Minister may withhold implementation of a ministerial regulation considered, on the findings of the Government Legislation Office, to be in conflict with the Constitution or other laws, and may request amendment or annulment within five days. If the minister contests this, Government may refer the matter to the Constitutional Court (Standing Orders of Government, Article 14).

Directives affecting the preparation of secondary instruments make little reference to verifications other than that concerned with legal compatibility. Yet, on some issues, the potential impact of regulations may be a significant matter. The choice of the mode of implementation, its costs and cost-effectiveness and the economic implications for the private sector may be important considerations. If analysis of this policy aspect has not been undertaken when the primary legislation was in preparation, RIA has a role in this regard, and should be carried out in the early stages of preparing the secondary instrument. This role should be part of the general strategy for developing RIA, and may have increased importance if a practice develops of making secondary legislation, under framework legislation, that has extensive impacts (See above, Section 6.1. "Setting Limits").

\subsubsection{Consultation}

Regulations governing secondary law-making typically provide for consultation with other concerned ministries and agencies. This can be of particular importance if implementation will affect or involve such a body. The responsibility for ensuring that consultation is carried out usually lies with the originating ministry. The legal office attached to the Government may be charged with the responsibility of checking that such consultations have taken place, at least in the case of Government regulations.

\section{Inter-Ministerial Consultation on Regulations in Estonia}

The Bill for the Law Drafting Act requires both Government and ministerial regulations to go through a concordance procedure involving other concerned ministries and bodies, to be completed within 20 working days. The results must be reported in the explanatory memorandum in the case of drafts submitted to Government for its collective decision. These may be checked by the State Chancellery ( $\$ 51,52,82 \& 85$; see Country Report).

Although, in many CEE countries, consultation with interests outside Government do take place if the drafting ministry considers it to be useful, such consultations appear to be rarer in the case of secondary instruments than for bills and to involve informal exchanges of view with representative or expert bodies or persons, but not with the general public. In this connection, two useful procedures that have been instituted by directives may be noted. The first enables Government to invite specialists or representatives of outside interests to take part in the discussions on draft Government regulations at a meeting of the Government. 


\section{Formal Consultation by Government with Outside Interests}

In Slovenia, Government may invite outside bodies and organisations to attend a specified meeting, and they and specialist or expert outsiders may be permitted to participate in the discussion of the matter (Standing Orders of Government, Articles 32 \& 36; see Country Report).

The second procedure is designed to allow greater public input into secondary law-making. The process for making regulations, unlike that for bills, involves no prior general publication of the draft before it is made. Accordingly, it lacks transparency. In a case where an instrument may impact heavily upon members of the general public, or a significant group, serious consideration should be given to enabling those people to comment upon the proposals during the preparation process. This may lead to greater understanding in Government of the issues and likely effectiveness of the proposals, and to greater acceptance of the regulations by those whose affairs will be regulated by them.

Clearly, an opportunity for the public to react to such a proposal must be confined to those important cases where the resultant extra time entailed is likely to be compensated for by the benefits to be gained from public responses. For that reason, a directive can only set out the mandatory mechanics of public consultation (to be legally enforceable) and a requirement that the results must be taken into account (and reported in, e.g. the an explanatory memorandum attached to the final draft). Whether such consultations must take place on any particular matter has to be settled by explicit provision in the primary law regulating the matter.

\section{Formal Consultation with the Public}

In Estonia, the Bill for the Law Drafting Act, §86, institutes a new procedure for public consideration of secondary legislation. It is to be used when so directed by the primary law which is to be implemented. The State Secretary must publish a public notice drawing attention to the proposal to make secondary legislation, where the concerted draft and its explanatory memorandum may be obtained, and inviting public comments. A minimum period of 10 days for responses must be set. The explanatory memorandum for the final version must give full details of the consultation results and how they have been used. (See Country Report.)

\subsubsection{Parliamentary Consideration}

It is not usually seen as the function of Parliaments in CEE countries to monitor the use by Government of its secondary law-making powers by systematically examining the instruments issued. Their rules of procedure typically direct that Parliament is to be generally concerned with the way executive functions are performed and to call for information about implementation of legislation. This is part of the process of holding government to account. But unlike with primary legislation, it is rarely provided that Parliamentary committees have to make a practice of verifying secondary instruments or of checking whether Government has used its secondary powers in an excessive or unexpected way. 


\section{Parliamentary Examination of Regulations}

In Slovakia, the Rules of Procedure of the National Council require all parliamentary committees to see how laws are implemented and whether the rules and regulations issued for implementation are in conformity with the laws. It can require immediate remedial action to be taken if the regulations are not in conformity or have been delayed or not issued, and to report to the National Council if no such action is taken (s.45(3)(b); see Country Report).

There is at present little recognition that some parliamentary procedure may be needed to review the way Government uses its implementation powers, or indeed to enable the instruments themselves to be scrutinised. This may become a more significant issue as drafters develop the device of the authorisation clause. Such a procedure could require that copies of at least the major instruments be remitted automatically to the committee having oversight of the issuing ministry, and for secretariat support to identify those deserving closer consideration by the committee.

\subsection{Improving Access to Legislation}

Ready access to written law by everyone who needs to refer to it is a central requirement for states practising the rule of law. It should be possible for any person to have recourse to, and if necessary to purchase at a reasonable cost, any law in which he or she is interested, as soon as it has been made. It should be possible (e.g. for a new lawyer) to acquire a complete collection of laws currently in force. The officials in all ministries and judicial bodies should have ready access to a complete set of such laws, and be able to gain access quickly to earlier laws that are no longer in force (which often continue to be relevant). They should also have a sufficient number of sets or copies of all those laws that relate to their particular area of competence. These requirements apply not only with respect to primary legislation, but with respect to all secondary instruments made to implement primary laws.

\subsubsection{Publishing Official Versions of Laws}

Typically, legislation is published, as a State responsibility, in more than one form. These editions may be supplemented by versions published in similar or different forms by commercial houses, although some of these are notoriously inaccurate. There is an important difference: the former must be recognisable as official publications which the State guarantees to be accurate and authentic, i.e. ones that will be accepted as such in a court of law. It is usual for law to indicate the features and formalities that such authentic versions must comply with. The following is the set of authenticated versions which are typically published: 


\section{Laws for Which Authenticated Versions Are Published}

1. Individual laws and other primary law instruments (e.g. Presidential decrees), as they are passed.

2. Individual secondary instruments implementing primary laws, especially if containing normative provisions affecting the public or groups of the public, as they are issued.

3. Annual volumes of those primary laws and secondary instruments passed or made in the previous calendar year.

4. A consolidation of the primary laws in force at a specified date, kept current by regular issue of supplements.

5. A consolidation of the secondary instruments in force at a specified date, and likely to have some permanence, kept current by regular issue of supplements.

6. A complete index to all primary laws currently in force and those repealed or replaced, issued at regular and frequent intervals.

7. A complete index to all secondary instruments currently in force, issued at regular and frequent intervals.

CEE countries appear, in the main, to be working towards these goals, although they are made more difficult to achieve by the need to collate and republish those laws made before the transition that are still in force. These countries invariably maintain an Official Journal in which new laws and other legal instruments must be published if they are to take effect and have authenticity. This is typically published by the Parliament or the Government. In some countries, its contents and mode of publication are regulated by law.

\section{Laws on the Official Journal}

In Bulgaria, the State Gazette is published by the National Assembly. The Law contains detailed provisions with respect to the matters to be published (which include Government announcements in an unofficial supplement), the regularity of publication and cost of publishing and acquisition (Law on the State Gazette, 1995, see Country Report).

In Lithuania, the State News is published by the Seimas (Law on the Official Announcement and Coming into Legal Force of Laws and Other Legal Acts, 1993). This Law has a similar coverage to that of the Bulgarian Law.

\subsection{2. $\quad$ Computerised Databases of Laws}

The publication process is now assisted by the wide-scale use of computers to create legislative databases. These not only enable laws to be collected and consolidated more efficiently and reliably, but can be made available through on-line access, through an internal ministry network but notably via the Internet. 
Computerised databases bring new possibilities and obligations for law drafters. If appropriate search facilities are provided, the availability to a drafter of a full text database of local legislation can greatly facilitate finding the existing legislation that may be affected by a new draft and may need to be amended or repealed. It also encourages standardisation of legislative writing when dealing with similar matters or different matters using similar legislative devices. It also permits the text of new legislation to be integrated with the existing law to produce a current version much more quickly than in the past. But this benefit must not obscure the importance to the drafter, as to other lawyers, of being able to refer to replaced law, as well as current law, and to know precisely when it was replaced. Specific legislative databases have to be developed with the special needs of lawyer users at the forefront.

These databases make their own demands on drafters. If new text is to be fully integrated into existing legislation, it must be drafted with that in mind. Amendments and repeals must be written in the form that enables existing law to be altered to accommodate the new text. Accordingly, such provisions must indicate precisely the effect of the new on the old and, as necessary, must substitute, delete from or add to the original text in specific terms. The revisions in the database must indicate the exact point of the text where a change has been made. Many CEE countries, in their directives on legislative techniques, require such practices of direct amendment to be followed.

\section{Amendment Techniques}

In Bulgaria, the Decree to Implement the Law on Normative Acts, Ch. 6 (Articles 18-52) contains a series of rules supporting direct amendment techniques.

In Estonia, the Bill for a Law Drafting Act, §§25-26, contains detailed rules for substituting and inserting text.

In Slovakia, the Legislative Rules on Law-making, Article 11. states that indirect amendment of laws (i.e. without a specific identification) is inadmissible.

Although a computerised database may be kept by an official authority and protected from external inputs, it is not possible to guarantee that an extract taken directly from it by a user is authentic. As most institutions, such as courts, work with hard copies, some method has to be found for confirming that a law reproduced in hard copy from a database is an authentic version.

\section{Authenticated Laws Printed from a Computerised Database}

In Lithuania, an extract must be taken by the authority maintaining the database (in this case, the Information Centre at the Ministry of Justice) and confirmed by the signature of the Minister of Justice (Law on the Register of the Laws and Other Legal Acts, 1995, Article 8).

\subsubsection{Registration System}

To be able to publish a comprehensive collection of laws, a complete record of all legislative instruments must be created and maintained. This entails establishing a central register of the different categories of 
instruments, and a system for registration. This is properly a Government function; the responsibility is typically discharged by the ministry principally concerned with legislative matters. Directives are necessary to establish the laws that are to be registered, the types and authenticity of information to be recorded, the system for recording and retrieving laws, and the right and terms of access, including the cost for persons or bodies in the private sector. If the register is to be complete, it should initially include a record of all laws made before the system was created and still in force, all primary laws passed and secondary legal acts made since that time, as well as their effect upon earlier instruments. It can usefully include treaties and important judicial decisions. Desirably, this register should be kept in computerised form.

\section{$\underline{\text { Registration of Laws in Lithuania }}$}

The Law on the Register of the Laws and Other Legal Acts, 1995, requires the Information Centre in the Ministry of Justice to maintain a comprehensive register of laws, legal acts and treaties in a computerised database. This includes detailed information enabling the legislation to be traced by users, as well as the full texts. After initial state funding to establish the system, it is largely self-financing through the wide scale use by persons outside Government (see Country Report).

\subsubsection{Format of Published Laws}

The physical characteristics of legislation can do much to assist or obstruct ease of access by users. Accordingly, laws and the different categories of legal acts should each be printed in uniform formats and styles, each using its own predetermined fonts and layout. It should be possible to pick up an instrument and tell by the way it is printed what kind of legal act it is. CEE countries for the most part respect this convention, which can be assured if the printing is carried out or controlled by the same body.

On the other hand, many CEE countries still publish in rather old-fashioned forms not designed to make the legislation easy to read and circumnavigate. The physical features of an instrument can markedly facilitate its use. Modern computer assisted publication methods, and the ready availability of a wide variety of fonts and printing styles for desk-top publishing, permit formats to be devised that are much more user-friendly. They provide an opportunity to re-examine matters such as the most convenient size of the page, the mode of binding, and how and to what extent readers' aids are provided (e.g. table of contents, internal numbering devices, direction notes to the content of parts and articles, and so on). This touches closely the work of law drafters and should be of considerable interest to them, as it is they who should be concerned to devise new ways to make legislation easier to use. 


\section{LAW DRAFTING AND THE REGULATORY PROCESS — REPUBLIC OF ALBANIA}

\section{Introduction}

Law drafting procedures in Albania are based on the Regulation of the Council of Ministers (CM) and on that of the Parliament. There are no authentic legislative techniques.

The drafting process is mainly based on international and more particularly European standards and requests. This is realised with the help of foreign specialists and different aid programmes. Albania must create a manual on drafting procedures of both primary and secondary legislation in order to help the drafting process at different governmental levels.

\section{System of Legal Acts}

In Albania the most commonly used types of regulatory instruments include:

\section{a) For Primary Legislation:}

- the Constitution (Main Constitutional Dispositions: MCD);

- laws and all legal acts approved by the Parliament;

- decrees approved by the President of the Republic;

- international conventions and treaties ratified by the Parliament (political treaties, military agreements or treaties, border agreements, agreements on basic citizen rights and duties, etc.);

- resolutions of the Constitutional Court (Article 26, $\$ 3$ of MCD declares that all laws; acts having the force of law; regulatory provisions and their particular dispositions that are proclaimed incompatible with the law on MCD, and with the law and with generally accepted international legal norms, or with agreements to which Albania is a party, are considered null and void the day following the publication of the decision in the Official Gazette).

\section{b) For Secondary Legislation:}

- decisions and orders of the Council of Ministers, ministries, or other central institutions;

- resolutions and other legal acts of the Government adopted in its sittings, signed by the Prime Minister and the relevant minister.

Laws and presidential decrees head the hierarchy of legal instruments in Albania. Decisions of the Council of Ministers are also very important and much used by the general public; they relate to the application of the existing laws and are therefore subsidiary to the main laws. 
The Government has the power to make secondary legislation, without consulting primary legislative bodies. During the transition period, no essential changes have been established in the process of law drafting.

\section{Regulatory Framework}

No specific legal instruments regulate the drafting process. A manual on the techniques of the drafting process is planned and shall include basic principles of the drafting process and drafting techniques.

Currently, the legal acts which regulate the order of the process of law drafting are:

- The Main Constitutional Dispositions (MCD).

- Regulation of the Parliament.

- Regulation of the Council of Ministers.

\section{Drafting Personnel}

In the Parliament, laws and other legal acts can be drafted by Parliamentary parties and informal groups. In the Government Office, legal acts are drafted by Government expert advisors and by the structural divisions of the Government Office. Laws can also be drafted by the ministries (groups of specialists on the issue).

Each ministry has the right to propose bills to the CM. No special units are assigned to compose bills, but this process is undertaken by jurists of the ministries who propose the bills. The process of law drafting can also be initiated by others who are experts in other fields but are well informed about the problem of the bill (engineers, agronomists, doctors, etc.). Several efforts are being made to create a centralised organ of drafting lawyers to serve all the ministries or other organs. No such body currently exists.

There is no "lawmaker" position in the Albanian Administration. Legal advisers in the Parliament and in the $\mathrm{CM}$ are considered the main lawmakers. Approximately ten lawyers in the central Government deal with the process of law composition. Before transition, they had not generally been involved in the drafting process.

Generally, national staff and rarely contracted staff are responsible for drafting the law, occasionally in collaboration with foreign advisers (formulation of the Labour Code, for example, is directed by a Swiss expert). The decision to hire external staff is made by the Chair of the Council of Ministers or the Chairman of the Peoples Assembly or by both (for example, the composition of the bills on constitutional law, and the organisation of justice).

Usually, the composition of both the general and particular legislation is assigned to specialised groups rather than to individuals. Some of the important bodies in the law composition process are the interministerial committees which deal with the important bills having financial-economic and social-cultural effects. These committees are consultant bodies to the $\mathrm{CM}$ and co-ordinate and determine the direction of governmental policies in important areas of state activities.

These committees judge, scrutinise and make recommendations on bills to assist the CM in making a final decision. They do not deal with the drafting process which explains why they have no draft personnel. Their normal responsibility is to deal only with evaluating bills proposed by the ministries or other central 
institutions - Parliament, Presidency, CM, ministries, municipalities, courts, banks, and all other institutions determined as such by the legal acts.

\section{Drafting and Approval Procedures}

\subsection{Primary Legislation}

Article 5 of the Main Constitutional Dispositions gives legislative power in Albania to the People's Assembly (Parliament).

Article 23 of the law on the Main Constitutional Dispositions gives the right to vote and propose a bill to: the President of the Republic, Council of Ministers, and a group of 20000 persons. Generally, drafts are proposed in Parliament by the Government which exercises the right of the legislative initiative collectively; no individual minister makes proposals.

Drafts are sent to Parliament; its Chairman is responsible for informing members in order to discuss and make decisions about them. Deputies thus learn about the drafts. After introducing them in the plenary session (only titles are read), the Chairman delivers them to the parliamentary commissions for scrutiny. After that, approval of the programme and agenda for scrutinising the drafts, prepared in the meeting of the Chairmanship based on decisions of the heads of the parliamentary Commissions. Drafts are then submitted for approval to the Parliament in plenary session in which the Government member always takes part.

In the plenary session, the draft is scrutinised according to an order fixed in the day's agenda prepared by the Chairman, after many consultations with the Chairmen of the parliamentary commissions. Before coming up for approbation in the plenary session, the draft must be examined by the relative parliamentary commission which scrutinises the drafts, following a programme prepared by the Commission Chairman which must comply with the programme of the Parliament's activity. Commission members organise discussions in which the authors of the drafts and specialists who can help for the scrutiny of different problems participate. At the end of the discussions, the Commission has to prepare a report to be presented in the plenary session. The report may proposes three alternatives, with appropriate justification: approbation of the law without changes, approbation with changes on particular articles, or disapprobation (in which case the draft is turned back to the initiating author). The report reflects the opinion of the minority when the commission has not agreed unanimously. The Commission of Laws scrutinises all the draft laws and gives an opinion on their compatibility with the Constitutional Dispositions. In the plenary session begins by an approval in principle of the draft. At this stage, all deputies have the right to take part in the discussion. The second step is the approbation of each article. Proposals for change cannot be presented directly in the plenary session unless they have been presented in written form prior to the respective commission for scrutiny and discussion. After approbation of each article, the entire law is approved with all the previously approved changes.

Article $23 \S 2$ of MCD stipulates that the laws and other acts of the People's Assembly, except for constitutional acts, are considered adopted when voted for by the majority of the deputies present, but no less than one third of the deputies.

The President of the Republic then proclaims the laws according to $\$ 4$ of Article 28 of the MCD, and he has the right to return the law to Parliament one time only, and for legitimate reasons, for scrutiny within 15 days from the date of approbation of the draft and by a motivated reason (Article 28, §5, MCD). The 
law takes effect 15 days after it is published in the Official Journal, except when the date is decided in the law.

Generally, in Albania, there is no direct consultation between draft laws and groups of common people. This dialogue is limited only between draft laws and the members of the Parliament in the role of the representatives of the public.

Groups of people which are interested in certain draft bills, have the right to discuss with their representatives in the Parliament, who take into consideration their opinions and demands in the parliamentary sessions. Time limitations make these discussions short.

\section{Parliamentary Control on Government Lawmaking Powers}

The most important Parliament responsibilities include legislative activity and control over the executive bodies. To realise these duties, Parliament is based on the application of the law on the Main Constitutional Dispositions (MCD). Article 16, point 10, of this law gives Parliament the right to control the activity of the Council of Ministers. Article 20 determines that the parliamentary commissions must control the activity of the ministries and other state organs and to present the problems to the Parliament or Council of Ministries.

The regulation of Parliament provides control through information.

The main parliamentary instruments for information are the questions and interpellation. Article 82 of the MCD gives the right to ask every deputy; questions may be directed to the CM or one of the ministers, in order to get information on one or some facts.

\section{Interpellations}

Article 82 of the regulation gives every deputy, group of deputies or parliamentary group the right for ask for interpellations. These are made in written form, in order to receive explanations on the activity of the Government and other respective institutions.

\section{Control Through Investigation}

Parliament elects permanent commissions from its ranks which are required to examine and to control the activity of the ministries and other state bodies in accordance with their respective areas and to submit issues to the Parliament or the Council of Ministers (Article 20, MCD). Parliament also creates temporary commissions for different issues. The chairman or at least ten percent of the members of Parliament can make proposals to create these commissions. All parliamentary groups take part in these commissions in proportion to their representation. The decision to create commissions also defines the concrete duties, the term of the activity and the day of the presentation of the report. The commission has the right to collaborate with different specialists on getting necessary information on the work of Government and also has the right to ask for any documents, except those considered to be state secret documents. The final report make the relative recommendations is voted upon in the plenary session.

\section{Policy Control}

The Parliament has political responsibility for the Government. Article 16, §9, MCD gives it the right to control the activity of the CM. In the beginning of its activity, the Government must take a vote of confidence by the Parliament for political support. During its 4 years in power, the Parliament can bring 
down the Government by an incredulity motion presented by a parliamentary group or by ten deputies. After hearing the Government representative, one deputy 'opposed' and one 'in favour', Parliament determines the day of debate. A debate on every motion shall be effected no later than three months from the date of its representation in Parliament. An absolute majority of votes is required to approve the motion. In Albania, secondary legislation mainly treats issues that complete and clarify issues within the relative legal system, that are treated by primary legislation.

\subsection{Secondary Legislation (Legal Acts of the CM)}

It is in the competence of the CM to issue decisions, orders and instructions in compliance with the Constitution and laws and their implementation.

According to the regulation of $\mathrm{CM}$, a draft should contain:

- introduction, the importance and project justification related to issues to be tackled and objectives to be achieved;

- whether or not there is a relationship with the programme of the CM;

- summary of the draft contents;

- harmonisation with existing legislation;

- detailed economic and financial analysis with the budgetary effects of the current and following years as well as the calculation of the additional budgetary cost that the draft will generate;

- explanations for ignoring the remarks and opinions of the concerned ministries.

Generally, the first draft is compiled in the respective ministry by the experts of the directorate making the proposal, but this operation differs according to the type of secondary legislation. This draft the goes to the minister's cabinet after being processed and approved by the head of the directorate, based upon an argued and professional explanation by area experts and those of the legal sector for compliance with the main principles of the Albanian legislation. The minister's cabinet, composed by experts of different areas, approves or rejects the proposal of the directorate during its regular meetings. When the draft is not approved, the cabinet, chaired by the minister, provides, in unanimity, a detailed argued commentary and attaches it to the draft. The draft can also be sent back to the proper instances for changes if the commentary suggests doing so.

When the draft is approved, the minister signs it and the ministry sends copies of it to the Council of Ministers and other ministries that address the problem generally or partly. In particular, the ministry sends a copy to the Ministry of Finance as it covers the budget, and another to the Ministry of Justice for compliance with the Albanian Legislation. (Article 12 of the Regulation of the CM).

Each ministry involved in this process prepares a commentary and sends it to the initiating ministry. It scrutinises in detail the commentaries, changes in the draft all points deemed reasonable and sends the material, together with the respective commentaries, to the $\mathrm{CM}$ for approval.

Only the members of the CM make proposals for drafts to the Council of Minister (Article 10, point 2, of the regulation of the Council of Ministers of the Republic of Albania ).

Regarding the legislative proposals of the different kind of ministries, ministries work on draft process by their proper initiative and then send the completed law to the Council of Ministers. Two copies are 
delivered to the General Secretary of the Council of Ministers by courier. The General Secretary sends copies of it to the advisers to the Prime Minister (for the appropriate area) and to the Legal Adviser (Legal Office).

These advisers, co-operating continuously with each other, scrutinise the draft in the professional and judicial context and make suggestions and suggestions for completion in the form of a commentary. All commentaries that accompany the drafts must contain: an introduction, the importance and the motivation of the draft, whether or not there are connection points with the CM programme, a resume of the contents, an analysis showing compliance with the existing legislation, financial and economic analysis, explanation for not considering the comments and opinions of the interested ministries. (Article 11, point 2, of the Regulation of the CM).

After all of these commentaries are complete, the material is delivered to the Prime Minister who decides whether the draft will be scrutinised at the earliest meeting of the Council of Ministers or in a later session.

The day order of the Council of Minister on approving new legislation has three phases:

1. Discussions on the draft laws and draft decrees put forth for approval by the CM and previously agreed by the respective or interested minister and the Prime Minister.

2. Drafts considered by the Prime Minister to be of an urgent character. This phase includes all drafts on which no previous consensus has been reached from interested ministries in the respective interministerial committee. The Prime Minister suggests that these issues be discussed and decided in the Council of Ministers.

3. Reports, information and other general problems presented by the members of the Council of Ministers and already approved by the Prime Minister (Regulation of the CM).

CM decisions are approved by the majority of the members. The drafts scrutinised in its meeting may be approved, changed, postponed for further examination or sent back to the respective ministries for closer examination.

The process of undersigning drafts already analysed and approved by the CM is headed by the General Secretary. These materials are than dispatched to Parliament or the Presidency.

Only CM members make proposals for draft laws in the Parliament (Article 10.2 of the Regulation of the Council of Ministers of the Republic of Albania).

The drafts that are scrutinised in the CM meeting may be approved, changed, forwarded for later scrutiny or turned back for co-ordination with the interested ministries. The drafts could be withdrawn by those that have proposed them or could be turned back to the respective ministries to be re-scrutinised. (Article 4 of the Regulation of the $\mathrm{CM}$ ).

CM decisions are taken with the approval of the majority of the members (Article 4 of the Regulation of the CM). The General Secretary prepares a final report of the meeting of the Council of Ministers and makes it known to the ministries. The CM Chairman also prepares a communication memo and sends it to the public media. The announcement contains a note for each draft scrutinised showing that the draft might have been approved without changes, with changes in order to be reviewed by the proposing ministry, or not approved. 
Members of the Council of Ministers must deliver to the Cabinet of the Prime Minister the proposals for the 3-monthly and yearly analytic programme for the drafts that will be presented. The 3-monthly and yearly programme of the Council of Ministers is compiled based upon these proposals, and approved in one of the CM meetings. The CM Chairman appoints a member of the Council to co-ordinate the legislative programme of the People's Assembly with the CM programme. At the end of each 3-month period and year, CM Members must present the effects of the implementation of the approved legal acts for the areas that they cover to the Chairman.

The Secretary General manages the process of signing and distributing the acts of the Council of Ministers which are initialled by the proposing minister, the State Secretary of the proposing ministry if there is any, and Secretary General and signed by the Chairman of the Council of Ministers. (Article $6, \S 1$, of the Regulation of the CM, changed by the decision of CM No. 136 of 20 March 1997).

The Secretary General manages the process of the compilation and signing of the draft laws and draft decrees examined and approved by the Council of Ministers and sends them respectively to the Parliament or to the President of the Republic. (Article 6, §2, of the Regulation of the CM.)

The Government regulation does not decide which matters should be dealt with by primary legislation and which can be left to secondary legislation regulation.

For important cases considered as such by the Constitution, the Parliament/President decides upon the legal instrument to be used, either by law (parliamentary decision, or President decree) or by other legal act (governmental decision).

In evaluating whether an issue must be regulated by primary or secondary legislation, experts base themselves on the local or general character of a given issue and on whether or not this issue derives from another issue previously resolved by a law. If it does derive from another issue, it is generally regulated by secondary legislation.

It is mainly preferred that laws regulate issues of primary political-economic and social importance such as the Main Constitutional Dispositions, the penal and civil codes, the code of penal and civil procedures, custom code, legal dispositions on Civil Service and other legal dispositions which are the foundations of the Albania State. Secondary legislation generally derives from primary legislation.

Secondary legislation is usually prepared after approbation of the primary legislation. It is suggested that items of great interest favour the preparation of both sets of legislation at same time, but in practice this does not happen very often.

The policy initiative for the drafting process of secondary legislation is undertaken by the high governmental levels (ministries, Council of Ministers) and sometime the same body undertakes the policy for drafting primary legislation.

Regulatory acts are published in the Official Journal, while others are included in other periodical publications prepared by the CM. The CM abrogates illegitimate acts of the ministries and other central bodies of state administration. (Article 37 of MCD) The Parliament has no power to amend secondary legislation made by the Government. 


\section{Publication and Dissemination of Acts}

\section{Secondary Legislation}

The Secretary General defines the acts of normative character to be published in the Official Gazette as well as other acts that are included in other periodical brochures or publications prepared by the CM. Official dissemination of the acts is carried out under the guidance of the Secretary General within two days after their signing.

\section{Legal Acts of the President of the Republic and Approval Procedures}

The President of the Republic carries out his legislative constitutional competencies through such legal acts as decrees, decisions and messages. The decrees of the President are divided into two main categories: the regulatory and individual decrees (point 19 of Article 28 of the MCD). The decrees must be signed by the Prime Minister and be approved by the Parliament in its earliest session. The MCD foresees particular terms for approving specific decrees, e.g. decrees on the nomination, dismissal, etc., of high level officials must be approved by the Parliament within 10 days; decrees proclaiming a general or partial mobilisation or decrees on extraordinary situations/emergencies, etc., are presented to the Parliament for approbation within five days. Individual decrees do not need Parliamentary approbation; they are published as a competence of the President.

The Albanian legislative practice, the legal acts of the President which have the form of a decree, do not usually pass in the Parliament for approbation. The President of the Republic also has the right to proclaim decisions with less judicial power in comparison with the decrees. Anyway this competence of the President is not practised so much as to become a judicial tradition of the Institution. The President may exercise his right to use the veto relating to the laws approved by the Parliament, through "motivated messages".

\section{Decree Approval Procedures}

Relating to the MCD, there are rules to define the steps of this procedure. The CM is the first to undertake this initiative. By law, the President of the Republic proclaims decrees based on the drafts given to him by the Council of Ministers in compliance with the base rules of its function. The President can also do so upon his own initiative. There is a particular procedure for decrees about proclaiming laws (point 4 of Article 28 of MCD). The Parliament gives approved laws to the President who can exercise his veto only within 15 days from the date of law approbation. Otherwise, he is obliged to proclaim the laws.

\section{Costs}

There is no standard practice for assessing costs for new legislation. Cost assessments are calculated based upon tradition and practice but not upon standard procedures.

The financial effect of the new legislation is calculated by the affected ministry which has prepared the draft, especially by the Finance Ministry or in collaboration with other financial central bodies. There are no standards procedures on making such calculations. In order to calculate the financial effect of new legislation on the private sector covered by the draft law, particular procedures are followed by the Labour Ministry and other affected ministries, especially by the Finance Ministry. Specialists from both work on 
the effect of the new legislation on the social cost without respecting any formal procedure. The information on the cost of draft is not confidential but can be made known to the Parliament and general public without any limits.

\section{Constitutional Compliance}

Compliance of policy options with the requirements of the Constitution during the drafting stages is verified by keeping present the clauses of the Main Constitutional Dispositions of Albania. Final verification is done during the approval process. All constitutional requirements are of equal importance and are kept present by draft personnel without differences.

Constitutional compliance is provided by the Constitutional Court which has the power to judge whether laws and acts that have the force of law are compatible with the Constitution, and whether the acts and regulatory provisions are compatible with the Constitution and with the law. The Constitutional Court has sole competence to decide on the compatibility of international agreements concluded in the name of the Republic of Albania with the constitutions before their ratification, and on the compliance of the laws with generally accepted norms of international law and with agreements to which Albania is a party.

\subsection{Compliance with EU Legislation and Case Law}

There are some special arrangements for verifying whether legislation is consistent with EU law. A group of specialists formed by the Government controls all the legal acts and makes the main necessary proposals. This group is comprised mainly of jurists of different central institutions such as jurists from Parliament, Government, university, ministries etc.

Some progress has been made in approximating the Albanian legal system to international legal standards. The process of enabling our legal system to meet the European Community standards is developed in close collaboration with foreign institutions which operate in Albania. The purpose of this approximation is to assist the Government in preparing new economic legislation and harmonising existing economic legislation with the EU standards. The project will accomplish these goals by providing the following services:

- Co-ordination: organisational support will be provided to ensure complete legal approximation, harmonisation, coherence, of existing and new Albanian legislation internally and with supranational EU law and other international legislation. This co-ordination will involve foreign donor efforts in the area of legislative reform.

- Commentary and background materials: Throughout the term of the contract, short briefing papers will be prepared in English and Albanian on draft laws which have been selected for completion.

- Drafting consultations: Experts will compile additional materials and provide prompt consultation on short- and medium-term drafting projects. These consultations are available at the simple request of Albanian Government personnel involved in the legislative process.

- Provisions of foreign legal materials: Relevant legal publications will be obtained and distributed.

- Training: Core personnel will be trained both in Albania and in Europe. In late 1995, the European Union Phare Project awarded the Approximation of Legislation Contract to a consortium of law firms, Claes \& Partners and Studio Legale Tonucci. The consortium Claes \& Tonucci is guided in the assistance it provides by the Legal Steering Committee. At the consortium's suggestion the 
Government of Albania formed this committee to reduce confusion and competition among the ministries.

Legislative drafting will be guided in large part by the EU White Paper "Preparation of Associated Countries of Central and Eastern Europe for Integration into the Internal Market." This 400-page document catalogues the EU directives, regulations and policies that must be complied with in order for a country to join the EU.

Other important programmes operating in Albania include:

- GTZ-Project, economic legislation in Albania.

- ABA CEELI Project, an American Bar Association Project funded by USAID.

- ANCA \& WBA, organising a retreat with the Council of Europe and ANCA to review and approve a Governing Statute and Code of Ethics, providing technical assistance to new professional associations, the WBA and the Young Jurist Association.

\subsection{Compliance with International Obligations}

There are no special arrangements for verifying whether legislation is consistent with the European Convention on Human Rights and other international conventions. This fact is kept present by our jurists during their ordinary work. No state organisations are charged with this process.

\subsection{Compliance with Legal Formalities}

There are no requirements as to standard drafting practices in written form to be followed in composing legislation. Draft personnel base their work mainly on tradition and practice. There is no manual or written regulation. As mentioned in the beginning of the material, a draft must contain all the formal elements determined by the regulation of the CM.

\section{Use of Computer Technology}

In Albania, legal acts are drafted using computer technology. The main programmes in both Parliament, Government, ministries and other state institutions, etc., are Windows 95 and Windows 3.11, Microsoft Office. Every drafter has the possibility of working on computer. The Government and Parliament have computer networks and can also work on Internet. A special programme called "The Jurist" contains all the laws, decisions, decrees titles entered in power during 1991-1996. Laws can also be found in the archives of the state institutions, in Government and Parliament archives.

\section{Publication of Legislation}

\section{Legislative Sources}

The legal acts (primary and secondary legislation) are published on the Official Gazette; bills are not included there. Secondary legislation is printed by the Council of Ministers and primary legislation by the Parliament. Primary legislation and secondary legislation in part are therefore published in the same 
publication and republished in annual volumes. The most recent volumes of both are dated November 1996.

During the transition (May 1992-April 1997) 3014 decisions and other legal acts were made by the Council of Ministers. A great part of these are published in the Official Gazette, along with all 631 laws approved by Parliament. A central registry in the Council of Ministers is responsible for registering a complete archive of all secondary legislation; a registry in the Parliament contains primary legislation. Complete collections of current legislation are also kept by the directorates, secretaries, advisers, high officials. Members of the public and lawyers in the private sector can acquire at any time and throughout the country an authentic and complete set of legislation in force, or copies of individual instruments. They are not expensive.

The Law Index provides a consolidated collection of primary and secondary legislation. The most recent copy was published in 1996. There are three index models based on chronology, the date at which the law took effect, alphabetical order and subject order, or the problem addressed. The bill introduced into Parliament should be printed within a day. The sector of the publication is responsible for sending it for printing and checking.

Bills are published only when they must be delivered to the deputies and experts, to whom they are automatically supplied gratis. They are not available for purchase by the public. The costs of printing and publishing the primary legislation are borne by the budget of the Parliament; for secondary legislation, they are borne by the Council of Ministers. No authority can make changes to the text contents of legislation after it is approved for publication. Only grammatical changes can be made.

After the legislation is passed or made (approved), an obligatory period of one week or ten days are required before its official publication. 


\section{LAW DRAFTING AND REGULATORY MANAGEMENT — BULGARIA ${ }^{23}$}

\section{Introduction}

According to Article 87 of the Constitution "The right to legislative initiative belongs to the each member of the National Assembly and to the Council of Ministers"; "The Budget Bill is prepared and submitted only by the Council of Ministers".

Therefore there are two basic, and very different, procedures through which a bill may be submitted to the Parliament. Both will be discussed in this paper; where no explicit mention is made of the drafting and submission of a bill by a member of Parliament it should be assumed that the relevant section refers only to the Council of Ministers procedure.

In specific answer to question 1.1 of the SIGMA questionnaire, bills submitted by members of Parliament are drafted either by the respective member(s) of Parliament or by outside experts; from persons associated with the respective member's political party, with a foundation or other non-profit organisation, with a business group or association or other interest group, or independent experts. Members of Parliament may hire within set limits outside experts to assist in drafting a bill.

All other instruments are drafted by officials working for the Government who are usually mid-level and low-level civil servants from sectoral ministries or agencies appointed either by the Council of Ministers or by the respective minister. The work group of such civil servants may be headed by a Deputy Prime Minister, a Minister or Head of other Government agency, a Deputy Minister or Deputy Head of other Government agency, or a Head of a directorate or department within a ministry. In some cases, e.g. for drafting laws which regulate specific legal or commercial matters, such as the civil and criminal procedural codes, the notaries public law, the registered pledges law, the commercial transactions part of the Law on Commerce, etc., the Minister of Justice may appoint, pursuant to Article 7 of Council of Ministers Decree No. 20 of 1992 on Establishing a Legislative Council with the Ministry of Justice, special work groups which include staff members of the Legislative Council, other civil servants and outside experts.

There is in effect fairly little continued reliance on provisions or practices which were in use before the transition as far as laws are concerned.

First of all, the new Constitution radically changed the list of persons who may actually submit bills to Parliament, limiting them to the Council of Ministers and members of Parliament.

Secondly, there is a whole new procedure for submitting, discussing and voting on bills, which was introduced with the Rules on the Organisation and Structure of the National Assembly.

23. This report attempts to describe the law drafting and regulatory management regime in force in Bulgaria as of $27 \dagger$ March 1997. 
Third, although the Law on Normative Acts and its implementing Decree were adopted respectively in 1973 and 1974 and have not been explicitly amended (except for two very minor amendments to the Law on Normative Acts of 1995), $\S 3$ of the Transitional and Concluding Provisions of the Constitution states that "The provisions of existing laws shall apply if they do not contravene this Constitution". Therefore certain parts of the Law on Normative Acts are now considered void, e.g. Chapter 2, Planning of Bills, parts of Chapter 3 dealing with the "Legislative Council" which no longer exists (although as will be seen later, there are now two separate bodies with that name but with different functions), parts of Chapter 5, etc. The same applies to certain parts of the implementing Decree. The remaining provisions either establish certain principles which are compatible with the democratic process or are technical in nature.

As far as drafting secondary legislation is concerned, the differences are less obvious. Nevertheless the Rules on the Structure and Organisation of the Work of the Council of Ministers and its Administration have attempted to streamline the process of drafting and adoption of secondary legislation and to establish the necessary safeguards for compatibility.

Another fundamental difference that occurred after the transition is due to an indirect factor - control by the Constitutional Court over the constitutionality of law-making instruments adopted by the National Assembly and the judicial control over secondary legislation. This control has had the effect of making the law-making bodies much more conscious of the need to verify acts before their adoption.

\section{Regulatory Framework}

The drafting process is defined first of all in several provisions of the Constitution: Article 87 dealing with legislative initiative; Article 88 dealing with the principles of voting; Article 114 dealing with the acts which the Council of Ministers may adopt; and Article 115 dealing with the acts which the individual Ministers may adopt.

Chapter 6 of the Rules on the Organisation and Structure of the National Assembly is relevant with respect to the drafting and adoption of laws. Section III of the Rules on the Structure and Organisation of the Work of the Council of Ministers and its Administration is relevant to the approval of draft laws and to the adoption of secondary acts by the Council of Ministers. The procedure for the adoption of acts by the Ministers and heads of other Government agencies is not regulated explicitly and is carried out on the basis of existing practice.

The Law on Normative Acts and its implementing Decree prescribe standard procedures that are to be followed in the drafting process, and lay down requirements as to the standard form, format, style of drafting or operation of legislation.

Verification is done at each stage of the drafting process of laws: by the Legislative Council with the Ministry of Justice, by the lawyers in the Legal Department of the Council of Ministers, by the Legislative Council with the National Assembly when bills are referred to it, and finally by the Parliamentary Commissions which review the bills. This verification process has proved quite effective and all laws are adopted under a unified format.

Secondary acts adopted by the Council of Ministers are subject to similar verification procedures. Verification of these instruments is done by the lawyers in the legal departments of the relevant ministries or agencies which may be the drafters of the instruments, and by the lawyers in the Legal Department of the Council of Ministers. The decrees of the Council of Ministers must also be consulted with the Legislative Council with the Ministry of Justice. The other law-making instruments adopted by the 
Council of Ministers (decisions and orders) are not subject to consultation with the Legislative Council with the Ministry of Justice. Nevertheless, as far as form is concerned, all such secondary instruments are adopted under a unified format.

Secondary instruments adopted by the ministries and agencies are subject to internal verification only, but nevertheless, as far as form is concerned, all such secondary instruments are adopted under a unified format.

\section{Regulatory Instruments}

The law-making regulatory instruments are listed in the Constitution and described in more detail in the Law on Normative Acts. These are first of all the primary law-making instruments - laws and decisions adopted by the National Assembly. They are provided for in Article 86 of the Constitution. Laws are described in detail in the Law on Normative Acts. Decisions are not regulated and are adopted on the basis of existing practice. As stated in paragraph 2 of Article 86 of the Constitution they have the same legal force as laws. The difference is that decisions are adopted for one-time regulation of certain relations, rather than for their permanent regulation. The National Assembly adopts also one additional instrument - the Rules on the Organisation and Structure of the National Assembly — pursuant to Article 73 of the Constitution.

The secondary law-making instruments are listed in Articles 114 and 115 of the Constitution. They are the Council of Ministers decrees, orders and decisions, as well as rules and regulations which must be adopted with a decree. The ministers may issue rules, regulations, instructions and orders. With the exception of decisions and of orders of individual ministers all other types of instruments are regulated in greater detail in the Law on Normative Acts. What an order is and in what cases it should be issued are probably considered self-evident. In any case the omission has not caused any practical problems.

The National Assembly may adopt laws or decisions on any subject matter it deems relevant, subject to the provisions of the Constitution. Secondary legislation may be adopted by the Council of Ministers pursuant to a law (Article 114 of the Constitution). There is no special provision in the Constitution stipulating that ministers may issue secondary law-making instruments only pursuant to a higher act. The powers of the ministers are defined in separate Council of Ministers decrees stipulating the functions of each individual ministry. The ministers issue rules on the organisation and activities of the ministry which are internal documents and are not published. These rules may contain certain provisions dealing with the internal drafting of instruments to be issued by the minister. In any case, it is accepted that a minister or head of other Government agency may issue the secondary law-making instruments which are required for the performance of the ministry's or agency's functions and are within its powers.

Therefore, there are four main tiers of law-making instruments: $i)$ the Constitution; ii) the laws and decisions of the National Assembly; iii) the instruments adopted by the Council of Ministers; and iv) the instruments adopted by individual ministers. The fifth tier are local ordinances of the boroughs, but they always have limited local scope and are not officially published in the State Gazette and therefore are not included in this paper.

There is no special single provision in the Constitution proclaiming the hierarchy of law-making instruments. Nevertheless from several provisions of the Constitution and the Law on Normative Acts one may deduce such a hierarchy. Article 149, paragraph 1, item 2 of the Constitution stipulates that "the Constitutional Court rules on requests for proclaiming the unconstitutionality of laws and other acts of the National Assembly"; Article 125, paragraph 2, of the Constitution stipulates that "the Supreme 
Administrative Court rules on disputes on the legality of acts of the Council of Ministers and of Ministers"; Article 107 of the Constitution stipulates that "the Council of Ministers may repeal acts of Ministers which contravene the law or are inappropriate"; Article 15 of the Law on Normative Acts provides for the conformity of lower acts with higher acts. These provisions have been effectively strengthened by the above cited provisions of the Constitution. The system has served in a number of cases as an effective check on the misuse of law-making powers of the legislature or the executive. Still, one major drawback concerning the Constitutional Court: application can be made to it only by the bodies listed in Article 150 of the Constitution - one fifth of the members of Parliament; the President; the Council of Ministers; the Supreme Court of Cassation; the Supreme Administrative Court; and the Chief Prosecutor - and not by individual citizens. This seems to a certain extent to put a greater emphasis on requests for review of legislation based on political rather than on purely legal grounds.

There are also non-law-making instruments. These are largely confined to certain areas which affect, for example, fiscal policy or labour relations. They are usually in the form of circular letters from, e.g. the Chief Tax Directorate to all tax offices, the Chief Customs Directorate to all customs offices, the Ministry of Labour and Social Welfare to all unemployment offices or to all offices dealing with pension rights or social security issues, the Bulgarian National Bank to commercial banks, etc. These circular letters either interpret the law or attempt to fill gaps by providing for uniform application. Unfortunately by exceeding their powers through such letters, the heads of the above-mentioned offices sometimes provide primary regulation of issues, in contravention of the law. These circular letters are not binding upon individuals or organisations but are binding upon the officers, who have to apply them. They may not be appealed but any individual acts issued pursuant to them may be appealed.

\section{Drafting Personnel}

The Ministry of Justice has a special unit called the Legislative Council. Since its establishment it has consisted of 21 staff lawyers but its staff has just been reduced to 12 (14 March 1997) by the caretaker Government. Additionally the Legislative Council may also employ outside experts (both civil servants and people not working for the Government, usually from academia). One of the functions of the Legislative Council, stipulated in Article 2, item 1, of Decree 20 of 1992 on Establishing a Legislative Council with the Ministry of Justice, is to "prepare upon a proposal of the Council of Ministers and the Minister of Justice drafts of laws and secondary legislation". In practice the Legislative Council does draft some of the legislation (as pointed out in the Introduction) but a major part of its work is focused on its other functions, i.e. conformity assessment. Drafts of law-making instruments are generally prepared by units of individual ministries or by ad hoc interagency groups.

Within a ministry the drafting of a law or act of the Council of Ministers is usually assigned to an ad hoc group consisting of officials from different departments. The group always includes at least one of the ministry's lawyers and is usually headed by a high official in the ministry, e.g. a Deputy Minister or a Head of a directorate. The drafting of law-making instruments issued by the minister is often much simpler - it may be assigned to the head of one internal unit who drafts the instrument and clears it with the other relevant units.

Typically, law drafters are ministry officials who are experts in a certain field but do not have legal education. As stated above, a work group always includes at least one of the ministry's lawyers.

There is no statistical information available as to the numbers of officers in Government service who regularly undertake law drafting. In fact, it is most probable that most drafters do not take an active part in drafting more than a single piece of legislation which is to be adopted by the National Assembly. Some 
Government officers may be involved fairly often in drafting new or amending existing law-making instruments to be adopted by the Council of Ministers or an individual minister. Of course this may vary considerably depending on the position of the relevant officer.

As pointed out in the Introduction consultants or contracted personnel may be involved in the law-drafting process. Regulation 31 of the Minister of Justice of 3 September 1996 regulates the fees which may be paid to outside consultants. The maximum fee for drafting a bill is set at 100000 Leva, except where the Minister of Justice decides that the draft is especially complex and increases the fee. Similar fees are paid to outside experts appointed in work groups by the Council of Ministers.

External experts (e.g. specialist lawyers, consultant economists or representatives from the part of the private sector to be regulated) may provide services in drafting, usually pro bono. Decisions are made on a case by case basis.

Public organisations, for example the National Association of Municipalities, which is entitled by Article 9 of the Law on Self-Government and Local Administration to draft proposals for changes and improvements of the legislation on self-government, may also carry out law drafting on their own initiative.

In the course of the last seven years, the turnover of civil servants has varied considerably from one ministry to another. The extent to which those currently undertaking law drafting within Government may be persons who were engaged in similar duties before the transition depends largely on the turnover of the staff of each individual ministry and this varies considerably.

Law drafting training is achieved exclusively through supervised learning on the job. Supervision and monitoring of the quality of law drafting are achieved through the approval of the draft by (sometimes) several levels of superiors before it can be sent to other ministries and agencies for consultation. Usually, once a draft is completed by those involved directly in its preparation, it must be presented to the heads of the relevant directorates or departments for approval and internal consultation, if it is a draft of a law-making instrument to be issued by the minister. If it is a draft of a law-making instrument to be adopted or approved by the Council of Ministers it must be sent for consultation to other ministries and agencies with the signature of the minister (or most often a deputy minister acting for the minister) who has the opportunity at that point to review the draft and, if not satisfied, to return it for further work.

The consultation process itself is also a form of supervision and monitoring.

Parliamentary commissions do in fact often call upon experts to explain or clarify their draft legislation. This is done in varying degrees by the different commissions and often depends on the complexity of the subject matter of a draft.

Government experts are routinely called by parliamentary commissions (but not by members of Parliament) to assist in the preparation of primary legislation that the legislators wish to introduce or in drafting amendments to primary legislation under consideration by the Parliament.

The draft laws of the Council of Ministers and the drafts of secondary law-making instruments are usually prepared by the same personnel. The drafts submitted by members of Parliament are of course most often prepared by entirely different people. 


\section{Drafting Procedures}

\subsection{Primary Legislation}

\section{Programming and Timetabling}

In accordance with Article 25 of the Rules on the Structure and Organisation of the Work of the Council of Ministers and its Administration the Council of Ministers adopts a plan for its legislative activity. This plan includes both the drafting of bills for submission to the National Assembly and the drafting of secondary implementing instruments. The plan (programme) is binding upon the respective ministries or agencies, or work groups, which must prepare the drafts and submit them within the prescribed time periods for consideration by the Council of Ministers. Although it generally follows the plan, it is not bound by it, and in the course of the term of a given cabinet, changes in its law-drafting activities occur. Every new cabinet adopts a new programme.

The general plan, which is valid for the expected four-year term of the cabinet, is then divided into specific plans for each Parliamentary session. Before each session, the ministries and other Government agencies are asked to submit their proposals for inclusions of bills in the specific plan for the respective session. Then the Ministry of Justice, based on the number of legislative days in the respective session, selects an appropriate number of bills and prepares a timetable for submitting each one. In doing this the Ministry of Justice tries to select bills from different areas. The plan is then submitted by the Minister of Justice to the Council of Ministers, and after approval the drafting process starts.

The timetable itself includes consecutive deadlines for submission of the bill to the Legislative Council, the Council of Ministers and finally to the National Assembly.

The general plan of the previous cabinet, approved in early 1995, included initially approximately 250 bills. The session plans usually included approximately 25 bills, of which 7-8 were for full new laws and the remainder were bills to amend existing laws.

The National Assembly also adopts a legislative programme for its full term. This programme is not binding and in the course of the term of a given Parliament numerous changes in it occur.

There is no formal procedure for comparing the policy objectives (as approved initially) and the final draft (before it is approved by Government) to determine whether both are consistent. Basically the drafters are bound by a certain mandate and are obliged to follow it. Inconsistencies may be established and removed during the drafting process and in the course of consultation between the ministries and agencies. They may also be established by the Council of Ministers and the draft may be returned for reworking.

Timetables for the preparation of each bill are set in the specific Council of Minister's plans as referred to above or rarely in ad hoc decisions assigning to certain ministries or agencies or work groups the drafting of certain instruments the need for which may arise based on the situation, e.g. recently certain banking laws. They are managed and monitored by the Council of Ministers. The Chief Secretary of the Council of Ministers is the official who should manage and monitor the timetables.

In accordance with Article 29 of the Rules on the Structure and Organisation of the Work of the Council of Ministers and its Administration, each bill may be submitted to the Council of Ministers only after it has been consulted with the interested Government bodies and organisations. In fact, the previous cabinet introduced the requirement of consulting the bills (but not secondary legislation, which is consulted only 
with the interested ministries and Government agencies) with all ministries and Government agencies. Following that, the bill must be submitted to the Legal Department of the Council of Ministers and then to the Legislative Council with the Ministry of Justice. Following review by the Legislative Council, the bill is submitted by the Minister of Justice accompanied by a report which must be signed also by the relevant minister who was initially responsible for the drafting of the bill. The bill must be approved by the Council of Ministers before it may be introduced into the Parliament. The bill is sent to Parliament with attached justification stating, as per Article 14 of the Decree to Implement the Law on Normative Acts: $i$ ) the reasons for adoption of the instrument; ii) its objectives; iii) the substance of its main points; and $i v$ ) the expected results from its application.

Bills may be introduced into the Parliament at the discretion of the Council of Ministers. There is no fixed rule requiring any advance notice. The Parliament has its rules and timetables once the bill has been filed (Chapter 6 of the Rules on Organisation and Activities of the National Assembly, which will be discussed in the relevant section).

A bill that is approved by the Council of Ministers is submitted to the Chairman of the Parliament who acts in accordance with Chapter 6 of the Rules on Organisation and Activities of the National Assembly. Once deliberation of the bill has begun in the respective commissions, it is a common practice to call mid-level or high-level officials from the ministries for defending the bill or clarifying certain points.

\section{Law Drafting}

The issues concerning policy making with respect to the law drafting process seem to be among the weak points in the Bulgarian regulation of law drafting. These issues are not covered explicitly by existing legislation and most often law-drafters have to rely upon their own understanding of the policy objectives. The guidelines which they can rely on are usually, first of all, the approval of a proposal for drafting new legislation (which proposal is often drafted by the law-drafters themselves but is approved by the respective minister before submission to the Council of Ministers). This proposal usually includes certain policy objectives to be achieved and its approval means that the objectives themselves have been approved. Additional policy issues may come up in the course of drafting the legislation and may be resolved either by the head of an interagency work group or by the respective minister or Head of other agency. Of course, the final assessment whether a certain policy as adopted by the drafters is acceptable comes when a draft is approved.

There is no special unit dealing with policy as opposed to law drafting. Directions on policy objectives or instructions on policy content, to the extent that these do not exist in the original proposal, may be provided in the course of the drafting process as stated above. Unfortunately, law drafters are often left on their own to make judgements on policy issues in the course of drafting.

There is no fixed procedure for law drafting. A law drafter may rely on foreign legislation, on EU legislation or on a treaty as a model. Typically much Bulgarian legislation is drafted by using foreign models. EU legislation has become the leading model for areas which it covers. Where foreign models are not readily available or are unsuitable, drafters have to rely on their intelligence and understanding of the situation. The consecutive steps given as an example in the question, i.e. analysis, research, design, composition and scrutiny certainly seem logical and probably a lot of Bulgarian legislation is drafted following that procedure.

The decision to form an interagency work group rather than to assign the drafting of a piece of legislation to one ministry is taken by the Council of Ministers in certain cases where it believes that this would serve better the drafting process, e.g. when the instrument to be drafted is complex, covers more than one area 
of expertise, etc. There is no fixed criterion and it is always a subjective decision. Additionally the Minister of Justice may form an interagency group for the drafting of certain bills. The issues of consultation and involvement of other ministries were discussed above under the subheading Programming and timetabling.

There is no general fixed statutory requirement for consultation with affected public interests during the policy making and the law drafting stages. In certain areas consultation is mandatory - e.g. labour legislation and other legislation which may affect living standards is discussed in advance with the unions and business organisations in the Tripartite Commission. This is done pursuant to Article 3, paragraph 1, of the Labour Code: "The State shall regulate labour and social security relations, as well as the issues of living standards, in co-operation and after consultation with the representative employees' and employers' organisations".

Comments are sought for important bills, for example by organising seminars or discussions. The frequency and form of these discussions varies considerably. The factors which determine whether extensive consultations should be conducted or whether there should be no such consultations at all range from the purely objective (e.g. time constraints or lack of initiative of a certain ministry).

The law drafter's responsibilities end with the submission of the bill to the Council of Ministers for approval and forwarding to the National Assembly, except for law-drafters who are called before a Parliamentary commission. Once the bill is forwarded to Parliament it is out of the hands of the law-drafters. Proof-reading is done in accordance with Chapter 4 of the Law on Normative Acts: the text is certified by either the Chairman of the National Assembly, the Prime Minister, or the minister who has issued the instrument and also signed by the chief secretary of the respective institution. The certification is done on the original copy of the instrument and this is kept by the body which has adopted it. A copy with a cover letter is sent for publication.

In practice, after a law-making instrument of Parliament or of the Council of Ministers is adopted, it is given to a style editor who can make minor editorial changes without altering the meaning of the text. This final edited text is certified as specified above.

Draft bills are not generally treated by law as an official secret. Nevertheless they are treated as confidential because they are internal documents and individuals and organisations do not have automatic access to drafts. Often the Government may choose to disclose to journalists the main points of a bill once it has been approved by the Council of Ministers. Unless the Government decides to involve certain groups, or there is a statutory requirement to do so, as in the case of the Tripartite Commission, there is no obligation for it, and no right of interested individuals or groups to be a part of the law-drafting process.

The problem of access to a bill stems from the fact that no law on access to information has yet been adopted. Article 41, paragraph 1, of the Constitution stipulates that "Everyone has the right to seek, receive and disseminate information ...". Paragraph 2 of the same article states that "Citizens are entitled to information from state bodies or institutions on issues which represent for them a lawful interest ...". Based on these two provisions and on Article 5, paragraph 2, of the Constitution, which states that its provisions find direct application, application was made recently to the Constitutional Court to interpret Article 41 of the Constitution as to whether interested parties could apply for information from state bodies and institutions pursuant to that article. The Constitutional Court in its decision stated that the issue was too broad and complex to be resolved with a Constitutional Court decision and that it would have to be regulated by a law. Therefore, pending the adoption of such a law, the Government is virtually free to decide in each case whether or not to disclose bills and therefore interested parties have no opportunity to 
acquaint themselves with bills and comment unofficially on them unless the Government decides to provide them with access to the bills.

\section{Parliamentary Consideration}

In accordance with Chapter 6 of the Rules on the Organisation and Structure of the National Assembly the Chairman of the National Assembly must assign the bill to the relevant Parliamentary commissions within three days of its filing. A permanent commission may begin discussion on a bill no earlier than 48 hours after it is received by the members of the commission. The time periods for the submission of the commission's report are determined in each specific case as a function of Parliament's legislative programme and the weekly or bi-weekly programme. Bills introduced by the Council of Ministers must be presented to the National Assembly for a first vote no later than one month after their introduction. Bills introduced by members of Parliament must be presented to the National Assembly for a first vote no later than three months after their introduction. Within 7 days after the first vote members of Parliament may make proposals in writing to amend the bill as adopted on a first vote. The bill then must be reintroduced for a second vote within 14 days.

Article 74 of the Rules on the Organisation and Structure of the National Assembly states timetables for draft decisions.

As per Article 14 of the Decree to Implement the Law on Normative Acts the justification should state: $i$ ) the reasons for adoption of the instrument; ii) its objectives; iii) the substance of its main points; and iv) the expected results from its application. The public nature of the justification is subject to the same regulation as stated above for the bills themselves.

The bill is considered by one leading commission, which has overall responsibility for it, and by certain other commissions as decided by the Chairman of the National Assembly pursuant to Article 64, paragraph 1, of the Rules on the Organisation and Structure of the National Assembly.

Before the first vote on a bill, the members of Parliament are free to propose any amendments they wish and the leading commission may finally submit a bill which differs substantially from the original version. As stated above, within seven days after the first vote members of Parliament may make proposals in writing to amend the bill as adopted on a first vote. The bill then must be reintroduced for second vote within 14 days. In accordance with Article 70, paragraph 2, of the Rules on the Organisation and Structure of the National Assembly, after the first vote proposals which contravene the principles of the adopted on a first vote bill are not admissible.

Article 88, paragraph 2 of the Constitution stipulates that decisions of the National Assembly are to be adopted only with one vote. Draft decisions may be submitted by members of Parliament or by Parliamentary groups. There is a simplified procedure for their adoption (Article 74 of the Rules on the Organisation and Structure of the National Assembly).

Amendments put forward in Parliament may be drafted by the same parties who are entitled to legislative initiative, i.e. the Council of Ministers and the members of Parliament. In the case of the Council of Ministers, drafting amendments would usually be assigned to the same body which drafted the original law.

Officials of the drafting ministry follow the progress of the bill in the Parliament to the extent they are asked to do so by the Parliament. 
According to Article 71 of the Rules on the Organisation and Structure of the National Assembly, the sponsor of a bill may withdraw it prior to the commencement of the first vote. After that the bill may be withdrawn pursuant to a decision of the National Assembly. Therefore in the first case the Government may withdraw the bill, make the necessary changes and reintroduce it. In the second case it may ask for permission to withdraw the bill. Of course, following unofficial consultations the bill may be amended by the leading Parliamentary commission before it is introduced on the floor.

Article 123 of the Rules on the Organisation and Structure of the National Assembly established the Legislative Council of the National Assembly. Although this body has the same name as the body with the Ministry of Justice they differ significantly. The Legislative Council of the National Assembly is a group of academics who are not in Government service. They are mostly acting or retired professors from the Faculty of Law of the Sofia University or from another academic institution engaged in legal matters. They meet occasionally to discuss drafts which may be assigned to them by Parliamentary commissions.

The National Assembly Legislative Council whose members are experts in different areas of the law civil lax, commercial law, international law, etc. - is not part of the formal legislative process per se. It may or may not be consulted by a Parliamentary commission depending on whether the commission thinks that a bill needs improvement, an expert opinion is required, or whether the timing of a bill's review allows for this. The Legislative Council with the Ministry of Justice, however, is a formal legislative process and must always be consulted.

The National Assembly Legislative Council, a structure involved in the legislative process, certainly plays a useful role. The quality of legislation is always enhanced when a given bill is scrutinised carefully by people who possess significant knowledge and experience in different areas of the law. Of course there are also critics of this structure which was established for the first time ever in Bulgaria in 1995. For some, the review of legislation by this informal group is either redundant or too time consuming. So the views on the National Assembly Legislative Council's role are not unanimous. Of course, one must bear in mind that due to the informal nature of this body, it may be simply by-passed when time constraints so require.

In practice, as evident from deliberations both on the floor and in commission, the Parliament does consider the central policy of a bill very closely. It also scrutinises the details of its provisions. This is done in greater detail in the commissions but provisions of certain bills may also be discussed in great detail on the floor.

According to Article 67, paragraph 4, of the Rules on the Organisation and Structure of the National Assembly, the Parliament examines the bill as a whole during the first vote. According to Article 70, paragraph 1, of the Rules on the Organisation and Structure of the National Assembly the Parliament examines the bill either chapter by chapter, section by section or clause by clause at any stage during the second vote.

Article 80 of the Constitution provides for an obligation for all officials and citizens to provide any information requested by a Parliamentary Commission. Article 24, paragraph 2, of the Rules on the Organisation and Structure of the National Assembly provides for an obligation for all state bodies, officials, public organisations and citizens to provide any information requested by a Parliamentary Commission.

There is no formal procedure under which the Parliament or political groups in it can consider and comment upon the form, structure or drafting of a bill before it is formally introduced into the Parliament. This may only be done informally. 
As stated above only members of Parliament or the Council of Ministers may introduce legislation into Parliament. One weak point in the system is that the Government has no formal rights to comment on legislation introduced by members of Parliament. Therefore all the verifications and checks discussed above are not applicable in this case, including the verification for conformity with EU legislation. The Parliament relies on its own Legislative Council and staff lawyers or, when it deems necessary, upon documents or testimony from Government officials.

According to Article 102 of the Constitution, after approval by Parliament the President must, within 15 days of such approval, either sign a Presidential decree (ukase) for publication or return of the bill to the Parliament. This is done upon discretion of the President and is not necessarily tied to any potential unconstitutionality of the bill. In order to adopt it again, the vote of a majority of all members is required (as opposed to a simple majority of those present for adoption the first time). If the bill is adopted again, the President must sign a Presidential decree (ukase) for its publication within seven days of receiving notification of the second adoption.

\section{Particular Legislation}

According to Article 87, paragraph 2 of the Constitution the state budget may be introduced only by the Council of Ministers. This is the only exception to the rule that members of Parliament may introduce bills. The procedure for its adoption is the same as for the other laws.

The particular manner of dealing in the Parliament with legislation concerned with approximating local law to EU law is discussed in detail in Section 6.3. "Compliance with EU legislation and case law".

International treaty obligations are given effect by a law. This is generally dealt with in the same manner as general legislation. The differences are provided for in Article 73 of the Rules on the Organisation and Structure of the National Assembly - the Commission on Foreign Policy must provide its opinion; the text of the treaty may not be amended and reservations to a multilateral treaty may be made only when they are admissible. Also, in accordance with Article 6 of the Law on the State Gazette, treaties may be published in a separate addendum to the State Gazette with a limited print run rather than in the body of the State Gazette itself. This could create potential problems in attempts by individuals and organisations to invoke and prove the existence of provisions of treaties which are published in this way.

Article 11, paragraph 3, of the Law on Normative Acts states that normative acts are repealed or amended with a specific provision of the new or amending act. Chapter 6 of the Decree to Implement the Law on Normative Acts deals with repealing or amending existing legislation in more detail and specifies that the repealed or amended act must be expressly and fully identified. In short, the new provision may either state that an existing provision is repealed or may provide the new wording in case an existing provision is only amended.

The same law may be amended as many times as necessary, even in the same Parliamentary session or calendar year. While certain laws have never been amended, most have been at least once. Certain laws have been amended more than once during the same Parliamentary session or calendar year. There are three main reasons for this. One is to fine-tune such laws as those dealing with, for example, privatisation or mass privatisation. Privatisation on the scale being carried out in Central and Eastern Europe is a new phenomenon and it was difficult to find the right legislative solutions in the first draft. Secondly, certain laws may have to be slightly amended when another law is adopted. For example the Law on Commerce (the fundamental Bulgarian company law) was slightly amended a number of times when the banking law and the stock exchange law, etc. were adopted. Thirdly, certain provisions of several laws which are politically and emotionally controversial, such as the restitution laws, have been subjected consecutively 
to several amendments and repeal of those amendments by the Constitutional Court, only to be amended again in a slightly modified form and to be challenged again.

\section{Formalities}

Primary legislation comes into force three days after publication, unless the legislation itself states another period of time or another date. The three-day standard rule is prescribed by Article 5, paragraph 5, of the Constitution.

Taking effect cannot be made to depend on a Government order. The actual implementation of a law can be made to depend on a Government order. In certain cases a law stipulates that "the terms and procedure for ... shall be adopted by the Council of Ministers". Obviously in such cases until the Council of Ministers has actually adopted the required secondary legislation implementation of the law itself cannot begin. There have been rare cases where for budgetary reasons the Council of Ministers has delayed adopting implementing regulations.

Primary legislation always comes into force. Its actual implementation may sometimes be delayed as stated in the previous paragraph.

\subsection{Secondary Legislation}

\section{Conferring the Authority to Make Secondary Legislation}

The subject matter to be regulated by primary legislation or which may be left to be regulated by secondary legislation are not defined. Article 3, paragraph 1, of the Law on Normative Acts does provide that laws should regulate in full all basic social relations which may be subjected to lasting regulation; this is the sole indication of this kind. Paragraph 2 of the same article provides that for the remaining social relations in the respective sphere, the law may provide for issuing secondary legislation. In each case, Parliament makes the decision on which "basic social relations may be subjected to lasting regulation" and which are the "remaining social relations."

Article 114 of the Constitution stipulates that "Pursuant to, and in implementation of, laws the Council of Ministers adopts decrees, orders and decisions". The following article lists the types of instruments which individual ministers may adopt rules, regulations, instructions and orders. Article 115 makes no direct mention of the need for conferring law-making power to ministers. The existing practice allows ministers to issue law-making instruments pursuant to a higher instrument or, within the framework of their authority, without any explicit authorisation when they judge that they must issue a secondary law-making instrument. The conferral requirement may be deduced from Article 3, paragraph 2, of the Law on Normative Acts, cited above, and Chapter 5 of the Decree to Implement the Law on Normative Acts. Nevertheless, these provisions are not explicit and ministers may therefore issue law-making instruments in certain cases upon their own initiative. The conferral requirement does not cover certain instruments issued by ministers which may be considered law-making, i.e. certain orders or instructions issued by a minister, or non law-making instruments such as circular letters. Additionally, Article 12 of the Law on Normative Acts provides clearly that "An act to implement a law may regulate only the subject matter for which it is provided that the implementing instrument be issued". Therefore, drafters of secondary legislation are generally confined to the authorisation given by the higher body.

The practice concerning the limits of the exercise of secondary law-making power is based on the general provisions of the Constitution and the Law on Normative Acts and its implementing Decree. Primary 
legislation simply states that a certain Governmental body must adopt a certain secondary instrument. The usual wording is "the terms and procedures for ... shall be regulated by the Council of Ministers" or "the Minister of Finance shall issue a regulation on ....".

The existing legislation and practice do not provide for a formal procedure to check that adequate legal authority has been provided to make all the secondary legislation that is likely to be needed or that the delegation of a power to make secondary legislation is constitutional. In the course of the drafting and consultation procedure and in adoption of the secondary legislation, checks should and usually are made by the drafters or higher authorities who approve the drafts (i.e. the relevant minister or deputy minister), by the other ministries and agencies who are consulted about the draft, and by the Legal Department of the Council of Ministers and the Legislative Council with the Ministry of Justice. Finally, a check should be made by the authority adopting the instrument (the Council of Ministers or the individual minister or Head of other agency). After a piece of secondary legislation is adopted, it may be challenged before the Supreme Court as to points of law, which includes issuing the possession of legal authority to adopt the instrument.

The question of whether a certain body has authority to issue a certain instrument has been challenged successfully on several occasions before the Supreme Court. A number of the challenges have been made with respect to the authority of the Government, for example, to determine tax brackets or specific tax rates. Based on Article 60, paragraph 2, of the Constitution and a decision of the Constitutional Court, which stipulates that the National Assembly may not confer the authority of determining the actual tax rates to the Council of Ministers, several Decrees were repealed by the Supreme Court.

Primary legislation always comes into force formally either three days after publication or after the expiration of the time period provided by the instrument itself, or on the date specified in the instrument, regardless of the coming into force of the implementing secondary legislation. The implementing secondary legislation must be adopted either within a time frame specified by the primary instrument or, if such a time frame is not specified, not later than six months following the entry into force of the primary instrument (Article 45, paragraph 1, of the Decree to Implement the Law on Normative Acts). Of course, prior to the entry into force of the secondary instrument the primary instrument (or parts of it) are inapplicable.

\section{Making Secondary Legislation}

Secondary legislation may be adopted either by the Council of Ministers as a collective body or by individual ministers or heads of other Government agencies. In the first case the Council of Ministers assigns to one particular minister (or to a group headed by a Deputy Prime Minister, a Minister or Head of other agency as per Article 24 of the Rules on the Structure and Organisation of the Work of the Council of Ministers and its Administration) the drafting of the legislation. In certain cases the drafting of secondary legislation may be assigned to the Legislative Council with the Ministry of Justice. In accordance with Articles 28 and 30 of the Rules on the Structure and Organisation of the Work of the Council of Ministers and its Administration each draft of secondary legislation which is to be adopted by the Council of Ministers may be submitted only after the interested Government bodies and organisations and the functional departments of the Council of Ministers have been consulted. Draft decrees must also be consulted with the Legislative Council with the Ministry of Justice.

In the other case, the respective minister appoints the drafting group. Co-ordination with the other interested ministries and agencies is mandatory. This type of secondary legislation is not subject to approval by the Legislative Council with the Ministry of Justice or by any departments of the Council of Ministers. 
The secondary legislation which is to be adopted by the Council of Ministers is mentioned in a law. The other secondary legislation may be adopted pursuant to a law or an act of the Council of Ministers. All acts of the Council of Ministers are adopted collectively.

Theoretically, secondary legislation should be prepared in the course of the same drafting process as the primary legislation with which it is connected. (Article 45 of the Decree to Implement the Law on Normative Acts). In practice, however, this doesn't always happen.

Concerning policy making with respect to secondary legislation, see the response given in Law Drafting above.

Drafting secondary legislation is undertaken by the same persons who draft primary legislation. See Section 4. "Drafting Personnel", which is fully applicable to this section as well.

The Government, or the minister or head of another agency who is to issue a secondary law-making instrument, may decide to hold informal consultations with affected parties or special interest groups. In some cases, e.g. labour legislation, these are compulsory. In many other cases such consultations are not held. In any case, except for the labour legislation consultations, they are informal.

Drafts are not published and the absence of a law on access to information, discussed under Law Drafting above, there is no mechanism for providing adequate advance information to interested or affected parties.

Checks for conformity and authority were discussed above. There are no special formal procedures other than the consultation of the draft with interested ministries and other Government agencies, with the legal department and the functional departments of the Council of Ministers, and with the Legislative Council with the Ministry of Justice.

Style and form are regulated by Chapter 3 of the Decree to Implement the Law on Normative Acts and will be discussed in detail under Section 6.5. "Compliance with legal formalities".

Secondary legislation which is not adopted by the Council of Ministers does not have to receive its approval.

A draft instrument becomes law following publication in the State Gazette. The standard time period for entry into force is three days following publication, unless the instrument states another period or a specific date (Article 5, paragraph 5, of the Constitution).

\section{Procedures After Making}

Article 17 of the Law on Normative Acts and Chapter 7 of the Decree to Implement the Law on Normative Acts provide for "studying the results of the application of normative acts". These provisions are broader than checking the instrument's validity or form, but include those elements as well. Likewise Article 2, item 6, of Council of Ministers Decree 20 provides that the Legislative Council "studies the results of application of laws" but this provision is seldom, if ever, applied. There is no formal procedure or timetable for checking the instrument's validity or form. In practice, when a ministry or agency which has to apply the instrument sees certain deficiencies in an act, or when an act is overturned by the courts, the ministry or agency may make a proposal for amendment or repeal of the act. There is no special body which routinely verifies the validity or form of secondary legislation. 
Secondary legislation adopted by the Council of Ministers is registered and kept centrally in a special records department of the Council of Ministers. Every law-making instrument is filed with all attached documentation - decision to draft the instrument, letters stating the opinions of ministries and agencies, minutes from meetings of discussion of the draft, justification, etc. This register contains the "certified copies" as per Article 36 of the Law on Normative Acts. After ten years the files are transferred to the National Archives.

There is a second computer register which is kept by the Legal Department of the Council of Ministers. It contains the full texts of all secondary legislation adopted by the Council of Ministers for instruments adopted since 1993. For the older instruments, it contains only the headings, but does contain the texts of all recent bills and the headings of older bills which have been approved by the Council of Ministers and forwarded to the National Assembly.

Neither register is regulated specifically concerning public access. In practice, written application can be made for information or a copy from either register and both registers routinely satisfy such requests.

The individual ministries and other Government agencies keep their own registers of the law-making instruments they issue These are centrally regulated by the general rules with respect to the manner of filing and storage, handing over to the National Archives after ten years, etc. Storage of such instruments as "certified copies" and public access to them are regulated by rules issued by the individual ministers or heads of other agencies. The Ministry of Foreign Affairs keeps the originals of all treaties to which Bulgaria is a party.

Secondary legislation must be published to be valid. In accordance with Article 11, item 1, of the Law on the State Gazette all law-making instruments, including secondary legislation, must be published within 15 days of filing with the State Gazette.

\section{Parliamentary Action}

Secondary legislation is neither sent nor reported to the Parliament. It is not subject to any confirmation or disapproval by the Parliament. The Parliament cannot examine, or debate, secondary legislation on its own initiative, nor may it amend secondary legislation made by Government. The Parliament can only affect secondary legislation indirectly, i.e. by repealing a law or a provision thereof, which would automatically lead to the repeal of the secondary legislation issued pursuant to the repealed law or provision (Article 13 of the Law on Normative Acts), or by amending a law in such a way to force the Government to amend the relevant secondary legislation, or simply by adopting a new law which provides primary regulation of certain matters and thus renders the secondary legislation inapplicable.

The Parliament has no commission charged with keeping under review the way in which secondary law-making powers are exercised. It may only authorise and require the Government or certain ministries or agencies to issue certain secondary legislation but has no control over the content of the issued legislation. Disputes are resolved through the Supreme Court.

During the last seven years, Parliament has in practice exercised little democratic control of the Government's use of its secondary law-making powers (through Parliamentary control, Article 90 of the Constitution; Chapter 7 of the Rules on the Organisation and Structure of the National Assembly). 


\section{Miscellaneous}

Secondary legislation can be challenged before the Supreme Administrative Court as to points of law (Article 125, paragraph 2 of the Constitution).

A number of challenges have been made to the Government's authority to determine tax brackets or specific tax rates. Based on Article 60, paragraph 2, of the Constitution and a decision of the Constitutional Court, which stipulates that the National Assembly may not confer the authority of determining the actual tax rates to the Council of Ministers, several Decrees were repealed by the Supreme Court. It must be noted that in drafting the most recent tax law, the law on the profits tax, the Council of Ministers amended an earlier draft, which had provided that depreciation norms would be left to regulation by secondary legislation, and included a table of depreciation norms in the body of the law. Other instruments have also been challenged successfully: a regulation on payments prohibiting cash payments in excess of 20000 Leva between companies; a regulation on gaming, etc. There clearly seems to be a tendency to challenge mostly secondary legislation with direct financial implications. In the past several years the Supreme Court has been prone to strike down the challenged secondary legislation, and this was based at least partially on political reasons.

One practice which has not yet been challenged is the Government's practice of sometimes adopting secondary legislation pursuant to a general provision of a higher act. For example, there are several Council of Ministers decrees which are adopted pursuant to Article 105, paragraph 2, of the Constitution. Article 105, paragraph 2, of the Constitution simply states that "the Council of Ministers ... carries out the general government of the state administration ...". On the one hand the Council of Ministers must have some freedom in deciding how best to regulate the issues within its competence and in certain cases should be able to adopt the required law-making instruments. (Decree No. 20, which is discussed in this paper is itself adopted pursuant to Article 105, paragraph 2, of the Constitution.) On the other hand, the widespread application of this practice would undermine the provision of Article 114 of the Constitution.

The numbering of secondary law-making instruments itself shows that during the period since the transition law-making powers are used much more extensively. It is difficult to provide accurate statistics but one could say, for example, that the number of decrees adopted by the Council of Ministers in a given year may have doubled after the transition for several reasons: the high rate of adoption of new laws by Parliament which require new secondary legislation, the repeal or amendment of many secondary law-making instruments, and the primary regulation provided on certain issues by the Council of Ministers.

The issues mentioned in Section 5.2. are generally regulated by primary legislation.

\section{Specific Draft Verifications}

\subsection{Constitutional Compliance}

There is no formal procedure for verifying compliance with the Constitutional requirements during the policy-making stages. Verification is an informal process which is part of the law-drafting process at every stages, including the policy-making stage.

During the drafting stages there are two specialised bodies: $i$ ) the Legislative Council with the Ministry of Justice, which reviews all drafts of laws which will be submitted by the Council of Ministers and in 
certain cases drafts of secondary legislation; and ii) the Legislative Council with the National Assembly which reviews draft laws upon request from a Parliamentary commission. These two bodies must specifically check, inter alia, for Constitutional compliance. There are no formal criteria or special requirements in checking for compliance with the requirements of the Constitution. Ultimately the Constitutional Court or the Supreme Court may rule that certain provisions do not comply with the Constitution; these powers are intended as a deterrent to law-drafters or to compromise issues of constitutionality. Both legislative councils have merely advisory powers and must state their position on a given draft instrument either, in the former case, to the Ministry or agency or work group which is in charge of the drafting or, in the latter case, to the Parliamentary commission which requested the review.

Again, no formal arrangements exist to verify that amendments proposed by the Parliament comply with constitutional requirements. The Legislative Council with the National Assembly, when asked by a Parliamentary commission to review a certain draft, will also state an opinion on its constitutionality.

Recently the Ministry of Justice prepared a form, called a "Certificate of Compatibility". This form must be attached to a draft at every stage of its consultation. The drafters must provide information on the degree of compatibility with EU legislation and with other international instruments. Specifically they must state whether the draft is fully compatible or to what extent otherwise, and to provide reasons for the partial incompatibility. The Legislative Council with the Ministry of Justice provides an assessment concerning: $i)$ the relevance of the respective EU legislation; ii) whether relevant EU legislation is exhaustively listed; and iii) whether it has been in fact taken into account in the draft.

Thus far, the Certificate of Compatibility is used only for compatibility with EU legislation. The scope of this procedure might be broadened to include other forms of verification would require legislative regulation and a significant change in the form itself.

Challenges were discussed above. Based both on the merits of certain issues and on the political configuration in Bulgaria it was clear from the very beginning that certain primary law-making instruments would be declared unconstitutional by the Constitutional Court. These are centred mostly around restitution laws which were adopted in 1992 by the UDF and Movement of Freedom and Rights majority and which the Socialist majority attempted to reverse partially in 1995 . There were several cases in which the Constitutional Court declared certain amendments to the restitution laws unconstitutional and the majority then proceeded to adopt substantially similar legislation a second time, only to have it redeclared unconstitutional Restrictive provisions in certain laws, e.g. the prohibition in the banking law for former bankers to hold high positions in banks for a number of years or the annulment of pension rights of certain categories of Communist Party officials and staff, both of which were adopted in 1992, could also fall into the category of instruments that might be foreseeably considered unconstitutional by the Constitutional Court Nevertheless, the latter decisions served as a deterrent for adopting legislation which limits basic rights of individuals.

In certain cases, though, challenges were unsuccessful contrary to expectations: the President's challenge of the law prohibiting medical workers from striking; opposition members of Parliament challenge in early 1996 of the part of the Concessions Law introducing concession requirements for telecommunications service were upheld by the Constitutional Court.

There were also cases where the Constitutional Court reversed itself. In 1992, it permitted the dismissal of the members of the Supreme Judicial Council in 1991, but then declared unconstitutional a substantially similar law for dismissing in 1995 the members appointed in 1992. 


\subsection{Compliance with the Existing Legal System}

The comments provided above for Constitutional compliance fully apply to verifying the consistency of policy proposals and policy options with the requirements of the existing law and legal structures. The consistency of each draft text of particular legislation (whether primary or secondary) with the existing law, legal structures and procedures is verified by the drafters or persons providing approval or comments at certain drafting stages as described above.

Policy planners and drafters have to rely on the general rules of Articles 3, 10, and 11 of the Law on Normative Acts in order to decide whether new legislation is required at all, because the matter may already be dealt with under existing law or could be dealt with without legislative action (e.g., administratively), and also whether proposed legislation may require that existing law be repealed or amended, or include transitional provisions.

\subsection{Compliance with EU Legislation and Case Law}

After the Europe Agreement too effect, the priority of the country to integrate the European Union was demonstrated by establishing a national mechanism for co-ordinating and implementing the obligations of Bulgaria under the Europe Agreement.

In March 1995, the Council of Ministers adopted Decree No 66, which consolidated and centralised the implementation process of the Europe Agreement by establishing four new bodies: $i$ ) the Governmental Committee on European Integration (GCEI); ii) the Co-ordination Commission on European Integration (CCEI); iii) a Secretariat (to the GCEI); (iv) Work Groups (WGs) of experts attached to the GCEI. Decree No 66 was amended on 8 May 1995 by Decree No 97, essentially to clarify the role of the new bodies with respect to Phare.

The Council of Ministers also created a new position within its own body, that of the Secretary of the Council of Ministers on European Integration ("The Secretary").

\section{Government Committee on European Integration (GCEI)}

Role: The GCEI oversees, elaborates, develops and monitors the policy of the country towards the European Union. It also makes proposals for decision by the Council of Ministers, co-ordinates the Public Administration in its relations with the EU as well as Phare.

Membership: The Committee is composed of eleven ministers ${ }^{24}$. Other members of the Government and heads of other government agencies may be invited to attend meetings, convened every month by the Prime Minister.

Chairmanship: The Prime Minister is Chairman of the GCEI.

24 The Deputy Prime-Ministers (DPM) and Ministers of: (1) Trade and Foreign Economic Cooperation; (2) Territorial Development and Construction; (3) Economic Development; (4) Foreign Affairs; (5) Interior; (6) Finance; (7) Justice; (8) Industry; (9) Agriculture and Food Industry; (10) Transport; (11) Defence. 


\section{Co-ordination Commission on European Integration (CCEI)}

Role: The Commission essentially oversees the operational work of the ministries and Departments in tasks related to the implementing the Europe Agreement. It also makes proposals to the GCEI and defines the specific tasks of the Work Groups.

Membership: The CCEI is composed of representatives, at the deputy minister level, of twenty ministries and Government Agencies ${ }^{25}$ closely involved in the European Integration process. Those representatives are appointed by their respective ministers or heads of other Government Agencies.

Chairmanship: The CCEI is chaired by the Secretary and meets twice a month.

\section{$\underline{\text { Secretariat }}$}

Role: The Secretariat's essential role is to assist the GCEI in carrying out its objectives. This assistance is provided by planning the work of the GCEI; liaising directly with Senior Officials, organisations and institutions involved in EU matters; ensuring that there is cohesion between Government policies with respect to the European Integration process, including approximation of legislation; planning and co-ordinating Phare.

The importance of the Secretariat is underscored by the fact that it is subordinated to the Chairman of the GCEI, i.e. the Prime Minister.

Structure: The Secretariat consists of a team of ten people, of whom eight are Advisers, who have been given responsibilities in specific subject areas related to the European integration process. Advisers are selected on the basis of their particular expertise and experience. There are twenty-three subject areas falling within five broadly defined categories: economic and industrial issues, institutional issues, including approximation of legislation, external assistance: e.g. Phare National, Phare CBC.

\section{Work Groups (WGs)}

Role: WGs prepare draft decisions on specific issues and organise activities geared to implementing EU programmes. Thirteen WGs were created by Decree 66, one per subject. In accordance with the Decree, the GCEI has since created additional WGs, which now total seventeen ${ }^{26}$.

25 The Deputy Ministers of: (1) Foreign Affairs; (2) Trade and Foreign Economic Cooperation; (3) Economic Development; (4) Agriculture and Food Industry; (5) Environment; (6) Transport; (7) Justice; (8) Labour and Social Welfare; (9) Interior; (10) Interior; (11) Industry; (12) Finance; (13) Territorial Development and Construction; (14) Culture; (15) Public Health; (16) Education, Science and Technology. The Vice-Presidents of the Committees of: (16) Energy; (17) Standardisation and Metrology; (18) Post and telecommunications. (19) The Vice-Director of the National Institute of Statistics. (20) The Vice-President of the Commission for the Protection of the Competition.

26 (1) Approximation of legislation; (2) Cooperation in the fields of Justice and Home Affairs; (3) Trade and Economic Cooperation and financial issues; (4) Balance of payments; (5) Agriculture; (6) Industry; (7) Transport; (8) Energy; (9) Telecommunications; (10) Local Government; (11) Regional Development; (12) Environment; (13) Phare; (14) Border and Customs Control; (15) Infrastructure; (16) Technical Regulations and Standards; (17) Public Administration Reform. 
Structure and Membership: Work Groups consist of experts appointed by their respective ministers or heads of other Government Agencies. WGs report to the CCEI on the specific tasks on which they are working. WGs vary in size between 6 and 16, depending on the number of ministries represented in the group. The Secretariat's staff member involved in the same subject area as that of the WG is an ex-officio member of that Group.

Chairmanship: Work Groups are chaired by Deputy Ministers or Deputy Heads of Government Agencies, Members of the CCEI, upon their appointment by the GCEI.

Within the framework of the mechanism, a Strategy Paper for the Implementation of the Recommendations of the EU White Paper on the preparation of the associated countries of Central and Eastern Europe for integration into the internal market was developed, and had three main objectives:

1. Taking an inventory of the existing Bulgarian legislation and its degree of compatibility with EU legislation.

2. Drawing up a comparative analysis by sector was made and based on it a concrete programme with the respective responsible ministries and agencies and the time periods for adopting new or amending existing Bulgarian legislation was drawn up.

3. Clarifying the state of the administrative infrastructure and its ability to provide an effective implementation of the new legislation, as well as the need to create new or reorganise existing structures

The first progress report on the implementation of the Strategy was submitted to the European Commission by the Bulgarian side during the Second Association Committee at the end of October 1996.

This Strategy Paper is the basic document for the process of approximating Bulgarian legislation with EU legislation. The legislative programme of each ministry follows the Strategy Paper and the terms set up in it, as well as the legislative programme of the Government.

The main responsibility for transposing specific pieces of legislation belongs to the line ministries and interministerial Work Group responsible for co-ordinating the European integration process. The ministry which has to submit the draft of a respective law has to fill out a Certificate of Compatibility in which it should point out the corresponding EU legislation which it is implementing with this law as well as whether it is fully transposed or not. In the second case, the reasons for non-implementation are requested. Ministries are also required to mention in the justification whether the respective EU legislation requires some administrative structure, whether it already exists, needs some adjustments or should build a new one. It is aimed at improving the enforcement of the newly adopted legislation.

This methodology for this year will fully cover secondary legislation as well.

In 1996, a special Framework Programme for the Approximation of Legislation under Phare was launched. It is being implemented by the Ministry of Justice. The first 6-months working programme was approved at the end of 1996. The first task was to prepare a glossary to accompany the White Paper and other EU legislation terminology in four languages. This will accelerate the process of approximation.

The main task of the Programme is to help make the laws having horizontal impact fully compliant with the EU legislation as well as to assist some ministries on specific drafts.

The services offered by TAIEX are used extensively as well. 
There is no formal determination, either in the Strategy Paper or in relevant legislation (Council of Ministers Decree 20 of 1992 on Establishing a Legislative Council with the Ministry of Justice, the Rules on the Structure and Organisation of the Work of the Council of Ministers and its Administration, etc.) of the criteria for this EU compatibility checking. The drafters of new legislation or those performing the compatibility checks have to rely, therefore, on the generally accepted criteria for assessing compatibility between two law-making instruments.

First of all, there should be an assessment of the principles and objectives of the relevant EU legislation and these should be checked against the principles and objectives of the relevant draft.

Secondly, a check should be made for compatibility of the substantial provisions of the relevant EU legislation and the relevant draft. This check, of course, would not require textual identity but rather a substantial similarity in the thrust of the main regulatory norms of the relevant EU legislation and draft.

Thirdly, an assessment should be made of the intended results and the results that would actually be achieved with the proposed draft and these should be compared with the intended or achieved results of the relevant EU legislation.

In any case, at least two things should be borne in mind. First of all, due to, as a minimum, the different levels of the two legislative systems (supranational v. national) ascertaining "compatibility" always includes an inherent relativity. Secondly, "degrees of compatibility" — a draft can be "fully" or "partially" compatible with EU legislation. These are also relative concepts. Therefore "compatibility" should not be treated as an exact science; a creative approach from drafters or checkers is not only welcome but imperative.

The final opinion on the compatibility of any law is given by the Legislative Council with the Ministry of Justice on the basis of the Certificate of Compatibility filled out by the line ministries or other Government Agencies. The final decision on whether the draft is "fully" or "partially" compatible with EU legislation and whether "full" compatibility is required at the respective point in time, or could be left for a later stage, is made by the body adopting the relevant legislation.

If there are some conflicts between the ministries at the preparation stage concerning technical aspects of the respective transposed legislation they should be resolved in the Work Group or within the framework of the Co-ordination Commission on European Integration at the level of deputy ministers.

After setting up the mechanism the Council of Ministers adopted an unpublished Decision No 192 trying to establish an appropriate mechanism for verifying the compatibility. Within the framework of this mechanism, it is mandatory that all drafts that regulate any of the areas listed in Article 70 of the Bulgarian Europe Agreement take into account EU legislation. The drafts in other areas may also take into account EU legislation. Each Work Group drafting an instrument in the former area must include experts from the relative ministry or other government agency familiar with EU legislation. Before a draft in the former area is submitted to the Legislative Council with the Ministry of Justice, the respective Work Group on approximation of legislation should be consulted.

The National Assembly has specific internal rules approved by its Chairman for checking the compatibility of drafts with EU legislation. A draft submitted by a member of Parliament must be forwarded first to the Legal Department of the National Assembly. The Legal Department must decide whether the draft is in any of the areas listed in Article 70 of the Europe Agreement. If it is, the Legal Department must find all the relevant EU legislation and attach copies of it to the draft. In addition, the Legal Department adds the draft to a special computerised list which means that the report of the leading 
Parliamentary commission which accompanies the draft for the second reading must include a conformity assessment. When a draft in any of the areas listed in Article 70 of the Europe Agreement is introduced by the Council of Ministers, the Legal Department must check whether it is accompanied by a Certificate of Compatibility and whether all relevant EU legislation is listed.

\subsection{Compliance with International Obligations}

Compliance with treaty obligations is assessed by a double procedure. One is by co-ordinating all draft legislation with the Legislative Council with the Council of Ministers. As noted above, one of the functions of this Legislative Council is to assess the conformity of the draft legislation with treaties to which Bulgaria is a party. The second procedure is to consult with the Ministry of Foreign Affairs on the draft legislation, which provides comments mostly on compliance with treaty obligations.

There is one special category of draft legislation submitted to the Ministry of Foreign Affairs for consultation, pursuant to the Decree on Participation of the People's Republic of Bulgaria in Treaties all international instruments to which Bulgaria may become a party (and which by virtue of Article 5, paragraph 4, of the Constitution become a part of domestic law) must be submitted to the Ministry of Foreign Affairs for consultation.

There are no special arrangements for verifying whether legislation is consistent with the European Convention on Human Rights or ILO conventions. This verification is done as part of the general verification for compliance with treaty obligations.

\subsection{Compliance with Legal Formalities}

Both primary legislation and secondary legislation must comply with the provisions of Article 9 of the Law on Normative Acts and Chapters 3 and 4 of the Decree to Implement the Law on Normative Acts. They list all the requirements as to form and format.

Article 9 of the Law on Normative Acts requires that "Provisions of normative acts shall be formulated briefly, precisely and clearly in the Bulgarian language as generally used".

Chapter 3 of the Decree to Implement the Law on Normative Acts provides for the titles and numbering of law-making instruments; their subdivisions - parts, titles, chapters and sections; the numbering of these subdivisions; the article as a basic provisions; the paragraphs, items and letters which an article may include; the section symbol "§" for the transitional and concluding provisions, etc.

The regulation is sufficiently detailed and clear and has established a uniform format for all legislation.

Chapter 4 of the Decree to Implement the Law on Normative Acts deals with the formulation of the provisions of normative acts, i.e. they must be formulated briefly, precisely and clearly. Deviations from the generally used Bulgarian language are allowed only where demanded by the subject of the act. Foreign words and phrases shall be used only if they have become permanent components of the Bulgarian language, or where they cannot be replaced by Bulgarian terms. Words and phrases with established legal meaning shall be used with uniform meaning in all normative acts. Where deviation from the generally acknowledged meaning of a word or phrase is necessary, an additional provision shall determine their meaning for the purposes of the respective act, etc. The chapter also covers references to other provisions. 
The Law on Normative Acts and the Decree to Implement the Law on Normative Acts establish both the overall and the detailed regulation of Bulgarian law drafting. They are well known to lawyers and are observed in most cases. In those rare cases where the drafters may have omitted them, the omission is rectified in the course of the consultation process.

\subsection{Compliance with Administrative and Information Technology Demands}

There is no formal system for carrying out systematic checks to establish the most appropriate level in government at which a new legislative scheme should be implemented.

Likewise, there is no formal system for establishing whether the necessary organisational structures and administrative procedures required to make new legislative proposals fully operative already exist and are adequate for the purpose, or whether these can and will be provided to the level necessary for effective implementation.

Nor is there any formal system for carrying out systematic checks to establish what resources, particularly human resources, already exist or will need to be provided to make the new legislation fully operational.

There is no formal system for carrying out systematic checks to determine whether draft legislation contains all the legal provisions needed to make it fully operational administratively so that the legislative scheme can be fully implemented.

Checks may be carried out as a matter of course by the authority which is charged with drafting legislation and by the authority which will adopt the draft. It seems that these checks, in most cases at least, would fall short of the criterion "systematic checks".

Computer-assisted administration and the impact of computer systems are generally not discussed during the drafting process in the systematic manner which the questions suggest. This does not mean that in certain cases the drafters would not discuss such considerations but again this seems to fall far short of the "systematic" criterion which the question seems to presuppose.

\subsection{Compliance with Environmental Standards}

Environmental issues are not given separate treatment. Conformity to existing national standards relating to the protection of the environment and to compliance with EU law or other international obligations relating to the environment is done as part of the process of consultation with ministries and agencies and with the Legislative Council with the Ministry of Justice on the draft. Any draft legislation which touches upon environmental issues must be cleared with the Ministry of Environmental Protection .

\section{8. $\quad$ Compliance with Textual Quality Standards}

Article 9 of the Law on Normative Acts provides that "Provisions of normative acts shall be formulated briefly, precisely and clearly in the Bulgarian language as generally used". Legislation generally is easy to understand and work with, clear in the way it sets outs its contents, and generally written in the language that is used by reasonably educated persons. Of course it does employ specific legal terms but this would not characterise it as "using legalistic terms". 
Drafting conventions follow the rules of Chapters 3 and 4 of the Decree to Implement the Law on Normative Acts. There is by now a well established tradition and practice and all legislation that is published in the State Gazette is uniform as far as form and style are concerned.

In 1992, the Council of Ministers submitted a new draft Law on Normative Acts to the National Assembly, to replace both the existing law and its implementing decree and bring the regulation of this subject matter into conformity with the new Constitution. This draft never reached the floor. Currently, supplementing of the Law on Normative Acts and its implementing decree does not seem to be a priority. This is due partly to the more or less satisfactory existing regulation of the technical issues and because those provisions which contravene the Constitution are simply not applied pursuant to $\S 3$ of the Transitional and Final Provisions of the Constitution. This has not created a legal vacuum because of the general nature of the provisions which are still in force (which allows them to be adapted to the new Constitutional order) and the well established practice of law drafting.

\subsection{Costs}

Cost assessment has quite limited use. It is used mainly in tax legislation or other legislation of a fiscal nature. It is done mostly by the Ministry of Finance staff. Cost assessment is part of the drafting process and has no formal foundation in legislation. When applied, it is usually done at the initial stage when the Ministry of Finance drafts a certain instrument, or at a later stage when it is consulted on particular draft instruments.

Cost assessment is not performed by any specialised unit but by the regular Ministry of Finance officers who either draft budget or tax legislation or provide opinions on other drafts on expected budgetary costs. The financial impact on private sector bodies or the indirect financial impact of new legislation on the private sector is generally not subject to cost assessment.

The procedures mentioned in Section 6.8. above are not applied in Bulgaria at present.

The Parliament may be given information on expected budgetary costs for certain drafts. This information may be included either in the report or in the justification accompanying the draft. As discussed in 5. "Drafting Procedures", "Law Drafting", drafts are not public unless the drafting or adopting authority wants to disclose them. This is also true for the report and justification.

There is no formal ex post evaluation for projected costings.

\subsection{Efficiency}

No such formal checks are carried out. The drafters or the body proposing the respective law-making instrument may try to make an assessment but it is not neither mandatory nor is there a particular procedure.

\subsection{Practicability}

The response is the same as in 6.10. "Efficiency". 
Implementation is generally a weak point in the Bulgarian legislative process. There is no formal method for judging potential compliance or determining the legal provisions necessary to ensure the effective implementation of the legislative scheme. Very often good laws on the books are simply not implemented or are not implemented properly.

Assessment in the drafting stage for determining what human, institutional and financial resources will be needed for the selected method of enforcement to take effect, whether enhancing existing resources, and how they will be provided, may be done informally by the drafters or by the body adopting the instrument; it is not a standard procedure.

The same applies to the checks mentioned in Section 6.11 .

\subsection{Control of Consultation}

The Council of Ministers monitors and enforces compliance with consultation procedures in the drafting stage. When it receives a draft for review and adoption (a draft bill to be sent to Parliament following it approval or a draft secondary instrument to be adopted) any minister may object that the draft includes issues which are of the competence of his or her ministry and were not cleared with it. In this case, the Council of Ministers must decide whether to proceed with the draft or to instruct the minister who has overall responsibility to first consult with the respective ministry and then reintroduce the draft for approval or adoption.

Pursuant to Article 107 of the Constitution, the Council of Ministers can decide at its discretion to repeal an instrument issued by a minister on which the respective ministries or agencies were not consulted. This is rarely, if ever, done in practice.

The potential non-observance of the obligation to consult has no effect on the validity of the instrument once it is adopted and may not be referred to, imposed, or enforced by a court.

The general public may comment upon legislative proposals or draft legislation only if the respective body decides to give it such an opportunity. As stated above drafts are not generally available.

In some cases, seminars or discussions are organised either by the drafting body or by certain public organisations in conjunction with it. As stated several times, the process is informal and depends wholly upon the discretion of the drafting body.

\section{Ex Ante Evaluation Instruments}

There are no formal instruments in use to assist in the ex ante evaluation of policy proposals for legislation (computer models, simulations, checklists), or of early drafts of legislation (checklists). Flow-charts, or critical path analyses may be used incidentally.

Legislation from another country is often used either as a model for policy makers or as a legislative precedent for law drafters, as discussed above in Law drafting. 


\section{Computer Technology}

Computers are used in the drafting process almost exclusively for word processing. Additionally, commercial data bases are supplied on disks, containing legislation which may be used in certain cases by law drafters. Most ministries are fairly well supplied with computers for word processing and drafts are commonly entered directly on a computer. This is customarily done by a member of the law-drafting team and not by a secretary.

Law drafters use a standard word-processing package - mostly Microsoft Word programmes. With the exception of the legislative data bases, computers are used almost exclusively for word processing.

The data-base legislation available in Bulgaria is not created specifically for law drafting but rather for lawyers to use in reference to their work. Therefore, although a search can be conducted, this is not a specialised search for law-drafting purposes. The exception is the data base of the Legal Department of the Council of Ministers, discussed above.

The law drafter has no legal obligation to provide the Government Printer with the text of legislation on diskette so that it can be printed without further type-setting. Nevertheless a diskette is provided fairly often with the official hard copy of the instrument.

\section{Publication of Legislation}

\section{Legislative Sources}

Official copies of legislation are published in the State Gazette. Bills are not published. In accordance with the Law on the State Gazette, is prepared by an editorial office which is under the control of the Chairman of the National Assembly. The editorial office has the status of a department of the National Assembly.

All primary and secondary legislation is also published in the State Gazette in the same manner.

Article 6 of the Law on the State Gazette allows one exception to this rule: lengthy treaties may be published in a separate addendum with a limited print run. As stated above, this could create potential problems if individuals and organisations attempt to actually obtain a copy of a treaty or invoke its provisions published in this way.

Article 5, paragraph 1 of the Law on the State Gazette states that treaties must be published within 15 days of their entry into force for Bulgaria. If observed properly, this will vastly improve the publication and entry into force of treaties. Treaties are ratified by Parliament with a law, but the standard procedure is to publish the law itself upon ratification, and not the text of the treaty itself which is published later once the treaty comes into effect, by the ministry charged with the treaty accession process. In the past, the publication of many treaties was delayed (some were never published). That Article 5, paragraph 4 of the Constitution requires that treaties be published in order to become part of domestic law means that until they are actually published, they are not part of domestic law. Therefore, an unpublished treaty would not be enforceable in domestic courts. This could create potential problems with treaty partners for whom the non-publication or delayed publication may be considered irrelevant to the status of the treaty. 
The 15-day requirement should solve these problems. It leaves open the question of retroactivity, i.e. whether the treaty should be enforced or could be invoked from the date of publication or retroactively, from the date it came into force for Bulgaria.

While commercial publications exist, the State Gazette is the only official publication of an instrument. Consolidated collections of primary and secondary legislation (including the law in force on the date of publication) are published commercially. One non-comprehensive collection of primary and secondary legislation which includes most important instruments, is published by a private company under a contract with the National Assembly. It is relatively inexpensive: an annual subscription provides monthly instalments consisting of pages to substitute for pages of repealed legislation or of pages to be added in the appropriate place.

The official "certified copy" of each primary legislative instrument is kept by the National Assembly. No comprehensive government registry of all legislation exists. See Section 5.2. "Secondary legislation" for registers of secondary legislation.

Of the several commercial computerised data-bases of legislation, the most widely used are called Digesta, Apis and Norma. For example the judges in the Sofia City Court use Norma in their work. These data bases vary in cost. For example, Digesta offers several different products ranging from USD 100 per year to USD 2000 per year for the full collection of primary and secondary legislation, including instruments which are no longer in force, and court practice. These data bases are usually updated once a month.

The ministries have ready access to the legislation that concerns them mostly through the commercial data bases and the registry of the Council of Ministers or the registries of other ministries, although the latter are not always reliable.

The drafters usually obtain a report on current secondary legislation in force from the Council of Ministers computerised registry. This report covers the instruments issued by the Council of Ministers. An additional report may be obtained from the ministry charged with implementing a specific instrument on the legislation it has issued. There is no official consolidation of the primary and/or secondary legislation currently in force.

\section{Publication of Legislation}

Bills are not published. Copies are automatically supplied to the members of Parliament who will debate them. Legislation is printed by the State Gazette editorial office which operates under an off-budget account. Funds in this account are accumulated from the price of the State Gazette and from fees for publication of items in the unofficial section.

Article 36, paragraph 3, of the Law on Normative Acts stipulates that errors must be corrected pursuant when a discrepancy is discovered between the certified text and the text actually adopted. Errors in the text sent for publication which are discovered before publication must be corrected pursuant to Article 40, paragraph 2, of the Law on Normative Acts. In both cases, the corrections must be made by the organ which certified the text. After publication errors must be corrected by the body that certified the text and be published in the same manner as the text itself (Article 42 of the Law on Normative Acts).

Legislation must be officially published. It may be retroactive subject to certain restrictions.

For the last three or four years, the Government Printer uses modern computerised publishing equipment. 


\section{Additional Notes}

The drafting mechanism as described above has both permanent and variable features. It is common for a new Government to either substantially amend the rules of the previous Government or to adopt new rules. The existing Rules on the Structure and Organisation of the Work of the Council of Ministers and its Administration were adopted by the previous government in July 1996 and they repealed the rules of the same government which had been adopted in February 1995. Nevertheless, the main points of the law-drafting procedure described above are fairly permanent. The substantive difference introduced by the present rules is the role of the Minister of Justice who, as stated above, is assigned the task of introducing all bills for deliberation by the Council of Ministers. This diverges from the long-established practice that bills be introduced by the minister or agency head actually responsible for the drafting. The idea behind this change is that introducing one more check and charging the Minister of Justice to submit bills will lead to better conformity assessment (with the Constitution and domestic legislation, with EU legislation and with treaties). Undoubtedly this is largely achieved. Nevertheless it is arguable whether this procedure really facilitates the law-drafting process. The Ministry of Justice is short of manpower, especially following the reductions made in the Legislative Council staff lawyers by the present caretaker government. Moreover, the Minister of Justice is required to submit even those drafts which he or his staff do not support to the Council of Ministers.

The situation with the Rules on the Organisation and Structure of the National Assembly is similar. It is common for a new National Assembly to adopt new rules. The present Rules on the Organisation and Structure of the National Assembly were adopted by the last Parliament. They introduced a new procedure and new timetables for processing draft legislation. In addition, the National Assembly's Legislative Council was set up with the present rules.

Three different bodies are named "Legislative Council":

i) The Legislative Council with the former State Council, referred to in the Law on Normative Acts and its Implementing Decree, no longer exists. The State Council was a body which existed under the previous Constitution of 1971.

ii) Decree 20 of the Council of Ministers established the Legislative Council with the Ministry of Justice in 1992.

iii) The Legislative Council of the National Assembly was set up in 1995 by the present Rules on the Organisation and Structure of the National Assembly.

Three types of instruments are called decrees:

i) The Law on Normative Acts and its Implementing Decree refer to "normative decrees". The Bulgarian term for these decrees is ukase" These were primary law-making instruments which, under the Constitution of 1971, the former State Council could adopt between sessions of the National Assembly. These were published and entered into force immediately and had the same legal force as a law adopted by the National Assembly. At its first session following the adoption of such a normative decree the National Assembly had to either approve or reject it. In practice the National Assembly under the 1971 Constitution, which met three or four times a year for several days only, approved en bloc upon commencement of its respective session the whole list of normative decrees which the State Council had adopted in the preceding period. 
Although the practice was discontinued in 1989, a number of such State Council Decrees continue in force: the Decree to Implement the Law on Normative Acts (the only one of its kind, a primary law-making instrument for implementing another primary law-making instrument), Decree 883 on Participation of the People's Republic of Bulgaria in Treaties.

ii) Decrees (ukase) signed by the President under the present Constitution. These are individual acts for ordering a law to be published or returning a law to Parliament; giving Bulgarian citizenship; appointing ambassadors, granting pardons, etc.

iii) Decrees adopted by the Council of Ministers (postanovlenie) are secondary law-making instruments which exist both under the previous and the present Constitutions. 


\section{LAW DRAFTING AND REGULATORY MANAGEMENT — REPUBLIC OF ESTONIA}

\section{Introduction}

There is no central body that deals with law drafting in the Republic of Estonia. Subsection 103 (1) of the Constitution, adopted 28 June 1992 on the referendum, published in the State Gazette, (Riigi Teataja ) 1992, 26, 349, gives the following the right to initiate laws:

- a member, faction, or Committee of the Riigikogu (Estonian Parliament);

- the Government of the Republic (hereinafter government);

- the President of the Republic, for amending the Constitution.

Generally, the entity that initiates the law drafts the bill. The government is the principle initiator, and initiated more than 60 per cent of laws in 1996. Bills are drafted by ministries when one or another of the issues belongs to its scope of government. There are units dealing with legal issues in all ministries that are responsible for drafting legal acts which regulate questions belonging to that particular area of government. Unfortunately, no unified law drafting organisation exists in all ministries; some ministries' legal acts are drafted by different outside specialists who are very often not lawyers.

Comparing the present organisation for law drafting with that of the Soviet era, the most significant change is that before the transition, Soviet republics in most cases had no need or possibility of drafting laws independently, as all legislation had to correspond to all-union legal acts passed by the central government (various grounds, regulations, etc.). The development of republican law was restricted. The second difference is that there are now real law drafters in Estonia whose main task is to draft laws.

In some ministries (the Ministry of Justice), the law-drafting process takes place mostly in the ministry itself and laws are drafted by ministry officials or the head of the working group is a ministry official). In these ministries, one if not the most important task of officials (lawyers) is to draft laws. As mentioned above, there is no supervisory system and it must be made clear that insofar as concerns organisational questions of law drafting, Estonia is still in the transition process.

Although no single central body deals with law drafting questions, the Ministry of Justice (Subsection 59(1) of the Government of the Republic Act) is responsible for co-ordinating law drafting and has therefore begun to lend order to legally regulating law drafting questions. At the moment, it has drafted a Bill of Legislative Drafting Act (also approved by the government) to regulate as yet unregulated law drafting questions and to unify its organisation. There is also an administrative reform in Estonia, designed to decrease the state government apparatus which can also modify the law drafting organisation. For this reason, this Article gives an overview of law drafting organisation and introduces the most important changes in the nearest future. 
There are currently many different legal acts in Estonia more or less regulating law drafting questions. The most important are the following:

1. The Constitution of the Republic [Clause 87 (6), Subsection 94(2), Chapter VII, IX and XII, §152].

2. Vienna Convention on the Law of Treaties 1969 (RT II 1993, 13, 16).

3. Riigikogu Procedure Act (RT 1994, 90, 1517; 1995, 20, 295; 74, 1285; 83, 1444) regulates law drafting and adopting process in Parliament.

4. Riigikogu Administration Act (RT 1992, 46, 582; 1993, 6, 97; I 1994, 37, 569; 66, 1145; 80, 1379; 1995, 14, 171) gives procedural norms.

5. Referendum Act (RT I 1994, 41, 659).

6. Government of the Republic Act (RT I 1995, 94, 1628; 1996, 49, 953) regulates the organisation and areas of competence of governmental institutions but does not include any procedural norms.

7. Foreign Relations Act (RT I 1993, 72/73, 1020; 49, 953) regulates questions of conclusion and ratification of international treaties.

8. Local Government Administration Act (RT I 1993, 37, 558; 1994, 12, 200; 19, 340; 72, 1263; 84, $1475 ; 1995,16,228 ; 17,237 ; 23,334 ; 26-28,355 ; 59,1006)$ also includes norms regulating questions of law drafting competence and local organisation.

9. Riigi Teataja Act (State Gazette Act) (RT I 1993, 20, 352; 1995, 19, 288; 1996, 49, 953) covers publishing of legal acts.

10.State Budget Act (RT I 1993, 42, 614; 1994, 30, 464; 69, 1194; 1996, 22, 436; 49, 953) gives special rules on drafting bills of state budgets.

11.Local Budget Act (RT I 1993, 42, 615; 1995, 17, 234) gives special rules on drafting bills of local budgets.

12. Order of the Government of the Republic (adopted by Government of the Republic on 11 June 1996, regulation No. 160) defines the law drafting process in the Government. Many questions regulated here will be regulated by Legislative Drafting Act in the future.

13.Government Regulation No. 199 of 1 July 1993 "On the organisation of concordance and legal expertise of legal acts proposed to the government" (RT I 1993, 68, 980; 1996, 27, 568; 43, 844). The area regulated by this act is currently mostly covered by the Order of the Government and will be covered by Legislative Drafting Act in future. Besides these acts, the board of Riigikogu adopted "Guidelines for drafting legal acts" on 22 November 1993. This area will also be covered by Legislative Drafting Act in the future. In addition, the President of the Republic Act has been prepared.

In the broader sense, law drafting questions are also regulated by the Administrative Court Procedure Act (RT I 1993, 50, 694), Legal Chancellor Activities Act (RT I 1993, 25, 436), Constitutionality Supervision Court Procedure Act (RT I 1993, 25, 435), etc.

Despite many legal acts, no single legal act regulates all questions of law drafting (organisation of law drafting and guidelines for drafting legal acts). The Bill of Legislative Drafting Act is the first step in this direction and it will be the basis for several regulations for the government and the Minister of Justice. Circulars and other documents with no legal power are not common in Estonia; as there is no long-time 
law drafting tradition, new rules must be established by legal acts which would be binding on law-drafters and institutions dealing with law drafting.

As already mentioned above, many non-lawyer specialists from different areas deal with law drafting. It is difficult to ensure generalised and exact knowledge of all these legal acts. It is impossible to educate all of them, because they change constantly. The Legislative Drafting Act regulates general questions of law drafting and its implementation acts shall be good guidelines to all law drafters.

A mechanism is in place to verify whether the demands set to drafts of legal acts are observed but it is not the same for all initiators of laws and all kinds of legal acts.

The Riigikogu Procedure Act $\$ 53$ prescribes the rules for handing over drafts of laws, decisions, statements, declarations to the board of Riigikogu. Subsection 4 of this Article stipulates that the board of Riigikogu will return the draft to the initiator if the formal demands and conditions for handing it over prescribed in subsections 1-3 have not been observed; the draft will be returned if it does not respect the guidelines for drafting legal acts set by the board of Riigikogu.. The Legislative Drafting Act will alter this Article of Riigikogu Procedure Act (§109) and all drafts of laws have to respect it.

The conformity to the laws, principles of Estonian law system and quality of the bills initiated by the government are checked by the concordance procedure (mostly by the Ministry of Justice). Article 41 of the Order of the Government stipulates that all drafts of legal acts proposed to a session of the government are checked by the State Chancery which, if necessary, will align the drafts with the technical and linguistic requirements before the session of the government. Article 42 of the Order of the Government stipulates that if there are minor technical, linguistic or other legal mistakes in the proposed draft, it will be proposed to the session of the government with an amended draft added by the State Chancery.

Although the Order of the Government stipulates that the State Chancery will supervise all materials proposed to a session of government, it most verifies drafts of regulations of government. $\$ 77$ of the Government of the Republic Act also prescribes that the State Chancery verify the conformity of drafts of legal acts of the government with the Constitution and laws.

Therefore, the role of supervisor of quality of drafts of legal acts is divided between the State Chancery and the Ministry of Justice; the former verifies mostly the quality of drafts of legal acts of the Government and the latter, which implements the co-ordination of law drafting, verifies the quality of drafts of legal acts of Riigikogu proposed by the government. This competence of the Ministry of Justice is given indirectly by the Order of the Government; Article 25 prescribes that all bills of laws must receive the approval of the Ministry of Justice. The Bill of Legislative Drafting Act more clearly specifies its competence in the concordance procedure.

This system is rather uncomfortable because it mixes two different theoretical models in the construction of an administration. In the future, there should be only a single supervisory institution controlling drafts of legal acts of Riigikogu and the government. It should be decided whether to gives this function to the State Chancery and eliminate the function of the Ministry of Justice of co-ordinating law drafting or to attribute the supervisory function totally to the Ministry of Justice. 


\section{Regulatory Instruments}

In Estonia, the principle of passing acts without any legal power (such as circulars) is not common and they are given very rarely. Legal acts are divided into legislative legal acts (including legal norms) and individual acts (single acts). The principle legislative legal acts are regulated by the Bill of Legislative Drafting Act, which will slightly change the concept of legal acts. The main legislative legal acts include the following:

1. Law: primary legislation, legislative act passed by the Riigikogu. In Estonia, laws should have as wide a regulating area as possible and all questions should be regulated by laws as thoroughly as possible.

2. Decree of the President of the Republic: $\$ 109$ of the Constitution stipulates that if the Riigikogu is cannot convene, the President of the Republic may, in matters of urgent state need, issue decrees with force of law and which shall bear the countersignatures of the Chairman of the Riigikogu and the Prime Minister. According to $\S 110$ of the Constitution, "The Constitution, the Acts set out in $\S 104$ of the Constitution that laws which establish state taxes, and the state budget shall not be enacted, amended or repealed by Presidential decree."

3. Regulation of the Government: secondary legislation. The principle is that the goal of passing government or ministerial regulations can be only implementing the law and only intra legem regulations are allowed.

4. Regulation of the Minister: secondary legislation has the same legal power as government regulation.

The Bill of Legislative Drafting Act thoroughly stipulates the competence of the government as the organ of executive power and the minister to pass regulations. §7 specifies the definition and concept of authorisation rule. The present concept of authorisation rule (or more exactly, the lack of any unified concept) has created many practical problems until now. However, the authorisation rule is one of the most important legal institutes regarding law drafting questions.

The bill establishes the exact system of authorisation and establishes the foundation for the legitimacy of by-laws. In current practice, the Riigikogu decides whether or not to give authority to the government to regulate some questions by regulation or to put this obligation to a minister. The Bill of Legislative Drafting Act describes the system as follows:

1. Riigikogu may generally authorise by law only the Government of the Republic or a rural municipality council or city council to enact regulations [Subsection 7(1)], and can grant them the right to delegate the authority to minister or local government [Subsection 7(6)].

In addition, Riigikogu can directly authorise minister(s) but only for internal regulations, i.e. when the regulation regulates ministerial administration or operations or an area of government of ministry (ministries).

2. Government of the Republic may delegate the authority to enact a regulation to an appropriate minister, if such a possibility for delegating authorisation is given by the Riigikogu and is set in the authorisation rule [Subsection 7(6) and Subsection 70(1)]. The principle, that in general it is not possible to authorise the minister to pass regulations directly, is in accordance with the principle of the hierarchy of legal acts and will exclude the possibility, that many questions are solved only by legislators and ministers, but not by the government, the main implementor of laws and possessing executive power ( $\S 86$ 
of the Constitution). If ministers are authorised directly to pass an external regulation, it is done over the government without relevant decision of the government and seems to be in violation of the Constitution.

In most cases, laws have to be implemented by the government and if the law stipulates, the government can delegate the authority to the minister(s), the government has the right to decide so and authorise the minister of the appropriate area.

Each chapter of the Bill of Legislative Drafting Act establishes that the regulation must correspond to the extent and conditions of an authorisation rule [Subsection 69(1), Subsection 89(1), Subsection 89(2)].

One legal instrument which can be emphasised is the decision of the government written down in the session protocol. This decision is binding for ministers concerned. Article 24 of Order of the Government says that the draft of the governmental decision will be proposed when it is not necessary to pass any legal acts of government to decide the question. For example, with such a decision the government can oblige any ministry to draft a law and propose it to the government.

We can also note the resolution of the Prime Minister which is binding on ministers. The right to pass resolutions comes from Article 8 of the Order of the Government: "The Prime Minister can assign ministers the tasks to propose materials to the government not included in the working-schedule". Resolutions of the Prime Minister are given mostly to guarantee the implementation of decisions of the government and Riigikogu, if no such obligation occurs in the decision of the government written down in the session protocol.

\section{Drafting Personnel}

As was already said, no ministerial units deal exclusively with law drafting. Ministries are only obliged to draft legal acts concerning their area of government set by the Government of the Republic Act and they must decide on the organisation of law drafting. This is apparent in the very different quality of legal acts in different ministries.

Many ministries use external law drafting specialists who are not lawyers and have no experience drafting law. But there are also other examples: officials of the Ministry of Justice also have to deal with law drafting. Moreover, most of the laws in the Ministry of Justice are drafted by officials. Lawyers from outside the ministry also generally work in working groups (judges, professors of law from Tartu University etc.). The drafting process is under the strict control of ministry leadership.

As said above, in the Soviet era there was practically no possibility of dealing actively with law drafting; few specialists therefore have long law drafting experience. Recently, many just graduated students and students in their last year of law have been drawn in law drafting to give them some practical education. This is also done because there is still no course on law drafting in Tartu University and periodical theoretical education of law-drafters is not reasonable because they change so often. The best solution is to acquire proper education by practising law drafting.

Drawing non-officials into law drafting is decided by each ministry itself and no precise statistics are available on this. As all ministerial budgets include sums for law drafting (not always indicated as a line item in the budget but included among "administrative expenses"; with the exception of the Ministry of Justice and Ministry of Social Affairs whose budgets show sums for law drafting), each ministry has to decide how to use this money. 
Every ministry decides how law-drafters participate in the process of law drafting after handing over the draft to the ministry and the answer differs considerably in different ministries. The law-drafter or head of the working group can participate in sessions of the government and of Riigikogu where the bill is discussed, but only with the permission of the minister who has proposed it. Ministers use this possibility quite a lot, because the questions that arise can often be resolved by knowing what the law-drafter intended when putting one or another rule into the draft and formulating it in a particular way.

In law drafting done by Riigikogu members, it is conceivable to use ministry officials for assistance in drafting laws initiated by the Parliament; in most cases, however, the work load makes this quite difficult. Frequently, one official takes part in drafting several laws while fulfilling his/her main duties.

The law-drafters personnel problem is very difficult in Estonia. An attempt has been made to improve the quality of law drafting by becoming more demanding and increasing law supervisory effectiveness to influence ministries to better organise law drafting in questions belonging to their area. That is one of main goals of the Bill of Legislative Drafting Act.

Laws initiated by the Parliament are often prepared by its members. Parliamentary officials or outside specialists are occasionally used in preparing bills. The qualification of law-drafters in the Parliament is also unequal which is another reason for needing the Legislative Drafting Act which sets equal conditions and demands on legislative drafting in both government and Parliament, i.e. the qualification of law-drafters preparing bills in the Parliament must also be improved.

\section{Drafting Procedures}

\subsection{Primary Legislation}

\section{Programming and Timetabling}

In planning law drafting, ministries are largely independent in their area. Section 2 of the regulation of Government No. 199 of 1 July 1993 "On the organisation of concordance and legal expertise of legal acts proposed to the Government" states that ministries have to submit the policy proposal of a bill to the Ministry of Justice for concordance and must indicate: its structure or the concept, name of the drafter or head of the working-group, date for completing work on the bill and salary for drafter(s). During the last years, at the end of calendar-year, the Ministry of Justice has asked all ministries to submit concordance policy proposals of all bills to be drafted and/or proposed by it to the government during next year.

At the same time, it must be mentioned that policy proposals are not submitted to the Ministry of Justice for concordance in several cases usually because there are no negative legal consequences for ignoring this requirement. However, a policy proposal is quite often sent for concordance while the bill itself is already being drafted and the budget for law drafting is already used. In the Bill of Legislative Drafting Act, policy proposal guidelines are regulated more thoroughly: comprehensive legislative drafting plan of the Government of the Republic (covers bills, or acts of primary legislation); binds the concordance of policy proposals with the use of budgetary funds (co-operation in the form of consultations between the Ministry of Justice and the Ministry of Finance); and returning the bill without review when it is sent for concordance if the procedure of concordance of policy proposals has been ignored.

On the basis of Ministry of Justice statutes, the ministry can make proposals to other ministries to draft bills according to their area of government. But this kind of proposal has no legally binding force, and the 
ministry which does not agree with the proposal of the Ministry of Justice can refer a question for discussion and decision to the session of the government. In this case, a ministry can be assigned the obligation for preparing a law by a decision of government. If a ministry wants to prepare a bill outside its normal purview, it must consult the relevant ministry with the policy proposal before consulting with the Ministry of Justice.

Section 2 in the Order of the Government prescribes: "In order to plan the work of the government, the State Chancery, on the basis of proposals of ministers, frames a separate working schedule for every quarter of a year. Government working schedules can also be framed for every single month of a year." In addition to drafts of primary legislation, the government working schedule also contains all other questions to be discussed at government sessions. For framing the working schedule, for all bills and other important issues belonging to that ministry's competence, ministers must give the State Chancery the issues for discussion and decision at the session of the government at least 15 working-days before the beginning of the next quarter or month. When giving relevant information to the State Chancery, the date of introducing the bill or other document must be indicated. A concordance letter from the Ministry of Justice about the positive consultation of relevant policy proposal must be added to the application for putting a bill into the working schedule. This working schedule is enacted by order of the government (individual act) and published in the official publication, Riigi Teataja.

The Bill of Legislative Drafting Act creates a new institute in the Estonian law-making process: comprehensive legislative drafting plan of the Government [covering bills, i.e. acts of primary legislation; $\S \S 42-50$ defined in Subsection 42(1): "A comprehensive legislative drafting plan is a plan for bills to be prepared in the ministries and the State Chancery in the following calendar year, which shall be approved by the Government of the Republic every calendar year."].

The creation of a new institute: comprehensive legislative drafting plan of the Government of the Republic: in the Bill of Law Drafting Act derives from the need to better co-ordinate and systematise law drafting. Currently, bills are very often drafted on the basis of occasional needs or of needs arising from a single fact while the principles of the entire legal system as such are not followed. Questions like whether a law fits the Estonian legal system or whether it is the right time to draft a law or whether some other legal act should be drafted and enacted before it are not usually asked or answered before starting to draft.

The differences between comprehensive legislative drafting plan of the government and its working-schedule are as follows:

1. The biggest problem is how to ensure a systematic approach and the right timing for preparing bills. Like the government working schedule, its comprehensive legislative drafting plan presupposes that ministries make policy proposals. Unlike the working schedule, the comprehensive legislative drafting plan is not simply a mechanically prepared chronological list of all government tasks but is prepared in the Ministry of Justice on the basis of policy proposals received from ministries and from the State Chancery [Subsection 44(4) of the Bill]. While framing this plan, the Ministry of Justice at first hand takes care of the appropriate timing for introducing bills to the government and Riigikogu. If it does not accept a policy proposal about a certain law, the preparing ministry can append its opinion to the Ministry of Justice to a draft of the comprehensive legislative drafting plan when proposed to the government [Subsection 44(5) of the Bill]. By framing a draft of comprehensive legislative drafting plan, the Ministry of Justice meets the obligation of Subsection 59(1) of Government of the Republic Act assigning the Ministry of Justice with responsibility for co-ordinating the law-making process since it has the best and most synthetic overview of the legal system. 
Ensuring the creation of a logical legal system is clearly connected with the period set for planning law drafting; there must be enough time to fulfil tasks in framing the comprehensive legislative drafting plan.

2. Unlike the working schedule of the government, the comprehensive legislative drafting plan covers a period of one calendar-year. As such, it is the sole, complete document to show government legal policy for the upcoming year.

A calendar year is the shortest period for planning what can be a long-term law-making process; in addition, the timing for introducing bills to the government and Riigikogu can be set right (put the bills into the right queue). At the same time, it is not reasonable to lengthen this period because it is difficult to foresee changes for longer period. A "comprehensive legislative drafting plan" document should be available in every governmental institution.

At the same time, it is also possible that comprehensive legislative drafting plan contains drafts to be introduced to the government two or more years hence. This possibility is prescribed in Subsection 42(3) in the Bill of Legislative Drafting Act. It would be ideal if all ministries were informed about all laws which should be drafted in their area of government and if these were listed in a comprehensive legislative drafting plan whether or not they are to be proposed in a year or more. Such a system would better co-ordinate drafting as an over-state planned and organised activity, covering all ministries with their area of government. The Bill of Legislative Drafting Act makes it possible to realise this system and the future will tell whether ministries can or want to follow it. They might not observe it because they are not informed and therefore unable to foresee all the drafting needs for their area of governments.

3. The comprehensive legislative drafting plan, a document indicating the government's legal policy for the following year, is enforced and amended in the same way as the working schedule, by order of Government Subsection 42(4) of the Bill and is published in an official publication according to the Clause 2(1)6) of Riigi Teataja Act. This comprehensive legislative drafting plan, an appendix to the calendar year working schedule of the government, is therefore visible to all.

4. The working schedule of the government is quite flexible and can be amended (Order of the Government Articles 6 and 7). This same flexibility is left in the bill for comprehensive legislative drafting plan $(\S \S 45,46,47)$, because the period is relatively long and the need for some kind of amendments during the year may definitely rise. Some new moments must be mentioned here.

So-called "bills justifying fast introduction" like laws for abrogating some valid law need to have the possibility for faster proceedings in governmental institutions. These bills do not therefore follow the scheme prescribed in $\S 45$, but are proposed by the relevant ministry in this case for decision to the government which uses its right prescribed in $\$ 49$ to assign the preparation of the bill to the ministry. It is important to stress that "bills justifying fast introducing" will not be listed in the comprehensive legislative drafting plan [Subsection 49(2) of the bill]. The concordance procedure must nonetheless be followed.

Subsection 48(1) stipulates an important rule giving the preparing ministry the option of extending the date for up to two months when proposing a bill to the government by notifying it. It is currently quite common that a bill cannot be proposed to government and discussed on the date laid down in the working-schedule because the concordance procedure is not finished yet (letters from ministries about concordance have not reached the proposing ministry). Such situations do not require extending the date set forth in comprehensive legislative drafting plan of the government; informing the government is sufficient. Two months is short if compared to the usual time for drafting a law, but simplified proceedings would help avoid bureaucracy and technical problems (separate application for extending the 
date, discussing questions again at the session of the government, publishing the order of the government in Riigi Teataja.

5. Unlike the working-schedule of the government, framing the comprehensive legislative drafting plan for the next year is connected with planning the state budget for the next year. Therefore, the principle given in Subsection 43(1) is worth emphasising: legislative drafting expenses of ministries and the State Chancery are prescribed in the state budget separately as expenses of the ministries and the State Chancery. For instance, in the law of state budget for 1996, separate lines for legislative drafting expenses were shown only for the Ministry of Justice and the Ministry of Social Affairs. This kind of situation allows ministries to be passive about legislative drafting, as they can always claim that they lack the funds for paying officials for drafting-work or for ordering drafting-work from outside experts. Unfortunately, this situation also allows ministries to use legislative drafting expenses for other purposes (according to practice, funds for law drafting are covered in the budget for "administrative expenses"). Requiring legislative drafting expenses to be shown a on separate line in the law of state budget for the next calendar year favours drafting because if the relevant funds are not used for the relevant purpose by the end of the year, they automatically turn back to the central state treasury. These funds can therefore be used only for law drafting. While framing the project of state budget for next year, ministries and the State Chancery have to know clearly the purposes for which the money will be used: list of legal acts, what must be drafted in their area during next year must be clear and well justified, as the wish has to be made to Ministry of Finance. To ensure that the funds drawn from the state budget by ministries are not too high, Subsection 43(2) of the Bill prescribes a principle, according to which the Ministry of Finance may hear the opinion of the Ministry of Justice before including legislative drafting expenses, prescribed in the draft budgets of the ministries and the State Chancery, in the draft state budget. This kind of system is also effective because the Ministry of Justice also has competence to frame the comprehensive legislative drafting plan of the government in October-November of the same year (framing a budget at this level usually occurs in the spring).

Therefore, the plan for drafting legislation for the next calendar year has to be largely ready at the beginning of the second quarter of the year when framing the state budget starts.

Framing the comprehensive legislative drafting plan of the government must continue to occur during the fourth quarter of the year during which guidelines from the budget project (amounts of funds) can already be taken into consideration (project of the state budget must be proposed to Riigikogu at latest three months before the beginning of the financial year according to Subsection 16(1) of State Budget Act). This ensures that the comprehensive legislative drafting plan will not include bills that must be proposed to the government during the next year and for which there are no funds in the budget of the ministry or State Chancery.

In conclusion, if the Legislative Drafting Act is adopted, the working schedule of the government will not have to be adopted for every separate quarter containing bills of law. Therefore relevant norms in the Order of the Government must be amended so that bills of laws are not included in the working-schedule.

After a bill is proposed to the government, it decides whether to send it to Riigikogu. At the same time, the minister who represents the government (usually the minister responsible for the ministry where the bill is drafted) in the discussion of Riigikogu must be nominated by the government. Decisions made at the session of the government must be included in the written protocol. When proposing the bill to the Parliament, a letter of explanation must be added.

Bills initiated by a member, faction or Committee of Riigikogu are sent by the leading Committee for the bill to the government for an opinion. This obligation for the leading Committee means that all bills go 
through government proceedings. The only problem that could be mentioned here concerns very short deadlines (prescribed in Riigikogu Procedure Act) for analysing bills in the government which usually lead to compiling insufficient and statements that are not thorough on a bill by the government.

\section{Law Drafting}

Policy making and law drafting can be made by different or the same ministerial units and in different ways in different ministries. Most important is that ministry leadership adopts a working plan for the ministry every year that includes all drafts be drafted during that year.

Several important laws have not been adopted yet in Estonia and some areas have not been regulated at all. Laws are therefore sometimes drafted and adopted quickly to fill in the gap which is why stable policy drafting and instructions to law-drafters are only quite occasional. In several cases, law-drafters are not given specific instruction to be observed when drafting law, but only the title and very general contents of the law. This occasionally produces surprising results for the ministry ordering the bill for it sees the bill only after the draft is already prepared. At the moment, more attention is paid to policy making while drawing up the contract and during law drafting, i.e. law drafters are given instructions on how to resolve particular problems.

If the law is drafted by ministry officials, it is easier to get information on possible political solutions, because it is easier to ask the ministry leadership. Outside specialists usually have no connection or only a weak connection with the leadership. Ministerial leadership oversees that political solutions and instructions are observed and these can change during the law drafting process.

There are no specific stages to the law drafting process (before handing over the draft to the leadership of the ministry) in Estonia. Nor are there detailed requirements for letters of explanation although these should be a precondition for determining the stages of law drafting. There are obligatory items in the letter of explanation so the law drafter must go through all these stages. Such requirements will be set by the Legislative Drafting Act $(\S \S 28-41)$ and by regulation of the government on demands to letter of explanation $(\S 108)$.

After drafting the law, handing over the draft to the ministry and receiving approval, the draft is sent to other institutions for concordance. According to the Article 25 of Order of the Government before being proposed to the government, the draft legal act must be submitted to all ministries whose obligations or responsibilities (area of government) are affected by it, and nation-wide to unions of local authorities when their interests are affected. The drafts regulating questions for which the State Chancery is responsible must be submitted to it.

All drafts of laws have to be submitted for concordance to the Ministry of Justice after concordance with other ministries. The draft is sent to Ministry of Justice after revision. Opinions and proposals of other ministries and other institutions have to be taken into account. Results of the concordance procedure (including explanations of why one or another proposal has not been considered) have to be shown in letter of explanation and a comparative table of European Community legislation and the Estonian draft must be added to the draft. If the Ministry of Justice does not approve the draft, it has to be revised, taking into account the proposals of the Ministry of Justice and resubmitted for concordance.

The ministry that drafted the law can send the draft to other related institutions (e.g. non-profit organisations) for their opinion; the ministry itself decides to undertake this. Law drafters can use the assistance of different specialists. These are not obligatory consultations and they are slightly complicated because of lack of time, but are quite widely used to improve the quality of the bill. Such opinions are not 
binding and the ministry does not have to explain why it did not consider the proposals made by such institutions or experts.

The only regulated expertise is legal expertise. During the concordance procedure, the Ministry of Justice can send every draft initiated by the government to independent legal expertise for opinions on difficult legal questions, using practising lawyers, law professors, foreign experts, etc. During this time, the procedure of concordance is stopped. Legal expertise has to be made in one month after getting the draft. The Bill of Legislative Drafting Act makes this period two months. Currently, legal expertise is usually not made. After adopting the Legislative Drafting Act, which regulates the stages of the concordance procedure and legal expertise ( $\S 51-58)$, the scope of persons being accepted as independent legal experts will be determined by the government or Minister of Justice ( $\$ 108)$.

Duties of law-drafter in further proceedings are not concretely regulated and it is up to ministers to decide. For instance, in the Ministry of Justice as said in the contract for law drafting (the form of this contract is adopted by the Chancellor of the Ministry of Justice) the law drafter has to revise the draft after the concordance procedure take part in further proceedings in the government and in Riigikogu. The minister decides whether or not the law drafter takes part in sessions of the government and/or Riigikogu.

According to the Article 48 of Order of the Government, the materials proposed for the session of the government are not published before a decision has been made by the Government. Article 88 of the same act says that information about the session of the government can be given to the press only by members of the government, State Secretary or persons having their permission and by officials dealing with government public relations.

No legal act prescribes by whom the draft decrees of the President of the Republic will be prepared. Normally they are prepared by the Chancery of the President. However, §§65-66 of the Bill of Legislative Drafting Act gives specific rules on drafting presidential decrees. Considering that the Government is the primary initiator of laws and has an appropriate legislative drafting bodies, Subsection 65(1) stipulates that the President of the Republic may propose to the government to prepare a draft presidential decree. Moreover, as the government is supposed to operate properly when Riigikogu is unable to convene, §66 stipulates that the government can propose to the President to enact a decree (it can be compared with the right of the government to initiate laws).

\section{Parliamentary Consideration}

The Bill with its letter of explanation will be introduced to the Chairman of the session of Riigikogu [Subsection 53(1) of Riigikogu Procedure Act]. Drafts ratifying or concluding international treaties will be introduced with copies of the treaty in Estonian and the foreign language. There is no regulation on how members of Riigikogu study drafts before they are introduced.

Letters of explanation are given to all members of Riigikogu with the draft, but it is not published. Letter of explanations are archived and available for later consultation if necessary for interpreting the law. The demands for letter of explanation will be set in Legislative Drafting Act in the future.

The Board of Riigikogu nominates the leading Committee from among its standing Committees which then oversees the procedure and proposes to the Board to begin the proceeding or justifies the decision not to proceed. This proposal must be done in three weeks if the initiator of law is the government, and in four if the initiator of law is Riigikogu. 
Laws can also be initiated by a member, a faction or a Committee of Riigikogu. As members of Riigikogu represent electors, laws can therefore be initiated by other persons or lobbies. If the law is initiated by Riigikogu, the leading committee will send the bill to the government for an opinion, to be given in three weeks. This opinion is not binding on the committee or Parliament, but has an importance for coalition parties. A government representative can report the opinion in a session of Riigikogu when the bill is read.

The proceeding in Riigikogu is mostly regulated in the Riigikogu Procedure Act (Chapter 14). Subsection 136(1) stipulates at least two readings for the bill procedure.

The first reading. Riigikogu will listen to the report of initiator of law or its representative, and that of the representative of the leading committee; members of Riigikogu can ask questions. At the time of the first reading, it can be decided not to proceed the bill in Riigikogu, if the leading Committee so proposes. After the first reading, the leading Committee informs Riigikogu about the date until which it is possible to propose amendments.

Between two readings, the leading Committee will investigate all amendment proposals. Members of the government can take part in and speak at meetings of the leading Committee. Representatives of state organs or local authorities can be asked to take part in meetings.

According to the amendments of Riigikogu Procedure Act, proposed in the Bill of Legislative Drafting Act, the amendment proposals must be sent to ministry or ministries drafting the bill.

The second reading takes place by the proposal of the leading Committee not later than three months after the first reading, although the term can also be longer. All amendment proposals with opinions of the leading Committee and the initiator of law, and a new formulation of the bill are given to all members of Riigikogu at 6 p.m. at the latest on the last working day before the session. Riigikogu will listen to the report of initiator of law or its representative, and to that of the representative of the leading Committee who will explain the work done between the readings and comment on the amendment proposals.

If, after the voting of amendment proposals, there is no proposal to interrupt the second reading of the bill or to send it to the third reading, the bill will be voted as a whole. Articles of the bill will be voted upon if the different laws being amended need different majority of votes (e.g. constitutional acts).

The bill will be sent to the third reading if the initiator of law or the leading Committee or Riigikogu so decides.

The third reading. Before the third reading, amendment proposals can be made only by a faction of Riigikogu or by one of its standing Committees. The third reading takes place not later than in one month after the second reading. All amendment proposals with the opinions of the leading Committee and the initiator of law and the new formulation are given to all members of Riigikogu no later than 6 p.m. on the last working day before the session.

In practice, Riigikogu discusses bills of great importance very carefully and thoroughly. The government should have more power to take part in bill procedures that it initiates in order to preserve the contents or underlying thinking.

The decree of the President of the Republic is another kind of primary legislation. When the Riigikogu convenes, the President of the Republic shall present decrees to it for prompt passage of a law for confirmation or repeal. The leading Committee will not be nominated for this. No amendment proposals can be made. The decree will be proceeded and voted on in one session. 
Laws passed by Riigikogu will be sent to the President of the Republic for proclamation ( $\$ 107$, Constitution). He may refuse to proclaim the law passed by Riigikogu and within fourteen days after its receipt, can return it with to Riigikogu, with justification, for a new debate and decision. If Riigikogu passes the unamended law returned to it by the President of the Republic again, he shall proclaim it or propose to the Supreme Court to declare it unconstitutional. If the Supreme Court declares the law constitutional, the President of the Republic shall proclaim the law.

\section{Particular Legislation}

Taxation legislation and legislation concerned with approximating Estonian law to EU law observe the same procedure. The only difference in budgetary legislation procedures in Riigikogu is that budget laws and additional budget laws as well as laws amending budget law take three readings or discussion (two readings are not allowed).

The bill on amending the law must prescribe which article, section or subsection of which law is to be amended and the new formulation. The Bill of Law Drafting Law (\$\$23-26) prescribe this quite thoroughly.

Currently, implementation norms of each bill include norms for amending laws. According to the Bill of Legislative Drafting Act [Subsection 23(1)] amendments of other laws must be proposed in separate bills for each act which makes it better and easier to understand the changing legislation, and especially to ascertain the valid formulation of the law while using electronic legislation databases.

If one law is significantly amended repeatedly, its valid text will be published in Riigi Teataja [See also Section 23(4) of the Bill of Legislative Drafting Act].

A single law can undergo unlimited changes in one year, as has often been the case because some areas are not legally regulated yet and when regulating them, other laws have to be changed. For example, the State Duty Act has been changed a lot. At the same time, some areas are regulated very quickly and "somehow", and a general overview of these laws should now take place. Other laws will therefore need to be amended in order for all laws to conform. Unfortunately, time remains the greatest problem and many laws are drafted very quickly which leads to poor quality.

\section{Formalities}

$\S 108$ of the Constitution stipulates that "A law shall enter into force on the tenth day after its publication in the Riigi Teataja, unless the law itself provides otherwise". The same rule is prescribed in Subsection 8(1) of Riigi Teataja Act.

Neither the Government nor other state institutions can be delegated to decide when a law takes effect. The Bill of Legislative Drafting Act (\$22) stipulates only the principles of determining the date at which a law takes effect. The most important of these is that the time needed to draft regulations of the government and other by laws must be taken into account. This principle is not given anywhere at the moment which has caused considerable problems. In some cases, some regulations of the government or ministers have not been adopted at all. Has a law entered into force, then, if there is no legal act for its implementation? The general point of view is that is has not.

The other possibility for not entering into force is that President of the Republic refuses to proclaim the law because there is some suspicion that it is unconstitutional. On the occasion when this happens, the procedure of the law continues in the order prescribed in Subsection 107(2) of the Constitution. 
No other possibilities exist for a law not entering into force; once passed, a law does not expire automatically unless the law itself so stipulates.

\subsection{Secondary Legislation}

\section{Conferring the Authority to Make Secondary Legislation}

Deciding which issues should be regulated by laws and which by secondary legislation (legal acts of local authorities excluded) are not determined in Estonia. In preparing each draft of law, it is decided whether and which questions have to be regulated by regulations of the Government or ministers. General principles (written down nowhere) of our legal system have to be to taken into account:

1. Most questions have to be regulated by laws. All important and generally obligatory legal rules have to be in laws.

Article 87 of the constitution stipulates "The Government of the Republic shall issue regulations and orders on the basis of and for the implementation of law". This rule determines the place of government acts in the hierarchy of legal acts. Article 94 says the same on minister's acts. Therefore, parts of the Estonian legal system can be only intra legem regulations. Regulations can only assist.

Regulations cannot determine the fields of law which have not first been regulated by law. In Estonia it is therefore not possible to issue praeter legem or contra legem regulations.

2. Laws which only delegate to the government are not acceptable.

3. Every law should regulate as wide an area as possible, i.e. all similar questions concerning one branch of law should be put together into one act (e.g. Commercial Code).

Regulations should regulate mostly different lists, procedures (orders) and instructions. So the goal is to strictly limit the areas regulated by secondary legislation. Observance of these principles is controlled by the Ministry of Justice and State Chancery as well as by the Parliament when adopting law.

After adoption, supervision on using power given by authorisation rules by different ministries is controlled mostly by the Government. Subsection 94(2) of the Government of the Republic Act stipulates that the Government shall repeal regulations and directives of a minister, directives of the State Secretary and orders of a county governor which do not conform with the Constitution, other laws, or regulations and orders of the Government of the Republic.

There is a real problem in harmonising Estonian legal acts with EU legislation. Many questions regulated in EU legal acts should be regulated by government regulations to guarantee a better possibility for changing them. But this would mean giving the government the right to issue praeter legem regulations which is not acceptable. This problem must be resolved; one solution is to have a ministry prepare the draft law that regulates as much as possible the entire field regulated in EU legal acts (giving basic rules) and determines the area of questions to be regulated by the government. The Government needs more power to issue intra legem regulations (in questions regulated in EU legal acts), but there must be some guarantee that legal acts of the government would not regulate questions unregulated by law.

Nevertheless, the non-concordance of bills on behalf of the Ministry of Justice is often due to the number of authorisation rules. 
The right to draft and pass regulation of the government or minister must come from the authorisation rule in general, where the regulatory area is specified. No additional conditions to draft regulations are set by law.

If some area belongs to an area of government shared by more than one ministry or belongs to no area of government or ministry, and the law does not specify which ministry will be authorised to draft the regulation, the Government will determine ministerial responsibility.

No one directly determines the terms for passing regulations. The State Chancery keeps the register of authorisation rules, which are not implemented, but this register is unofficial. Laws do not actually enter into force unless implementation acts are passed and this has been one of the major problems for a long time. In the Bill of Legislative Drafting Act this problem is potentially solved by unifying the norms governing entry into force of laws and regulations of the Government and ministers ( $\$ 22$ and 81).

\section{Making Secondary Legislation}

Government regulations are drafted by the competent ministry, ministry regulations by ministry leaded by a minister who gives the regulation. The usual practice is to have regulations drafted by the same persons who draft bills of law which determine the basis for the regulation. This kind of practice is quite normal as these persons are probably most experienced in the relevant field of activity and legislation. Drafters should also already know while drafting the bill of law and prescribing the authorisation rule what the regulation area and objectives will be.

There are currently virtually no prescriptions or guidelines for drafting (framing principles into legal norms) a legal act. In the future, $\$ 108$ of the Bill of Legislative Drafting Act will determine these guidelines by giving the basis for the prescription of framing principles into legal norms to be adopted by regulation of the Government or by the Minister of Justice.

Making secondary legislation, like making bills, has no clearly distinct stages for determining specific legal meanings and what should be followed.

Like bills of law, drafts of secondary legislation must be submitted to all ministries for approval when the draft touches upon their responsibilities or area of government. Drafts must be also submitted for concordance to central nation-wide organs of local authorities, if the draft is connected with their principal interests (Article 25 in Order of the Government). Concordance of ministry to a draft must be given in ten days from the day of receiving the draft which must be correctly written out in legal form. If more time is required, the ministry having drafted the legal act must be informed in writing. Unlike bills, drafts of regulations must not be submitted for concordance to the Ministry of Justice; the State Chancery supervises compliance of regulations of the Government with the Constitution and laws.

Sending drafts to other institutions (interest groups) follows the same procedure as that for bills of law, i.e. the minister or ministry drafting the act decides whether or not it is necessary. Opinions received from interest groups are not legally binding. The reasons for considering or not the suggestions of an interest group or a person can be heard if especially and directly requested of the drafter(s).

A new institute of public consideration will be established in Estonian legislation with the Bill of Legislative Drafting Act. According to $\S \S 86$ and 103, public consideration will be carry out drafting regulations of the Government, regulations of ministers and of local authorities. This innovation is motivated primarily by wanting to make the process of law drafting more open and democratic, closed to the public, in contrast with the current drafting process of legal acts which is usually very closed and 
bureaucratic. At the same time, norms prescribed in regulations do affect often very deeply individual rights and duties.

Subsection 86(1) of the Bill of Legislative Drafting Act stipulates that a draft regulation shall be made available to the public for examination, comments and proposals after concordance only when the authorisation rule in the law so requires. Public consideration must be carried out only once during the drafting process after the procedure of concordance (if it is necessary). After this, no supplementary concordance or second public consideration will be carried out [Subsection 86(4)]. The term of public consideration can not be shorter than ten working days from the date of publication of the note about opening the public consideration.

When public consideration is closed, the letter of explanation must indicate the comments and proposals made and by whom, those taken into consideration or not and why.

Subsection 111(2) of the Bill of Legislative Drafting Act stipulates that ignoring public consideration in the drafting process is a basis for demanding invalidation of a regulation.

Unfortunately, drafts of regulations are very rarely proposed to the government at the same time with the bill. It is currently impossible to demand that this be done since the government does not yet decide whether a certain field should be regulated by regulation at all.

Regulations of the Government are adopted at the session of the government by a simple majority vote, regulations of ministers are not discussed at these sessions. If the regulation of the government is altered at the session where it is adopted, the ministry drafting the regulation makes changes in five working-days and sends them to State Chancery for conclusive formulation.

Regulation of the Government will first be proposed for signing to the State Chancellor, then to concerned minister and finally to the Prime Minister. If the regulation proposed for signing does not correspond to the Constitution or other laws, the State Chancellor may justifiably refuse to sign it, in which case the Prime Minister is asked to put the issue for discussion again at the session of the Government. If the Government maintains its position, the State Chancellor signs the regulation and adds its opinion in a written appendix. Such a legal act has to be immediately sent to the Legal Chancellor. After signing, the regulation is sent for publication. Enforcement depends on this.

\section{Procedures After Making}

According to Clause 77(1) 4) of Government of the Republic Act, the State Chancery has to inspect whether drafts of legal acts of the Government correspond to the Constitution and to other laws. If appendixes marked in an introduction letter (bill, letter of explanation, documents about concordance, other documents) are not attached or if documents are not signed as required, the State Chancery does not take the bill into register and returns it to the bearer. The State Chancery returns documents with its explanation, if a draft of the legislative act:

- does not correspond to the Constitution, other laws or legislative legal acts;

- is not supplied with supplementary documents required for deciding and adoption at the session of the Government;

- requires a supplementary procedure of concordance. 
There is no register of regulations of the Government. All originals of legislative legal acts of the Government and protocols of the sessions of the Government are held at State Chancery and are not available to the public. A register of authorisation rules not followed is held at the State Chancery. Ministries keep account of ministers' regulations.

Legal acts of the Government of the Republic are published in Riigi Teataja during ten days after signing, regulations of ministers ten days after handing over to the State Chancery. Regulations of the Government and regulations of ministers come into force on the day after publication if a different date is not prescribed in the act itself.

\section{Parliamentary Action}

There is no parliamentary supervision of Government legal acts and the Riigikogu has no right to intervene in actions of the Government. The principle of separation of powers determines this. The only control which Parliament has over the Government is the expression of no confidence.

\section{Specific Verifications of the Draft}

It must be reiterated that no unified, integral supervisory body exists for dealing with law drafting. Several analyses and controls were therefore difficult to carry out and most of the topics described below were addressed by the proposer of the bill. Given the problems connected with the lack of professional personnel for law drafting in Estonia, it is easy to understood why several of the analyses described below are neither thorough nor sufficient. Everything depends on civil servants engaged in law drafting, whereas their professional skills, unfortunately, are often inadequate.

Articles 28-41 of the Bill of Legislative Drafting Act regulate prescriptions for the letters of explanation of bills: the drafter has to analyse certain fields using methods of its choice and the results must be described in the letter of explanation. More thorough analysis will be carried out in the nearest future, it is to be hoped. Currently, the letter of explanation typically consists of one or two pages which means that the necessary analyses and research have not been carried out.

\subsection{Constitutional Compliance}

The responsibility of verifying the compliance of drafts to the Constitution is divided mostly between the Ministry of Justice and the State Chancery.

The Legal Chancellor, whose legal status and working order are regulated in Chapter XII of the Constitution and the Legal Chancellor Activities Act (RT I 1993, 25, 436) is the important constitutional institution carrying out constitutional supervision of legislative legal acts. According to $\$ 139$ of the Constitution, the Legal Chancellor shall be an independent official who reviews the legislation of the legislative and executive powers and of local governments to ensure their conformity with the Constitution and the laws. The Legal Chancellor carries out preliminary and follow-up verification of legislative legal acts.

\section{Preliminary Verification}

Subsection 141(2) of the Constitution prescribes that the Legal Chancellor may participate in sessions of the Riigikogu and of the Government of the Republic with the right to speak. Moreover, §24 of the Legal 
Chancellor Activities Act stipulates that schedules of the sessions of the Government and sessions of Riigikogu with drafts of legal acts to be discussed will be sent to Legal Chancellor for an opinion on drafts before the acts are passed.

\section{Follow-up control}

According to $\$ 12$ of the Legal Chancellor Activities Act, every person has the right to apply to the Legal Chancellor to verify the compliance of a law or other legislative legal act to the Constitution or the law. According to $\S 13$, the Legal Chancellor is sent copies of all legislative legal acts passed by legislative and executive state and local government organs, also copies of international treaties not entered into force yet and court decisions of the Riigikohus (the Supreme Court) relating to the cases on constitutionality. According to $\$ 142$ of the Constitution, if the Legal Chancellor finds that legislation passed by the legislative or executive powers or by local government is in conflict with the Constitution or a law, he/she shall propose to the body which passed the legislation to bring it into conformity with the Constitution or a law within twenty days. Otherwise, the Legal Chancellor shall propose to the Supreme Court to nullify relevant legislative legal act. Besides, according to $\$ 16$ of Legal Chancellor Activities Act, the Legal Chancellor proposes to the state or local government organ to stop the act from functioning until it is brought into conformity with the Constitution or the law, if it is found to endanger the life or health of physical persons or to violate an international treaty entered into force by international practice or ratified by the Riigikogu. The Legal Chancellor appoints counsellors who help to carry out his functions.

\section{Court supervision on legislation (after passing legal acts)}

After passing legal act, the Board of Constitutionality Supervision of the Riigikohus (the Supreme Court) verifies its compliance with the Constitution; the relevant procedure is prescribed in Constitutionality Supervision Court Procedure Act (RT I 1993, 25, 435). Subsection 3(1) specifies that the Riigikohus will nullify totally or partially any legal act that conflicts with the Constitution.

The Riigikohus can discuss matters of constitutionality of laws, decisions of the Riigikogu, bills not proclaimed by the President, presidential decrees, legislative legal acts passed by the bodies of executive power and local authorities, international treaties not entered into force, and legal acts passed before the Constitution entered into force.

Those who can appeal to the Riigikohus to proceed to the issue of constitutionality include:

1. the President, in cases prescribed in $\S 107$ of the Constitution;

2. the Legal Chancellor, in cases prescribed in $\S 142$ of the Constitution, and concerning international treaties not entered into force;

3. courts, as prescribed in $\$ 5$ of Constitutionality Supervision Court Procedure Act, if it finds that a legal act which should be considered in court proceeding conflicts with the Constitution, it declares it unconstitutional and will not consider it. The court will notify the Riigikohus and the Legal Chancellor about such decision and the constitutionality verification will begin by this notice.

According to $\$ 20$ of the Constitutionality Supervision Court Procedure Act the decision of the Riigikohus will enter into force on day it is proclaimed; the decision is final and cannot be appealed. 


\subsection{Compliance with the Existing Legal System}

Verifying the compliance of drafts with the existing legal system legislation is mostly divided between Ministry of Justice and State Chancery to prevent processing acts which do not comply with existing legislation. Occasionally, ministries do not investigate an area they want to regulate very carefully and there have been cases when the drafts have been proposed for areas already covered by existing legislation.

\subsection{Compliance with EU Legislation and Case Law}

On 30 July 1996, regulation No. 199 of the Government from 1 July 1993 "On the organisation of concordance and legal expertise of legal acts proposed to the Government" was amended in order to ensure the verifying of compliance of bills with EU legislation. By this amendment "Demands for letters of explanation of the bill on analysis of compliance with European Community legislation" and "Table of comparison between sources of European Community legislation and Estonian bill" were added to the regulation. So, only compliance of bills (drafts of laws) with EU legislation and case law must now be checked in Estonia, although mostly directives and other sources of EU legislation are implemented in Estonia by regulations of the Government and ministers.

According to the "Demands to letter of explanation of the bill on analysis of compliance with European Community legislation" the letter of explanation of the bill must contain a list of EU legal acts and case law related to the regulating area of the bill. The letter of explanation must also show if the bill conforms or not or only partially with EU legislation, and if the sources of EU legislation are not taken into account, why not. Moreover, whether or not the expertise of compliance of the bill with EU legislation has been made should be mentioned and the opinion of experts added.

Table of comparison between the sources of European Community legislation and the Estonian bill must be added to the letter of explanation , if the area of the bill is also regulated by EU legislation.

Ministerial observance of these demands is checked by the European Community Bureau of Ministry of Justice during the concordance procedure.

The methodology for checking compatibility with EU legislation is now prepared in the Ministry of Justice and will be sent to all ministries as soon as possible.

\subsection{Compliance with International Obligations}

No specific system is created for compliance; the proposing ministry is obliged to undertake this procedure. The Constitution specifies only that if laws or other legislation conflict with international treaties ratified by Riigikogu, the provisions of the international treaty shall apply ( $\$ 123$, Constitution).

\subsection{Compliance with Legal Formalities}

Such demands are set in different acts at the moment. In the future, the legal formalities of legislative legal acts will be prescribed in Legislative Drafting Act (also linguistic questions) and government regulation ( $\$ 108$ of Legislative Drafting Act). All law-drafters must observe these formalities and drafts that do not comply with legal formalities will not be agreed to by the Ministry of Justice or by the State Chancery which bars proposing the draft to the Government. 


\subsection{Compliance with Administrative and Information Technology Demands}

Systematic control of effectiveness and the need for administrative solutions described in drafts is not always carried out and is mostly overseen in the procedure of concordance. For example, an administrative reform is now in process to decrease the state apparatus and make it more effective. Nonetheless, several drafts set the creation of new state institutions which conflicts with this administrative reform. Observing the idea of reform is controlled mostly by the Ministry of Justice during the procedure of concordance.

There is no supervision of unified use of databases because there is no unified network of all state institutions yet.

\subsection{Compliance with Environmental Standards}

There are no specific regulations. Compliance of the draft with environmental standards is the task of the proposing ministry itself. Showing the results of environmental analysis in the letter of explanation is prescribed in $\S 35$ of the Bill of Legislative Drafting Act.

\subsection{Compliance with Textual Quality Standards}

The comprehensibility of legislation has always been a great problem. At the moment, the improving linguistic quality of drafts is a complicated goals because laws have been drafted by many different people and institutions. The central body dealing with linguistic questions is the Legal Terminology Committee of the Government, staffed by 18 linguists and lawyers among others, whose task is to make proposals to improve the linguistic quality of legal acts. The ordinary meetings of Legal Terminology Committee take place four times a year.

Some members of this Committee are also officials of Ministry of Justice (Bureau of Terminology). One of their tasks is to make proposals to revise drafts proposed by the Ministry of Justice.

To improve the quality of legal acts, the Legal Terminology Committee organises work-shops and seminars for law-drafters to explain different linguistic questions and to give them possible solutions. The Legal Terminology Committee has its own periodic publication, Õiguskeel (Legal language) published five times a year with a print run of 2000 and is delivered by order. It is generally available and contains articles on using language in legal texts, on legal terminology, on translating legal texts (increasingly important) etc. as well as concrete proposals on how to word certain rules. Proposals of Legal Terminology Committee are not compulsory to law drafters, as they have no legal power but are quite often observed. According to $\$ 108$ of the Legislative Drafting Act, the technical rules for draft legislation will be established by the government or with its authority, by the Minister of Justice, some decisions of the Legal Terminology Committee will be prescribed in these rules and so they will have a legal power as well.

According to $\S 30$ of the Legislative Drafting Act, the letter of explanation of the draft must include the name of linguist who has revised the draft. Linguistic revision will be obligatory and must be organised by each ministry proposing the draft. 


\subsection{Costs}

Clause 34 (3) of Order of the Government makes it obligatory to analyse economic costs of the draft and to show financial sources in the letter of explanation of the draft. Despite this, this has not been always observed. A good example is the Public Service Act passed without taking into account state budget possibilities; the act was amended even before it entered into force. The Ministry of Finance verifies economic costs accounting and financing sources during the procedure of concordance (i.e. all drafts requiring direct costs for implementation have to be discussed with the Ministry of Finance) and without such an analysis, the draft is not concordant.

Subsection 22(3) of the Bill of Legislative Drafting Act stipulates for entry into force there must be enough money to implement the act; enforcement will be postponed until the necessary funds are found. Whether the law is initiated by the Riigikogu or the Government the cost analysis is obligatory.

Cost analysis means the analysis of direct costs or state and local income; indirect costs (including costs of private sector) are not usually taken into account (only drafting tax legislation). At the same time, according to Clause 34 (4) of the Order of the Government (See also $\$ 35$ of the Bill of Legislative Drafting Act) a prognosis of possible legal, economic and social impacts (conditional indirect costs) must be described in the letter of explanation of the bill, but such analysis is, unfortunately, quite occasional at the present. There is no follow-up analysis of costs.

The results of analysis have to be shown in letter of explanation presented to the Riigikogu with a bill. In the future (by Legislative Drafting Act) the letter of explanation will be published only in the case of public consideration, which will be used in processing drafts of regulations of the Government and ministers.

\subsection{Efficiency}

This kind of control is not carried out. Implementation usually determines how a legal act functions. This is one reason for altering legal acts continuously. Secondly, several bills do not have real regulatory areas and adopting such laws causes no real changes; bills consist of empty norms and there is no reason to enforce them. Such bills are usually returned to the relevant ministry already by the government. Frequently introducing such bills to the government and Riigikogu is one indicator about the unsatisfactory situation in this area.

\subsection{Practicability}

Occasional analysis occurs, and when it does occur, it takes place at different stages: sometimes through policy making the purpose of a bill occasionally changes and with it the entire content alters significantly in the drafting process. Many incorrect solutions become evident in the procedure of concordance, when the bill is already drafted.

\subsection{Implementation Assessment}

The ministry that drafted the bill usually assesses its applicability and implementation. Unfortunately, implementation assessment is not done effectively or rationally enough. As described before, administrative reform is currently underway and one of its main objectives is to optimise government 
machinery. On the other hand, new bills frequently establish new government institutions quite often for fulfilling tasks prescribed in law but which could be fulfilled more rationally without establishing any new government body and assigning the tasks to existing structures.

This question is closely related to other assessments analysed here; in general, essentially no assessment practices exist.

\subsection{Control of Consultation}

Consultation processes are not very developed in Estonia and have been described above.

\section{Instruments for Ex Ante Evaluation}

No instruments for ex ante evaluation are used in Estonia.

\section{Use of Computer Technology}

Computers have become urgently needed tools and most persons engaged in law drafting use them. No unified rules for drafting exist, so computers are used differently in different ministries. No special programs for law drafting have been developed and unified prescriptions do not exist.

Personal computers are mostly used for word processing, i.e. for text formatting. The development of computer technology is quite rapid. Most ministries use different versions of MS Word for Windows and have Internet connection. However, connection of different authorities via Internet is not used yet.

In form-contract for ordering bills of law, validated by the Chancellor of the Ministry of Justice, a bill ordered by a ministry has to be handed over on paper and on diskette. Article 31 in Order of the Government stipulates that drafts of laws, regulations and international treaties and long drafts of orders of the government must be handed over to State Chancery on diskette or via Internet. This make it easy to modify drafts being processed in the Government and Riigikogu.

As persons engaged in law drafting are professionals from very different walks of life and from very different government offices, it is impossible to guarantee everyone access to the electronic database of Estonian legal acts "Estlex" (See also Chapter 9). Anyone can buy the right to use this database and government offices have access to it. However, it is quite complicated to use this database in law drafting at the present time, because information can be searched by name of legal act or by part of the name of a legal act. There is no over-text searching or connections-systems developed in this database which does not contain court precedents.

\section{Publication of Legislation}

\section{Legislative Sources}

Publication of legal acts is regulated in Riigi Teataja Act (State Gazette Act) (RT I 1993, 20, 352; 1995, $19,288 ; 1996,49,953)$. 
All primary and secondary legislation is published in Riigi Teataja. According to Clause 77(1) 3) of Government of the Republic Act State the Chancery is responsible for issuing Riigi Teataja. The Editorial Office of Riigi Teataja was founded under the State Chancery for this purpose.

Legislation is not usually republished unless many changes have been made in a particular legal act which will be republished entirely and if needed, this obligation will be prescribed in the bill of amendment act.

Volumes of consolidated legislation in paper (Eesti seadus, Estonian legislation) are published privately only and are amended 4-5 times per year and are accessible for all. Estlex contains a consolidated collection of legislation and is kept by the Estonian State Computing Centre (a private company, currently state-owned, but relations of this database with the state are not very certain. Estlex gets the data from the Editorial Office of Riigi Teataja by agreement, from some ministries, etc. As it contains the consolidated collection of legislation, the Estonian State Computing Centre itself prepares the consolidated versions of legal acts without supervision by any state organ. Mistakes can and do occur. Also, as Estlex gets the texts from the Editorial Office of Riigi Teataja after publishing them, data are renewed not promptly, but approximately twice a month. Everybody can use Estlex for a fee.

The only consolidated collections of legislation are therefore now published by private companies. The only authentic source of official texts of legal acts (e.g. in court) is Riigi Teataja. Subsection 2(1) of Riigi Teataja Act stipulates that Riigi Teataja is the official publication of the Republic of Estonia.

There is no central registry (complete archive) of all legislation now in Estonia. In two-three years, the Ministry of Justice has planned to create an electronic register of legal acts. It would contain the following:

1. laws;

2. presidential decrees;

3. regulations of the government, ministers and local authorities passed on the basis of authorisation rules;

4. Riigikogu decisions;

5. decisions of the President of the Republic;

6. international treaties of the Republic of Estonia;

7. legislative legal acts of the Estonian Bank;

8. court decisions of Riigikohus (the Supreme Court) entered into force.

All original examples of acts and consolidated examples of acts will be kept in central register. The data (texts of legal acts) will be printed in by different institutions (Chancellery of the Riigikogu, State Chancery, Chancellery of the President, ministries, Estonian Bank and the Riigikohus). The consolidated examples of acts will be kept by Ministry of Justice.

The register belongs to the state (whose representative is Ministry of Justice).

The register will be kept by the company with which the Ministry of Justice will conclude the contract. The keeper of the register will hand over the data to register users and does not itself have the right to use the database under the terms of contract concluded for keeping it. 
Register users will be different legal and private persons who want to create different products for the public on the basis of an electronic register of legal acts and who conclude relevant contracts with the state (Ministry of Justice). Such a contract will also stipulate that Riigi Teataja will be published in paper and in electronic database. All data being published would be authentic and be guaranteed by the state.

\section{Publication of Legislation}

As said above, bills are not published during the drafting process. In the future, only drafts of regulations of the government and ministers will have to be published if public consideration has to be carried out.

As the Editorial Office of Riigi Teataja comes under the purview of the State Chancery, it bears the publishing costs.

Publishing legal acts, the Editorial Office of Riigi Teataja can only correct printing errors in legal act text before publication; the contents cannot be changed. Article 76 of the Order of the Government stipulates that if the regulation of the government passed by the government or proposed by a ministry for signature contains linguistic or printing errors, the State Chancery can corrects them before signature, if the proposer agrees and the content remains unchanged.

$\S 108$ of the Constitution stipulates that "A law shall enter into force on the tenth day after its publication in the Riigi Teataja, unless the law itself provides otherwise". The same rule is prescribed in Subsection 8(1) of the Riigi Teataja Act.

Legal acts of the Government of the Republic are published in Riigi Teataja during ten days after signature, regulations of ministers during ten days after handing over to the State Chancery. Regulations of Government of Republic and regulations of ministers come into force on the day following publication in Riigi Teataja, unless a different date is prescribed in act itself.

Subsection 7(1) of Riigi Teataja Act stipulates that laws will be published during seven working days after presidential proclamation; Subsection 7(3) stipulates that other legal acts, not passed by Riigikogu, will be published during ten working days after they are handed over to the State Chancery. 


\section{LAW DRAFTING AND REGULATORY MANAGEMENT — LITHUANIA}

\section{Introduction}

Lithuania had a tradition of law-making in the eight centuries before it was occupied by the Soviet Union in 1940. During the 50 years of Soviet occupation, Lithuania became part of the unified Soviet Republic legal system, national legal traditions were interrupted and in essence destroyed. After independence was restored on 11 March 1990, it was necessary to progressively restore the national legal system so that it took into account new requirements occasioned by the return to democracy and the changes of circumstances and prospect. Progressive improvement of legal acts followed from implementing of this evolutionary principle and the wish to draft high quality new legal acts that would remove obstacles to taking part in the process of co-operation among democratic states. However, Lithuania did not escape the state of chaos, conflicts between legal acts and other negative consequences experienced in the transition period by other states restoring their independence.

At the moment, drafts of laws are drafted by those who possess the power of legislative initiative either themselves or appoint working groups or competent subordinate state institutions. All natural and legal persons have the right to present proposals to those with legislative powers for drafting of legal acts.

Article 68 of the Constitution of the Republic of Lithuania stipulates that the power of legislative initiative in the Seimas (the body of legislation and representation of national interests) is vested in its members, the President of the Republic, and the government. In addition, a group of 50000 citizens with the right to vote may present a draft law.

The Basic Provisional Law, in force from 11 March 1990 until the adoption of the Constitution by referendum of 25 October 1992, and which had effect as the Constitution for that period, lengthened the list of those with powers of legislative initiative. Powers were vested in the deputies of the Supreme Council (the body of legislation and representation of nation interests till 25 November 1992), the Presidium of the Supreme Council, the Chairman of the Supreme Council, permanent commissions of the Supreme Council, the Council of Ministers, the Supreme Court, the Prosecutor of the Republic of Lithuania, as well as in political parties and the governing authorities of public organisations. A similar list of those having this power (but including other commissions of the Supreme Council) was established in the last Soviet Constitution adopted in 1978.

During the transition period (1990-1997) laws created and introduced the order of drafting, adoption, announcement and coming to legal force of laws and other legal acts.

\section{Regulatory Framework}

Laws and other legal acts regulating the order of drafting the laws and other legal acts are the following: 
1. The Constitution of the Republic of Lithuania. Approved by referendum on 25 October 1992, describes the list of subjects possessing legislative powers, sets the competence of the state power subjects (while adopting particular legal acts) the order of adoption and coming into legal force of laws, and other essential questions.

2. Law of the Republic of Lithuania on Drafting Procedure of Laws and other Legal Acts (No. I-872; adopted 2 May 1995). This law of six pages regulates the main requirements for drafting laws and other legal acts and for the stages of the drafting process, as well as requirements on form, structure, contents and language.

3. The Statute of the Seimas of the Republic of Lithuania (No. I-399; adopted 17 February 1994). Relevant chapters regulate the stages from the presentation of a particular draft through its final adoption in the Seimas. Sets out the main requirements for drafts that are to be presented to the Seimas.

4. The Law of the Republic of Lithuania on International Treaties (No. I-1344, adopted 21 May 1991). This law describes all the main requirements on entering into international conventions.

5. The Law of the Republic of Lithuania on the Order of Announcement and Coming into Legal Force of the Laws and Other Legal Acts of the Republic of Lithuania (No. I-119, adopted 6 April 1993). This law regulates the order of announcement and coming into legal force of laws and other legal acts.

6. The Law on the Register of Laws and Other Legal Acts of the Republic of Lithuania (No. I-873, adopted 2 May 1995). This law regulates the establishment of laws and other legal acts, registering the data to the register and dealing with it, the order of its use.

7. Working Regulation of the Government of the Republic of Lithuania (adopted by the Government on 11 August 1994, resolution No. 728). This regulation establishes requirements for drafts of laws presented to the government determining the institution possessing powers of legislative initiative, requirements to legal acts adopted by the government, indicates institutions vested with the right to submit particular proposals and drafts, regulates the drafting stages until the draft is submitted to the Seimas, regulates relations of the government with the Seimas concerning law drafting.

\section{Regulatory Instruments}

Legal acts (regulatory instruments) are the only written sources of law in the Republic of Lithuania. The Constitution does not systematise legal acts; no precise hierarchy of the system of legal acts exists. The Constitution delimits the competence of the bodies exercising state power (the Seimas, the President of the Republic, the government and the Court). It establishes which legal acts are being adopted by the subjects of state power within the scope of their competence. The Constitution prescribes the basic principles: no law or other legal act has effect if it does not conform to the Constitution (Article 7 of the Constitution); laws or other legal acts of the Seimas cannot contradict the Constitution; the legal acts of the President of the Republic and the government must not contradict the Constitution and the laws (Article 102, Constitution).

The legal acts in force in Lithuania at the moment can be divided into the following:

The Constitution can be amended by referendum (a referendum is necessary to amend Chapter 1 "The State of Lithuania" and Chapter 14 "Amendment of the Constitution") or by the Seimas under special procedures established by the Constitution. The Constitution in force has only one amendment (Law No. I-1390, adopted 20 June 1996). 
Constitutional laws must be adopted by over one half of all members of the Seimas and amended by a majority of three-fifths of its members and can also be adopted by referendum. The list of constitutional laws is established by the Seimas with the voting majority of three-fifths of its members. Two constitutional laws have been adopted since independence: "On the State of Lithuania" (No. I-1051, adopted 11 February 1991), "The Constitutional Law is Established in the Second Part of the Constitution of the Republic of Lithuania Providing Conditions and Restrictions for the Subjects Obtaining the Land Plots" (No. I-1392, adopted 20 June 1996).

Laws (adopted by Seimas if over one-half of its members participate in the sitting voted "for" and signed by the President of the Republic or adopted by referendum). 1352 laws have been adopted between 11 March 1990 and 1 January 1997.

International treaties. Only the treaties ratified by the Seimas have the power of law. According to the Law on International Treaties, these shall be entered into to only if adopted by the government or the Ministry of Foreign Affairs under the order prescribed by the government, joining them or ratifying them in the Seimas. This law sets the list of treaties which should be ratified as well as international treaties are being ratified in which ratification is established.

Other legal acts adopted by the Seimas:

- Decrees of the President of the Republic. 1145 decrees of the President of the Republic have been adopted between 25 February 1993 (Inauguration Day) and 1 January 1997.

- Resolutions of the Government (must be adopted in the sitting of the government by the majority and signed by the Prime Minister and the minister responsible for this area. 6911 resolutions have been adopted between the restoration of independence and 1 January 1997.

- Resolutions, conclusions and other decisions of the Constitutional Court. 63 resolutions, conclusions or other decisions have been adopted until 1 January 1997.

- Legal acts adopted by the Bank of Lithuania, ministries, departments and government institutions as well as other institutions of state government.

- Decisions of the Senate of Judges of the Supreme Court (adopted by the Senate of Judges of the Supreme Court, the courts; the state and other institutions and other subjects must take into account the judicial explanations of law while applying laws (Article 20 of Law on Courts).

- Court Decisions (although they affect only the particular case, the whole of body of court decisions influences the formation of law).

\section{Drafting Personnel}

Law drafters can be specialists in the institutions with power to take legislative initiative who draft legal acts as part of their general duties, working groups appointed to undertake particular drafting projects, individuals or a group of persons appointed or selected through competition by an institution dealing with the drafting of particular legal acts, or an individual or a group of persons involved with a legislative initiative.

In the Seimas, laws and other legal acts can be drafted by one of its factions, a committee or an informal group or by a member of the Seimas personally. 
Legal government acts are drafted by government advisors with subject competence and structural divisions of the Government Office (who may or may not be lawyers).

Most ministries have legal divisions or departments that are given competence to draft legal acts and to submit legal opinions concerning law drafts submitted to them.

The Ministry of Justice's responsibilities include, at its own initiative or according to an order of the Seimas or the Government, drafting codes and other laws and resolutions of the government and participation in the drafting legal acts with other state or public organisations under assignment by the Seimas or the Government, and submission of legal opinions concerning drafts of laws and resolutions of the Government. These tasks are carried out in the main by a legal department comprising 16 specialists with advanced university legal qualifications.

\section{Qualifications}

The specialists drafting laws and other legal acts in the Government Office and in particular ministries are not assigned by law or secondary legislation to any special category and no special qualification skills are required. Officials are required to have general qualification skills; the majority are expected to undertake particular drafting.

The qualifications for appointment as a "B" level state official (i.e. official employees appointed by the Seimas, the President of the Republic, the Government, their structural divisions, ministries, Government institutions and other institutions of state government and other official employees indicated in posts list) are prescribed in the Law on Officials of the Republic of Lithuania, which came into force on 1 May 1995 and the secondary legislation supplementing this law.

These include the general knowledge and skills required to carry out the official's job (knowledge of the laws of the Republic of Lithuania, government resolutions, other legal acts concerned with the official's activities and profession, computer skills, clerical work experience etc.).

Any special qualification skills requirements for specialists of the Seimas, the government, ministries and other state organisations who draft laws and other legal acts must be established in post instructions approved by the head of particular institution. At the moment, the newly formed government is re-organising its structures so no post instructions have been approved yet. In practice, appointees have high educational qualifications and are specialists in the particular branch of law.

At the moment, acceptance as a "B" level official is extremely strictly regulated. The Law on Officials specifies that these officials can be accepted only through public competition or after passing a qualification examination. Special qualification skills requirements will be required for every individual employee accepted and included in the employment contract. Employees are rated once every three years (by evaluation of professional readiness, competence, efficiency, practical activities).

Specialists drafting laws and other legal acts are expected to improve their qualification skills under a general order prescribed for all officials. According to the Regulations on Qualification Improvement (approved by the Government on 26 June 1996) each official must improve qualifications as per post requirements. No fewer then 15 days and no more than 30 days every two years must be designated for improving qualification skills (to be paid for by the state government institutions or municipalities). No limits are imposed for this period if the financial means are obtained by the initiative of the drafters and not from state budget. 
The general method of improving law drafters' qualification skills is through seminars and courses that examine particular law topics or particular legal problems. See Annex for those organised in Lithuania in the first half of 1996 in which specialists directly involved in law drafting participated. In addition, law drafters participate in international conferences abroad. Inter-institutional meetings on improving legislation are often organised as well.

\section{Working Groups}

In addition to drafting of legal acts as part of the functions prescribed for a particular post, drafting may be carried out by a working group. Working groups for preparing a draft of a particular legal act or block of legal acts are appointed by presidential decree, resolution of the Seimas, government resolution, order of the Prime Minister or instructions from the head of a particular state institution. They can be used even though they may require additional external financing.

These working groups are formed of competent specialists in the appropriate field and are selected by the persons who set up the group or by the head of the group. No requirements regarding the specialists who may participate in these groups are laid down by primary or secondary legislation.

Ministries, Government institutions, regional and municipal boards, enterprises, institutions and organisations must, upon request, provide these groups with all necessary information and other material on the subjects discussed by working groups. Unless they are financed from outside the state budget, working groups are supported in the economic and technical sense by the Government Office or ministries and the government institutions whose heads are appointed as the heads of working groups. Where the working group is financed from outside the state budget or a particular fund, all economic and organisational expenditures must be kept within approved estimates.

The period for drafting any particular legal act is established by the person or institution forming the working group or by agreement between the parties.

\section{Use of Consultants}

When drafting legal acts, consultants and experts are often employed which creates a problem of payment. This form of consulting is therefore more often used when a legal act is drafted by a group paid from external financing. Informal consultations with foreign or local specialists are not subject to restrictions.

\section{Involvement of Drafters after Completion of the Drafting}

Upon completion, the draft law is submitted to the body with the power of legislative initiative that is vested with the right to present the draft before the Seimas; an expert can also be appointed at that body's discretion. The law drafters involved may be invited to defend the draft before Seimas committees. Drafts are accessible to all persons and institutions interested in them. 


\section{Drafting Procedures}

\subsection{Primary Legislation}

The trends of new government policy are being described in the programmes of the government being approved by the voting majority in the sittings of the Seimas. The last programme was approved by the Seimas on 10 December 1996.

\section{Work Programmes and Timetabling}

All drafts of laws discussed in any particular session of the Seimas must be included in its work programme for the session. With the exception of the first session, the work programme is prepared by the Seimas Speaker working with the Seimas Chancellor. Draft programmes are provided to Seimas members two business days before the beginning of the session and indicates which committees are responsible for the matters included on the programme and when it will be presented for discussion in a sitting of the full Seimas.

The programme is presented to the President of the Republic and the government and is discussed by the meeting of the body of Monitors ${ }^{27}$ after receiving written proposals from them. Monitors have the right to amend the programme by approval of no fewer than two-thirds of the Monitors at their meeting. The draft with the amendments, supplements and recommendations of the meeting of Monitors is submitted to the Seimas for discussion.

Once the session work programme is approved, the Seimas Speaker with the Seimas Chancellor prepares precise weekly timetable of sittings and presents it for discussion to a meeting of Monitors. Proposals may be made by members of the Monitors or Seimas committees, other members of the Seimas and the Government. The meeting of Monitors adopts the timetable of sittings as described above. The right to propose to include additional questions in the daily or weekly sittings timetable as adopted is vested in the Board of the Seimas, the meeting of Monitors and the Government. Such a proposal can be adopted if supported by the votes of over the half of members of the Seimas taking part in the sitting. If the proposal is rejected, it can be presented again only the next day. Matters requested by the President of the Republic are automatically included in the timetable of the sitting (without voting). The government has the right to request that a report on an important question be included in the weekly sitting timetable.

Proposals concerning drafting of laws and of the session work programmes are prepared and submitted to the government by the Representative of the Government for Seimas relations, after taking into account requests of the ministries and other Government institutions, the Government Office structural divisions and advisors on particular questions. Once approved, proposals to the Seimas of the Republic of Lithuania are signed by the Prime Minister.

\section{Formal Drafting Stages}

Drafting of the law or other legal act proceeds through the following formal stages:

- establish purpose of a legal act and the task of its drafting;

27. Structural body of Seimas consisting of the members of the Board (Speaker, three deputies, Seimas Chancellor) and representatives of the factions of the Seimas. 
- appoint law drafter;

- draft text of legal act;

- co-ordinate and approve legal act.

The purpose and needs of the law can be determined unofficially by the initiators of the particular draft. Official approval is always required from the person empowered with legislative initiative however, in order to take into account all the requirements prescribed by laws before the draft can be discussed in the Seimas.

Time needed to draft the legal act can be established when the drafting is initiated by the head of the competent state institution or the state politician responsible for initiating the drafting process. In this case, the drafting timetable for the particular act may be scheduled. These timetables are usually scheduled when the block of legal acts is being drafted to carry out the particular government programme. These plans are prepared by the state institution or group of persons authorised to prepare draft outlines. The plans are approved by the body that ordered the draft.

Competent ministries and government institutions responsible for carrying out the programme of the government as well as working groups appointed for the purpose make and submit drafts of laws and other legal acts to the Seimas for discussion. These drafts are submitted to the government by the competent ministers, heads of Government institutions (or by their substitutes, or by duly authorised deputy heads of government institutions) or by heads of divisions of the Government Office and advisors for particular questions (or in their absence, by deputy officials and duly authorised employees). Ministries and Government institutions are not entitled to present drafts of laws and other legal acts directly to the Seimas.

Enterprises, institutions and organisations, political parties and political organisations, trade unions and public organisations and citizens must observe the hierarchy system prescribed by laws while submitting a particular draft law.

\section{Justifications/Explanatory Documents}

Working Regulation of the Government, Article 95 stipulates that the draft of law must be supplemented by an explanatory document which usually indicates:

- draft aims and tasks;

- current legal regulation of the subject dealt with by the draft;

- new provisions of legal regulation established in the draft;

- positive results forecast after the matter is regulated;

- possible negative consequences of adoption and how to avoid them;

- the ways in which the draft law would supplement legal system, which acts in this area remain (the list is submitted) and which legal acts in force should be amended or repealed after the draft is adopted;

- if secondary legislation is needed to execute the law, who will draft these acts (the outlines of secondary legislation are submitted), and when;

- evaluations and conclusions of the specialists involved in the drafting process; 
- names of the draft author or group of authors;

- key words of the draft law that will be required to include the draft in the computerised search system;

- other substantiation and explanations considered necessary by the authors.

The draft of law is supplemented by the conclusions from a criminological examination of the impact of any draft that affects the crime situation. The main draft of law is usually supplemented by drafts of laws making amendments, supplementary provisions or repeals of other laws consequential on the adoption of the draft. When appropriate, the draft of a Seimas law for implementing the law is included.

The Legal Bureau is going to be established within the government to co-ordinate the entire drafting process independently of subject. This project is currently being drafted by the Ministry of European Affairs.

\section{Examination of Drafts}

All drafts of laws must be submitted for examination to the Legal Department of the Ministry of Justice responsible for these examinations. This department could require an examination for other structural divisions (Public law, Private law). Conclusions are to be submitted within eight days to the Legal department of the government.

Drafts submitted to the government that do not comply with the Working Regulation of the Government are returned to the ministry, government institution or working group by the Secretary of the Government (in his absence, by the Deputy Secretary of the Government).

The drafts of laws and other legal acts which receive the visa of the Legal Department of the Government Office are presented within three days by the heads of divisions of the Government Office or the advisors for the particular matter to the Secretary of the Government who transmits them to the Prime Minister.

\section{Adoption of the Draft}

Draft laws are discussed in the government as provided by the Working Regulation of the Government. If adopted, the record of the meeting of the government states who will represent the government when the draft is discussed in the Seimas.

After adopting the draft, the government also adopts a resolution to submit it to the Seimas, indicating where necessary that the draft be discussed urgently or very urgently. If, during the discussion by the government, remarks, additions or amendments are proposed, the institutions which produced the draft, the Government Office divisions or advisors for particular questions finalises it as directed by the meeting. Documents relating to submission to the Seimas (assignments) must be signed within three business days from the day of discussion in the Government meeting, unless another period is specified.

\section{Submission to the Seimas}

Drafts of laws submitted to the Seimas must be supplemented by the resolution of the Government and explanatory document. The statement indicating the government representative in the Seimas is signed by the Prime Minister or competent Minister or head of the government institution; the explanatory document is usually signed by the initiator of the draft. 
The explanatory document must generally correspond with the requirements prescribed for such documents. In addition, it should indicate if the draft meets the requirements of the European Convention on the Protection of Human Rights and Basic Liberties (procedures are currently being developed) and stating how the matters are regulated in other Baltic states.

\section{Seimas Examination}

When a draft of a law registered is in the Seimas, its Legal Department, employing eight lawyers, must submit an opinion as to whether the draft contradicts other laws in force and meets technical legal requirement, not later than seven business days after its receipt. The draft of law registered together with this opinion is submitted to the Seimas Chancellor who submits it within three business days to the Seimas Speaker, committees and factions, the government, the office of the President of the Republic, and as necessary to particular municipalities. Seimas members are informed of the draft in the Seimas Chronicle.

Drafts of legal acts supplemented by explanatory documents are distributed to Seimas members not later than one day before being presented at a Seimas sitting.

The Seimas Speaker or its Board is entitled to submit the draft law for preliminary examination and opinion to one of the committees. The Board of the Seimas or the committee has the right to request the opinion of the government concerning the draft law under discussion.

The committee which receives the draft law for a preliminary or additional examination must present a written evaluation. Disapproval should be justified. Approval can be expressed with or without comments, or on condition that the draft will be amended in a specified way. In this case, exact amendments can be submitted.

During the Seimas sessions the committees must draft their opinions within ten days. The initiators of the draft are informed of these. The committee examining the draft, in addition, is entitled to submit its opinion to the meeting of the main committee which is to discuss the draft of law, and to delegate a representative for that meeting.

The initiators of the draft of law are entitled to withdraw it before discussion but if it is officially supported by another person with the power of legislative initiative not later than the next day, proceedings on the draft continue. The last provision does not apply to the drafts of laws submitted by the President of the Republic or the Government.

\section{Seimas Consideration and Adoption}

Only drafts included in the session work programme can be discussed. The procedure consists of discussion in the main committee, in a Seimas meeting and adoption.

\section{Discussion in the Main Committee}

After making a decision to start the procedure on the discussion of a draft law, a preliminary date must be set during the same session for discussion in the Seimas not earlier than one week and not later than the end of the session, and must appoint the main committee to further consider and improve the draft. It may also adopt a resolution to open the draft to public discussion. This is not yet obligatory however in practice all significant drafts are published in State News, in daily papers or in the theoretical magazine Law Problems for public discussions. 
The main committee appointed by the Seimas to consider the draft law under discussion is entitled to appoint members responsible for examining it, to involve experts, to request additional opinions from other committees and state institutions. A working group may be appointed to improve the draft. This committee must send the draft to the interested state institutions and public organisations, as necessary, for their evaluation.

All material received relating to the draft law is evaluated and summarised by this committee. If the Seimas decides to discuss the text of the draft as presented by the initiators, the main committee has the right to present its own version as well. If the draft of law has been opened to public discussion, any proposals received are submitted to the main committee which discusses not later than three days before discussion by a meeting of the Seimas. Representatives of the initiators and of committees preparing an opinion, as well as experts, are invited to the discussion in the main committee. Representatives of other state institutions and public organisations interested in the subject may also be invited.

After discussion, the draft is transmitted to the Documents Division for editing. Representatives of the initiators and the committees must agree with the text of the edited draft. which must be distributed to the members of the Seimas and submitted to the government not later than two business days before discussion in the Seimas meeting. Additional data with a covering letter must be distributed to Seimas members not later than one business day before the meeting.

\section{Discussion}

Discussion in the Seimas considers the expediency of the draft, its conception, main provisions and principles according to the following order:

- report of the main committee which investigated the draft law;

- voting when the main committee proposes to return the draft to initiators or to reject it;

- reports of representatives of the initiators of alternative drafts, if any;

- reports of other committees;

- general consideration of the main provisions of the draft, speeches of the government and other representatives;

- specific consideration of draft structure and chapters, divisions and articles. If no proposal is made for this special consideration, the Seimas can dispense with it or combine it with the general consideration;

- the final speech of the principal speaker and representatives of the initiators of alternative drafts.

The adoption date may not be earlier than at least two business days later. If it becomes clear that Seimas members need additional information before adopting the law, discussion of the draft law may be adjourned.

If the committee submits a new edited draft, it should be distributed to the members of Seimas and the government not later than two business days before the sitting.

All amendments, additional provisions and repeals must be submitted to the official serving the sitting signed by the members of the Seimas, factions, committees, the government proposing them not later than 24 hours before the beginning of the sitting in which adoption is planned. Amendments or additional provisions should be drawn up in the appropriate form and conform to the subject matter of the draft. 
During the meeting, new amendments, additional provisions and repeals are not accepted, with the exception of editorial corrections, which are not discussed and voted on. These are submitted to the main committee which considered the draft. In some cases, substantiated amendments can be presented by a committee, but upon the recommendation of the proposer, their adoption may be postponed until the next sitting.

If the substantive amendments or additions are made to the draft, a further criminological examination is required.

\section{Seimas Adoption}

In order to adopt a law, the separate parts of the draft are voted upon. Unless the Seimas decides otherwise, draft chapters, divisions and articles are adopted in turn. Articles for which no proposals are made may be adopted without voting if there are no objections from any of the members of the Seimas. In other cases, each article, division, and chapter is voted on.

During proceedings for the adoption of the law, rejection proposals are not accepted. The draft is considered rejected if the votes required are not forthcoming. After discussion of all individual articles, the entire draft is voted on. If the law is not adopted, the Seimas may require draft initiators or the main committee to prepare a new draft.

During these proceedings, enforcement of the law and laws making consequential amendments or repeals of other laws or articles in them relating to the subject of the law are considered and adopted.

Before the law is submitted to the President of the Republic for signature, the Seimas Speaker, a committee or not less than one-fifth of all members of the Seimas have the right to apply to the Seimas by petition indicating their opinion that breaches of the Statute of the Seimas have occurred during passage of the law. This petition has to be submitted to the Commission of Ethics and Procedure which must report to the Seimas its findings and proposals within five days. The Seimas Speaker may not transmit the law to the President of the Republic for signing before the Commission report.

If the Commission of Ethics and Procedure concludes that the legislative procedure was seriously breached and influenced the decision of the Seimas, it must vote to decide on revoking or leaving the law is in force. If the Seimas decides that the law is revoked, consideration of the draft may begin from the stage where the violation occurred.

If a draft law is rejected at any stage of the discussion, it cannot be brought back earlier than six months after the rejection.

\section{Amendment of Laws}

Amendments and additions to the law in force may be made only by law. One law usually amends only a single law. If the law is concerned with making amendments to several other laws, they can be amended or supplemented by the one law. If more than half the articles of a law are amended, a new edition of the law is usually published or a new law drafted.

In Lithuania, there are no restriction on the right of those bodies with legislative power to supplement or amend the laws. The laws of wide application or great importance adopted before restoration of the Independence, i.e. the Criminal code, Civil code and other codes, are usually added to and amended several times during each session of the Seimas. 
All laws are drafted, discussed and adopted under the general order described, with the following exceptions:

- Extraordinary procedures for adopting amendments to the Constitution and of Constitutional laws.

- Procedures for the Seimas decide to discuss a draft of law urgently.

- The President of the Republic, the Seimas Speaker, the Board of the Seimas, the main committee, a faction of the government can propose this type of discussion by substantiated assignment. Applying the urgency procedure order reduces the time between the stages of discussing the draft although this cannot be shorter than one business day (the particular terms are fixed by the Seimas in each case).

- Special drafting and discussion procedure for the budget draft.

- Procedures for adopting the laws for ratifying international conventions are adopted by the majority of the members of the Seimas, subject to a vote of not less than two-fifths votes of all members of the Seimas.

- Procedures for adoption of a law for denunciation of a convention. This is considered to be adopted if voted for by no less than $3 / 5$ of all members of the Seimas.

- Procedures for ratifying an international convention which changes the borders of the Republic of Lithuania. This requires a vote by $4 / 5$ of all members of the Seimas.

- Where financial means required for a draft under discussion require that the state budget be corrected, the proposals of the draft initiative must be reviewed in terms of anticorruption. This evaluation is being carried out by the Law Institute of the Ministry of Justice ${ }^{28}$. The questionnaire is being used by experts when evaluating the draft in terms of anticorruption. However, this practice is in the process of being created.

\section{Coming into Force of Laws}

The laws adopted by the Seimas come into force when signed and officially announced by the President of the Republic unless another date is stipulated in the law. If, within ten days of receiving a law adopted by the Seimas, the President of the Republic does not sign or return it to the Seimas, it comes into force and is officially announced by the Seimas Speaker.

A law adopted by referendum comes into force when signed and officially announced by the President of the Republic. If the President of the Republic does not sign it within five days of receiving this law, it comes into force when signed and officially announced by the Seimas Speaker.

Official announcement of laws and other legal acts occurs when they are published in State News.

If the President of the Republic returns a law adopted to the Seimas for further consideration, the Seimas must decide, not later than the next sitting day, by voting, whether to reconsider the law or to treat it as not

28. Law Institute is the scientific research institution with a staff of 27 . Institute activities are: independent scientific researchers, execution of government programs and orders from particular foundations in the spheres of legal policy, crime prevention, economic and organised crime. 
adopted. If further discussion s decided upon the Seimas in the same sitting must fix the date of discussion. This discussion must take place within one week.

The Seimas may further discuss and adopt a law returned by the President of the Republic. Such a law is adopted if supported by the vote of over $1 / 2$ or, in the case of a Constitutional law, of over $3 / 5$ of all members of the Seimas. The President of the Republic must sign such a law within three days and announce it without it delay (Article 72 of the Constitution).

If the law without amendments is not adopted, a vote is taken on whether to adopt the law with all the amendments and additions proposed by the President. In this case, it is considered adopted if it supported by the votes of a majority of members of the Seimas participating in the sitting; a Constitutional law needs a majority of over the half of all members.

\subsection{Secondary Legislation}

The Constitution of the Republic of Lithuania lays down and delimits the general competence of the authorities exercising state power (the Seimas, the President of the Republic, the Government, the Court). Constitutional norms establish which types of legal acts may be adopted by these authorities in carrying out governmental functions in the area of their competence.

Neither laws nor other legal acts stipulate in detail which areas of state government should be regulated by primary and which by secondary legislation.

However, adoption of secondary legislation is regulated in detail in the regulations governing the activities of each authority exercising state power: the Seimas - Statute of the Seimas, the Government - Working Regulation of the Government, the President of the Republic — Law on the President, the Courts - Law on Courts, Statute of the Supreme Court, regulations of the ministries, departments and other state institutions.

In seeking to provide effective legal procedures, law drafters are necessarily obliged to evaluate the range of relations to be regulated by a particular draft. When sending it to the government or the Seimas, the explanatory document must indicate the impact of particular draft on the legal system and which secondary legal acts will be needed. It must also indicate who should draft them or provide outlines of those legal acts (as mentioned above).

To the extent of its competence the Government executes laws, resolutions of the Seimas on the execution of laws and decrees of the President of the Republic. During the process of execution it may find certain legal conflicts or inadequacies or public relations that are not regulated by legal acts. In these circumstances, the Government has the power to adopt secondary legal acts as well as to propose draft of new laws or other legal acts.

The Government is in general responsible to the Seimas for the general activities of the Government which are carried out according to the Government programme approved by the Seimas. The Government, not more than once a year, presents to the Seimas its account of the execution of the Government programme. Lithuanian ministers are responsible for their activities to the Seimas, the President of the Republic and directly subordinate to the Prime Minister. The Seimas, according to the competence prescribed by the Constitution, monitors the Government's activities, and may express lack of confidence in the Prime Minister. Under directions from the Seimas the Government or the separate ministers present accounts for their activities to the Seimas. 
Responsibility for the validity and truthfulness of the material in the resolutions of the Government or orders of the Prime Minister lies upon the minister who produced them, and the heads of Government institutions or other officials.

\section{Supervision of Secondary Legislation by the Constitutional Court}

The highest safeguards for the Constitution and Constitutional lawfulness are found in the court institutions - the Constitutional Court. According to the Constitution the Constitutional Court decides whether laws and other acts of the Seimas contradict the Constitution and whether legal acts of the President of the Republic and the Government contradict the Constitution and laws.

The legal force of a legal act is suspended when the Constitutional court adopts a decision to examine a request concerning conformity with the Constitution or laws. A legal act which the Constitutional court finds to contradict he Constitution ceases to apply from the day when the resolution of the Constitutional Court is officially announced. The resolutions of the Constitutional Court have power of a law and are binding on all state power institutions, courts, all enterprises, institutions and organisations, officials and citizens. All state institutions must revoke their secondary legal acts or provisions which are based on proven unconstitutional legal act.

The Constitutional Court between he date of establishment (in the Constitution of 1992) and 1 January 1997 has adopted 26 resolutions by which parts of particular laws were found to contradict the Constitution or other legal acts conflicted with the laws. 19 resolutions of the Constitutional Court found conformity of laws to the Constitution and of other legal acts to the laws.

The procedures for making secondary legislation are equivalent to those for primary legislation since all these legal acts are drafted by the same institutions. Procedures for the submission, registration, discussion and adoption of secondary legal acts are regulated by the Working Regulation of the Government and by similar regulations of other institutions of state power.

Requirements for structure and contents are prescribed by the Law on Drafting Procedure of Laws and other Legal Acts. In the main, they are comparable to the requirements set for laws.

The requirements about drafters of secondary legal acts are the same as those for drafters of laws.

\section{Adoption and Coming into Legal Force of Secondary Laws}

Resolutions of the Government are signed by the Prime Minister and the minister in charge of the particular area of government. If a resolution is concerned with several areas of government, it is signed by the Prime Minister and the minister who submitted the draft resolution. If such a draft was submitted by the Prime Minister, it is decided in the Government meeting who from the ministers will sign the resolution together with the Prime Minister.

Resolutions of the Government which amend or supplement previous resolutions are signed together by the Prime Minister and the minister who signed the previous resolution regardless of who submitted the new draft resolution for the government's discussion. Therefore resolutions which amend or supplement several (two or more) previous resolutions concerned with different areas of government are not permissible.

The Prime Minister or minister cannot refuse to sign the resolution adopted in the government meeting even if they voted against the resolution. If the Prime Minister does not agree with the terms set in a 
resolution adopted in his absence and does not sign it, the resolution must be submitted for further discussion at a meeting of the government.

These resolutions are signed within three business days after they are adopted unless the government prescribes another period.

Government resolutions are registered officially on the day of their signature and within two business days are sent to the Seimas, the President of the Republic, the Constitutional Court, the Supreme Court, the Ombudsman, and the executors - the ministries, government institutions and other addressees on the list provided by particular divisions of government office or advisors (consultants, reviewers).

Those resolutions of the Government which establish, amend or repeal legal norms come into force the day after they are signed by the Prime Minister or a particular minister and are announced in State News unless a later date is fixed in the resolution. Where necessary, resolutions of the government may be announced through other means of mass media.

Resolutions of the Seimas, decrees of the President of the Republic, resolutions of the Government, legal acts of the Bank of Lithuania, ministries, departments, Government institutions and other institutions of state government which do not establish, amend or repeal legal norms may be not announced in State News at the discretion of the persons who signed them. Whether or not they are announced in State News, these acts must be sent to the state institutions mentioned in them, and the affected enterprises, institutions and organisations, legal and natural persons.

Resolutions of the Government which do not establish, amend or repeal legal norms or orders of the Prime Minister come into force the day they are signed unless they fix another date.

Legal acts of the Bank of Lithuania, ministries, departments, Government institutions and other institutions of state governing which establish, amend or repeal legal norms come into force the day after they are announced in State News unless a later date is fixed in the legal acts. They have no legal force before they are announced.

\section{Specific Verifications of the Drafts and Instruments for Ex Ante Evaluation}

Specific verification of the drafts is not regulated legally in detail in Lithuania and is not a compulsory requirement for drafting of laws and other legal acts. The procedure of specific verification of the drafts is in development at the moment.

Some verification is necessary for the draft to meet general requirements: validity, lawfulness, clarity, forecasting of possible negative consequences, etc. Special verification of the draft is carried out in the course of preparing the opinion of the Legal Division of the Government Office on a draft registered with it, or during discussion of particular drafts in the main committee of the Seimas, or when preparing an opinion after a criminological examination conclusion or when evaluating a legal act from an anticorruption point of view.

The initiators of a specific draft, drafters or the bodies receiving it at every stage of drafting may initiate additional special verification. At the moment, there is no formal system for verifying drafts of legal acts. Law Institute specialist mainly carry out criminological examinations and evaluate legal acts from an anticorruption point of view. 
The clearest example of a special verification is the creation of a balanced system of penal and administrative impact measures established for the Criminal Code and Code of Administrative Offences, and which were carried out while drafting these codes. This project is carried out under the scientific programme "Criminality and Criminal Justice". One of the trends of this programme is to create the system of penal and civil measure of impact.

The aim of this research is to balance and give maximum effectiveness to the sanctions provided in Criminal and Administrative codes. All the following whole of methods are being implemented: axiology, expert evaluations, collection, systematising and processing of empirical data, comparative analysis of laws and legal informatics. This project is carried out by a working group of specialists at the Law Institute and the Institute of Mathematics and Informatics.

The main tasks completed by the group are:

- determining the main principles of comparative analysis of the norms of Criminal and Administrative codes;

- analysing sanctions of the Criminal code in force;

- classifying the articles of the draft Criminal Code according to a productive criterion;

- a partial analysis of legal norms of the Criminal and Administrative Codes;

- analysis and evaluation of the expert's questionnaire results;

- preliminary proposals derived from a scientific study relating to limits on the use of criminal sanctions.

This project will continue although the main proposals have already been submitted to the drafters of codes and responsible institutions.

In mid-May 1997, the National Crime Prevention Centre, an NGO, is going to be established by the initiative of UNDP and Law Institute. Examination and specific verification of drafts is going to be one of its functions.

\section{Use of Computer Technology}

Legal acts are drafted using computer technology. PCs and Windows 95 and Windows 3.11 are most popular in Lithuania and are used by the Seimas, the government and ministries offices in particular, most of which have computer networks. The network, servers, PC and Fax pro computers are used in the Ministry of Finance. Windows NT is installed in computers of this ministry. Drafting the stage budget uses UBAM created on the basis of Navision.

The majority of drafters compose their drafts directly on computers; some are assisted by secretaries. Almost every drafter of legal acts can work with a computer.

Programmes for searching of legal acts ("Litlex" or "Netscape") are broadly used by great majority of state institutions. These programmes renew there data-bases weekly; in the Seimas and the Government renewal is even quicker.

Program for searching of legal acts Litlex is created by the NGO Centre of Legal Information near the Ministry of Justice. It is very easy and convenient to use however the authenticity of legal acts can not be 
guaranteed. The program for searching legal acts Netscape is created in the structures of Seimas and texts of legal acts are being taken from the same sources as a State News which guarantees greater authenticity. Both programs could be used from the Internet.

Printing houses of the Seimas and government receive the texts of legal acts on the computer network on which they are sent immediately, along with drafts, after their registration as required by the relevant order.

\section{Publication of Legislation (Register of Legal Acts and State News)}

Legal acts are registered and systematised in the register of legal acts which is composite part of the State Register of the Republic of Lithuania. The Ministry of Justice is the founder and manager responsible for the register which is managed by the Centre of Legal Information near the Ministry of Justice. It includes the following:

- legal acts of the Republic of Lithuania, starting with the acts of 11 March 1991 relating to the restoration of the Independent State of Lithuania;

- legal acts in force from 15 June 1940 unamended by subsequent legal acts or repealed as of 11 March 1991;

- legal acts in force from 16 February 1918 until 15 June 1940 if their legal validity has been confirmed by current legal acts of the Republic of Lithuania.

The following legal acts must be registered in the register:

1. The Constitution;

2. Constitutional laws;

3. Laws of the Republic of Lithuania;

4. International conventions signed by the Republic of Lithuania;

5. Other legal acts adopted by the Seimas;

6. Decrees of the President of the Republic of Lithuania;

7. Resolutions of the Government of the Republic of Lithuania;

8. Resolutions, conclusions and other decisions of the Constitutional Court;

9. Legal acts issued by the Bank of Lithuania, ministries, departments and government institutions and other institutions of state government.

Register finances come from budget funds and from finances data users.

As mentioned above, the announcement of laws and other legal acts is made by publishing them in State News. The date of publication is the day of issue.

The following legal acts must be published in State News:

- Laws of the Republic of Lithuania.

- International conventions ratified by the Seimas 
- Presidential decrees;

- Government resolutions;

- Resolutions and opinions of the Constitutional Court and decisions to consider issues concerning the Constitution;

- Other legal acts adopted by the Seimas or by the Bank of Lithuania, ministries, departments and Governmental institutions as well as institutions of state government, which create, amend or repeal legal norms.

The institutional services of the Seimas, the Government, the Bank of Lithuania, ministries, departments and Governmental institutions as well as other services of state governing institutions must guarantee that the laws and other signed legal acts will be submitted to the editorial board of State News within three days after signature. Legal acts presented to the editorial board must already be edited; the editorial board does not provide editing services.

State News is normally published no more than twice a week (eight times per month), though if necessary it can be published more often. It can be published in other languages to announce the main legal acts adopted.

Where there is an immediate need, the laws of the Republic of Lithuania, other legal acts adopted by the Seimas, and presidential decrees can be announced in a special issue of the Seimas or central newspapers or through the Lithuanian Telegram Agency (ELTA). In this case, laws and other legal acts adopted by the Seimas come into force on the day they are announced or the day following but they must be published in State News at the earliest opportunity.

The Collection of Seimas Documents is being issued in which the laws, other legal acts of the Seimas, presidential decrees, resolutions of Constitutional Court are published, these are derived from the texts published in State News. This collection is drawn up and prepared for publication by the Documents Division of the Seimas. In the most recent volume, legal acts adopted through 21 February 1996 are published. Consolidation of the Republic of Lithuania is planned. 


\section{ANNEX 1. LITHUANIA: SEMINARS AND COURSES IN WHICH LAW DRAFTERS PARTICIPATED ${ }^{29}$}

- Law and Morals, 27 October 1996, organised by Lithuanian Lawyers society;

- Legal Reform in Lithuania and Central Europe, 23-24 February 1996, organised by the Homeland Union (Conservative Party of Lithuania);

- Personal Constitutional Rights in Lithuania, 5 March 1996 organised by Lithuanian Human Rights Centre and the Constitutional Court;

- Police and Society. Human Rights in Police Activities, 14-15 March 1996, international scientific conference;

- Series of seminars concerning legislation, May 1996;

- Legislation during the First Republic of Lithuania;

- Examination of the Object of Legal Regulation and Necessity of Legal Regulation;

- The Process of Legal Acts Drafting;

- Evaluation of Economic and Social Influence of Legal Acts;

- Evaluation of Conditions to Observe Legal Acts;

- Children's' Rights, 25-26 April 1996, organised by the Lithuanian Human Rights Association;

- Peculiarities of Organised Crime in Baltic States, 8-10 May 1996, international conference organised by the Seimas National Security Committee and international organisation;

- Europe 2000 ;

- Regulating Conflicts in Today's Society, 16-17 May 1996, international conference organised by Lithuanian Conflicts Prevention Centre and Vilnius Pedagogical University;

- Social Work with Prisoners and those Released from Prison, 30 May-2 June 1996, international conference organised by the International Council for Social Welfare (ISCW).

- At the second Congress of Lithuanian lawyers, the work was organised in four sections in June 1996:

1. Problems of Lithuanian legislation.

2. Private Law.

3. Criminal Law, Criminology, Criminal Procedure and criminal studies.

4. Professional ethics of a lawyer.

- Police in the Society during the Transition, 5-6 June 1996, seminar organised by the Council of Europe and Ministry of Internal Affairs;

- Lithuanian Way to European Union: the Role of Insurance Laws, 10 June 1996; conference organised by KPMG Cologne, Ministry of Finance and the Council of Insurance Affairs at the Ministry of Finances.

29. January-July 1996. 


\section{LAW DRAFTING AND REGULATORY MANAGEMENT — SLOVAKIA}

\section{Introduction}

The new concept of the legislative process has become a fundamental part of the political, economical and social changes experienced by Slovak society since 1989. This is evident not only in the creation of a pluralist political system and market economy, but also with the revitalisation of the civil society. Conceptual changes of the legislative process are closely bound with the qualitatively different understanding of the problems connected with basic rights and freedoms, as well as with the new task of legislation in a newly developing society.

The socialist legal system did not distinguish between public and private law. Private law was more or less suppressed, and a majority of legislative areas have characteristics of public law. The interest of the state was paramount and the interest of the individual was expressed through it. Progressively transforming these methods of legal regulation of social relations, transforming the basis to a private legal type and modifying the public legal type of adjustments of social relations has created one of the basic problems of legislation during the transformation.

The previous period was characterised by an overwhelming majority of secondary legislation. Nonetheless, as instruments of the highest legislative power, laws created the basis of the actual legal system, although in reality, much of the main influence of the obligatory rules of behaviour were transferred to secondary legislation. This situation contradicted the concept of the Rule of Law.

At present, the principles of the Rule of Law are significant because they influence the nature of legislation in this transformation period. Article 2 paragraph 3, Article 1 of the Constitution of the Slovak Republic (Constitution) defines it as a "democratic state governed by the rule of law" wherein "everybody is free to do anything that is not prohibited by law and nobody shall be forced to do something that is not imposed by law."

"Duties may be imposed only on the basis of law, within the limits of law, while respecting the basic rights and freedoms" (Article 13 paragraph 1). On the other hand, Article 2 paragraph 2 stipulates that "the state authorities shall act only on the basis of the Constitution and to the extent and in the manner stipulated by law."

New aspects include respect for the principles of checks and balances in legislation, as well as a judicial review of legislation undertaken primarily by the Constitutional Court (Constitution, part 7, Chapter 1)

Despite conceptual changes in the legislation where the context has changed, the legislative technique has not changed very much because prior legislative techniques were relatively sophisticated.

Legislation may be prepared on every level of government, from local bodies of state government to Parliament. The majority of bills and other regulatory instruments are prepared in the ministries and in other central bodies of state government. Article 87 paragraph 1 of the Constitution stipulates that expressis verbis bills can be introduced by the Committees of the National Council of the Slovak Republic, by the National Council Members and by the Cabinet. 


\section{Regulatory Framework}

The system of legal and non-legal instruments regulating law-making process in the Slovak Republic consists of the following.

\subsection{Basic Legal Instruments}

- Constitution of the Slovak Republic (No. 460/1992 Coll.) namely articles 68, 71 paragraphs 2, 72, 84, 86 items a,c,f, 87, 102 item n, 119 items a,b, 120, 123, 125, 132.

- Act of the National Council No. 350/1996 Coll. on the Rules of Procedure of the National Council of the Slovak Republic (part 10) and Act of National Council No. 1/1993 Coll. on the Collection of Laws of the Slovak Republic.

2.2. Law-making of local self-government and local state government is also regulated by the Act of the National Council of the Slovak Republic No.396/1990 Coll. on Municipal System with Amendments (Articles 6 and 11 paragraph 3 item g), and Act of the National Council No. 222/1996 Coll. on the Organisation of Local State Government and on Alternation and Amendments to Certain Acts (Article 3 paragraph 2) and Article 5 of the Act of the National Council of the Slovak Republic No. 295/1992 of the Coll. on Some Measures in the Local Self-government and Local State Government.

\subsection{Non-Legal Instruments}

- Legislative Law-Making Rules approved National Council Resolution No.519 of 18 December 1996 (No. 19/1997 Coll.).

- Legislative Rules of the Cabinet approved by Cabinet Resolution No. 241 of 8 April 1997.

- Ministry of Interior regulation No. 202/96/06237 from 22 January 1997 on Stating the Process of Issuing Generally Binding Regulations of Regional and District Authorities.

- Conception of the Approximation of Law of the Slovak Republic to the European Union Legislation and to the agreements of the Council of Europe approved Cabinet resolution No.70 of 1 February 1996.

- The Main Tasks of the National Council within Approximation of Law System Process for the Slovak Republic to the European Union Legislation and ensuring that it be within the Framework of the Chancellery of the National Council of the Slovak Republic, adopted by National Council Resolution No. 403 of 11 September 1996.

The Legislative Rules of the Law-Making of December 1996 and Legislative Rules of the Slovak Cabinet of April 1997, are non-law-making instruments frequently used by law drafters in their work.

Law-Making legislative rules of 1996 involve details about the system that are important for law drafting on "parliamentary ground", meaning proceedings are not arranged at the executive level although they do contain legislative-technical instruments such as legislative language, legal structure, title of the law, use of citations and abbreviations, derogation etc. These legislative rules also regulate the form and content of the amalgamating clause of a bill with EU legislation.

This situation causes some problems for those seeking to truly understand the level of legislation in Slovakia. The new Rules of Procedure which are the basis of the new concept of rulemaking, entered into effect on 1 January 1997. There is therefore no experience in their application. Until now, the system was applied in the old "socialist" manner, with amendments of the modified Rules of Procedure since 1989. 
Legislative Rules of the law-making mentioned above entered into effect at the same time, that is on 1 January 1997.

The Cabinet has created its own Legislation Council headed by a Deputy Prime Minister. This council is an advisory body to the cabinet and professional guarantor of governmental preparation of primary and secondary legislation. The New Rules of Procedure of the National Council of the Slovak Republic (e.g. Article 68 to Article 70) arrange the verification mechanism of particular standards as well.

\section{Regulatory Instruments ${ }^{30}$}

\subsection{Primary Legislation}

1. The Constitution (ústava) and its amendments (zmeny ústavy)

2. Constitutional statutes (ústavné zákony)

3. acts (zákony);

4. generally binding municipal regulations (vseobecne záväzné nariadenia) concerning the problems of territorial self-government (Article 68 of the Constitution) with local competence.

The primary legislation group also contains international treaties which do not require a specific law for their application (Constitutional Article 11) are therefore "directly applicable" treaties.

Currently, a serious theoretical and political dispute over whether the results of a referendum with the power of constitutional law, or the power of law, can become a part of primary legislation. Not only do politicians and members of parliament have different opinions on this question, but so do legal experts and theoreticians. The Constitutional Court may have to convey its position on this problem. At the same time, results of a local referendum with the power of legal instruments (See 4 above) can also be included into the primary legislation group.

Legal instruments introduced (1-3 above) are passed by the National Council of the Slovak Republic. Their validity depends on their promulgation in the Collection of Laws (Article 87 paragraph 5 of the Constitution.)

Legal instruments introduced ( 4 above) are passed by municipalities or cities in the framework of local self-government performance. The condition of validity of these instruments is to display generally binding regulations on the official notice-board (Article 6 paragraph 4 of the Act on Municipality System).

30. Slovak terminology varies significantly in naming regulatory instruments; no explicit translation is therefore possible. 


\subsection{Secondary Legislation ${ }^{31}$}

1. governmental regulations (governmental decrees, nariadenia vlády);

2. ordinances (vyhlásky) of ministries and other central bodies of state government;

3. sheets (vynosy) of ministries and other central bodies of state government;

4. generally binding regulations (vseobecne záväzné nariadenia) of the municipality issued in the framework of local state government performance (Article 71 paragraph 1 of the Constitution) with local competence;

5. generally binding ordinances (vseobecne záväzné vyhlásky) of regional authorities and district authorities with local competence.

Paragraph 120 of the Constitution gives the power to pass regulations (decrees) for implementing acts within legally defined limits (see 1 above). Secondary legislation of the Cabinet does not therefore need in each case special delegation by primary legislation. In some cases the Cabinet is delegated by a single law to pass regulations.

Generally binding instruments (see 2 and 3 above) are passed by ministries and other central bodies of state government as per Article 123 of the Constitution on the basis of laws and within their limits if they are empowered to do so by law. The limits can be set by a single law.

Legal instruments 1 and 2 above are valid when the full text is published in the Collection of Laws. Legal instruments ( 3 above) are valid upon their announcement in the Collection of Laws by published notice of ministerial or other central body of state government sheets. There are fewer addressees and as a rule these regulate less substantial or essential or technical affairs (announcements by the Ministry of Labour, Social Affairs and Family of the Slovak Republic No. 19/1995 Coll. on the edition of the sheet regulating the details on drawing and settling the premium paid by the state). Ministries and other central bodies of state government must ensure that the sheets issued are accessible for everybody everywhere introduced in the announcement from the day of proclamation.

Generally binding regulations (see 4 above) are passed by the municipality or the city within the framework of delegated performance of state government, which means not by the performance of local self-government introduced sub 4 . Of course these regulations can be passed by the municipality only on the basis of empowering by a single law and within its limits. The validity of these generally binding regulations of municipalities or cities is the same for regulations (see 4 in previous section).

District authorities and regional authorities may issue, within their function and on the bases of special law, generally binding ordinances (vseobecne záväzné vyhlásky) for their area (see 5 above). Article 123 of the Constitution and Article 3 paragraph 2 of the Act on the Organisation of Local State Administration gives Law-making power to these local government authorities. Their publication validates them in the same way; individuals and legal persons can read them within the region of local authority of state government. Otherwise, these generally binding ordinances are announced by publishing the notice about their issuing in the Journal of the Cabinet of the Slovak Republic.

31. Secondary legislation, from the Latin lex for law is appropriately connected only with law drafting and not with drafting legal instruments with lower legal power. 


\subsection{Non Law-Making Instruments}

Many directives not of legal character clearly influence the behaviour of individuals or legal persons by mandating or prohibiting actions; they are not obligatory and belong to the regulatory instruments group. These regulations are issued by state authorities or by public administration bodies and are therefore obligatory within the administrative or professional hierarchy, which means they influence the infrastructure. National Council Resolutions (uznesenia), decisions (rozhodnutia) of the President of the Republic, resolutions (uznesenia) of the Cabinet, measures (opatrenia) of the ministers, statutes (statúty), directives (smernice), methodical directions (metodické pokyny) etc. may be included among these. Inherently the instruments (see 2 below) also belong to non law-making instruments.

While it is impossible to provide a detailed categorisation of non law-making instruments, they may be classified as follows:

1. internal executive instruments which should give more detailed instruction for applying legal enactments;

2. business instructions which regulate internal working order in state government (the technology of working process), orders to write, archive, and destroy documents, etc.;

3. internal organisational instruments which determine organisational structure in detail and which set up internal organisational relations.

From the point of the relationship in law between primary (3.A) and secondary legislation (3.B) it is possible to state that laws must be in accordance with the Constitution and constitutional statutes. Cabinet regulations (decrees) or generally binding instruments passed by the ministries or other central state government bodies must be in accordance with the Constitution, constitutional statutes or other laws. Generally binding instruments passed by local self-governing bodies must be in accordance with the Constitution or other laws. Generally binding instruments passed by local state government authorities must be in accordance with the Constitution, other laws or other generally binding instruments. Legal enactments (3.A and 3.B) must be in accordance with international treaties promulgated as fixed by law. The Constitutional Court of the Slovak Republic has the power to make decisions about the accordance of the legal instruments.

\section{Drafting Personnel}

Ministries and other central governmental bodies have their own units of specialised law drafters who are engaged principally in the law-making process. The Chancellery of the President of the Republic, the Chancellery of the National Council, the Supreme Audit Office of the Republic, the Supreme Court of the Republic and the Office of the Public Prosecutors of the Republic also have created similar units.

There are approximately 140 officers in the ministries and 35 officers in other central governmental bodies whose main task is law-making. Certainly, they have to co-operate with public servants from other units of ministries and other central governmental bodies in law-making process. The majority of them have legal qualifications and they have several years practice.

The majority of the bills are prepared directly in the ministries and other central governmental bodies. Certainly, there are several acts which were made by contracted personnel from universities, Slovak Academy of Sciences and law consulting firms. Several acts were drafted in co-operation with 
international consultants, for instance the Act on Environmental Impact Assessment and Act on Public Attendance, etc.

The chairpersons responsible for ministerial legislative units usually take part in the policy making process of new legislation. There are no differences, in terms of personnel used, between drafting primary legislation and secondary legislation.

Law drafters are educated in the law schools; these now include several specialised courses on the theory of legislation. Experience shows that good performance in this area, in addition to the personal interest in the work also requires the connection between significant theoretical preparation and several years of practice. The meetings of law drafters organised every year by the Department of the Governmental Legislation of the Cabinet of the Slovak Republic contribute to a higher level of the legislative work.

Bills introduced by a committee or by a Member of Parliament to the National Council are drafted by single members of Parliament (more than ten percent of members of the National Council has a legal education) or by experts of members of Parliament or political groups. Law drafters from the ministries or other central bodies of the state government often help members of Parliament by drafting their "own" bills. Legal experts from the Chancellery of the Parliament are not obliged to draft the bills which the members or the committee of the Parliament intend to introduce. Naturally informal co-operation among members of Parliament and law drafters from the Chancellery of the National Council exists in drafting bills.

Improving the level of the law drafter requires paying attention to post-graduate specialisation. This educational process should be organised for university graduates as well as for law drafters with many years of practice. Law school graduates should have organised courses oriented to the work with legislative text (aims of future legal enactment to legal language).

Skilled experts should improve their comparative methods of work in connection to the approximation of the law with the EU legislation. Generally, improving their language ability by sending them to long-term language and professional training abroad to places where law drafting occurs.

\section{Drafting Procedures}

\subsection{Primary Legislation}

\section{Programming and Timetabling}

Programming and timetabling the process of primary legislation depends on a formal or informal agreement between Parliament and the Cabinet. The practice from the period prior to 1989 when Parliament adopted acts in accordance with the approved legislative program of the Slovak National Council has not acquitted itself well. Some bills are submitted by the Cabinet on the basis of Parliament's advice.

As the main bill drafter, the Cabinet works according to its own legislative program which is usually prepared for a 4-year functional period and which is specified in the legislative plans for a period of 1 year. This legislative work is based on the Governmental Program approval which is conditio sine qua non of a vote of confidence (Article 113, Constitution). Adoption of these legislative Government Programs by the Parliament clearly depends on composition of the political powers in the National Council whose 
members are informed about governmental legislative plans, namely the Committee on Constitutional and Legal Matters of the National Council.

In connection with the issues of primary legislation it is useful to repeat that bills may be introduced by the Committees and members of the National Council, and by the Cabinet of the Slovak Republic (Article 87 paragraph 1, Constitution).

The Cabinet may submit a bill to the parliamentary proceedings as a complex because Article 119 item a of the Constitution provides that the Cabinet shall decide collectively on bills. Only a member of the Cabinet presents a government bill in National Council proceedings. The Cabinet resolves which member will justify the bills in the National Council.

In the parliamentary committee, the government bill is justified by a member of Cabinet or head of a central body it empowers to do so. Another authorised person may do so only with the consent of the committee. (Where a bill has been introduced by a committee or a group of Members, the bill is substantiated by a duly authorised member, and in the case of a member's bill, the member introducing the bill gives the grounds).

\section{Law Drafting}

In the rulemaking process, a specific law drafter in the ministry or other central bodies of the state government is usually responsible for preparing or co-ordinating a particular bill (in co-operation with other organisational units within the ministry, and in other ministries, mostly the Ministry of Finance). This person regulates the process of bill drafting until its adoption by Parliament and verifies, together with the law drafter of the Office of the Cabinet and the law drafter of the Chancellery of the National Council of the Slovak Republic, the precise wording of the text of the law (Legislative Rules item 59, Annex No. 2). The law drafter in the Parliament is responsible for proof-reading in the Editorial Office of the Collection of Laws.

At every stage of the law-making process, the law drafter co-operates within "his/her" ministry, the Office of the Cabinet and often within the Chancellery of the National Council:

- experts of his/her ministry on the issue to be regulated by de lege ferenda concerning the concept, aims and means of the drafted legal instrument.

- economists of their home ministry and the Ministry of Finance about financing effects of the drafted legal instrument on the national budget, individual economic standing and that of legal persons.

- law drafters of the Office of the Cabinet and sometimes of the Chancellery of the Parliament on compliance with the Constitution and other acts, with international treaties and eventually with the EU legislation.

Drafts are not considered confidential by the Cabinet. The bill is viewed by a number of state and non-state authorities during the amendment procedure.

\section{Parliamentary Consideration}

The bill has to be delivered to members of Parliament within 15 days before the session of the National Council during which it is presented for first reading. Apart from exact wording the bill must include a justification comprising the evaluation of the current social, economic and legislative background and explain why the new enactment is necessary, its methods of implementation, and economic and financial 
impact, particularly upon the national budget, human resources and organisational structure, an analysis of other issues all of which are necessary for a general evaluation of its merits. This justification shall also include details of the compatibility of the bill with the Constitution, other laws, international treaties, and the EU legislation; this is explicitly stated in a clause confirming compatibility with EU legislation. In addition, the justification shall also give the reasons for the intent of each provision.

The law drafter is responsible for preparing the justification which is used as the explanatory instrument not only in the rulemaking process but also for implementing the act. Regarding the interface between Parliamentary amendments and the justification report, pertinent provisions of the Act on the Rules on Procedure provide that amendment proposals be exactly formulated and justified (Article 29 paragraphs 1, 78 and 79 paragraph 4 item d.). Article 96 paragraph 1 of the Act on the Rules on Procedure provides that "written justification of approved amendments shall be considered part of the bill and shall be used in interpreting or implementing the law". The justification report of the adopted act is not officially published. Justification of adopted amendments are archived in the Chancellery of the National Council where they are available for interested persons. Justifications of amendments moved during the session of the National Council are simultaneously published in the Minutes of the Proceedings (Official Journa).

New Rules of Procedure have substantially changed the legislative process in the National Council. The law discussion process was changed and divided into three readings, following general international practice, and most closely resembling the German Bundestag process. New Rules of Procedure have cancelled the submission of the proposal of the bill's principles.

The new enforceable Rules of Procedure determine several of the responsibilities of the law drafters (Article 67 to Article 69) of introducing the bill in the numbers of copies needed, and introducing the harmonisation of the law to the EU legislation in the justification report. Therefore, the "zero-reading" of a bill exists; if it fails to comply with the requirements prescribed by the Act on the Rules of Procedure or the Legislative Rules, the President of the National Council shall recommend to the introducer to correct its defects. In the event the introducer disagrees with such a recommendation, the President of the National Council shall present a recommendation together with the opinion of the introducer at the following session of the National Council, which shall decide on it without a debate.

Members of Parliament are practically free to propose amendments to the bill. Article 94 paragraph 2 of the Act on the Rules of Procedure stipulates the sole exception and provides that "in debate on the bill by which the existing law will be amended, no amendments extending the scope of the bill under consideration may be moved". When the introducer of the bill comes to the conclusion that the former bill is modified and no longer reflects the original idea, the bill can be withdrawn. In the third reading such a withdrawal will be possible only with the consent of the National Council.

If a bill has been introduced by a committee or by a Member, the necessary number of copies and the electronic form shall be provided by the Chancellery of the Parliament. The Legislative Department of the Chancellery prepares its position for the President of the National Council of the Slovak Republic (for the zero-reading) whether the bill fulfils the duties assessed by the Rules of Procedure and the Legislative Rules. The Legislative Department of the Chancellery of the National Council of the Slovak Republic shall prepare for the Members of Parliament the position for the second reading. The specialists from the Legislative Department of the Chancellery express their own positions mainly with regard to the compliance of the bill with the Constitution, constitutional statutes, international treaties binding on the Slovak Republic and the EU legislation. The staff of the chancellery also generally formulate concrete proposals for the amendments of certain enactments of the bill. This depends on the opinion and will of the members of Parliament as to whether or not they adopt these proposed changes. The law drafters of the Chancellery also verify the Clause of Compatibility of the Bill to the EU legislation. Chancellery 
experts prepare professional positions not only from the legislative but also from the economical and social point of view etc. regularly to the Bill on the National Budget. Bills are not reviewed in the Parliament merely by Chancellery staff; individual political clubs, individual members of Parliament have created expert groups. Members of Parliament usually also use informal help from ministry specialists.

Twelve law drafters work within the Legislative Department of the Chancellery of the National Council who are considered to be experts in particular law branches. The Legislative Department is divided into the Legislative Division and the Division of Approximation of Law.

The Legislative Division fulfils particularly these tasks:

- considers the bills from the stage of their initial stage and prepares positions on them concerning the compliance of the bill with the Constitution, constitutional statutes, the Act on the Rules of Procedure and the Legislative Rules;

- in co-operation with the secretary of the lead committee prepares the groundwork for the final discussion of the lead committee on the bill when needed;

- participates in discussions concerning the bill at the committee meetings;

- provides professional assistance to Common Rapporteur of the committees to the bill, after signature by the president of the National Council, the Prime-Minister and the President of the Slovak Republic, provides its issue in the Collection of Laws and participates in the proof-reading in the Editorial Office of the Collection of Laws;

- expresses its opinions on the legal questions of application addressed to the National Council and to its Chancellery;

- provides expert legal consultations to Chancellery departments.

The Division of the Approximation of Law fulfils these tasks:

- judges the compliance of bills with EU legislation, international agreements and treaties by which Slovak Republic is bound;

- judges the amalgamation clause with the EU legislation;

- co-operates with expert bodies from the European Community, Council of Europe; European Parliament, the Delegation of European Commission in Bratislava and foreign experts on approximation of law;

- if necessary, prepares short-term analyses connected with legal problems from the area of approximation of law.

The committees may also invite various specialists and other persons and request their expert opinions etc. to their meetings. The committees co-operate with the authorities of public administration and undertake Parliamentary investigations and the surveys and committee meetings outside Parliament.

According to the Article 87 paragraph 2 of the Constitution, the act shall be signed by the President of the National Council, the President of the Slovak Republic and by the Prime Minister. The President of the Republic has the right to return the law with comments to the Parliament. The National Council must reconsider this act and when it is passed, the law must be promulgated. The President of the Republic must return the act and submit comments whenever the Cabinet of the Slovak Republic so requires. As a rule, the President of the Republic returns the laws for reconsideration when it conflicts with the 
Constitution. Such a law has been on the program of the Constitutional Court several times. Discussion on a law returned by the President of the Republic to the National Council of the SR is regulated by Article 90 of the Act on the Rules of Procedure.

\section{Particular Legislation}

Article 87 of the Act on the Rules of Procedure of the National Council arranges the discussion concerning the Bill on the National Budget. At the same time provision Article 88 of the same law regulates Parliamentary discussion concerning an international treaty.

Amendment is done directly; the first sentence of the law precisely expresses which law is to be amended. It must be as transparent and clear as possible. Amendments of a different law by the provisions of a bill are not permissible without fully identifying the modified law. Then it is necessary to state the specific provisions that should be changed by the bill.

\section{Formalities}

Article 87 paragraph 5 of the Constitution unambiguously provides that any law shall enter into effect after promulgation. The Act on the Collection of Laws provides that the Constitution, constitutional statutes, laws, governmental regulations, ordinances and sheets of the ministries and other central bodies of the state government (all legal instruments specified in part 3.A.1. to A.3. and B.1. to B.3.), as well as some decisions of the Constitutional Court of the Slovak Republic and some international treaties become valid on the day they are promulgated in the Collection of Laws.

Legal instruments mentioned above come into force by the fifteenth day after promulgation in the Collection of Laws if there is no later date is stated for coming into force. For reasons of general urgent interest, legal instruments can exceptionally state an earlier date of coming into force, but not sooner then the date of publication in the Collection of Laws.

These legal instruments are published (promulgated) no later then 15 days from the date of delivering the text of the law signed by the Presidents of Parliament, of the Republic and by Prime Minister.

There are no cases in which primary legislation has not been brought into force.

\subsection{Secondary Legislation}

\section{Conferring the Authority to Make Secondary Legislation}

The Cabinet does not stipulate which matters should be dealt with by primary legislation and what may be left to be regulated by secondary legislation. The principle criteria are determined by the Constitution and as was already mentioned in connection with the principles of the Rule of Law (part 1) "everybody is free to do anything that is not prohibited by law and nobody shall be forced to do something that is not imposed by law" (Article 2 paragraph 3, Constitution). "Duties may be imposed only on the basis of law, within the limits of law,..." (Article 13 paragraph 1, Constitution). "Taxes and duties can be levied by and under the law" (Article 59, paragraph 2, Constitution), "...any restriction thereof /municipality/ may be imposed only by law" (Article 67, Constitution) and "the municipality may be delegated by law to exercise the powers of state administration" (Article 71, Constitution). 
However, "state authorities shall act only on the basis of the Constitution and to the extent and the manner which will be stipulated by law" (Article 2 paragraph 2). "The central and local government authorities shall be established by law" (Article 122), etc.

Paragraph 120 of the Constitution gives the Cabinet the power to pass regulations for implementing laws within limits defined by law. As was mentioned, secondary legislation of the cabinet does not requires special delegation by primary legislation in each case but in some cases, the cabinet is delegated by law to pass regulation. On the other side, "ministries and other governmental bodies shall, by and under the law and within its limits, pass generally binding regulations (ordinances, sheets and so on) provided they are empowered to do so by law" (Article 123 first sentence of the Constitution).

There are several possibilities for determining whether the delegation of a power to make secondary legislation is constitutional. (See 6). In addition, the Office of the Public Prosecutor (Act No. 314/1996 Coll.) has several opportunities to be vigilant about the constitutionality of delegation of power for making secondary legislation.

Parliamentary committees carry out how laws are observed and implemented, and whether the enactments issued for their implementation conform with the laws. If a committee finds that an enactment of implementation violates the law or is inconsistent with it or that no such legal instrument of implementation has been issued or delayed, it shall notify the appropriate member of the Cabinet, or the head of the appropriate central governmental body, and shall require immediate remedial action; if no remedial action is taken, the committee shall report to the National Council.

\section{Making Secondary Legislation}

Secondary legislation is regularly prepared in the course of the same drafting process as the primary legislation with which it is connected because if enactment for implementation is needed for the final act, the president of the Parliament may request the person introducing the bill to present its draft. A draft of the enactment of implementation shall be presented by the person introducing the bill whenever the bill and legal instrument of implementation are to come into effect concurrently.

Secondary legislation is prepared regularly by the same persons who drafted the primary legislation. The Cabinet has its own Legislative Rules approved in 1997.

Legislative Rules of the Slovak Cabinet react on the adoption of the new Act on the Rules of Procedure of the National Council of the Slovak Republic. At the same time, Rules of Procedure take over the verified methods of the law drafting at the executive level. It is assumed that Legislative Rules will unify formal-legal requirements of the draft of the enactments from the branch of secondary legislation and will unify discussion and adoption methods.

Only governmental regulations (as a part of secondary legislation) must be approved by the Cabinet. Article 119 item b of the Constitution regulates that the Cabinet "shall decide collectively on the governmental regulations".

Part 3.B mentioned that the draft of the secondary legal instruments becomes law by promulgation. 


\section{Procedures After Making Parliamentary Action}

Not all secondary legislation must be sent or reported to the Parliament. Some cases draft of secondary legislation may be presented to the Parliament (see above) and tasks of parliamentary committees in the relationship to secondary legislation are similarly mentioned earlier in this report.

The National Council has no specific power to initiate secondary legislation. There are checks and balances between legislative power and executive power in legislation. Secondary legislation in the political and legal system of the Slovak Republic is considered part of executive power which is why the Parliament does not deal particularly with a secondary legislation as it is first a matter of judicial power. Legislative Rules on Law Drafting may "serve" as example of secondary legislation passed by the Parliament but they are non-legal instruments.

The Constitutional Court has the principle task of a court review of the exercise of secondary law-making powers (see above very briefly.) These responsibilities are stipulated in articles 125, 130 to 132 of the Constitution and Act of the National Council of the Slovak Republic No. 38/1993 Coll. on the Structure of the Constitutional Court of the Slovak Republic, Proceedings Before It and the Status of Its Judges.

Secondary legislation is not used to regulate matters with significant policy content or that substantially affect the rights, duties or interest of the general public but rather with several principles of the Rules of Law, mentioned above.

\section{Specific Draft Verifications}

\subsection{Constitutional Compliance}

Compliance of the law with the Constitution and existing legal system is an organic part of the legislative process. It means the law drafter (or drafters) already at the beginning (by creating their basic ideas) take into account the compliance of the future law with the Constitution, other constitutional statutes and acts, that is with de lege lata as the whole.

Several "filters" verify the compliance of the bill with the Constitution and positive law. Every ministry and every central body of the state government has not only "branch", so-called "professional" departments (organisational units) but also a special department that take care of the legislative question. For a short reference the position and tasks of the legislative departments see part 4. These departments generally guarantee the constitutionality and other compliance of the bill.

The Ministry of Justice has the same position in the process of law drafting as other ministries have. But like the Ministries of the Interior, Finance and Labour, Social Affairs and Family, this ministry ensures the activity of the one of the professional commissions of the Legislative Council of the Cabinet. This commission evaluates drafts of enactments of secondary legislation in the branch of Civil law and Commercial law. The Ministry of Justice according to the Act No. 347/1990 Coll. on Organisation of Ministries and Other Central Bodies of State Government is the central body of the state government for courts and for prison service. It exercises state supervision (charge) to notaries and also represents the Slovak Republic before the European Commission for Human Rights and before the European Court for Human Rights. 
As was mentioned above, the bill can only be submitted by the Cabinet as a whole, except for members and committees of Parliament. For this reason, the Cabinet has created the Legislation Council of the Cabinet as its advisory body to consider every bill and draft of governmental regulation in detail before they are passed to the Cabinet. The Legislative Council has created several professional commissions: the Commission for Administrative Law, where drafts of governmental regulations and drafts of ordinances from the ministries are opposed in detail.

Members of Legislative Council are appointed and dismissed by the Cabinet on the basis of the proposal of the Vice-Prime Minister. They are the significant law drafters from ministries, law schools, the representatives of entrepreneurs, trade unions, financial institutions and from the Supreme Court and Office of the Public Prosecutors. They have legal education and a practice in their legal profession. The composition of the Legislative Council is relatively stable.

The Legislative Council is highly credible. Its opinions on the drafts of single legal enactments are generally adopted by the Cabinet. The Council meets prior to each session of the Cabinet. It judges the concept of the bill, its compliance with the Constitution and other laws, and with international treaties or EU legislation if necessary. At the same time, the Legislative Council evaluates the formal-legal character of the draft of the legal enactments.

The Department of the Governmental Legislation in the Office of the Cabinet prepares professional positions not only for the debate of the Legislative Council of the Cabinet but also for the negotiation of the Cabinet.

\subsection{Compliance with the Existing Legal System}

A similar situation applies when the bill is being discussed in Parliament. Specialists of the Legislative Department of the Chancellery of the National Council of the Slovak Republic prepare professional standpoints to the bill being prepared for second reading. Legislative specialists from the Chancellery of the Parliament take into account the questions discussed in this part of the report in their positions constitutional compliance with the existing legal system, etc.

The Law on the Rules of Procedure determines that the bill is always committed in the Second Reading to the Committee on Constitutional and Legal Matters of the National Council. This committee debates all bills on the basis of the Act on the Rules of Procedure, mainly with regard to their compatibility with the Constitution, constitutional statutes, international treaties binding on the Slovak Republic, laws of the Slovak Republic, and the EU legislation.

The Committee on Constitutional and Legal Matters of the Parliament in the interface with the other parliamentary committees has a position comparable with non-formal primus inter pares. It results among other things from the fact that each bill in the process of second reading has to be discussed by this committee (Article 74 paragraph 1 of the Act on the Rules of Procedure); here we must indicate that the Committee on Constitutional and Legal Matters has a special position regarding the explanation of the Rules of Procedure. The National Council may resolve "that the Chair should decide on any doubts regarding the procedure under this Act after an opinion has been submitted by the Committee on Constitutional and Legal Matters" (Article 146).

It is natural that as a new legal system is being created in transition countries, restricted time for passing bills and a certain polarisation of the society and political élites as well lead to several proposals to the Constitutional Court to pronounce non-compliance of some parts of laws with the Constitution of the 
Slovak Republic. The National Council adopted 365 acts from January 1, 1993 to December 31, 1996 of which 23 acts or their parts, were or are being submitted to the Constitutional Court to pronounce them in accord with the Constitution.

Contrary to past practice, the Rules of Procedure of the Parliament creates conditions for less hectic discussion concerning bills. The Act on the Rules of Procedure of the National Council also regulates particular "urgent legislative procedure". Under extraordinary circumstances, when fundamental human rights and freedoms, national security or economic prosperity may be in jeopardy, the Parliament may, at the request of the Cabinet, resolve to consider a bill under an urgent legislative procedure. Several restrictions of the Rules of Procedure in this case shall not apply (Article 89).

\subsection{Compliance with European Union Legislation and Case Law and 6.4. Compliance with International Obligations}

It should be said at the outset that the problems of the discussion concerning harmonising Slovak legislation to the EU legislation, that a three-level system of approximation of Slovak legal system with the EU legislation is being created at present.

The activity of ministries and other central bodies of the state government may be considered as the first level of law approximation. Separate ministries and other central bodies of the state government have created, in addition to the legislative departments mentioned above, departments or organisational units of European integration that co-operate in the corresponding section for the law approximation. These units can best judge the direction and scope and time necessary to harmonise the national legal provisions with the EU law, and eventually the conventions of the Council of Europe. Ministries and other central bodies of the state government prepare the bills and drafts of governmental regulations within the area of their competency and present them in the first stage to an intersectoral process of suggestions, then to the Legislative Council of the Cabinet and finally for negotiation in the Cabinet of the Slovak Republic. The presenter must include in a presentation report accompanying the proposal a brief commentary of the scope of the proposed legal provision approximated to a particular EU directive, and eventually to the Convention of the Council of Europe. The amalgamating clause will be signed by the corresponding Minister or head of other central body of state government.

The activities of the Institute for Approximation of Law - a highly specialised co-ordinating, methodological and documentary body - "created" a part of a second-level of law approximation. Its permanent obligation is to offer commentaries on the amalgamation clause to all presented legal proposals of the sections for the negotiation of the Legislative Council of the Cabinet. This institute fulfils other tasks: methodological control over the activity of the single sections co-ordinating it while co-operating with the Department of the European Integration of the Office of the Cabinet; preparing and implementing the Phare programmes and other programmes of foreign assistance when they concern the law approximation and are of rather universal nature; communicates with foreign institutions and their bodies.

The Cabinet also created the Council of the Cabinet for Integrating the Slovak Republic into the EU. This professional body discusses the key materials from the area of approximation of law before they enter the Cabinet meeting.

At the executive level, the process of approximation is finished by approval of the proposal of the legal instruments at the Cabinet negotiation. In the case of the approval of the draft of an act, principles, and eventually governmental resolution, the amalgamation clause is signed by the Prime Minister. The legal process of preparing acts is concluded by the debate and approval of the draft by the National Council 
presenting the third level in the sense of the material The Main Tasks of the National Council within the Process of Approximation of the Law System of the Slovak Republic to the European Union Legislation and Its Ensuring within the Framework of the Chancellery of the National Council of the Slovak Republic, as approved by NC SR resolution No. 403 of 11 September 1996.

One part of the process of discussing the bill involves having legislative specialists from the Division of Approximation of Law of the Chancellery of the NC SR check the correct data in the bill's amalgamating clause with the EU law. The obligation to submit the amalgamating clause to the bill is given by Article 68 paragraph 3 of the Act on the Rules of Procedure. Necessary data and the form of the clause are determined by the Legislative Rules of the Law-Making. The law drafter must determine whether the problems of the bill within the framework of EU legislation is adjusted or not, and must specify the precise EU legal enactment. The law drafter must determine whether the bill belongs to the group of high priority of law approximation stated in the Article 70 of the European Association Agreement, and if so must assign the name of the area, or whether it belongs to the priorities recommended in the document Preparation of the Associated Countries of Central and Eastern Europe for the Integration to the Internal Markets of EU, the White Paper. The third possibility is to take to account the proclamation of the law drafter that the bill does not belong to the priority group of law approximation stated in the Article 70 of the European Association Agreement or to the priorities recommended in the White Paper. The law drafter must express the level of compatibility of the bill to the EU legislation, which may be full, partial or not at all; in the two last cases, the law drafter must state the supposed date of reaching the harmonisation of the bill with EU legislation.

As was already stated, each bill is discussed in the Committee on Constitutional and Legal Matters of the National Council and is also assessed for compliance with EU legislation. This committee has created the Commission for the Approximation of the Legislation of the Slovak Republic to the EU Legislation, which deals with this problem, as is clear from its name.

Here it is appropriate to state that the Council of the Cabinet for Integration of the Slovak Republic to the European Community is a Cabinet advisory body whose members are state secretaries (in Slovak terminology, "deputy ministers") of ministries and deputy chairpersons of other central bodies of state government. The chairperson of the Cabinet Council for European Integration is Vice-Prime Minister. This Council has a similar position to the Legislative Council of the Cabinet.

The Commission for the Approximation of the Legislation of the Slovak Republic to the EU Legislation is a commission of the Committee on the Constitutional and Legal Matters of the Parliament (Article 61 of the Act on the Rules of Procedure of the National Council). Its members are the members of Parliament only. Parliament has created also the Committee of the National Council of the Slovak Republic for European Integration.

The Institute for Approximation of Law is a state budgetary organisation (legal body) affiliated to the category of budget of the Office of the Cabinet. Its director is appointed and dismissed by the Chairperson of the Office of the Cabinet. The Division of the Approximation of Law of the Chancellery of the Parliament is a part of the Legislative Department of the Chancellery of the National Council of the Slovak Republic. The staff of these state institutions are part of the Civil Service. Its employment conditions are regulated by the Labour Code. 


\subsection{Compliance with Legal Formalities}

Legislative Rules of the law drafting determine relatively precise requirements of legal formalities. These rules (enclosed) are obligatory for the law drafter: when the bill does not fulfil the duties determined by the Legislative Rules, the situation is the same as in item 5.A.20 of the questionnaire.

\subsection{Compliance with Administrative and Information Technology Demands}

The same relatively great attention is given to the bill's compliance with administrative and information technology demands. The justification (Article 68 paragraph 3 of the Act on the Rules of Procedure) must contain the necessity of new legal enactment also "the manner of implementation of the new enactment", "economical and financial impact on the national budget" and the claims of the new legal enactment for the human resources.

\subsection{Compliance with Environmental Standards}

The Act No. 127/1994 Coll. on Environmental Impact Assessment was adopted and assigns the obligations of evaluating separate drafts of the legal instruments from the perspective of their supposed impact on the environment. At the same time, this act is the basis for compliance of bill with environmental standards. It is a good example of Slovak and foreign "co-operation". Its basis is the Council Directive No. 85/337/EEC of 27 June 1985 on the Assessment of the Effects of Certain Public and Private Projects on the Environment. The preparation also involved the UNO Convention of European Economical Commission on the Evaluation of the Effects on the Environment out of the Borders (E/ECE/1250: Espoo, Finland, 25 February 1991) was taken into account. Some other foreign valid acts were taken as the basis for preparing this act: Holland, 1986; Norway, 1990; Germany, 1990, and it was also debated with Austrian specialists.

\subsection{Compliance with Textual Quality Standards}

Legislative Rules of law drafting require the law to be understandable, clear, succinct, precise in terminology and uniform. The drafting process must take care of language correctness, stylistic proportionality and general clarity (see Article 4 paragraphs 2. and 3. of the Legislative Rules). Empirical experience confirms that generally the "law language" is clear, although this clarity mostly depends on the character of the issue.

\subsection{Costs}

It was already stated that bills must include in its justification report an economic and financial analysis, and particularly the impact of the drafted legal enactment on the national budget. This issue is regulated not only in the Rules of Procedure of the National Council, but also in the Act No. 303/1995 Coll. on Budgetary Rules (Article 51). The law drafter must state in the justification report the result of the debate on the impact of the bill on the national and municipal budgets with the Ministry of Finance. Naturally this requirement holds in cases when a member or the committee of the Parliament acts as the law drafter. Where the Cabinet introduces the bill, this requirement is nearly almost fulfilled because the Minister of Finance is the member of Cabinet and the Cabinet adopts the bill as a whole. The absence of information 
concerning the result of the debate on the impact of the bill on the national and municipal budgets with the Ministry of Finance causes the bill not be set up for first reading in Parliament.

In this as in other cases, if the bill fails to comply with the requirements of the Act on the Rules of Procedure of the National Council or of the Legislative Rules, the President of the Parliament shall recommend to the person introducing the bill to correct its defects. If the person introducing the bill disagrees with this recommendation, the President of the National Council shall present a recommendation together with the opinion of the person introducing the bill at the following session of the National Council which shall decide on it without debate. In fact this "zero-reading" was already mentioned in part 5. (sub Parliamentary Consideration).

\subsection{Efficiency and 6.11 Practicability}

Law-making process in general and particularly in countries in the transition is a "never ending story". No formal assessment procedures exist for determining whether a proposed legislative scheme will achieve its objectives. There is some question of whether this is possible in societies with "hectic" development conditions which is why legal enactments are often subjected to amendments with unrealisable goals unable to perfectly judge all factors which influence the implementation of legal instruments.

\subsection{Implementation Assessment and 6.13. Controls of Consultation}

It was briefly mentioned above that justification of the bill has to describe how the new legal instrument will be implemented, its economic and financial impact on the national budget and the claims for human resources.

There are relatively large "interministries" amendment procedures to the bill. The introducer of the bill must introduce in the introductory report the result of amendment procedure. Certain constants of the amendment procedure are the effort to uniform opinions to the bill. There is an effort to resolve the contraversions within the bill earlier than in the Cabinet level.

As was mentioned above, the amendment procedure involves a relatively wide range of subjects. This is why the public is relatively well informed on legislature being prepared. The same was said in connection with advisory activity towards the members of Parliament.

\section{Instruments for Ex Ante Evaluation}

There are no formal instruments in use to assist in the ex ante evaluation of policy proposals for legislation. Legal theory experiments used computer models, simulation, etc. in the law-making process. Their results had no influence on the law-making process.

Certainly, ex ante evaluation is an organic part of law drafting process. For example, the Cabinet was discussing several documents of this kind before a final decision on the Bill on Territorial and Administrative Division of the Slovak Republic (Act No. 221/1996 Coll.), the Draft of Criterion of Territorial and Administrative Division in 1995. Similarly in co-operation with other ministries and other central state body the Ministry of the Interior has prepared the Analysis of the Public Administration 1995 (Complex Analysis of Personal, Space and Financial Impact of New Territorial Division on Local State Government Authorities and other State Authorities), of approximately 300 pages and other analytical 
documents before final decision of the Cabinet on the Bill on the Organisation of Local State Government (Act No. 222/1996 Coll.).

\section{Use of Computer Technology}

The Act of the National Council of the Slovak Republic No. 350/1996 Coll. on Rules of Procedure of the National Council of the Slovak Republic regulates that "a bill shall be presented in electronic form" (Article 67 paragraph 2). Article 9 paragraph 2 of the Legislative Rules of Law-making (No. 19/1997 Coll.) concretises "exchange format of text files ASCII a text code PC-Latin II" as mentioned "electronic form". One can presume that in the near future more developed forms of PC language will be used.

Personal computers are not used only for word-processing. Different electronic data bases of legislation in addition to the electronic systems of the Collection of Laws mentioned in part 9., the Collection of Court Decisions, the Financial Reporter, the Commercial (Official) Journal etc. are used relatively often.

The inevitable precondition of approximation of legislation and legal comparison is the use of computer technology. This is why the legislators have at this level at their disposal in the Parliamentary Library:

- CD-ROM databases: JUSTIS CELEX, JUSTIS European References, JUSTIS Official Journal, Federal Register, West Legal Directory, US Code Annotated, Statutory Instruments, etc.;

- hypertext systems: MEDIAL, FILIT etc.;

- databases accessible in the local automated network of acts passed in the National Council, the minutes proceedings etc.).

Greater use of computer technology in the law-making process tends to help to improve the legal system. The next stage of the computer technology expansion is to provide all law drafters with personal computers and appropriate software providing all necessary information at the same time. Unified Automated System of Legal Information is being created and should be accessible for law drafters in all stages of the law-making process.

\section{Publication of Legislation}

In connection with 5.A.37 of the questionnaire, promulgation of the act in the Collection of Laws is a condition of its validity and force. Act No. 1/1993 Coll. on the Collection of Laws stipulates that issuing the Collection of Laws is the responsibility of the Ministry of Justice. As was said, legal enactments are promulgated at least 15 days after giving the authorised text of the act or other legal instruments.

Only texts authorised by signatures that are for the individual kinds of legal enactments set up by the constitution or other acts can be accepted for publication in the Collection of Laws. In the case of acts, as already said in 5.A, these are signed by the Presidents of Parliament, of the Republic and the Prime Minister.

The Editorial Office of the Collection of Laws issues a yearly register that consists of:

- Part A. contains chronological register of legal enactments, international treaties, other legal and non-legal instruments published in that year; 
- Part B. contains subject register of legal enactments, international treaties, other legal and non-legal instruments published in that year: e.g. Attorneys, Bar Association, Taxes, District and Regional Authorities, Labour Law Relationship, Education, Environment.

The Ministry of Justice must ensure that every person interested in the Collection of Laws can receive if for a determined price. Municipalities must make the Collection of Laws accessible in each authority of its self-government for everybody interested. For this reason, every municipality is sent one copy of the Collection of Laws free of charge.

A private company prints and distributes the Collection of Laws. Other private companies issue electronic versions of the Collection of Laws. Naturally, an authentic official text is the one issued in the Collection of Laws and not in the electronic version.

Passed texts of the acts or other legal enactments like non-official texts are also published in newspapers and magazines, depending on their specialisation.

Several electronic database systems of legislation exist (e.g. JURIX, ASPI), and several systems of collection of legislation according to separate legal branches exist as well (e.g. commercial law, labour law), but it is necessary to state again that the only official "resource" of legislation is the Collection of Laws. It publishes on the basis of the decision of the President of the National Council the complete wording of the acts ("re-publication") when so empowered by law.

Bills are generally accessible because there is a relatively significant amendment procedure, including a number of state authorities, trade union bodies and "interest" organisations (e.g. the Association of Municipalities and Towns of Slovakia) in the rule-making process. The most important bills are also published by the daily newspapers. The bills submitted to the Parliament are free for the journalists. 


\section{LAW DRAFTING AND REGULATORY MANAGEMENT — SLOVENIA}

\section{Introduction}

Legislation is drafted by the state and by local communities; no mezzo-level (regions) has been established yet. Independence has brought two changes:

- the division of legislative competencies between republics and the federation has become obsolete; the state has assumed all legislative competencies;

- 147 local communities have been established and the principle issue regarding them is the division of competencies between them and the state.

Regulations stipulating drafting procedures and requirements are mostly contained in laws, establishing the state constitution and competencies of state institutions; however, practices for drafting legislation in use before the transition continue to be used. These rules were created by a long-established practice of drafting personnel involved in drafting procedures, and their application has been systematically controlled by mechanisms and institutions created for that purpose.

Creating an independent state and institutions has created structural and procedural changes in Parliament as well as changes in the structures and procedures of the government, including reorganisation of ministries. These are the principle changes since independence, which are also reflected in the drafting procedures.

Some dispersed and unco-ordinated attempts to codify the rules in the area have been made in order to facilitate wider access to them and to make the procedures more transparent.

Basic material requirements (i.e. what can and cannot be regulated by law, and the limits of regulation) as well as basic procedural requirements are set by the Constitution, which is in force since 23 December 1991 (Official Journal of the Republic of Slovenia, No. 33/91).

Other requirements are set by laws regulating state organisation and the execution of state powers, like Law on the State Council, Law on Administration, Law on Organisation and on Working areas of the Ministries, Law on Local Self Government and others (see Annex 1 for references).

Additional mainly procedural requirements are set by Standing Orders of the respective institutions (Parliament, i.e. State Assembly, State Council, government, some ministries, local communities, etc., see Annex 2).

The basic rules for drafting legislation are set by the Standing Orders of both Government and Parliament; apart from these, specific regulatory instruments do not exist. Of course there are some instructions, issued mainly by the Secretaries General of the different bodies, which contain some standardised forms. 
Some technical issues are also regulated by regulations of the Government and of the Minister of the Interior, especially with regard to treating and preparing documentation and documents.

Law drafters are obliged to follow procedural requirements and to know the subject matter they are about to regulate; in any case, procedural rules always provide for some degree of co-operation and verifying the drafting quality of the text.

Apart from rules set by the Standing Orders, a variety of professional standards (conventions) exists. These rules were recently (April 1997) selected and compiled with a view to codify them.

Both Government and Parliament have established bodies specifically charged with verifying that standards are being followed: Office for Legislation on the side of the Government, headed (until February 1997) by a minister without portfolio, and now by the director, and the Secretariat for Legislation and Legal Affairs in the Parliament. In addition to these, services of the Secretaries General take care that the procedural requirements are met.

\section{Regulatory Instruments}

There are several regulatory instruments and their division may be made upon different criteria. But essentially, one could distinguish between primary and secondary regulatory instruments. Primary instruments are:

- the Constitution;

- Acts of Parliament: State Assembly (laws, state budget and other budgetary acts, national programmes in the areas of social activities and economic infrastructure where specified by law, declarations, resolutions, recommendations, decrees, decisions and authentic, obligatory interpretations of laws);

- international treaties.

Secondary instruments are:

- Acts of Government. These include:

Regulation (uredba): legal instrument by which government regulates in greater detail and clarifies relations regulated by law or by other acts of Parliament. This must be done in accordance with the legally set purpose and criteria.

Another possibility for regulating by regulation exists where, pursuant to such authorisation under the law, the Government may also regulate how citizens exercise their rights and obligations.

Decrees (odlok) serve to regulate individual questions or to adopt individual measures of general importance, and to adopt other decisions, for which it is stipulated by law or by regulation that they shall be regulated by a decree.

Standing Orders (poslovnik) regulate internal governmental relations and manner of work.

Resolutions (sklep) exist in principle for the same purpose as the Standing Orders, but in practice, are used to regulate individual situations 
At the same time, resolutions may be used in cases where the Government neither makes a decision nor adopts another act.

Decisions (odloèba) serve in administrative matters within the government's competency and when deciding on other specific matters, in matters of appointments and dismissals.

(Article 26 of the Law on Government - LOG)

Acts of Ministers:

Regulations (pravilniki), decrees (odredbe) and instructions (navodila) are issued for implementation of laws, other regulations and acts of the Parliament and acts of the Government.

Regulations are used to elaborate individual provisions of a law, regulation or act for the purpose of its implementation.

Decrees serve to determine measures of general importance.

Instructions serve the implementation of individual provisions of a law, regulation or act and prescribe the manner of their realisation.

Decisions and conclusions may be issued by ministers and heads of departments within ministries, when deciding on administrative matters.

(Article 99 and Article 100 of the Law on Organisation and on Working Areas of the Ministries LOAM)

Relationship between different types of regulatory instruments may best be seen through an analysis of the relevant provisions of the Constitution and of the Law on Constitutional Court.

The Constitution stipulates (Part 7, Constitutionality and Legality, Article 153 on Conformity of Legal Acts) that laws, secondary legislative acts and other regulations must conform with its provisions. Laws must further conform with generally applicable principles of international law and with applicable international agreements, ratified by Parliament, while secondary legislative acts and other regulations must also conform with other ratified international agreements.

Regulations and other legislative measures must conform with the Constitution and with the laws.

Individual acts and individual activities of State bodies, local government bodies and holders of public authority must be founded in law or in other legal acts.

The Law on Constitutional Court (Article 21) provides that the Constitutional Court shall decide, among other issues, on the conformity of the laws with the Constitution, on the conformity of laws and other regulations with ratified international treaties and general principles of international law, on conformity of local community regulations with the Constitution and laws, on conformity of general acts issued for the exercise of public authority with the Constitution, the laws and secondary legislation.

When deciding on these matters, the Constitutional Court shall also decide on the constitutionality and legality of procedures in which these acts were adopted. 
The Constitutional Court may also be called upon (upon proposal of the President of the Republic, the Government or one third of all members of Parliament) to give its opinion in the procedure of ratifying international treaties on their conformity with the Constitution.

Article 8 of the Constitution stipulates that laws and other legal acts must comply with generally applicable principles of international law and with international treaties which bind Slovenia. Ratified and published international treaties shall be directly applicable.

The Government has no general or inherent power to make secondary legislation.

Primary legislation may only be made by the Parliament, while secondary legislation may be made by the government; it is an open question of where in the hierarchy of norms acts of local communities should be put.

With regard to secondary legislation, the role of the government is to head, direct and co-ordinate the implementation of national policy determined by the Parliament and to ensure the implementation of laws, other regulations and general acts of Parliament by adopting and proposing political, legal, economic, financial, organisational and other measures necessary for the execution of tasks within the competency of the state in individual areas.

To this end, the Government proposes to the Parliament the adoption of laws, other regulations and general acts, and the formulation of policy for individual areas of social life.

\section{(Articles 3 and 4 of the $L O G$ )}

\section{Drafting Personnel}

Ministries have their own units, or their own drafting staff, and ministry legal officers undertake drafting as one of their functions. However, the situation varies from ministry to ministry. The central drafting the Office for Legislation - exist but it does the drafting itself by special decision of the Government only if there are no other competent ministries in the area.

There is no specific post of a law drafter, although some job descriptions require this kind of experience.

Typical qualifications for those who undertake law drafting would be a university degree (a diploma, not necessarily a law degree), the rest of training is done on the job or in seminars and other in-service activities. Unfortunately, there is no statistical information on this issue; a rough estimation would be that approximately 30-50 people regularly undertake law drafting.

Law drafting is also undertaken by consultants, both local and international, and by contracted personnel. The competent minister decides on the use of external drafting personnel. Outside experts are mainly used if specific knowledge or expertise which does not or does not yet exist in the ministry is required, or when there is a need to involve an external expert because of lack of time or personnel in the ministry etc. The costs are borne by the budget of the ministry, which ultimately means by the state budget (due to the principle of integrity of the budget).

No specific law drafting training exists for the time being, but there were some attempts to establish a system of training at least in the form of seminars or specialised workshops. 
It is common that more than one law drafter is involved in drafting particular legislation. It is also the policy that the same personnel engaged in drafting the primary legislation are involved in drafting secondary legislation, together with other specialists. The composition of working groups depends on subject matter, but are mainly people with an economics background (or other specialists) and lawyers. One third of the personnel is likely to have legal qualifications, but this varies depending on subject matter.

Quality standards are monitored within the ministry and externally. Internally, monitoring is done by checking and discussing the draft, externally by committees (preparatory work for the sessions of the government) and by a specialised office. Law drafters are also called upon to explain and clarify their draft legislation before parliamentary and similar commissions.

In principle, government draftsmen work and assist the government while the Parliamentary draftsmen work and assist the Parliament.

Nevertheless, the Law on Government as well as the Standing Orders of the Government stipulate that the government must co-operate in the work of the Parliament and its working bodies on adopting bills and other regulations which the government itself proposes, as well as to have the right to give an opinion on a bill or other regulation which it has not proposed itself.

Of course, there are differences between drafting primary and secondary legislation. While primary legislation has to comply with different, primarily substantive requirements, secondary legislation is often considered to be a matter of feasibility, technicalities have to be observed and practical questions take precedence over questions of principle. Therefore, personnel with specific knowledge, namely with organisational, managerial, technical and other skills would normally be included in the preparation of secondary legislation.

\section{Drafting Procedures}

\section{Programming and Timetabling}

The Government agrees upon a formal programme for bills that are to be considered in forthcoming sessions of Parliament. An annual work programme is compiled, consisting of legislative and substantive parts, further elaborated by periodic trimestrial work programmes. These programmes are agreed upon once a year (they have to be compiled by the end of December for the following year). Amendments to the annual work programme and to the periodic work programmes must be submitted at least 15 days before the scheduled day for completing the task by the annual and periodic work programmes.

With regard to the level at which the decision to initiate a new legislative project is taken, two common situations can be distinguished:

- where, according to its work programme and policy, a ministry initiates and prepares a new legislative project and submits it for approval to the Government;

- where the Government, following mostly its policy and established need to regulate certain questions or areas, decides to regulate and entrust a ministry with the task of preparing a legislative project.

Policy objectives are ordinarily approved and confirmed only upon submission of an already drafted legislative project to the government, although it is a practice, especially in situations where the 
government entrusts the ministry with preparing a concrete legislative project, to set the guidelines and establish the policy objectives to be followed.

The government collectively determines its priorities with respect to new legislative projects by its legislative programmes; legislative projects are then submitted to the permanent or ad hoc working committees of the government and finally to the government itself.

Permanent working committees of the government and services of the Secretariat General compare policy objectives and the final draft. Inconsistencies and digressions from the policy objectives have to be specifically laid out and grounds therefore have to be given. The government makes the final comparison and evaluation.

Timetables for preparing ills are given by work programmes of the government; they are managed by individual ministries and monitored by services of the Secretariat General. Each year, a report on the work of the government is compiled, which also comprises the analysis of the extent to which the work programme has been accomplished.

Each bill requires the approval of the relevant minister upon its completion. Bills must be prepared in accordance with the Standing Orders of the Parliament which stipulate that a bill must contain the title, an introduction, the text and an explanation.

The introduction includes an evaluation of the current situation, reasons for adopting the bill, its goals and principles, an estimation of the financial means from the state budget required for implementation and other consequences entailed therein.

The text of a bill contains legal provisions, which are again explained in the explanation, briefly.

\section{(Article 175 of the Standing Orders of the Parliament - SOP)}

Standing Orders of the Government stipulate that all material submitted to it or to its working committees must be accompanied with documentation containing all relevant data and information needed for informed decision making. Materials consisting of more than twenty pages must be accompanied by a summary.

The government informs the ministries and the services of the Government as well as the Parliament about its annual and periodic work programmes

Materials are submitted to the Parliament through the Secretary General, together with a proposal to Parliament to initiate the discussion procedure. Parliament is further informed about representatives of the government who will participate in its work and in its working committees.

Regarding Parliament, on the basis of the work programme and after consultation with his collegium, the President of the Parliament includes individual questions on the order of business of sessions of the Parliament and determines parent committees for debating individual items on the order of business. 


\section{(Article 107 of SOP)}

Working bodies formulate and mutually co-ordinate their programmes in accordance with the work programme of the Parliament.

The government is responsible for the actual introduction of the bill to the Parliament. On a case by case basis and depending on the agenda of the session of the Parliament, it appoints its representatives (ministers, state secretaries or senior civil servants) to represent it and to give expert opinions and other information. Law drafters assist government representatives in the Parliament, even though they do not have the right to represent the government.

\section{Law Drafting}

Policy making and law drafting are in principle separate activities but they are often done simultaneously. Law drafting requires specialisation and technical skills, while policy making is reserved for ministers and senior civil servants, which results in the definition of steps to be taken: drafting normally starts only after policy objectives have been determined but an existing piece of legislation can also serve as a basis for discussing and preparing a bill.

Requirements of the policy makers are communicated to law drafters in working groups and in direct or indirect contacts, which may be formally or informally established.

In principle, a law drafter has complete control over legal issues related to the solutions contained in the draft, namely questions of constitutional compliance of the draft and its legality as well as the observance of procedural and stylistic requirements. First of all, after having received the necessary indications of the objectives to be followed, a law drafter would normally analyse the existing legislation (i.e. study and research the existing legal framework from the perspective of constitutional requirements through requirements, set by law and finally the practice of the courts and administration), design the first draft containing main solutions, describe their general implications, seek the approval of the policy makers and then transpose the given objectives into legal language and format, ending with a scrutiny of the draft by policy makers and law drafters and other relevant profiles of the staff.

Personnel from more than one ministry are very often involved in policy making since all important drafts substantively affect working areas of different ministries. Therefore, various forms of co-operation between ministries exist. Such consultations can be deemed to be a standard procedure conducted on the initiative of the ministry primarily or predominantly responsible for the draft, which calls upon other interested ministries to express their opinion on a prepared draft or to nominate representatives of various ministries into a working group, charged with preparing a draft.

Outside advisers are more often used in law drafting stages (especially initial ones) than in policy making. Decision on whether or not to include outside advisors depends largely on the judgement of the relevant ministry which depends in turn on various factors, from financial to political.

In principle, the ministry which undertakes law drafting must carry out the necessary consultations with the affected public interest, to ensure its acceptability to the Parliament and its members and to eliminate any possible contradiction and clarify eventual outstanding issues.

Comments on drafts are primarily sought from colleagues within the ministry and other ministries or Government Office for Legislation, especially on matters of legality of solutions proposed in the draft. A time frame is set by Standing Orders only for the interministerial relations and in the relation ministry - 
Office for Legislation. Otherwise, the time frame is set by work programmes but is binding upon ministries that have to ensure the proper and timely preparation of drafts, and therefore must choose the appropriate form and decide on how to ensure the timely co-operation of other ministries.

It is normal that ministerial law drafters are responsible for the bill until its adoption in the Parliament. Therefore, a law drafter would normally also be responsible for proof-reading the bill but with an important distinction: as soon as a bill is submitted to the Parliament, it is considered to be Parliament's responsibility. Nevertheless, law drafters are informed about procedures and changes and are normally also responsible for interpreting the bill once it has become law.

The work of the government is public. Publicity is regularly assured by informing the public by press conferences and official communications. In some cases, according to the law, it may be decided that individual data or materials or certain decisions constitute official secrets and that the public has no access to them or that they will become public only after a certain lapse of time.

\section{Parliamentary Consideration}

A bill can be studied by MPs at least 30 days before its first Parliamentary consideration, according to Article 177 of the SOP (President of the Parliament shall send a bill to members of Parliament not later than 30 days before the day of the session at which the Parliament is convened to consider it).

Article 175 of the SOP stipulates that a bill must contain a title, an introduction, the text and an explanation.

The introduction includes the evaluation of the current situation, reasons for adopting a bill, its goals and principles, an estimation of the financial means required of the state budget for its implementation and other consequences entailed therein.

The text of a bill contains legal provisions, which are again briefly explained in the explanation.

If an amendment is being proposed, then the bill must include the text of those provisions of the law for which amendments are being proposed.

The full text of bills are published in the Herald of the Parliament (Poroèevalec), that can be obtained by anybody.

Three readings or phases of the parliamentary legislative procedure exist.

Every bill is considered by at least one parliamentary committee (parent committee), but other committees may express their interest in being involved in the consideration of a particular bill (interested working body).

Article 178 of the SOP stipulates that the President of the Parliament designates the parent committee to participate in the consideration of a bill and to prepare a report thereon to Parliament.

When a bill contains provisions which require funds from the state budget, the President of the Parliament assigns it for debate to the working body competent for financial matters which presents an opinion on those amendments which have financial consequences for the state budget. This working body may present its report on the financial consequences of a bill or amendment directly to the Parliament. 
When a bill also regulates the rights of national communities, the Commission for National Communities may report directly to the Parliament on relevant provisions.

An amendment may be proposed by at least ten members of Parliament, a group of members of Parliament or the parent committee up until the end of the debate on an individual article, or up until the end of the debate on an individual chapter of a bill.

Article 190 of the SOP stipulates that during the second reading of a bill, deputies, the parent committee (also in the report on the bill) an interested working body and the proposer may submit amendments proposing changes and supplements to the bill.

Amendments must be submitted to members of Parliament 15 days before the day determined for the Parliamentary session at which the bill for which amendments have been submitted will be considered.

The amendment must be submitted in writing and must be explained. Its proposer may also explain the contents and objectives of the amendment orally at the session.

A representative of the proposer of the bill or of the government may propose amendments up until the end of the debate on each individual article, or up until the end of the debate on an individual chapter of a bill and only to those articles for which amendments were proposed within the time limits prescribed. Amendments may also be proposed for those articles which need to be changed due to the interdependence of individual provisions with respect to amendments submitted for other articles of the bill.

Before voting in the Parliament, the parent committee presents its opinion on a proposed amendment, if it is requested to do so by the majority of members of the committee or by the Parliament. The Secretariat for Legislation and Legal Affairs may also present its opinion on an amendment.

If a proposed amendment necessitates a change, an addition or a deletion of another article or of individual provisions of the bill, the other related amendments shall be debated and decided upon immediately after the amendment is adopted.

If, during the second reading, no amendments were adopted to the text of the bill or only amendments of editorial nature in the opinion of the Secretariat for Legislation and Legal Affairs are proposed, the Parliament may, at the same session, continue on to the third reading of the bill. In this case, amendments may be submitted up until the conclusion of the debate on an article which may be amended.

If amendments to the text of the bill are adopted during the second reading, the third reading may be conducted after at least seven days from the day when members of Parliament received the text of the bill with adopted amendments.

For the third reading of the bill, the Secretariat for Legislation and Legal Affairs prepares the complete text of the bill with adopted amendments and with an explanation of changes in the wording of articles submitted for the second reading.

The Parliament may assign this task to the proposer of the bill. 


\section{(Articles 191-195 of the SOP)}

Officials of the drafting ministry (in particular, law drafters) follow the progress of the bill in the Parliament.

This progress is normally followed by senior staff from ministries, including law drafters for essentially two reasons: to be kept informed on changes made to the bill, and to have the opportunity to intervene where necessary because they will also be responsible for implementing the law. Knowing the historical development of a law is thus necessary for correctly implementing and interpreting the law.

A ministry can draft the necessary amendments itself, but these have to be submitted to the government for its approval. In principle, ministries cannot communicate directly with the Parliament.

If adoption of an amendment is proposed, the Secretary General sends it to the ministry with a deadline for preparing an opinion on the amendment to be submitted to the government.

\section{(Article 72 of the SOP)}

In order to perform expert, administrative and other activities and technical tasks to ensure the conditions for the work of the Parliament, the Parliament has different services (e.g. the Secretariat for Legislation and Legal Affairs is established for legal formulation of bills and other regulations and for delivering opinions on their conformity with the Constitution and with the legal system).

The organisation and work of the services of the Parliament are regulated by a decree of Parliament.

The Parliament examines the bill clause by clause (debate article by article) in the second reading. When the Parliament concludes the debate on an individual clause, members vote on it. At the end of the debate members vote on the title of the bill.

The second reading of a bill may as well be conducted as a general debate on the proposed bill at the proposal of the parent committee, a member of Parliament group or at least ten members of Parliament.

In addition, during the second reading of a bill, Parliament may decide to change the order of the debate and the voting on individual articles of the bill, to combine the debate and the voting on several articles, to conduct the debate and the voting by chapter, to debate and to vote separately on individual parts of articles of the bill, or to vote jointly on several chapters or on the bill as a whole.

Such a resolution cannot be adopted if at least one third of the members of Parliament oppose it nor can it be resolved to debate and vote on a bill as a whole if amendments to it have been submitted within the time limits prescribed.

The Parliament can also (through its working bodies) take evidence from officials, experts or members of the public when considering a bill.

Strictly speaking, there is no procedure by which the Parliament or its political groups could consider and comment upon the form, structure or drafting of a bill before it is formally introduced into the Parliament. Nevertheless, in implementing its steering and supervisory tasks, a working body of the Parliament in particular is responsible for determining the situation in an individual area, examines the legitimacy of interests of various groups of citizens attached to it, ascertains the suitability of legislation, in particular that of legislative arrangements in this area, with respect to processes in the rest of the world, examines 
the effectiveness of the implementation of laws that have been adopted, proposes policies, and monitors their implementation in its area of work.

\section{(Article 140 of the SOP)}

A working body may also request (from the government, from other state bodies, from public institutions and funds), information and individual documents which are important for formulating policy and laws, or for determining the effectiveness of their implementation. Such a request must specify the time limit within which it shall be necessary to respond and to submit the requested information and documents.

\section{(Article 141 of the SOP)}

Some other possibilities also exist. A working body may propose that expert or analytical and research specialists conduct a survey or other kind of research or expert work.

In order to acquire information, a working body may also organise public hearings to which it may invite members of the government, representatives of various interests, experts or other persons whom it considers capable of providing useful information. A working body shall be obliged to do this if at least one-quarter of its members so request. The announcement of the public hearing shall be published in the media so that interested individuals may participate.

When preparing a public hearing, a working body must inform those invited of the issues that are the subject of the public presentation in advance. The working body may also ask them to prepare their opinions in writing. The order of business for a public hearing is determined at a session of the working body.

A parent committee may invite external experts and representatives of the interested public to its sessions when particular bills and wider-ranging questions are deliberated.

Experts and representatives of the interested public may explain their views and opinions, but may not participate in the decision making.

\section{(Article 157 of the SOP)}

According to the Constitution (Article 88, Initiatives to propose adoption of Laws) legislation may be introduced to the Parliament by the government, by individual members of Parliament or by no fewer than five thousand voters.

Almost the same provision is contained in Article 174 of the SOP, with an additional possibility for the State Council to propose the adoption of a law as well.

Drafting such legislation is responsibility of the proposer.

Apart from the general possibility of the government to express itself on any law introduced into the Parliament, SOP also has a provision to avoid duplication or competition among bills. Thus the President of the Parliament withholds the allocation of a bill if the legislative procedure for another bill with identical or similar content is not yet completed.

The Constitution (Article 91, second paragraph, Proclamation of Laws) stipulates that the State Council may require Parliament reconsider any bill within seven days of its being adopted and prior to its proclamation. On its reconsideration, the same bill shall be deemed adopted if a majority of all members 
of Parliament votes in favour of it, save where the Constitution requires a greater number of votes for adoption. Any such reconsideration by the Parliament is final.

A bill is then proclaimed by the President of the Republic no later than eight days after its adoption, which is considered a formality.

SOP stipulates that when the Parliament reconsiders a bill at the request of the State Council and before the official proclamation of the law, the President of the Parliament sends the request of the State Council to the parent committee, which delivers an opinion on the content of the request submitted.

The Parliament votes on reconsideration at its next session. A representative of the State Council may explain the request of the State Council before the vote. The proposer of the bill and the government, if the government itself is not the proposer of the bill, may explain their opinion before voting. A rapporteur of the parent committee presents the opinion of the working body before voting.

\section{(Articles 205-207 of the SOP)}

\section{Particular Legislation}

Special provisions and procedures for adopting the state budget exist, but no special provisions exist for tax legislation. Procedures vary in that that every bill is assigned to its parent committee while all the committees have a say in the preparation of budget.

The government must submit the proposal of the state budget no later than October 1 of the current year. A part of the budgetary debate is also the budgetary memorandum, which is an act of the government in which the government sets out the basic goals and tasks of its economic, social and budgetary policy and the overall framework for public financing in the following year. The budgetary memorandum also contains the overall goals of public finance policy for the following year as a basis for the composition of the state budget.

The proposal of the state budget is sent to all chairpersons of working bodies and to all members of Parliament (which is different from the situation for 'ordinary' bills that are assigned to one parent committee), together with the budgetary memorandum and the notification of the convening of the session at which the Parliament will conduct a general debate on the proposed state budget.

When the proposed state budget is submitted at a session of the Parliament, the Prime Minister and the Minister of Finance shall present the budgetary memorandum and the proposed state budget. No debate follows this presentation.

Chairpersons of working bodies may convene sessions within 25 days of the submission of the state budget proposal at which representatives of the government explain the state budget proposal. After this, the Parliament conducts the general debate on the proposed state budget no later than seven days after expiration of the 25-day time limit.

Upon conclusion of the general debate, Parliament decides either to continue the procedure to adopt the state budget or not; in the latter case, it sets a time limit within which the government must prepare a new proposal of the state budget.

Amendments may be submitted within 15 days of the conclusion of the general debate. All proposers of amendments must take into consideration the rule concerning the balance between budget revenues and 
expenditures. Working bodies form their opinions on submitted amendments within ten additional days and send a report containing the opinions, views, opinions on amendments, and amendments of the working body to the parent committee.

The role of the government is to take position on all submitted amendments and on this basis of this position, the latest analyses of economic trends and the implementation of the state budget for the previous year, to prepare a supplemented proposal of the state budget which it must send to the President of the Parliament no later than 15 days before the session of the Parliament.

Meanwhile, the parent committee must formulate a position on the supplemented proposal of the state budget, on reports of working bodies, on the opinion of the Secretariat for Legislation and Legal Affairs, and on submitted amendments. On the basis of these reports and its own opinions, proposals and amendments, the parent committee prepares a combined report on the state budget which it must send to the President of the Parliament ten days before the session of the Parliament.

The debate can then start again. But before the debate in which the Parliament deliberates on individual parts of the proposed state budget, a representative of the government may first provide additional explanation of the proposed state budget. Thereafter the rapporteur of the parent committee presents the committee's report.

With regard to voting on amendments, the Parliament decides on amendments to the state budget proposal at the end of the debate on that part of the budget for which the amendment was submitted and it first votes on the amendments submitted by the government, and then on other amendments. When the voting on parts of the budget is completed, the chairperson verifies whether parts of the budget and the revenues and expenditures are balanced, and, when in doubt, requests the opinion of the government and of the parent committee. If the budget is balanced, the Parliament votes on it as a whole. If the state budget is not adopted, Parliament sets a time limit within which the government must submit a new proposal, on which it deliberates and decides following the fast-track procedure for the adoption of a bill.

\section{(State Budget: Articles 215-224 of the SOP)}

\section{Approximation of Laws}

Legislation concerned with approximating national law to EU law is in principle not dealt with by the Parliament any differently from general legislation. In October 1996, a special working body, the Committee for European Affairs, was formed to check upon compliance with EU legislation. This committee:

- discusses matters of general importance related to European integration;

- co-ordinates functioning of the parent committees in relation with European integration and delivers opinions, recommendations and draws their attention to particular questions;

- analyses the consequences of Slovenia's participation in European integration and prepares global assessments;

- organises public presentations of opinions on individual questions of participation in European integration;

- discusses the programme for integration of the Republic of Slovenia into the European Union and monitors its implementation; 
- monitors the process of approximation of Slovenian legislation with the law of the European Communities;

- co-operates with institutions within Slovenia, of the European Union and of other states with regard to participation in European integration;

- keeps record on requests from the European Union and stores literature and other materials related to it;

- organises and co-ordinates technical assistance offered to Slovenia for training for approximation to the European Union;

- performs other tasks, related to European affairs that do not fall within direct competence of the parent committees.

Legislation designed to give effect to other international treaty obligations is prepared and dealt with in Parliament in a somewhat different manner from general legislation. International agreements are ratified by Law and the fast-track procedure is used for reading a bill on ratification and for amendments to the articles of a law on ratification.

If no written amendments to the bill are submitted by the beginning of the reading, Parliament may decide to vote only on the bill in its entirety. Such a decision may not be adopted if opposed by at least one third of the members of Parliament present.

Alterations of existing legislation must be made explicitly. The legislation is amended by enacting provisions that specifically alter or add to its text.

There are no restrictions as on how many times the same law may be amended, but it happens frequently in the field of certain legislation (e.g. financial, privatisation), while it does not happen in some other fields. This usually happens for very different reasons, mostly because a situation changes and it has to be sanctioned anew, or because the bills were not prepared adequately.

\section{Formalities}

Rules for having primary legislation into force are set by the Constitution (Article 154: Validity of Legislative Measures and their Publication), requiring that laws, regulations and other legal acts be published before they come into force. A law, regulation or other legal act comes into force fifteen days after it has been published unless otherwise provided in the regulation or in other act itself. Legislative measures must be published in the Official Journal of the Republic of Slovenia. Commencement cannot be made dependent upon a government order and there are no cases in which primary legislation has not been brought into force.

\subsection{Secondary legislation}

\section{Conferring the Authority to Make Secondary Legislation}

The areas or matters dealt with by primary legislation are either explicitly or implicitly prescribed by the constitution, while primary legislation stipulates what and under what circumstances may be further regulated by secondary legislation. 
Law drafters decide what to include or regulate at the level of primary legislation, when preparing a draft law, and what is to be left to be regulated by secondary legislation and under what conditions.

Purposes or matters for which secondary legislation should be used are technical questions linked to implementing primary legislation, while secondary legislation should not be used to regulate individuals' rights and obligations. This knowledge is generally intelligible from the primary legislation and the practice in this respect is also quite consistent.

The authority to make secondary legislation is usually conferred by primary legislation upon government (ministries), local communities (municipalities) and other regulatory bodies (e.g. Agency for Securities Market, Agency for Restructuring and Privatisation, Bank of Slovenia, Development Fund.)

Limits and conditions governing the exercise by governmental bodies of their powers to make secondary legislation are set by the constitution and individual laws.

It is the practice to set limits to the exercise of the secondary law-making power in the specific primary legislation. In particular, the primary legislation typically states procedures that must be complied with when the secondary legislation is made. Of course, procedures have to be observed anyway for secondary legislation to be valid. The procedure is the same for all secondary legislation.

Checks are regularly carried out on whether delegation of a power to make secondary legislation is constitutional. This does not differ from any other procedure. With regard to questions of constitutionality, the Government Office for Legislation delivers opinions on these issues as a kind of "cautelary" or "preventive" jurisprudence.

Checks are also carried out to ensure that primary legislation will not come into force before any secondary legislation required to implement it has been drafted and can itself be brought into force, but not as a rule. Instead, it is very common to extend vacatio legis for the period needed for preparing secondary legislation.

\section{Making Secondary Legislation}

Formally, a decision to make secondary legislation must first be adopted. Formal steps vary according to the type of secondary legislation, i.e. the body and its internal procedures for making secondary legislation differ (government from ministries).

If the government makes secondary legislation, the competent ministry would prepare (according to time limits set by government work programmes) a draft of secondary legislation, conduct the necessary consultations and submit a co-ordinated proposal to the Secretary General who then sends these drafts to working bodies and finally includes it in the agenda for the session of the government. After adoption, the secondary legislation is signed by the Prime Minister and sent to be published.

In accordance with adopted policy, a minister heads and represents the ministry, issues policy guidelines for the work of the ministry and its departments bodies, supervises their work, issues regulations and other acts within the competency of the ministry and its departments, and carries out other tasks prescribed by law or other regulation. 


\section{(Article 24 of LOG)}

The first draft is then prepared, other ministries and institutions consulted, and depending on the subject matter, the legislation in question is signed by a competent minister (or co-signed by an other competent minister or his consent is given) and sent for publication in the Official Journal.

Normally the law itself would provide for secondary legislation to be prepared, but the effect of primary legislation is never made dependent on the existence of secondary legislation.

Secondary legislation is normally prepared in the course of the same drafting process as the primary legislation with which it is connected, especially in some areas (e.g. customs legislation, taxation).

Policy making depends on the organisation of ministries and the vertical division of competencies. Thus, the ministers head and represent the ministry, issue policy guidelines for its work and that of its departments, supervise their work, issue regulations and other acts within the competency of the ministry and its departments, and carry out other tasks prescribed by law or other regulations.

Responsibility for professional work in individual fields within a ministry lies with State Secretaries appointed and dismissed by the government at the proposal of the minister; a State Secretary is accountable to the minister. Constituent bodies within a ministry are headed by Directors who are appointed and dismissed by the government at the proposal of the minister to whom they are also accountable.

Normally the same unit would develop the policy for the primary legislation undertake drafting secondary legislation, but its composition would depend on the subject matter to be regulated. As an unwritten rule, law drafters are normally included (at the latest) before submission of the secondary legislation to the minister.

Secondary legislation would normally be drafted by both technical and legal units. The situation varies from ministry to ministry, although it is more or less a rule that the same persons or the persons from the same unit that drafted the primary legislation also draft secondary legislation.

In principle, the draft must be discussed with all ministries concerned. This requirement is set by the Standing Orders of the Government.

Drafts that are intended to be submitted to the government must undergo the consultation procedure among relevant ministries. The proposer of a draft must specify which questions are still unresolved and the proposed solutions. These (and other specific questions) are dealt with by the Standing Orders of the Government. The proposed legislation is communicated as draft legislation. General time-frames are set by the work programmes while specific time-frames are set by Standing Orders of the Government (e.g. primary and secondary legislation has to be submitted to the Office for Legislation five days before it is submitted to the government, or at least fifteen days before the submission to the government, if it implies new systemic solutions respectively).

With regard to the public consultations, the Secretary General may decide to send the invitation to a session of the government with relevant materials to other bodies and institutions; following the proposal of the proposer of the material and upon the consent of the Secretary General, representatives of other bodies and organisations and outside scientific and professional collaborators may participate in the debate on individual agenda items. 


\section{(Article 32 And 35 of SOG Respectively)}

No requirement exists that secondary legislation (or particular types) must be published in draft before the final act of making.

Formal requirements that law drafters must observe when drafting secondary legislation are set by the Standing Orders of the Government.

Checks are made internally (within a ministry) as well as externally, with other ministries, the Office for Legislation and government services as well as with permanent committees of the Government.

There are also conventions, particularly as to style and form, with which law drafters are expected to comply when drafting secondary legislation. These conventions are established by practice and instructions (informal) of the Office for Legislation when correcting the texts. They are largely followed but not without exceptions.

In principle, ministerial regulation does not need to be approved by the government, although ministers sometimes decide to inform it about the principle policy issues contained in their regulations before having them really made effective.

Supporting documentation must be prepared in its entirety by the proposer of the secondary legislation. It must contain several groups of information, together with the secondary legislation to be adopted or the decision to be taken. Approval is given by voting on the proposal.

A draft document becomes Law by signature and after having been published in the Official Journal.

\section{Procedures After Making}

Responsibility for carrying out a final check, after secondary legislation is made, with respect to its validity or form, is given to the Secretary General and Office for Legislation; the latter makes the final checks of secondary legislation, before sending it for printing. If formal defects are found, the instrument would be returned to the issuing body to make the corrections of it and to submit it again.

Secretary General keeps all originals of government-made secondary legislation, while ministries keep their originals.

Apart from that, no formal register exists. Every piece of secondary legislation is published, therefore anybody can rely on that. Secondary legislation has to have its foundation in primary legislation and has to contain reference as to its legal basis (article of primary legislation).

\section{Parliamentary Action}

Secondary legislation does not need to be sent or reported to the Parliament, but the SOP (Article 270, Government reports to the Parliament) stipulates that each member of Parliament may propose to a resolution to it requesting the government or an individual minister to report to Parliament on the implementation of laws and other regulations adopted by it, and on other measures from the competence of the government or the individual minister, and their effects.

Other forms of reporting are regulated in Articles 271-273 of the SOP. Thus, the government has the right to report at its own initiative to the Parliament on its work and on the situation in an individual field. The 
Parliament must deliberate a report by the government no later than 30 days after it receives notification of the government's request to report to the Parliament. The report may be written or oral.

If the government submits a written report, the President of the Parliament must immediately acquaint the members of Parliament with it. In this case, the Prime Minister has the right to offer a short explanation of the written report at the session of the Parliament.

The Parliament may adopt an opinion on the work of the government or on a situation in a particular area, after the conclusion of the debate on the government's report on its work.

Secondary legislation is not subject to confirmation or disapproval by the Parliament, but it can examine or debate secondary legislation of its own initiative, without having the right to amend it. Parliament normally discusses the policy emanating from secondary legislation and its political implications rather than secondary legislation as such.

\section{Miscellaneous}

The exercise of secondary law-making powers is subject to constitutional review by the Constitutional Court. Secondary legislation can also be declared void by a court because it is outside the terms of the legislative power or the scope of the primary legislation which it supplements. Legal challenges to the use of secondary law-making powers or secondary legislation are made quite often and are very successful in terms of percentage but not so successful in terms of quantity of secondary legislation.

Making of secondary legislation very often lags behind the requirements of the primary legislation, especially in the areas regulated by laws, prepared by MPs.

There are some subject matters for which secondary legislation is used significantly more frequently, e.g. privatisation; in principle, depending on how broad (or ambiguous) the primary legislation is: the broader the primary legislation, the broader the powers to make secondary legislation.

Secondary legislation is not used to regulate matters that have a significant policy content or that substantially affect the rights, duties or interests of the general public or important parts of the private sector. This area is tackled very carefully since rights and obligations may only be substantively regulated by primary legislation.

\section{Specific Verifications of the Draft}

Compliance of policy proposals or policy options with Constitutional requirements during the policy-making stages is verified by identifying the relevant legal framework, studying the options, political decision, testing of the field, drafting and co-ordination of the actors involved. As the highest act in the hierarchy of norms, the Constitution is a starting point for designing the texts of legislation. Arrangements to verify that amendments proposed by the Parliament comply with its requirements exist and a specialised body of the Parliament exists for that purpose. Its role is broadly defined by Article 333 of the SOP, while other specific questions are regulated with regard to individual situations.

Thus, in order to perform expert, administrative and other activities and technical tasks to ensure the conditions for the work of the Parliament, the Parliament has offices headed by the Secretary General of the Parliament. It has a Secretariat for Legislation and Legal Affairs, headed by a secretary, for the legal 
formulation of bills and other regulations and for delivering opinions on their conformity with the Constitution and with the legal system.

Article 181 of the SOP stipulates that at each reading of a bill and before voting on it, the Secretariat for Legislation and Legal Affairs shall deliver an opinion on the its conformity with the Constitution and with the legal system, and proposals in relation to its legal and technical treatment. These proposals and opinion shall be discussed by the parent committee which shall state its opinion on an amendment. This opinion shall be a constituent part of the report on the bill it submits to the session of the Parliament. This report shall also contain a report by the Secretariat for Legislation and Legal Affairs if the Secretariat for Legislation and Legal Affairs submitted an opinion in the debate on the amendment in the parent committee.

Between 1 January 1993 and 31 April 1996 for which the official statistical data are available, the Constitutional Court has decided, either by decision or by resolution, more than 255 cases (laws). This number does not mean that 255 laws were reviewed by the Constitutional Court; some were subject to review several times (as many as ten times).

\begin{tabular}{|l|c|c|c|c|c|}
\hline Decision & $\mathbf{1 9 9 3}$ & $\mathbf{1 9 9 4}$ & $\mathbf{1 9 9 5}$ & $\mathbf{1 9 9 6}$ & Total \\
\hline Declared Compatible & 15 & 39 & 29 & 9 & 92 \\
\hline Declared Incompatible & 1 & 7 & 6 & 2 & 16 \\
\hline Motion Withdrawn & 2 & 10 & 7 & 3 & 22 \\
\hline Annulment & 4 & 11 & 7 & 4 & 26 \\
\hline $\begin{array}{l}\text { Law came out of force during the } \\
\text { procedure }\end{array}$ & 3 & 3 & 1 & 5 & 12 \\
\hline Declaration of lack of jurisdiction & 5 & 7 & 1 & 2 & 15 \\
\hline Non-adoption/refusal of the motion & 12 & 16 & 27 & 17 & 72 \\
\hline Total & $\mathbf{4 2}$ & $\mathbf{9 3}$ & $\mathbf{7 8}$ & $\mathbf{4 2}$ & $\mathbf{2 5 5}$ \\
\hline
\end{tabular}

The consistency of policy proposals or policy options with the requirements of the existing law and legal structures during the policy-making stages is verified internally (within ministries) and externally (other ministries, Office for Legislation), through governmental procedure and finally through the Parliamentary process. The Consistency of the text of each draft legislation (whether primary or secondary) with the existing law, legal structures and procedures during the drafting stages is verified by considering other similar legislative solutions, practice (judgements) of the Constitutional Court and practice of other relevant institutions.

The Office for Legislation verifies the need for new legislation because the matter may already be dealt with under existing law or need no legislative action (e.g. administratively). Special arrangements exist for verifying whether legislation is consistent with EU law, both on the side of government and Parliament. Article 20, paragraph 3 of the SOG stipulates that the proposer must specifically explain the compliance of an individual bill or other general regulation with Regulations and Directives of the European 
Communities and with other national regulation, adopted on the ground of these directives and with other legal acts of the European Communities. Special arrangements for verifying whether legislation is consistent with the European Convention on Human Rights also exist. That kind of checking is done by the Ministry of Justice. Special arrangements for verifying whether legislation is consistent with other treaty obligations already entered into or likely to impact upon the particular matter covered by the legislation in the future are also set. Ministries themselves therefore pursue activities related to international co-operation within their competency according to the Law on Organisation and on Working Areas of the Ministries. Each ministry individually and the Ministry of Foreign Affairs in general must take into account existing or future international obligations. Since international treaties form part of the legal system, compliance with them is part of the normal verification procedures regarding the definition of the current legal framework.

Primary and secondary legislation must comply with prescribed requirements as to form and format (e.g. inclusion of a title, and technical provisions as to the objects, operation and application, and numbering of the instrument and its internal divisions; as to the opening formula (e.g. stating the enacting authorisation) and closing formulae (e.g. providing for enforcement or repeal of other legislation) and to lay-out and printing style. Where no explicit requirements exist, they are followed as a professional standard.

Writing style, use of language and structure of legislation are considered to be part of convention and an essential element of intelligibility of every legislative text. Similarly, drafters are expected to follow a standard style in writing particular types of legislative provision (e.g. in creating criminal offences or setting penalties; in drafting amendments or repeals; in making cross-references). Their observance is checked by Office for Legislation. Systematic checks are also carried out to establish the most appropriate level in government at which a new legislative scheme should be implemented. Furthermore, systematic checks are carried out to establish whether the necessary organisational structures and administrative procedures required to make new legislative proposals fully operative already exist and are adequate for the purpose, or whether these can and will be provided to the level necessary for effective implementation. By their nature, these questions fall within the working area of every ministry, particularly and in general sense within area of work of the Ministry of Interior.

Systematic checks are carried out to establish what resources, particularly human resources, already exist or will need to be provided to make the new legislation fully operational, and the draft legislation is also systematically checked to determine whether it contains all the legal provisions needed to make it fully operational administratively and so that the legislative scheme can be fully implemented. In the course of these verifications, attention is paid to whether and in what ways computer-assisted administration could be used in implementing the process. Activities to prepare computer-assisted network and the necessary arrangements are made before the legislation is adopted.

Attention is also paid to the impact upon implementation of using computer systems in terms of costs or delay to commencement until the computer technology and systems, and the effective training has been completed.

Verifications are carried out to establish whether implementing the proposed legislation will meet existing national standards relating to protection of the environment and whether the draft conforms with existing legal requirements that prescribe environmental standards. In the government, these issues are dealt with by the Ministry of Environment and Space which performs duties related to protection of the environment and of nature; the waterways and water boards; geological, seismological, meteorological and other geophysical or natural phenomena; physical planning having to do with actions altering the environment; construction of facilities and legal affairs in connection with property; nuclear safety; housing affairs; geodesy and geo-orientated information systems; and inspection in all these fields. Parliament has 
specialised committee for this purpose. Similar verifications are carried out to check compliance with EU law or other international obligations relating to the environment. For this purpose, some studies, known as environmental impact studies have already been produced.

It is difficult to answer if the legislation is generally regarded as easy to understand and work with, clear in the way it sets outs its contents and generally written in the language used by reasonably education persons, rather than using legalistic terms. That depends very much on the area of regulation, but legislation is regarded as easy to understand.

Drafting conventions are well-established and have a long history. They have not been changed much since the transition and are thus known among drafting personnel. The Office for Legislation, in co-operation with other relevant bodies is currently examining the question of how to improve the quality of law drafting, in particular the language and style, to make legislation more accessible to a wider audience.

Cost assessment is a standard practice for all new legislation. Article 20 of the SOG stipulates that the proposer give details about financial means needed to realise envisaged solutions, possible sources and manner of securitisation of financial means, organisational or other implementing measures which will have to be adopted, and the effects and consequences of proposed solutions respectively, when proposing a regulation or another measure to be adopted. The Ministry of Finance is the competent authority in this area.

Such assessments are also made with respect to legislation proposed by the Parliament or with respect to amendments to legislation, whether proposed by government or by the Parliament, normally on the initiative of the government or following a decision of the Parliament that the government should prepare such an assessment.

Special procedures are followed for assessing the impact on the Government's budget of proposed new legislation, in terms of both capital and recurring costs, in particular personnel and organisational running costs. Article 23 of the SOG stipulates that if budgetary financing is proposed or if the proposal concerns regulation of questions with financial implications to the public expenditure, then the proposer must consult the Ministry of Finance in advance on these questions and submit its opinion.

In principle, the same procedures are followed for assessing the impact on the budgets of other governmental authorities of proposed new legislation. Similar procedures for assessing the financial impact on private sector bodies which are likely to be affected by the proposed new legislation, in terms of increased costs of administration and capital expenditure and for assessing its indirect financial impact on the private sector - investment strategies and possible reductions in tax payments, are followed, but with the distinction that significant analysis are produced with regard to the implications on the state budget (one-way assessment). Generally speaking, these analyses are very common at the macro-level of the national economy. All information on projected costings is given to the Parliament which normally prints it as a whole, thus making it available to the general public.

Steps are also taken to find out by ex post evaluation whether projected costings were realistic, although this is not a systematic approach. There are also some other kinds of checks done in order to assess whether or not:

- a proposed legislative scheme will achieve its objectives; 
- the scheme will achieve its objectives at the minimum cost or may produce counterproductive effects or unintended and inappropriate consequences;

- a proposed legislative scheme will meet the needs of those intended to benefit from it and of the administration that is to execute it.

These checks specifically examine whether the scheme will lead public administration into unnecessary or excessive bureaucracy or to applying unnecessarily complex administrative procedures. But the debate on this issues focuses on how to deal with new tasks with the existing personnel, because a ban is imposed on new employment in administration.

The consultation procedure is an essential condition for the legislation to become effective (perfect). The general public has the opportunity to comment upon legislative proposals or draft legislation: the government informs the public in general (press conferences, media) as well as by informing specific, expert public (representative groups of various social interests).

Advisory groups, whether permanent or temporary, assist in developing new laws.

\section{Instruments for Ex Ante Evaluation}

Formal instruments are also in use to assist in the ex ante evaluation of policy proposals for legislation (e.g. computer models, simulations, checklists) for specific purposes, mainly for specific and complex projects (e.g. budget, privatisation, road building).

For the time being, no specific checklists exist as they are deemed to be a part of every reasonable activity and are developed for each project individually. Existing formal instruments for ex ante evaluation have been developed and are usually used by particular (technical) ministries. This is not a recent development, but is mainly limited to economic legislation. Modelling, algorithms, flow-charts, or critical path analyses depend on the ministry involved and on the nature (subject matter) of the draft legislation. Legislation from another country is very often used as a model for policy makers or as a legislative precedent for law drafters.

\section{Use of Computer Technology}

Computers are regularly used in the drafting process for word processing and a link to existing databases. Law drafters are typically supplied with a computer exclusively for their own work and use them widely.

Composing drafts directly on computers depends on personal attitudes towards information technology, availability of administrative staff and other factors (e.g. seniority). Law drafters have to satisfy themselves with the use of a standard word-processing package, since no special application has been developed for law drafting. The use of other computer applications, in addition to word processing, depends on the area of law drafting; in technical areas, it is very common to use other applications, such as graphics, tables and similar. Law drafters have access to a database of legislation which is also used for searching for affected laws or precedents.

The law drafter provides the Government Printer with the text of legislation on diskette, which enables the legislation to be printed without further type-setting. 


\section{Publication of Legislation}

\section{Legislative Sources}

Legislation is printed by a printing firm and published by a public company, which will be (after privatisation) state owned up to approximately 70 per cent. It is published in the Official Journal of the Republic of Slovenia. The area is regulated by the Law on Official Journal, Official Journal of the Republic of Slovenia, No. 57/96.

Publication of all legislation, primary and secondary, in the same publication, depends on space and technical feasibility. Manner f publication differs solely in the headings (e.g. Acts of Parliament, Acts of Government, Ministries, Bank of Slovenia, local communities, etc.).

Primary legislation and secondary legislation are republished in annual volumes by some commercial companies. Normally, at the end of the year, issues of the Official Journal would simply be physically bound into one or several volumes.

A central registry is responsible for registering and maintaining a complete archive of all primary and/or secondary legislation in the sense that it contains authentic texts of legislation. Several data bases also exist, maintained by Parliament, the government, the Supreme Court and the Constitutional Court. There is some question as to what would officially maintained in this context would mean.

Consolidated collections of primary and/or secondary legislation (containing the law in force on the date of publication) are printed by commercial companies. Dates of publication vary, but normally they are published after some significant changes are made to a legislative area they cover. Some are also updated on a regular basis (monthly, quarterly).

No official, up-to-date index of legislation currently in force including amendments to earlier legislation still in force exists and has as to be established in 1997.

Generally, one can make use of commercial databases which are not always accurate, although quite reliable. The only reliable method of finding applicable legislation remains to historically follow the progress of a particular piece of legislation.

Every ministry has ready access to all the legislation likely to concern it, and each maintains a complete collection of current legislation. Law drafters typically have access to a full set of legislation. Complete collections of current legislation are also kept with commercial companies (Gospodarski vestnik, Ius Software, Bonex and other specialised companies). The general public has access to these and they are generally well maintained.

The public and lawyers in the private sector acquire an authentic and complete set of legislation in force, or copies of individual instruments by subscribing to the Official Journal or by buying separate issues of the same. They are readily available and not expensive. In addition, the Law on the Official Journal of the Republic of Slovenia stipulates that every state body having working hours for direct contact with the clients must ensure that the Official Journal is available to the clients at no cost.

\section{Publication of Legislation}

The printing time for a bill depends on technical feasibility, from hours to of days. The Secretary General is responsible for sending it for printing and for checking the printed versions. Bills are published in the 
Herald of the Parliament before each of the three readings in the Parliament and can be bought by anybody. Copies are automatically supplied to the MPs at no charge and to the government and other bodies and individuals for a fee. Printing and publishing costs are borne by the state budget.

The authority to change ( obvious mistakes) the text of legislation after it is made but before publication lies with the Secretary General.

Time limits for legislation to come into force after it has been passed can only be defined in the negative sense (because of the requirements of the procedures). Legislation cannot come into force before being published.

The Government Printer uses modern computerised publishing equipment. 


\section{ANNEX 1. LIST OF SLOVENIAN LAWS}

(accurate as of 17 February 1997)

1. Constitution of the Republic of Slovenia - CONS (Official Journal of the Republic of Slovenia, No. 33/91-I, 1409), in force since 23 December 1991.

2. Law on the Constitutional Court - LOCC (Official Journal of the Republic of Slovenia, No. 15/94, 562), in force since 2 April 1994.

3. Law on the State Council (Official Journal of the Republic of Slovenia, No. 44/92, 2069) in force since 27 October 1992.

4. Law on Elections to the State Assembly (Official Journal of the Republic of Slovenia, Nos. 44/92, 2068, 13/93, 66/93, 60/95 and 14/96 - decision of the Constitutional Court), in force since 27 October 1992.

5. Law on the Government of the Republic of Slovenia - LOG (Official Journal of the Republic of Slovenia, Nos. 4/93, 124, 71/94 and 23/96), in force since 17 January 1993.

6. Law on Organisation and on Working Areas of Ministries - LOAM (Official Journal of the Republic of Slovenia, No. 71/94, 2546), in force since 3 December 1994.

7. Law on Administration - LOAD (Official Journal of the Republic of Slovenia, Nos. 67/94, 2393, 20/95 and 29/95), in force since 11 November 1994.

8. Law on Official Journal (Official Journal of the Republic of Slovenia, No. 57/96), in force since 3 November 1996. 


\section{ANNEX 2. LIST OF SLOVENIAN STANDING ORDERS}

1. Standing Orders of the Council of State (Official Journal of the Republic of Slovenia, No. 44/93, 1747), in force since 13 August 1993.

2. Standing Orders of the State Assembly - SOP (Official Journal of the Republic of Slovenia, Nos. 40/93, 1659, 80/94, 1/95 and 28/96), in force since 18 July 1993.

3. Standing Orders of the Government of the Republic of Slovenia - SOG (Official Journal of the Republic of Slovenia, No. 13/93, 599), in force since 13 March 1993. 


\section{ANNEX 3. LIST OF SLOVENIAN DECREES}

1. Decree on establishment and on working area of the Office for Legislation, Official Journal of the Republic of Slovenia, No. 34/96, in force since 30 June 1996.

2. Decree on Establishment and functions of the committees and working groups of the State Assembly, Official Journal of the Republic of Slovenia, No. 5/97, 261, in force since 16 January 1997.

3. Decree on composition and elections of the Committee of the State Assembly for European Affairs, OJ 5/97, 270, in force since 16 January 1997. 


\section{ANNEX 4. SLOVENIA COUNTRY REPORT: ADDITIONAL INFORMATION}

Specific methodology designed or foreseen for checking compatibility with $E U$ law principles which applies when verifying the drafts.

The methodology (steps in checking) are the following:

1. Identification of existing legal framework within the Communities in the area to be regulated by a national legislation; identification comprises primary sources of law (constitutional treaties, conventions between Member States, external treaties) and secondary sources of law (obligatory and non-obligatory acts, non-treaty acts and jurisprudence of the court).

2. Development of understanding the relevant legislation of the Communities (translations, verifications, working groups) and substantive designing of the first draft of the national legislation; at this stage, relevant legislation of three to four Member States is also analysed.

3. Identification of already existing or anticipated obligations of Slovenia toward the Communities and time schedule for abolishing possible solutions that would be incompatible with current obligations. For the time being, however, Slovenia has few 'perfect' obligations since the Europe Agreement has not been ratified yet on either side. Nevertheless, the attitude is to act in accordance with the pacta sunt servanda principle already at this stage.

4. Composition of both substantive and time requirements into a bill.

After this, a bill is processed like any other piece of draft legislation.

Foreign assistance especially used for this purpose.

There has been some, through the Phare Programme.

Criteria for EU compatibility checking. Which authority decides upon them and possible concrete examples of criteria chosen.

As above.

A specific body in charge of implementing criteria/filtering the drafts along these criteria/granting possible 'rubber-stamp' of compatibility before the draft is forwarded to the cabinet or to the Parliament? Who makes the final decision in the case of conflict between the draft text and corresponding EU principles?

The Office for Legislation. 
Status and location of this body (department within one ministry, independent body, authority attached to the PM, others).

The Office for Legislation is organised as an independent professional government service directed by a Director appointed by the government (on the Prime Minister's proposal) accountable to both the Prime Minister and to the Government. The Office has organised its work in organisational units headed by Under-secretaries of State. One of these is the Department of European and Comparative Law, established in January 1997.

- Deals with questions of building up the legal system and of fulfilling constitutionality and legality.

- Deals with questions of harmonising the legal system with EU law.

- Comparatively studies law of other countries and international integration.

- Designs the rules of legal technique for preparing draft laws and other legal acts, proposed to the Parliament by the government, as well as legal acts of the Government and Ministers,

- Deals with all proposals of laws sent to the Parliament by the government as well as with all acts sent to the government by the Parliament, delivering an opinion, then, with all proposals of legal acts of government and ministers, everything from Constitutional and legal compliance with EU law and with the rules of legal technique.

- Prepares draft laws and other acts proposed to the Parliament by the Government and proposals of legal acts of the Government which do not belong to working areas of individual ministries or other government offices, everything according to the resolutions of the Government.

- Performs professional tasks connected with supervising constitutionality and legality of regulations, issued by ministers.

- Issues, according to the law, the Official Journal of the Republic of Slovenia and a register of legal acts in force.

- Decides on the publication of regulations of government and ministers in the Official Journal of the Republic of Slovenia.

In performing its tasks, the Office for Legislation co-operates with legal departments of all ministries and other governmental services, with legal department of the Parliament, and with other domestic, foreign and international institutions.

The Department of European and Comparative Law, established within the Office for Legislation in January 1997, performs the following tasks:

- Comparatively studies law of other states and international integration.

- Follows and studies questions of building up the legal system from the perspective of comparing legislation of other states and with EU law. Gives opinions and suggestions concerning these questions to the government, to governmental working bodies and offices, and to the ministries.

- Performs professional tasks concerning approximation of legislation with the EU legal system.

- Follows the work and co-operates with Council of Europe and European Union.

- Organises working visits abroad. 


\section{Current Situation:}

The Office for Legislation, in co-ordination with ministries, is responsible for managing the process of approximation of Slovene legislation.

In 1994, the Government established the Commission for legal harmonisation, led by the Office for Legislation. It consists of heads of legal departments from all ministries and is a co-ordinating body in charge of fostering preparation and implementation of approximation legislation, and of co-operation with foreign legal experts.

The government also established the Secretariat for legal harmonisation with its seat in the Office for Legislation, which takes care of the work of the Commission and is a technical co-ordinator on Slovenian side for Phare projects of approximation of legislation.

\section{Future Activities of the Office for Legislation (Department of European and Comparative Law):}

The creation of the Department of European and Comparative Law restores only a strong core and forms a cross-functional team is formed informed in the following fields:

- experience in the work of government and Public Administration;

- language skills;

- studying questions of European integration;

- managing and maintaining the register of legal acts and data bases;

- Project Management skills and experience;

- teamwork.

The Department of European and Comparative Law Office for Legislation Will Undertake the Following Co-Ordinated and Professional Tasks:

- strengthen the role of Office for Legislation in managing the process of approximation;

- lead a co-ordinating working body consisting of heads of legal departments of all ministries clearly intended to foster approximation of legislation and with strong governmental support, on the principles of Project Management;

- co-operate with all ministries especially in exchanging information and co-ordination between those concerned with the same legislative area;

- co-operate with Parliament in the legislative process of adopting laws to prevent delays and misunderstandings;

- strong co-operation with Phare assistance, especially in providing Project Management expertise and assistance in managing approximation by training public officials to cope with the enormous workload generated by the approximation process for which specific skills in EU legislation and process management must be developed;

- select priorities for approximating legislation following the government's strategy and preparation of all steps which must precede legal approximation together with ministries;

- compile Strategic Plans, Work Programmes and budgets in co-operation with line ministries; 
- advising line ministries on how to establish or improve their structures for preparing and drafting legislation. Organising seminars for officials to discuss intended concrete projects of legal harmonisation;

- establish a register of legal projects proposed by line ministries to be updated and followed until the respective legislation is in force;

- develop recommendations for rationalising the law and regulatory making process and a system for appraising administrative and budgetary consequences of introducing new legislation with a particular focus on the efficiency of the EU compatibility checking of the draft texts;

- manage projects and associated contracts, monitor Phare Programme progress, monitor and manage Phare Programme and projects budgets;

- analyse progress, issues and problems, devise and recommend necessary remedial action;

- report on progress, issues and problems to the Government;

- organise study visits to the EU Commission and member states;

- co-ordinate the actions with the Commission's TAIEX Office and creating synergies with other forms of technical assistance including the TAIEX expert pool;

- co-ordinate the assistance provided by other bilateral or multilateral sources.

Implementation of these activities requires co-operation with Programme Implementation Units within all ministries and strong governmental support.

Which sources of legislation according to the Constitution are covered by this EU compatibility checking mechanism, if any? Are the drafts, initiated in Parliament, covered by this mechanism?

All sources.

Yes, since the Parliament has followed the example of the government and has established its Committee for European Affairs (Decree on Establishment and functions of the committees and working groups of the State Assembly - OJ 5/97, 261 as from 16 January 1997) and elected its President, Vice-President and fifteen members (Decree on composition and elections of the Committee of the State Assembly for European Affairs, OJ 5/97, 270 as from 16 January 1997).

The Committee for European Affairs:

- discusses matters of general importance related to European integration;

- co-ordinates functioning of the parent committees in relation to European integration and delivers opinions, recommendations and draws their attention to particular question;

- analyses the consequences of Slovenia's participation in the European integration and prepares global assessments;

- organises public presentations of opinions on individual questions of participation in European integration;

- discusses the programme for integrating the Republic of Slovenia into the European Union and monitors its implementation; 
- monitors the process of harmonising Slovenian legislation with the law of the European Communities;

- co-operates with institutions within Slovenia, institutions of the European Union and other states with regard to participation in European integration;

- keeps a record of requests from the European Union and stores literature and other materials related to it;

- organises and co-ordinates technical assistance offered to Slovenia for training for approximation to The European Union;

- performs other tasks, related to European affairs which do not fall within direct competence of the parent committees. 


\section{APPENDIX 1. LIST OF COUNTRY REPORTS AND AUTHORS}

\section{Albania}

Law Drafting and the Regulatory Process, by Rustan Petrela, Head of the Public Administration Department, Office of the Prime Minister, Albania.

\section{BULGARIA}

Law Drafting and Regulatory Management in Bulgaria, by Chadar Popov, ExLege Consulting Ltd, Sofia, Bulgaria.

\section{ESTONIA}

Law Drafting and Regulatory Management in Estonia, by Raigo Sõlg, Head of the Law-Drafting Methodology Department, Ministry of Justice, Estonia.

\section{LITHUANIA}

Law Drafting and Regulatory Management in Lithuania, by Vita Neverauskaité, Research Assistant, Law Institute, Ministry of Justice, Lithuania.

\section{SLOVAKIA}

Law Drafting and Regulatory Management in Slovakia, by Peter Kukliš, Adviser, Legislative Department, Office of the National Council of Slovakia.

\section{SLOVENIA}

Law Drafting and Regulatory Management in Slovenia, by Miro Prek, Under-Secretary of State, Office for Legislation, Government of the Republic of Slovenia. 


\section{APPENDIX 2. GLOSSARY OF TERMS USED}

Amending legislation: legislation that alters the effect of existing legislation, whether by modifying or repealing provisions or by adding or substituting new provisions.

Approximation of law: the process of bringing the contents of existing legislation into harmony with the requirements of EU law.

Bill: draft of primary legislation in the form that will be considered by Parliament.

Consolidation: the process of producing a comprehensive and coherent collection of legislation, or of legislative rules on a specific subject, in an organised format.

Ex ante assessment: the process of assessing qualitatively a feature of proposed legislation before a final decision is made to adopt it.

Law drafter: a person (whether a Government official or a contracted consultant) engaged in producing the text of new legislation.

Law drafting: the process of converting new policy into legal rules in legislation, in the appropriate legal form and style, prior to the act of law-making.

Legislation: written law (normative acts) made by Parliament, Government or other body with power (e.g. conferred by the Constitution) to issue law-making instruments.

Policy developer: a person (whether a Government official or a contracted consultant) engaged in working out the policy that is to be given effect by new legislation.

Primary legislation: legislation made by Parliament (i.e. the body vested with the principal law-making function for the State).

Regulatory Impact Analysis (RIA): a verification process to assess the impact of alternative policy choices or of a legislative proposal, particularly the economic and financial impacts.

Regulatory framework: the standard arrangements (as dictated by law) for preparing legislation, including any legal requirements as to the standard procedures to be followed and the form and style in which legislation is to be drafted.

Regulation: any of the range of legal instruments that may be made by Parliament, the Government or the public administration to influence behaviour (i.e. law-making instruments, such as primary and secondary legislation, and non law-making instruments, such as circulars, directives, guidance or instructions).

Regulatory management: the systematic management of the processes of developing, drafting and making new legislation.

Secondary legislation: legislation made by Government or another executive body that is vested with power to issue law-making instruments (e.g. decrees, directives, regulations, rules, orders).

Verification: a process for scrutinising a policy proposal or draft legislation in order to check that it meets some specific standard or required quality. 


\section{APPENDIX 3. COUNTRY DOCUMENTS RELATING TO THE LAW-MAKING PROCESSES}

\section{Albania}

Constitutional Laws of the Republic of Albania - Law No. 7491 (dated 29 April 1991): "On the main Constitutional Provisions", as at December 1993.

Functioning Rules of the Council of Ministers - Decision No. 81 of 6 February 1995, in support of Law No. 7491 (dated 29 April 1991) "On the main Constitutional Provisions".

Regulation of the People's Assembly - Decision 206 of 2 July 1991, as at July 1996, in support of Law No. 7491 (dated 29 April 1991) "On the main Constitutional Provisions".

\section{BULGARIA}

Law on the State Gazette Act; Promulgated State Gazette No. 89, 06 October 1995.

Decree No. 66 of 22 March 1995 on the Establishment of a Mechanism for Co-ordination and Implementation of the Obligations of the Republic of Bulgaria under the Europe Association Agreement between the Republic of Bulgaria and the European Communities; Promulgated State Gazette No. 29, 30 March 1995.

Decree No. 166 of 12 July 1996 - Regulation on the Structure and Organisation of the Activities of the Council of Ministers and its Administration; Promulgated State Gazette, No. 61, 19 July 1996.

Law on Normative Acts, Promulgated State Gazette No. 27, 3 April 1973.

Decree No. 883 to Implement the Law on Normative Acts; Promulgated State Gazette, No. 39, 21 May 1974.

Decree No. 1496 on the Participation of the People's Republic of Bulgaria in Treaties - Promulgated State Gazette, 12 February 1975.

Decree No. 20 on Establishing a Legislative Council within the Ministry of Justice; Promulgated State Gazette, No. 12 of 1992.

\section{ESTONIA}

The Constitution of the Republic of Estonia, Chapter VII — Legislation.

The Government of the Republic Act, Division 6 - Legislation of the Government of the Republic and $\S \S .41(6) ; 42 ; 50 ; 51$.

Riigikotu Procedure Act, passed 15 November 1994, as at 18 May 1996.

Bill for Legislative Drafting Act. 


\section{LITHUANIA}

Law of the Republic of Lithuania on the Official Announcement and Coming into Legal Force of Laws and other Legal Acts (adopted on 6 April 1993).

Law of the Republic of Lithuania on the Register of the Laws and Other Legal Acts (adopted on 2 May 1995).

Law of the Republic of Lithuania on Drafting Procedure of Laws and other Legal Acts (adopted on 2 May 1995).

Working Regulation of the Government of the Republic of Lithuania (adopted 11/08/1994) Extracts concerning Legislation.

Statute of Seimas of the Republic of Lithuania, 17 February 1994, No. I-399 - As it concerns legislative procedure, Chapters 10; 15, 18-29.

\section{SLOVAKIA}

The Constitution of the Slovak Republic.

Act on Rules of Procedure of the National Council, passed on 24 October 1996.

Legislative Rules on Law-Making, National Council Resolution No. 519, passed on 18 December 1996.

\section{SLOVENIA}

The Constitution of the Republic of Slovenia.

Law on the Government of the Republic of Slovenia, No. 4/93, as at 17 January 1993, Articles 1-4; 26.

Law on the Constitutional Court, No. 15/94, Articles 1; 6; 21.

Law on Administration, No. 67/94 (as amended), Articles 1-14; 99; 100; 106.

Law on Organisation and Areas of Work of the Ministries, No. 71/94, Articles 1;2;29.

Standing Orders of the State Assembly of the Republic of Slovenia, No.40/93 (as amended), Articles 166-212.

Standing Orders of the Government of the Republic of Slovenia, No. 13/93, 25 February 1993. 


\section{APPENDIX 4. OECD REFERENCE CHECKLIST FOR REGULATORY DECISION-MAKING}

\section{Recommendation of the Council of the OECD, adopted 9 March 1995}

The following ten questions about regulatory decisions reflect principles of good decision-making that are in use in OECD countries to improve the effectiveness and efficiency of government regulation by upgrading the legal and factual basis for regulations, clarifying options, assisting officials in reaching better decisions, establishing more orderly and predictable decision processes, identifying existing regulations that are outdated or unnecessary, and making government actions more transparent. But they have to be applied within a broader regulatory management system that includes elements such as information collection and analysis, consultation processes, and systematic evaluation of existing regulations.

\section{Is the problem correctly defined?}

The problem to be solved should be precisely stated, giving clear evidence of its magnitude, and explaining why it has arisen (identifying the incentives of affected entities).

\section{Is government action justified?}

Government intervention should be based on clear evidence that government action is justified, given the nature of the problem, the likely benefits and costs of action (based on a realistic assessment of government effectiveness), and alternative mechanisms for addressing the problem.

\section{Is regulation the best form of government action?}

Regulators should carry out, early in the regulatory process, an informed comparison of a variety of regulatory and non-regulatory policy instruments, considering relevant issues such as costs, benefits, distributional effects, and administrative requirements.

\section{Is there a legal basis for regulation?}

Regulatory processes should be structured so that all regulatory decisions rigorously respect the "rule of law"; that is, responsibility should be explicit for ensuring that all regulations are authorised by higher-level regulations and consistent with treaty obligations and comply with relevant legal principles such as certainty, proportionality, and applicable procedural requirements.

5. What is the appropriate level (or levels) of government for this action?

Regulators should choose the most appropriate level of government to take action, or, if multiple levels are involved, should design effective systems of co-ordination between levels of government.

6. Do the benefits of regulation justify the costs?

Regulators should estimate the total expected costs and benefits of each regulatory proposal and of feasible alternatives, and should make the estimates available in accessible format to decision-makers. The costs of government action should be justified by its benefits before action is taken.

7. Is the distribution of effects across society transparent?

To the extent that distributive and equity values are affected by government intervention, regulators should make transparent the distribution of regulatory costs and benefits across social groups. 
8. Is the regulation clear, consistent, comprehensible, and accessible to users?

Regulators should assess whether rules will be understood by likely users, and to that end should take steps to ensure that the text and structure of rules are as clear as possible.

\section{Have all interested parties had the opportunity to present their views?}

Regulations should be developed in an open and transparent fashion, with appropriate procedures for effective and timely input from interested parties, such as affected businesses and trade unions, other interest groups, or other levels of government.

10. How will compliance be achieved?

Regulators should assess the incentives and institutions through which the regulation will take effect, and should design responsive implementation strategies that make the best use of them. 


\section{APPENDIX 5. LEGISLATIVE VERIFICATIONS}

\section{A. Checks in Respect of Policy Options}

\section{General Regulatory Checks:}

- to ascertain that the problem has been correctly identified;

- to confirm that the problem cannot be resolved by taking some action under existing law;

- to find out whether the policy objectives could be secured without resorting to new legislation, e.g. by following other procedures, such as contract or negotiation and agreement or by using non law-making instruments;

- to verify that the policy proposal complies with the Constitution and will not give rise to irreconcilable conflicts with other legislation or with the structures of the legal system.

2. Checks on Administrative Requirements:

- to ascertain the levels in government or the agencies through which the new scheme will be implemented;

- to check whether existing administrative structures, and human resources, will be adequate or will have to be supplemented or additional ones provided.

\section{Costs and Economic Impact Checks:}

- to determine the cost effectiveness of alternative policy options;

- to quantify in money terms as many of the benefits and the costs of a policy option as possible to help establish its efficiency;

- to determine the fiscal/budgetary implications of a policy option for government or other governmental authorities;

- to estimate the likely financial impact on the private business sector in complying with the policy option, e.g. in terms of greater administrative costs or expenditure or, indirectly, reduced financial flexibility;

- to quantify the social costs to the general community, e.g. in terms of costs to consumers or of reduction, or changed patterns, in expenditure by the public;

- to estimate likely effects in increasing or reducing employment;

- to predict possible indirect economic risks or adverse consequences, e.g. as a result of unintended responses to the new policy.

\section{Efficiency Checks:}

- to check that the policy option will achieve its objectives in ways that are administratively efficient (i.e. require the minimum of additional administration) and are proportionate to the intended objectives;

- to establish that the policy option will not result in new hazards or consequences that outweigh the intended benefits. 


\section{Practicability Checks:}

- to check that the policy option does not involve unnecessary or unduly complex procedures, for the administrators or those required to comply, that could make the policy less effective;

- to determine whether the policy option could create opportunities for corruption or criminal enterprises;

- to ascertain whether the policy option takes full account of the ways in which the activity to be regulated is currently conducted;

- to determine that the procedures for implementing the policy option will be the minimum necessary to make it effective and are capable of being put into effect by those required to comply with it, without unnecessary disruption.

6. Implementation Checks:

- to check that the methods adopted for securing compliance with the policy option will achieve a satisfactory level of implementation;

- to check that these methods and those involving enforcement measures and for adjudicating disputes are effective, fair, consistent and open in their operation;

- to ascertain that the modes of securing compliance and enforcement, and those concerned with adjudication, are likely to command the confidence and co-operation of those affected and are within their capacity to implement.

B. Checks of Legislative Drafts

1. Checks for Constitutional and Legal Compliance:

- to check that the provisions of the legislative draft are not in conflict with the Constitution, in particular the provisions which guarantee rights and freedoms;

- to check that the provisions are not in conflict with some higher level of law (e.g. secondary law is consistent with the primary legislation which it implements);

- to check that every provision in the draft is in fact needed and not made superfluous by some existing law nor could be covered by some non-legislative means;

- to check that the concepts and legislative approach is consistent with existing law and legal structures and procedures;

- to ascertain all the provisions of existing law that must be repealed or amended as a consequence of the new legislation are dealt with, and that all transitional provisions are included that are necessary to ensure legal continuity.

2. Checks for Approximation to EU Law:

- to ascertain the extent to which the draft gives effect, and should give effect, to the EU law on the relevant topic.

3. Checks for Compliance with International Treaties:

- to ascertain that the provisions of the draft are consistent with the European Convention on Human Rights;

- to ascertain that the draft is consistent with all treaties, relating to the subject matter of the draft law, to which the country is a party. 


\section{Implementation Checks:}

- to ascertain whether all the legal provisions have been included that are necessary to enable the legislative scheme to be fully operational and in particular cover fully the proposed methods for securing compliance;

- to check that these provisions, and those providing for enforcement and adjudication, are effective, fair, consistent and open in their operation;

- to check that the legislative language facilitates the settlement of disputes and the functioning of the courts in adjudicating issues;

- to ascertain whether the actual users of the law will find it easy to use and can readily find the answers to their legal questions.

\section{Checks as Secondary Law-Making Powers:}

- to check that the law contains adequate provisions to enable government or ministries to make all the secondary legislation that may be needed to implement it;

- to check that appropriate limits and conditions have been set in the law upon the exercise of those powers of secondary law-making, in particular to control the extent to which they may be used to deal with policy matters.

6. Checks on Legal Form, Clarity and Comprehensibility:

- to check that uniform requirements as to the form, structure and presentation of legislation have been followed;

- to check that the language of the legal provisions follows standard language usages, is easily comprehended and free of unnecessary legalistic terms;

- to check that the organisation of the provisions in the law is logical and facilitates its use. 